Department für Nutzpflanzenwissenschaften

Georg-August-Universität Göttingen

Grisebachstraße 6

37077 Göttingen

\title{
Beteiligung systemischer Signale an der Symptomauslösung bei Brassica napus nach Infektion mit Verticillium longisporum und V. dahliae
}

\author{
Dissertation zur Erlangung des Doktorgrades \\ der Fakultät für Agrarwissenschaften \\ der Georg-August-Universität Göttingen
}

\author{
vorgelegt von \\ Nadine Riediger \\ geboren in Georgsmarienhütte
}

Göttingen, im April 2008 
D 7

1. Referent : Prof. Dr. Andreas von Tiedemann 2. Referent : Prof. Dr. Petr Karlovsky

Tag der mündlichen Prüfung: 14.05.2008 


\section{Inhaltsverzeichnis}

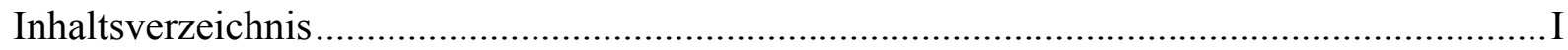

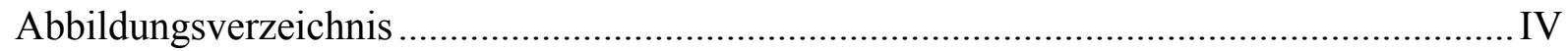

Tabellenverzeichnis................................................................................................... VII

Abkürzungsverzeichnis …………………………………………………………….....

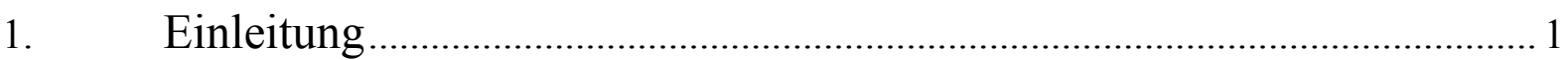

1.1. Bedeutung von Raps in der deutschen Landwirtschaft............................................ 1

1.2. „Krankhafte Abreife“ durch Verticillium longisporum ............................................ 1

1.3. Nachweis und Symptome von V. longisporum-Befall ............................................ 2

1.4. V. dahliae, Erreger der „Verticillium-Welke“ ........................................................... 4

1.5. Mögliche Auslöser der $V$. longisporum-Symptomatik .............................................. 4

1.6. Funktionen von $\mathrm{H}_{2} \mathrm{O}_{2}$ in der Pflanzenzelle ...................................................... 5

1.7. Funktionsweise und chemische Eigenschaften von NO......................................... 7

1.7.1. Bildung, Reaktionspartner und Funktion von $\mathrm{NO}$ in Pflanzenzellen.................. 8

1.7.2. NO-induzierte Effekte in der Pflanze............................................................. 11

1.7.3. NO in der Wirt-Pathogen-Interaktion ......................................................... 13

1.7.4. $\quad \mathrm{H}_{2} \mathrm{O}_{2}$ und $\mathrm{NO}$ in der systemisch erworbenen Resistenz (SAR) ....................... 14

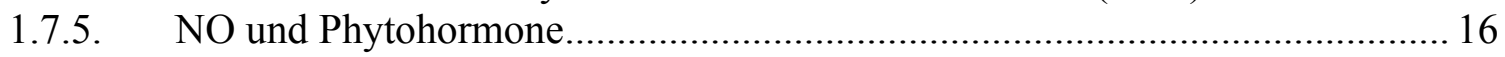

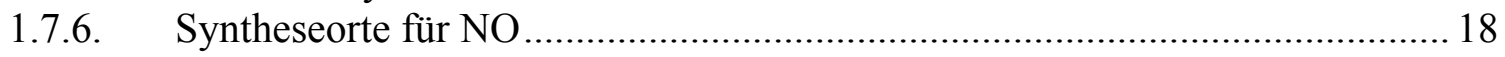

1.7.7. Detektionsmöglichkeiten von NO in Pflanzen...............................................2 20

1.7.8. Bedeutung von NO für Pilze .................................................................. 23

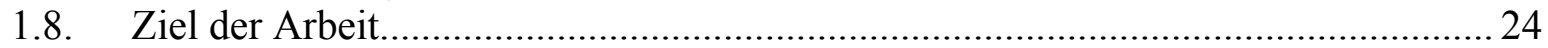

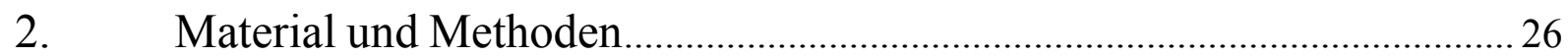

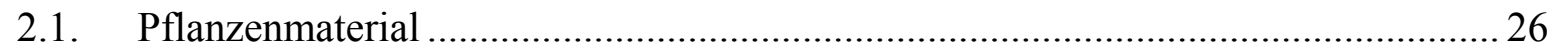

2.2. Pilzisolate

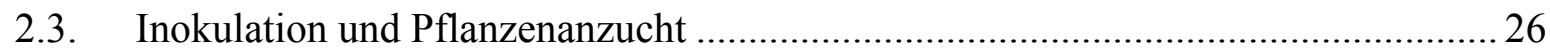

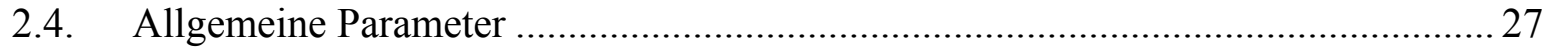

2.5. Nachweis der Pathogenausbreitung durch Real-Time-PCR .................................... 27

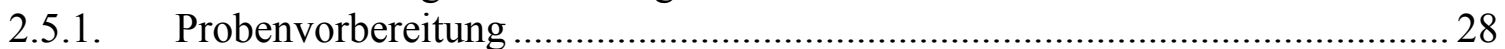

2.5.2. DNA-Extraktion ..................................................................................... 28

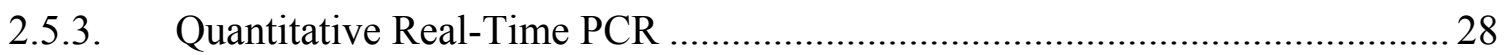

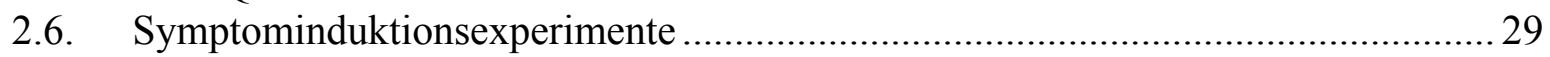

2.6.1. Inokulationsversuche in Töpfen .................................................................. 29

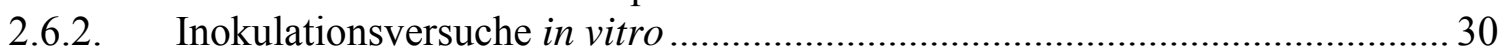

2.7. Effekt von $\mathrm{NO}$ auf das vegetative Wachstum von $V$. longisporum ........................... 31

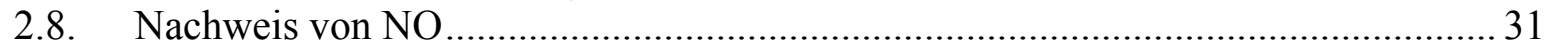

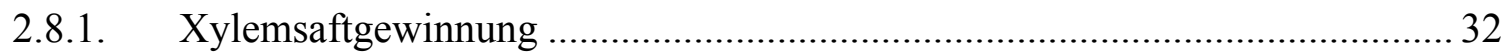

2.8.2. Probenaufbereitung zur ESR-Analyse von Xylemsaft.......................................32

2.8.3. Probenaufbereitung von Xylemsaftmischproben zur ESR-Analyse .................33

2.8.4. Detektion von NO-Signalen in Pflanzengewebe................................................. 33

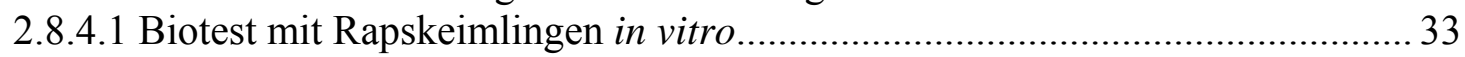

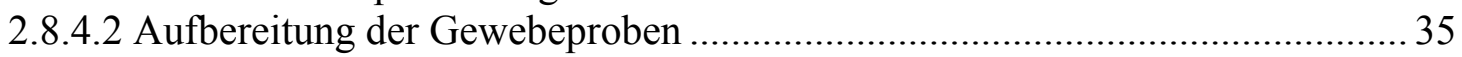

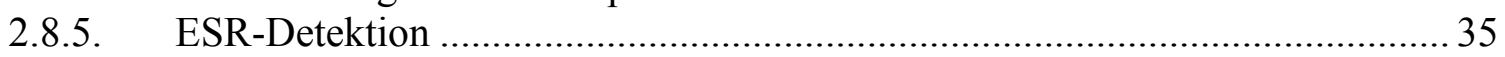

2.8.6. Detektion von NO in Pflanzengewebe mit HPLC und Fluoreszenzmarker..... 35

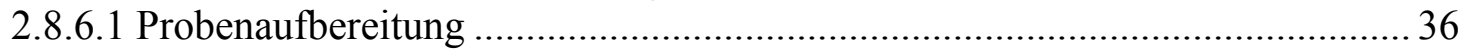

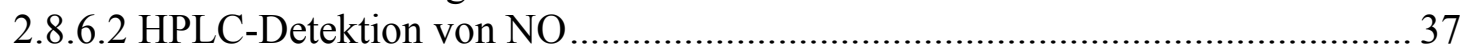

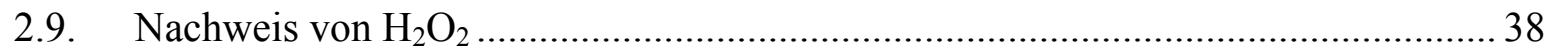




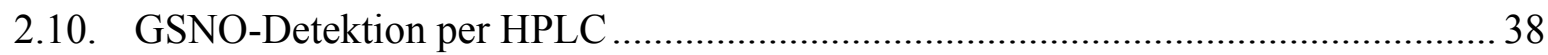

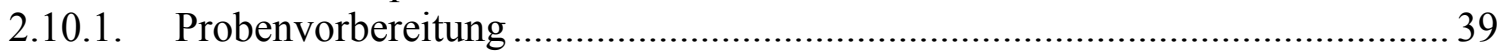

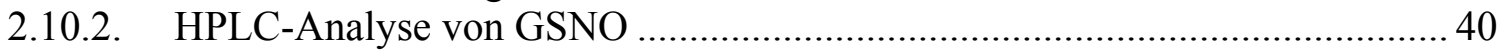

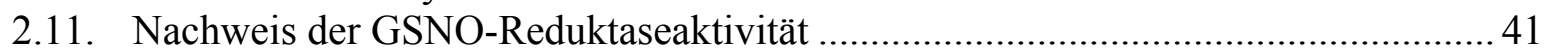

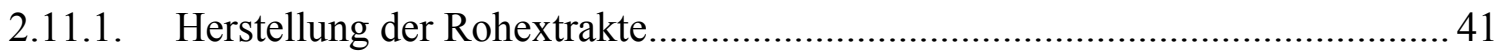

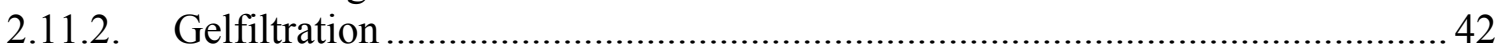

2.11.3. Photometrische Bestimmung der GSNO-Reduktaseaktivität ......................... 42

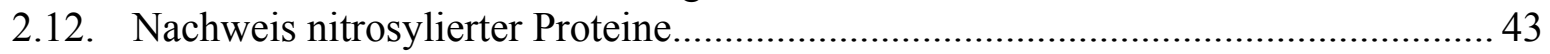

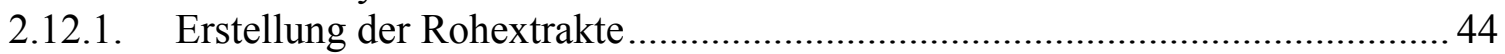

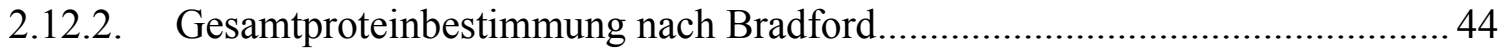

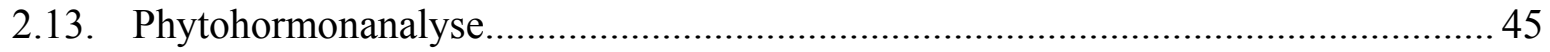

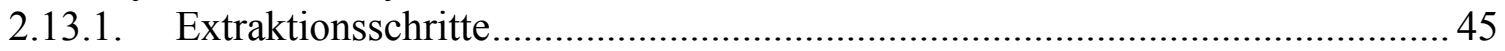

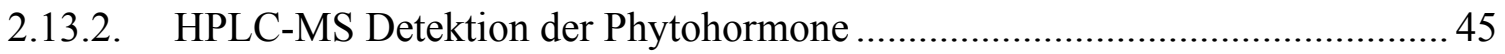

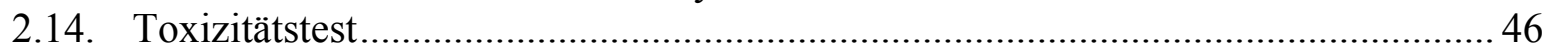

2.14.1. Petiolentoxizitätstest mit CzD-Medium ....................................................... 46

2.14.2. Stauchetest mit sterilen Kulturfiltraten in Topfversuchen .............................. 47

2.14.3. Stauchetest mit sterilen Kulturfiltraten in vitro................................................... 47

2.14.4. Stauchetest mit membranfiltrierten SXM-Kulturfiltraten in vitro .................... 48

2.14.5. Stauchetest mit Acetonitril-fraktionierten SXM-Kulturfiltraten in vitro .......... 50

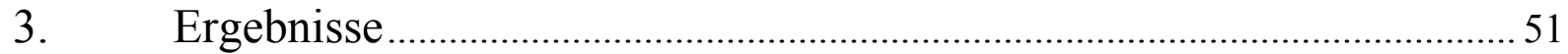

3.1. Auswirkungen der V. longisporum- und V. dahliae-Infektion auf Vergilbung,

Spross- und Wurzelwachstum ............................................................................... 51

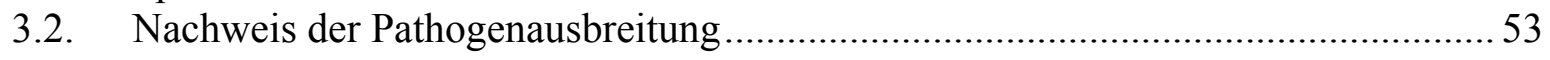

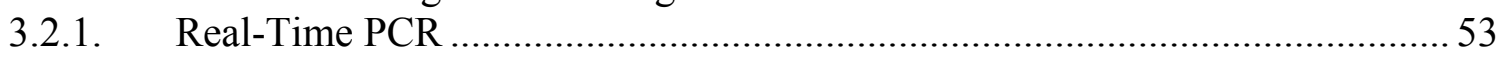

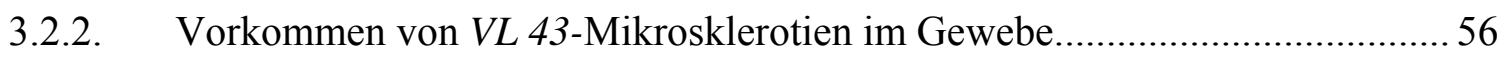

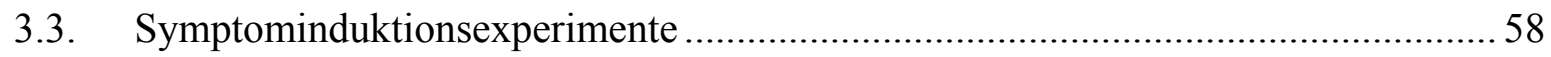

3.4. Effekte von NO auf das vegetative Wachstum von $V$. longisporum ...........................60

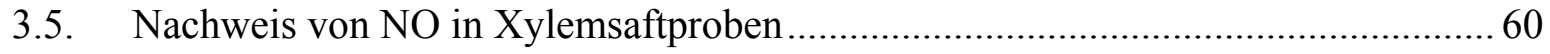

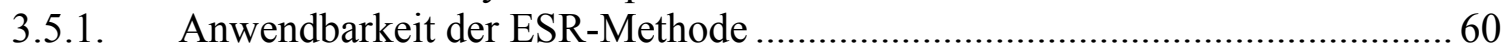

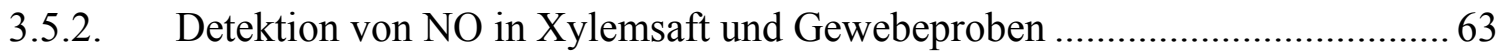

3.5.3. Nachweis von NO mit HPLC und dem Fluoreszenzmarker DAF-2DA .......... 67

3.5.4. Anwendbarkeit des Biotest (Nachweis der Interaktion von B. napus und $V$.

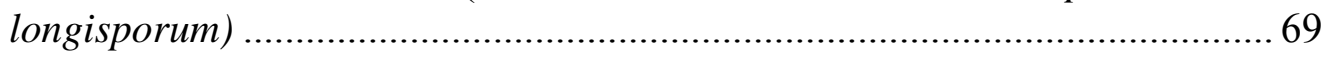

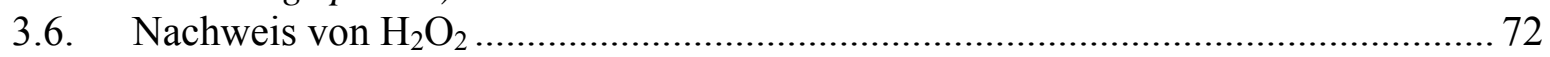

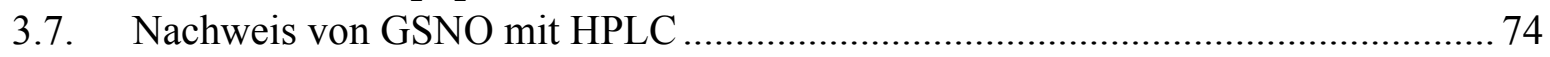

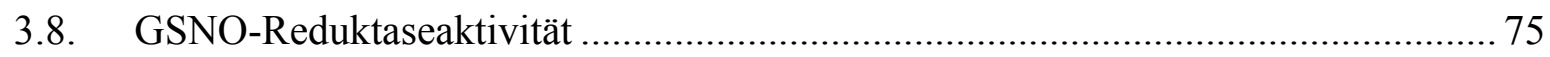

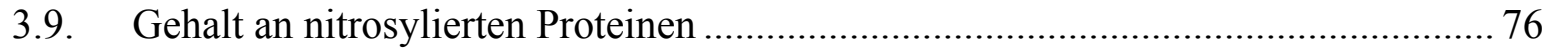

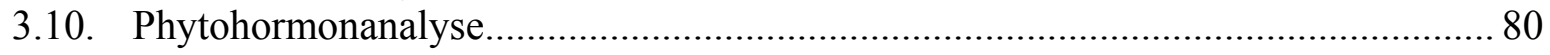

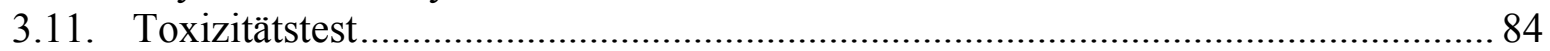

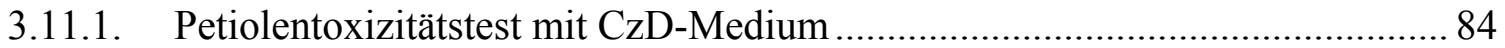

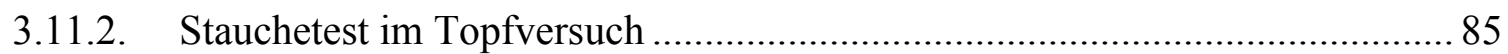

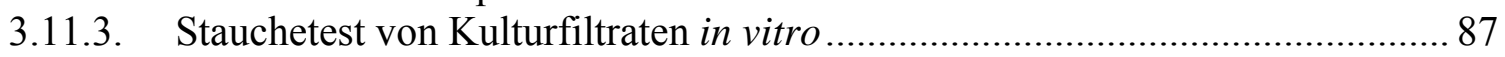

3.11.4. Stauchetest membranfiltrierter SXM-Kulturfiltrate in vitro ............................. 88

3.11.5. Stauchetest Acetonitril-fraktionierter SXM-Kulturfiltrate in vitro ................... 90

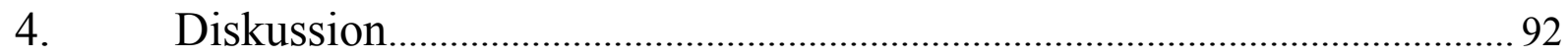

4.1. Auswirkungen der V. longisporum- und V. dahliae-Infektion auf Vergilbung, Spross- und Wurzelwachstum von RCR ............................................................ 92

4.2. Ausbreitung der Pathogene in Wurzel und Spross in Bezug zur Symptombildung. 93

4.3. In vivo und in vitro Experimente zur Staucheinduktion durch NO-Donatoren .........96 
4.4. Effekt von NO auf das vegetative Wachstum von $V$. longisporum ..........................97

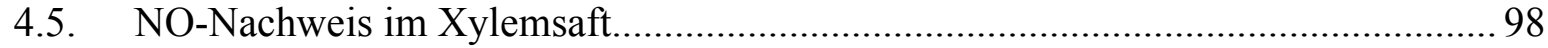

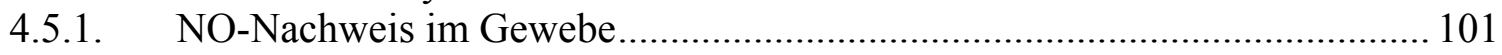

4.5.2. Nachweis von NO mit HPLC und dem Fluoreszenzfarbstoff

Diaminofluorescein (DAF) ............................................................. 102

4.5.3. Nachweis von $\mathrm{H}_{2} \mathrm{O}_{2}$ in Gewebeproben und mögliche Erklärungen zum

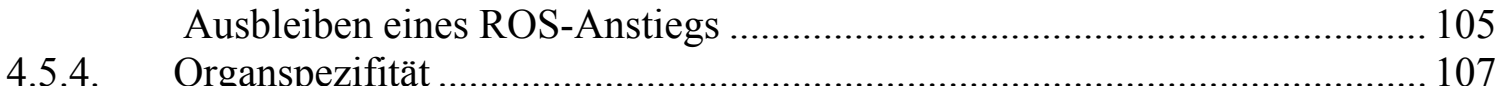

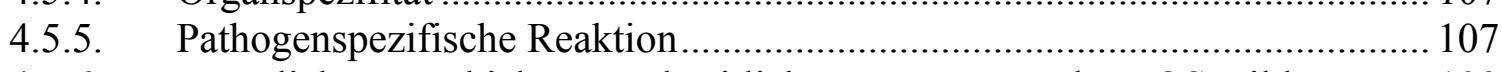

4.5.6. Räumliche Verschiebung und zeitliche Verzögerung der ROS-Bildung ....... 109

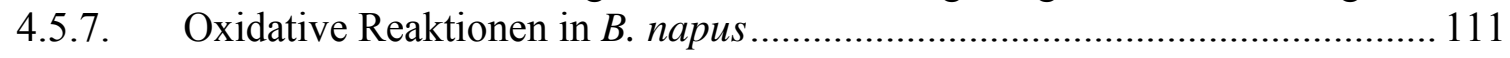

4.5.8. Zusammenfassung der ROS-Untersuchungen ............................................ 111

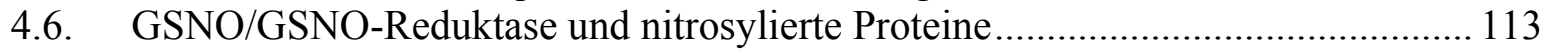

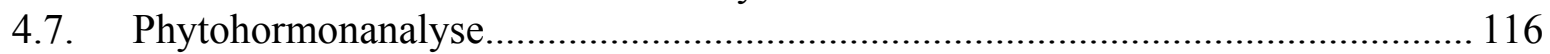

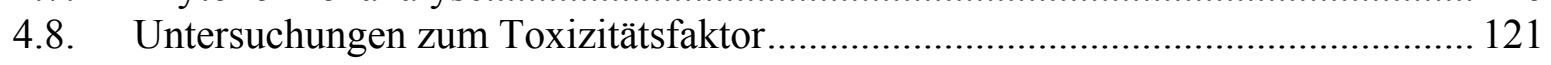

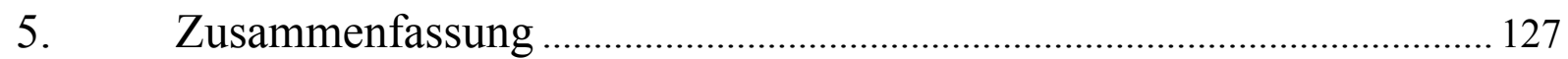

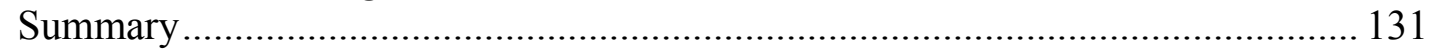

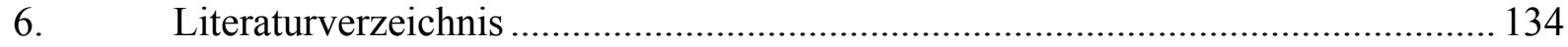

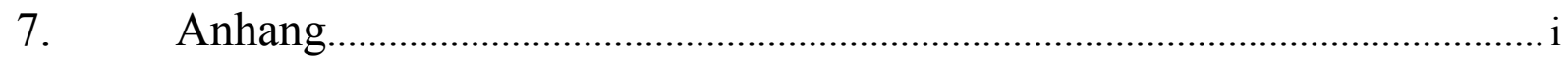

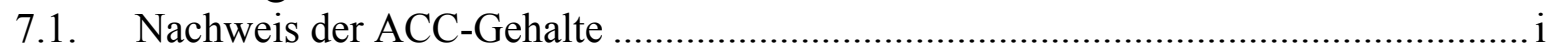

7.2. Chemikalienverzeichnis....................................................................................... ii

7.3. Verwendete Medien, Puffer und Lösungen .............................................................. iv

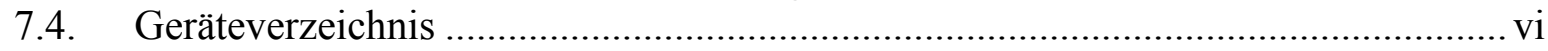




\section{Abbildungsverzeichnis}

Abb. 1: Übersicht der chemischen Reaktionen endogen produzierten oder aus Donatoren freigesetzten NOs in Pflanzen

Abb. 2: Durch Pathogenbefall ausgelöste Reaktionen von $\mathrm{NO}$ und $\mathrm{H}_{2} \mathrm{O}_{2}$ und deren mögliche Signalwege auf Seiten der Infektionsstelle und im systemischen Bereich von Pflanzen. ....... 16

Abb. 3: Durchführung des in vitro-Versuch zur Symptominduktion mit RCR-Keimlingen mittels Applikation von NO-Donatoren.

Abb. 4: Schematische Darstellung des in vitro-Biotests

Abb 5: Reaktion des NO-Fluoreszenzmarkers 4,5-Diaminofluorescein-Diacetat (DAF-2DA) mit NO auf Zellebene. 36

Abb. 6: Darstellung des Biotests zur Applikation von steril filtrierten Kulturüberständen auf sieben Tage alte RCR-Keimlinge im Biotest......

Abb. 7: Einfluss von V. longisporum (VL)- und V. dahliae (VD)-Befall im Verlauf eines Zeitreihenexperiment (14-35 dpi) auf die Sprosslänge und den Grad der Vergilbungserscheinungen erfasst als Boniturnoten..... 52

Abb 8: Spross- und Wurzeltrockengewichte [g] V. longisporum (VL)-, V. dahliae (VD)- und nicht-inokulierter RCR-Pflanzen (LK) über den Zeitraum 14-28 dpi..... 52

Abb. 9: Hypokotyldurchmesser [mm] V. longisporum (VL)-, V. dahliae (VD)- und nichtinokulierter RCR-Pflanzen (LK) aus einer Zeitreihe zu 21dpi, bis zum Austreten des ersten Xylemsaftes benötigter Druck [bar] derselben Pflanzen.

Abb. 10: PCR-Daten der ersten Zeitreihe; Nachweis von Verticillium-DNA [ng DNA g FW ${ }^{-1}$ ] in Hypokotyl- (H) und Sprossproben (S) V. longisporum (VL)- und V. dahliae (VD)-infizierter RCR-Pflanzen aus dem ersten Zeitreihenexperimente im Zeitverlauf von 14-35 dpi. .55

Abb. 11: PCR-Daten der zweiten Zeitreihe; Verticillium-DNA [ng DNA g FW ${ }^{-1}$ ] aus Hypokotyl (H), unterstem Sprossabschnitt (S bzw. S1), mittlerem Sprossteil (S2) und oberstem Sprossteil (S3) V. longisporum (VL)- und V. daliae (VD)-infizierter RCR-Pflanzen aus dem zweiten Zeitreihenexperiment im Zeitverlauf von 14-35 dpi. .55

Abb. 12: A: Wurzelansatz zwei Monate alter VL43-infizierter RCR- Pflanze mit Mikrosklerotienbesatz; B: Detailaufnahme der Mikrosklerotien (Pfeile) am obersten Wurzelansatz. .56

Abb. 13: Schwarzadrige Schoten zwei Monate alter VL43-infizierter RCR-Pflanzen ..... 56

Abb. 14: Auf Wasseragar ausgelegte Gewebestücke zwei Monate alter VL43-infizierter RCRPflanzen nach 4 Tagen Inkubation bei $23^{\circ} \mathrm{C}$ im Dunkeln 57

Abb. 15: Einfluss verschiedener Konzentrationen des NO-Donors Sodiumnitroprussid (SNP) auf das radiale Myzelwachstum [mm] von VL43 auf PDA 
Abb. 16: Relative Intensität des Elektronen-Spin-Resonanz (ESR)-Signals von Standardreihen des MGD-Fe ${ }^{2+}$-NO Komplexes mit unterschiedlichen Konzentrationen MGD-Spin-Trap..... 61

Abb. 17: Relative Intensität des Elektronen-Spin-Resonanz (ESR)-Signals einer Standardreihe des MGD-Fe ${ }^{2+}$-NO Komplexes nach unterschiedlicher Lagerung der Proben.....

Abb. 18: Relative Intensität des Elektronen-Spin-Resonanz (ESR)-Signals von Standardreihen des $\mathrm{MGD}_{-\mathrm{Fe}^{2+}}$-NO Komplexes. Überprüfung eines linearen Zusammenhangs zwischen der gewählten Amplitude (Verstärkung des Signals) und der tatsächlichen Signalhöhe. 62

Abb. 19: Relative Intensität des Elektronen-Spin-Resonanz (ESR)-Signals einer Standardreihe aus lyophilisierten SNP-Proben [mM] mit MGD als Spin-Trap. 62

Abb. 20: Dreifach-Spektren des MGD-Fe ${ }^{2+}$-NO-Komplexes aus MGD und Xylemsaft. 63

Abb. 21: Elektronen-Spin-Resonanz (ESR)-Spektrum des MGD-Fe ${ }^{2+}-\mathrm{NO}-\mathrm{Komplexes}$ in lyophilisierten Xylemsaftproben aus $V$. longisporum-, $V$. dahliae- und nicht-inokulierten Kontrollpflanzen vier Wochen nach Inokulation (28 dpi) 64

Abb. 22: Relative Intensität der Elektronen-Spin-Resonanz (ESR)-Spektren des MGD-Fe ${ }^{2+}$ NO Komplexes in lyophilisierten Xylemsaftproben aus einzelnen $V$. longisporum (VL)-, $V$. dahliae (VD)- und nicht-inokulierten Pflanzen (LK) über einen Zeitraum von 14-28 dpi,. 65

Abb. 23: Relative Intensität der Elektronen-Spin-Resonanz (ESR) Spektren des MGD-Fe ${ }^{2+}{ }_{-}$ NO Komplexes in lyophilisierten Xylemsaftmischproben V. longisporum (VL)-, V. dahliae (VD)- und nicht-inokulierter Pflanzen (LK), über einen Zeitraum von 14-35 dpi

Abb. 24: Relative Intensität der Elektronen-Spin-Resonanz (ESR)-Spektren einer Standardreihe aus NO-Donor MAHMA-NONOate $[\mu \mathrm{M}]$ und DETC als Spin Trap. 66

Abb. 25: Nitrit induziertes, mittels DETC Spin-Trap und Ethylacetat extrahiertes, NO-Signal aus Sprossgewebe sieben Tage alter RCR-Keimlinge 66

Abb. 26: Abhängigkeit der Fluoreszenzintensität von der Konzentration des NO-Donors MAHMA NONOate (A) und von der Länge der Inkubationszeit (B).

Abb. 27: Anstieg des DAF-Triazol Signals mit zunehmendem Volumen an Xylemsaft [ $\mu 1]$. 68

Abb. 28: Mit HPLC und DAF-2DA detektierte NO-Gehalte aus Spross- und Wurzelgewebeproben von RCR-Keimlingen $14 \mathrm{~h}$ nach Inokulation mit $V$. longisporumSporensuspension $(V L)$ und nach Wasserbehandlung (LK).

Abb. 29: Interaktion von Hyphen $(\mathrm{H})$ und Mikrosklerotien (M) mit der Wurzeloberfläche und Wurzelhaaren (WH) nach $24 \mathrm{~h}$ Inkubation von RCR-Keimlingen auf vorinokulierten $V$. longisporum WA-Platten für den Biotest. 70

Abb. 30: Interaktion von Hyphen $(\mathrm{H})$ und Mikrosklerotien (M) mit der Wurzeloberfläche (WO) und Wurzelhaaren (WH) nach $24 \mathrm{~h}$ Inkubation von RCR-Keimlingen auf vorinokulierten $V$. dahliae WA-Platten für den Biotest. 
Abb. 31: Effekt der Inkubation (sieben Tage) von RCR-Keimlingen im Biotest auf $V$. longisporum (VL)- und $V$. dahliae $(V D)$-vorinokulierten oder nicht behandelten (LK) WAPlatten unter standardisierten Bedingungen auf A. das Sprosswachstum, B. die Anzahl der Seitenwurzeln $>2 \mathrm{~mm}$ und C. die Primärwurzellänge. 71

Abb. 32: Mittels Titan-Oxalat-Methode photometrisch bestimmter $\mathrm{H}_{2} \mathrm{O}_{2}$-Gehalt $\left[\mu \mathrm{M} \mathrm{H}_{2} \mathrm{O}_{2} \mathrm{~g} \mathrm{FW}^{-1}\right]$ in gepoolten Spross- und Wurzelproben von sieben Tage alten $V$. longisporum (VL)-, V.dahliae (VD)- oder nicht-inokulierten Rapskeimlingen (LK); Zeitverlauf 1,5 bis 96 hpi 72

Abb. 33: Mittels Titan-Oxalat-Methode photometrisch bestimmter $\mathrm{H}_{2} \mathrm{O}_{2}$-Gehalt $\left[\mu \mathrm{M} \mathrm{H}_{2} \mathrm{O}_{2} \mathrm{~g} \mathrm{FW}^{-1}\right]$ in Spross- und Wurzelproben gepoolter Keimlinge (1-4 dpi) und einzelner Pflanzen (7-35 dpi). .73

Abb. 34: Mittels Titan-Oxalat-Methode photometrisch bestimmter $\mathrm{H}_{2} \mathrm{O}_{2}$-Gehalt $\left[\mu \mathrm{Mg} \mathrm{FW}{ }^{-1}\right.$ ] aus Hypokotylproben einzelner V. longisporum (VL)-, V. dahliae (VD)- oder nicht inokulierter Kontrollpflanzen (LK), Zeitverlauf 14 bis 35 dpi .... 73

Abb. 35: Mittels Titan-Oxalat-Methode photometrisch bestimmter $\mathrm{H}_{2} \mathrm{O}_{2}$-Gehalt $\left[\mu \mathrm{Mg} \mathrm{FW}{ }^{-1}\right.$ ] im Xylemsaft $V$. longisporum (VL)-, und nicht-inokulierter Kontrollpflanzen (LK), Zeitverlauf 14 bis 35 dpi 74

Abb. 36: GSNO-Reduktaseaktivität [nkat g FW-1] in gepoolten Spross- und Wurzelproben, $V$. longisporum (VL)-, V. dahliae (VD)- und nicht-inokulierter Kontrollpflanzen (LK) über den Zeitraum 14-35 dpi 76

Abb. 37: Cysteingebundenes NO [pM mg Protein ${ }^{-1}$ ] in gepoolten Spross- und Wurzelproben, V. longisporum (VL)-, V. dahliae (VD)- und nicht-inokulierter Rapspflanzen (LK) im Zeitraum 14-35 dpi... .77

Abb. 38: GSNO-Reduktaseaktivität [nkat $\mathrm{g} \mathrm{FW}^{-1}$ ] und Gehalt an cysteingebundenem NO $\left[\mathrm{pM} \mathrm{mg}^{-1}\right.$ Protein] aus gepoolten Sprossproben V. longisporum (VL)-, V. dahliae (VD)- oder nicht-inokulierter (LK) Pflanzen im Zeitraum von 14-35 dpi. .78

Abb. 39: GSNO-Reduktaseaktivität [nkat $\mathrm{g} \mathrm{FW}^{-1}$ ] und Gehalt an cysteingebundenem NO [pM mg ${ }^{-1}$ Protein] aus gepoolten Wurzelproben V. longisporum (VL)-, V. dahliae (VD)- oder nicht-inokulierter (LK) Pflanzen im Zeitraum von 14-35 dpi. 79

Abb. 40: Cysteingebundenes NO [pM mg Protein $\left.{ }^{-1}\right]$ in gepoolten Sprossproben nichtinokulierter (LK), V. longisporum (VL)- und V. dahliae (VD)-inokulierter Pflanzen im Zeitraum 14-35 dpi

Abb. 41: A. Cysteingebundenes NO $\left[\mathrm{pM} \mathrm{mg}^{-1}\right.$ Protein] und B. GSNO-Reduktaseaktivität in [nkat $\mathrm{g} \mathrm{FW}^{-1}$ ] aus Spross- und Wurzelproben V. longisporum (VL)-, V. dahliae (VD)- und nicht-inokulierter Keimlinge (LK) 24 hpi 80

Abb. 42: ABA-Gehalte [ppb g FW ${ }^{-1}$ ] einer Zeitreihe in A. Spross- und B. Wurzelproben $V$. longisporum (VL)-, V. dahliae (VD)- und nicht-inokulierter Rapspflanzen (LK) über einen Zeitraum von 14-35 dpi..... 
Abb. 43: SA-Gehalte $\left[\mu \mathrm{M} \mathrm{g} \mathrm{W}^{-1}\right]$ in A. Spross- und B. Wurzelproben V. longisporum (VL)-, $V$. dahliae (VD)- und nicht-inokulierter Rapspflanzen (LK) über einen Zeitraum von 1435 dpi..... 82

Abb. 44: JA-Gehalte [ppb g FW ${ }^{-1}$ ] in A. Spross- und B. Wurzelproben V. longisporum (VL)-, $V$. dahliae (VD)- und nicht-inokulierter Rapspflanzen (LK) über einen Zeitraum von 14-35 dpi; $\mathrm{n}=10, *=$ signifikant unterschiedlich für $\mathrm{P}<0,05$ (LSD-Test).

Abb. 46: IAA-Gehalte $\left[\mu \mathrm{M} \mathrm{g} \mathrm{FW}^{-1}\right.$ ] in A. Spross- und B. Wurzelproben V. longisporum (VL), $V$. dahliae (VD)- und nicht-inokulierter Rapspflanzen (LK) über einen Zeitraum von 14-35 dpi..... 84

Abb. 47: Petiolentoxizitätstest; von links nach rechts angeordnet jeweils 10 Blätter 21 Tage alter RCR-Pflanzen in $\mathrm{H}_{2} \mathrm{O}$ (Kontrolle), nicht-inokuliertem CzD-Medium (K), V. longisporum- und V. dahliae-inokuliertem CzD-Medium .85

Abb. 48: Applikation steriler CzD-Kulturfiltrate im Topfversuch .86

Abb. 49: Effekt steriler V. longisporum (VL)-, V. dahliae (VD)- und nicht-inokulierter Kulturfiltrate aus unterschiedlichen Medien auf das Sprosswachstum [cm] von RCRKeimlingen in vitro nach einer Inkubationszeit von 5 Tagen 87

Abb. 50: Effekt steriler V. longisporum (VL)-, V. dahliae (VD)- und nicht-inokulierter Kulturfiltrate unterschiedlicher Medien in vitro auf A. die Sprosslänge $[\mathrm{cm}]$, B. die Primärwurzellänge und C. Anzahl der Seitenwurzeln $>2 \mathrm{~mm}$ von RCR-Keimlingen nach einer Inkubationszeit von 5 Tagen .88

Abb. 51: Effekt membranfiltrierter Fraktionen V. longisporum-inokulierter (VL) und nicht inokulierter (LK) SXM-Schüttelkulturen auf das Sprosswachstum [cm] von RCR-Keimlingen 7 Tage nach Applikation unter in vitro-Bedingungen

Abb. 52: Effekt membranfiltrierter Fraktionen V. longisporum (VL)- und nicht-inokulierter (LK) SXM-Schüttelkulturen auf die Boniturnote von RCR-Keimlingen sieben Tage nach Applikation unter in vitro-Bedingungen 90

Abb. 53: Effekt der Applikation verschiedener AcN-Fraktionen (10, 20, 40, 60 und $80 \%)$ aus $V$. longisporum (VL)- und $V$. dahliae $(V D)$-SXM-Schüttelkulturen sowie nicht-inokuliertem SXM-Medium (LK) in vitro auf sieben Tage alte RCR-Keimlinge nach sieben Tagen Inkubation. 91

Abb. 54: Darstellung des ACC-Gehaltes $\left[\mathrm{nmol} \mathrm{g} \mathrm{FW}^{-1}\right]$ in Einzelsprossproben $V$. longisporum- und nicht infizierter Rapspflanzen über den Zeitraum 14-35 dpi ..... 


\section{Tabellenverzeichnis}

Tab. 1: Stickstoffmonoxid (NO)-Synthase Aktivität in verschiedenen Pflanzenspezies und verschiedenen Zell- und Gewebetypen und die entsprechenden Detektionsmethoden 20

Tab. 2: Boniturskala zur Befallserfassung von V. longisporum an B. napus anhand der Symptomausprägung nach künstlicher Inokulation unter konstanten Klimakammerbedingungen (modifiziert nach ZEISE 1992). 27

Tab. 3: Zusammensetzung des PCR-Reaktionsmix zur Detektion von Verticillium-DNA aus Pflanzengewebe

Tab. 4: Real-Time PCR-Programm zur Detektion von Verticillium-DNA aus Pflanzengewebe.

Tab. 5: Varianten und Konzentrationen der Donatoren sowie Anzahl der verwendeten Keimlinge im in vivo NO-Applikationsversuch zur Symptominduktion.

Tab. 6: Zusammensetzung der verwendeten Laufmittel zur Analyse von NO per HPLC. 37

Tab. 7: Laufzeit, Flussrate und Volumenanteile der Laufmittel zur Analyse von NO per HPLC

Tab. 8: Zusammensetzung der verwendeten Laufmittel ${ }^{1}$ zur Trennung von Thiolen per HPLC. 40

Tab. 9: Laufzeit, Flussrate und Volumenanteile der Laufmittel zur Trennung von Thiolen per HPLC.

Tab. 10: Übersicht der Varianten und verwendeten Amicon-Filter zur Überprüfung der Stauchewirkung von SXM-Fraktionen unterschiedlicher Molekülgrößen.

Tab. 11: Visuelle Boniturnoten und entsprechende Symptombilder für RCR-Keimlinge nach Applikation der Amicon-filtrierten SXM-Kulturen und sieben Tagen Inkubation. 49

Tab. 12: Einfluss der NO-Donatoren SNP und SNAP sowie einer Eisencyanid (FeCN)- und unbehandelten Wasserkontrolle nach in vitro-Applikation auf die Parameter A. Anzahl Seitenwurzeln B. Pflanzenlänge und C. Primärwurzellänge von RCR-Keimlingen sechs Tage nach Applikation . 59

Tab. 13: Mittelwerte der Boniturnoten und Sprosslängen $(\mathrm{cm})$ von RCR-Keimlingen sieben Tage nach Applikation membranfiltrierter Fraktionen V. longisporum-inokulierter $(V L)$ und nicht inokulierter (LK) SXM-Schüttelkulturen unter in vitro-Bedingungen ...ii 


\section{Abkürzungsverzeichnis}

Formelzeichen und Einheiten

\begin{tabular}{|c|c|}
\hline$\%$ & Prozent \\
\hline$\lambda$ & Wellenlänge in $\mathrm{nm}$ \\
\hline${ }^{\circ} \mathrm{C}$ & Grad Celsius \\
\hline$\mu g$ & Mikrogramm \\
\hline$\mu 1$ & Mikroliter \\
\hline $\mathrm{d}$ & Tage \\
\hline $\mathrm{Da}$ & Dalton \\
\hline $\mathrm{g}$ & Gramm \\
\hline $\mathrm{G}$ & Gauss (magnetische Flussdichte) \\
\hline $\mathrm{GHz}$ & Gigahertz \\
\hline $\mathrm{h}$ & Stunde \\
\hline ha & Hektar \\
\hline $\mathrm{kHz}$ & Kilohertz \\
\hline 1 & Liter \\
\hline M & molar \\
\hline $\mathrm{mg}$ & Milligramm \\
\hline $\min$ & Minute \\
\hline $\mathrm{ml}$ & Milliliter \\
\hline $\mathrm{mM}$ & millimolar \\
\hline $\mathrm{mW}$ & Milliwatt \\
\hline $\mathrm{nm}$ & Nanometer \\
\hline $\mathrm{rpm}$ & Umdrehungen pro Minute (,roundings per minute“) \\
\hline RT & Raumtemperatur \\
\hline $\mathrm{s}$ & Sekunde \\
\hline $\mathrm{t}$ & Tonne \\
\hline $\mathrm{U}$ & Einheit (,Unit“") \\
\hline \multicolumn{2}{|c|}{ Allgemeine Abkürzungen } \\
\hline Abb. & Abbildung \\
\hline bspw. & beispielsweise \\
\hline $\mathrm{cv}$. & cultivar \\
\hline et al. & et altere \\
\hline Fa. & Firma \\
\hline f. sp. & forma specialis \\
\hline Kap. & Kapitel \\
\hline mind. & mindestens \\
\hline $\mathrm{n}$ & Anzahl der biologischen Proben \\
\hline Nr. & Nummer \\
\hline pv. & Pathovar \\
\hline Tab. & Tabelle \\
\hline u.a & unter anderem \\
\hline usw. & und so weiter \\
\hline var. & Varietät \\
\hline Vol. & Volumen \\
\hline z.B. & zum Beispiel \\
\hline
\end{tabular}


Fortführung allgemeine Abkürzungen

\begin{tabular}{|c|c|}
\hline $\mathrm{ABA}$ & Abscisinsäure (,,abscisic acid“) \\
\hline $\mathrm{ACC}$ & 1-Aminocyclopropan-1-Carboxylsäure \\
\hline AVG & (S)-Trans-2-Amino-4-(2-Aminoethoxy)-3- \\
\hline & Butenoic Acid Hydrochlorid \\
\hline bidest. & bidestilliert \\
\hline CHES & 2-[N-Cyclohexylamino]-Ethansulfonsäure \\
\hline CLSM & $\begin{array}{l}\text { Konfokale Laser Scan Mikroskopie ("Confocal Laser Scanning } \\
\text { Microscopy") }\end{array}$ \\
\hline cPTI & 2-(4-Carboxyphenyl)-4,4,5,5-Tertramethylimidazoline-1-Oxyl \\
\hline cPTIO & $\begin{array}{l}\text { 2-(4-Carboxyphenyl)-4,4,5,5-Tetramethylimidazoline-1-Oxyl-3- } \\
\text { oxide, potassium salt }\end{array}$ \\
\hline CTAB & Cetyltrimethylammoniumbromid \\
\hline $\mathrm{CzD}$ & Czapek Dox \\
\hline DAF-2 DA & 4,5-Diaminofluorescein Diacetate \\
\hline DAF-2 & 4,5-Diaminofluorescein \\
\hline DAF-FM & 4-Amino-5-Methylamino-2',7'-Difluorofluorescein Diacetate \\
\hline DETC & Natriumdiethyldithiocarbamate Trihydrate \\
\hline DMSO & Dimethylsulfoxid \\
\hline DNA & Desoxyribonukleinsäure („desoxyribonucleic acid“) \\
\hline dNTP & Desoxyribonukleosidetriphosphat (G/A/T/C) \\
\hline dpi & Tage nach Inokulation (,days past inoculation“) \\
\hline EDTA & Ethylendiamintetraessigsäure \\
\hline ELISA & $\begin{array}{l}\text { Enzym gekoppelter, Antikörper gebundener Nachweis } \\
\text { („Enzyme-linked Immunosorbent Assay“) }\end{array}$ \\
\hline ESR & Elektronen Spin Resonanz Spektrometrie \\
\hline $\mathrm{EtBr}$ & Ethidiumbromid \\
\hline $\mathrm{EtOH}$ & Ethanol \\
\hline FAD & Flavinadenindinukleotid \\
\hline FMN & Flavinmononukleotid \\
\hline $\mathrm{FeCN}$ & Eisen(III)-Hexacyanoferrat \\
\hline GFP & Grün fluoreszierendes Protein (,Green Fluorescent Protein“) \\
\hline GSH & Glutathion \\
\hline GSNO & S-Nitrosoglutathion \\
\hline GSNOR & $\begin{array}{l}\text { GSNO-abhängige Formaldehyd-Dehydrogenase (GSNO-Reduktase) } \\
\text { EC 1.2.1.1 }\end{array}$ \\
\hline GSSG & Glutathiondisulfid \\
\hline HEPES & Hydroxethylpiperazinethanylsulfonsäure \\
\hline HPLC & "High Performance Liquid Chromatography" \\
\hline HPLC-MS & HPLC mit angeschlossenem Massenspektrometer \\
\hline HR & Hypersensitiver Respons „Hypersensitive Response“ \\
\hline IAA & Auxin (Indol-3-Essigsäure, "indole acetic acid") \\
\hline $\mathrm{JA}$ & Jasmonsäure (,jasmonic acid“) \\
\hline KPP & $\mathrm{K}_{2} \mathrm{HPO}_{4} / \mathrm{KH}_{2} \mathrm{PO}_{4}$ \\
\hline MAHMA NONOate & 1,6-Hexanediamine, NO-Donor \\
\hline $\mathrm{mBrB}$ & Monobrombiman (Thiolyte ${ }^{\mathrm{TM}} \mathrm{MB}$ ) \\
\hline MGD & $\mathrm{N}$-(Dithiocarbamoyl)-N-Methyl-D-Glucamine. Na. $\mathrm{H}_{2} \mathrm{O}$ \\
\hline mRNA & messenger-RNA \\
\hline $\mathrm{N}_{2}$ & Stickstoff \\
\hline NADH & Nicotinamid Adenine Dinucleotid (reduziert) \\
\hline $\mathrm{NiR}$ & Nitrit Reduktase \\
\hline
\end{tabular}




$\begin{array}{ll}\text { NOS } & \text { NO-Synthase } \\ \text { PCD } & \text { Programmierter Zelltod (,Programmed Cell Death”) } \\ \text { PCR } & \text { Polymerase Kettenreaktion ("Polymerase Chain Reaction”) } \\ \text { PDA } & \text { Kartoffel-Dextrose Agar (,Potato Dextrose Agar“) } \\ \text { pH } & \text { Negativer dekadischer Logarithmus der } \\ & \text { Wasserstoffionenkonzentration } \\ \text { PR } & \text { Pathogenese bezogen ("Pathogenese Related”) } \\ \text { PVPP } & \text { Polyvinylpyrolidon } \\ \text { RCR } & \text { „rapid cycling rapeseed“ } \\ \text { RNA } & \text { Ribonukleinsäure (,ribonucleic acid“) } \\ \text { ROS } & \text { Reaktive Sauerstoff Spezies (,,Reactive Oxygen Species“) } \\ \text { RT } & \text { Raumtemperatur } \\ \text { SA } & \text { Salicylsäure (,,salicylic acid“) } \\ \text { SNAP } & \text { S-Nitroso-N-Acetylpenicillamine } \\ \text { SNP } & \text { Sodium Nitroprusside Dihydrate } \\ \text { SOD } & \text { Superoxid-Dismutase } \\ \text { TBAHS } & \text { Tetrabutylammonium-Bisulfate } \\ \text { TG } & \text { Trockengewicht } \\ \text { TiOx } & \text { Kaliumtitanoxidoxalat Dihydrat } \\ \text { Tris } & \text { Tris(hydroxymethyl)-Aminomethan } \\ \text { Triton-X } 100 & \text { Octylphenol-Polyethylenglycolether } \\ \text { ÜS } & \text { Überstand } \\ \text { UV } & \text { Ultraviolett } \\ \text { v/v } & \text { Volumen/Volumen } \\ \text { w/v } & \text { Gewicht/Volumen }\end{array}$




\section{Einleitung}

\subsection{Bedeutung von Raps in der deutschen Landwirtschaft}

In der EU wurde im Anbaujahr 2006/2007 auf etwa 6,2 Mio. ha Fläche Raps (Brassica napus) angebaut. Dabei stellte Deutschland hinter Frankreich das zweitwichtigste EU-Anbauland für Raps dar (ZMP 2007). Laut der Union zur Förderung von Öl- und Proteinflanzen e.V. (UFOP) wurde die Rapsanbaufläche aufgrund des hohen Fruchtfolgewertes und guter Marktperspektiven deutschlandweit im Vergleich zum vorangegangenen Jahr um 6,5 \% (um 91.760 ha auf 1.495.060 ha) gesteigert (UFOP 2007a). Vor allem die Lebensmittelindustrie verzeichnet eine verstärkte Rapsnachfrage in der Ölsaatenverarbeitung (6,2 Mio. t oder 63 \% der Gesamtverarbeitung) (Verband Deutscher Oelmühlen 2004). Positive Fruchtfolgeeffekte wie Verbesserung der Bodenfruchtbarkeit, weniger Unkrautentwicklung und frühe Feldräumung zeichnen Raps als wertvolles Glied vor allem in getreideintensiven Fruchtfolgen aus. Auch die erhöhte Nachfrage nach Pflanzenölen als alternativer Energiequelle (Biodiesel) und die gesteigerten Erdölpreise machen Raps als Ölsaat für Landwirte besonders lukrativ (DBV 2006). Einer Mitteilung der UFOP zufolge werden für den Rapsanbau 2007/2008 die Anbaukapazitäten für Winterraps durch die gesteigerte Marktnachfrage und sinkende Rapsvorräte sowie die Aussetzung der obligatorischen Flächenstilllegung durch den EUAgrarrat bis an die Fruchtfolgegrenzen gesteigert werden (UFOP 2007b). Mit der zunehmenden Anbaufläche und den immer enger gestellten Fruchtfolgen erhöht sich jedoch die Wahrscheinlichkeit des Auftretens von Rapskrankheiten.

\section{2. „Krankhafte Abreife“ durch Verticillium longisporum}

Neben Insekten, Nematoden, und Unkräutern sind für den Rapsanbau vor allem Schäden durch pilzliche Pathogene von wirtschaftlicher Bedeutung. Insbesondere die durch Sclerotinia sclerotiorum (Lib.) de Bary (AMELUNG et al. 1996) ausgelöste Weißstängeligkeit und die durch Phoma lingam (Tode ex Schw.) Desm. hervorgerufene Wurzelhals- und Stängelfäule (ZHOU et al. 1999) verursachen große Ertragsverluste. Des Weiteren sind Kohlhernie (Plasmodiophora brassicae) und Rapsschwärze (Alternaria brassicae) für den Rapsanbau von Bedeutung. In Schweden hat sich mittlerweile der Befall von Raps mit Verticillium longisporum, dem Erreger der „krankhaften Abreife“, zur bedeutendsten Gefahr für den Rapsanbau entwickelt (DiXELIUS et al 2005). Auch in der Bundesrepublik hat sich dieses Pathogen seit den 80er Jahren insbesondere in Gebieten mit hohen Anbauintensitäten wie Schleswig-Holstein oder Mecklenburg-Vorpommern, stark ausgebreitet 
(KRÜGER 1989; AHLERS 1987). Ertragsverluste von bis zu $25 \%$ wurden z.B. auf Fehmarn ermittelt (GÜNZELMANN \& PAUL, 1990). Problematisch für die Bekämpfung ist, dass dieser auf Brassicaceen spezialisierte Pilz ein bodenbürtiges Pathogen ist, das seine Wirtspflanze über die Wurzel infiziert und sich vaskulär ausbreitet. Da sprossapplizierte Fungizide basipetal nicht systemisch über das Xylem verteilt werden, ist diese Möglichkeit der Bekämpfung oder Verminderung des Befalls nicht möglich (AHLERs 1989; HoRNIG 1986; Fradin \& ThOMma 2006). Des Weiteren sind bisher keine resistenten Rapssorten auf dem Markt, obwohl mittlerweile viel versprechende Genotypen von Brassica oleracea für Züchtungszwecke identifiziert wurden (HAPPSTADIUS et al. 2003; DiXELIUS et al. 2005; RYGULLA et al. 2007). Erschwerend kommt für die Landwirte die schwierige Diagnose der Krankheit hinzu.

\subsection{Nachweis und Symptome von $V$. longisporum-Befall}

Das Hauptinfektionspotential im Feld bilden im Boden überdauernde Mikrosklerotien. Konidien und Myzel sind in der Regel nicht lange im Boden überlebensfähig (Galanopoulus \& Tribe 1974; Menzies \& Griebel 1967). Bei für den Pilz günstigen Bedingungen und unter Einfluss von Wurzelexudaten keimen die Mikrosklerotien aus (Mol \& Scholte 1995). Der erste Kontakt der Hyphen mit der Wirtspflanze erfolgt in der Wurzelhaarzone (ZHOU et al. 2006; EYNCK et al. 2007). Die Hyphen können intakte Zellen der Wurzelepidermis penetrieren und dringen dabei inter- oder auch intrazellulär bis in die Leitgefäße der Wurzel vor. Die Vermehrung des hyalinen, septierten Myzels erfolgt nur in einzelnen Gefäßen (EYNCK et al. 2007). Die ovalen bis länglichen Konidien mit zwei typischen Lipidtröpfchen werden an langen Phialiden gebildet, die spiralförmig oder wirtelig um die Konidiophoren angeordnet sind. Die Konidien werden durch den Xylemstrom akropetal in den vaskulären Elementen verbreitet, wodurch sie bis an die Tüpfel gelangen. Hier keimen sie wieder aus und die Hyphen dringen ins nächste Leitgefäß vor. Neue Konidien werden gebildet und die Kolonisierung der oberen Leitgefäße wird fortgeführt (BeCKMAN 1987; Gold et al. 1996). Mit dem Beginn der Seneszenz verlässt der Pilz die Leitbahnen und besiedelt das umliegende parenchymatische Gewebe. Fast zeitgleich werden die Mikrosklerotien im absterbenden Gewebe v.a. unter der Stängelepidermis gebildet (Mol 1995; Mol \& Scholte 1995). Die von V. longisporum in der Pflanze gebildeten Überdauerungsorgane, die typischen schwarzen Mikrosklerotien (50-70 $\mu \mathrm{M})$, gelangen mit Ernterückständen in den Boden und können dort bis $\mathrm{zu} 14$ Jahre überdauern (HEALE \& KARAPAPA 1999). Eine eindeutige Identifizierung erkrankter Pflanzen ist erst zur 
Abreife mit Ausbildung Mikrosklerotien unter der Stängelepidermis möglich (ab BBCH 80) (ZeISE \& SteINBACH 2004). Symptome wie einseitige Verbräunung des Stängels sowie Vergilbung des Blattapparates und auch die ersten Grau- und Schwarzfärbungen des Stängels können nicht immer eindeutig V. longisporum zugeordnet werden. Abiotische Faktoren, vor allem aber Mischinfektionen mit anderen verbreiteten Rapspathogenen wie dem Erreger der Wurzelhals- und Stängelfäule $P$. lingam, können ähnliche Symptome verursachen (ZeISE \& STEINBACH 2004; KUUSK et al. 2002). Da die Ausbildung der Krankheitssymptome relativ spät in der Pflanzenentwicklung erfolgt, sind die ertragsbildenden Prozesse allerdings auch schon so gut wie abgeschlossen. Der ertragsmindernde Effekt der Krankheit tritt durch die Notreife und das dadurch hervorgerufene Aufplatzen der Schoten auf (DUNKER \& VON TIEDEMANN 2005). Allerdings scheinen Befallshäufigkeit und Befallszeitpunkt eine große Rolle auf die Ertragsverluste zu haben. Bei Befallshäufigkeiten von $50 \%$ traten keine, bei Befallshäufigkeiten von $75 \%$ hingegen hohe Verluste von bis zu 13-22 \% auf (DUNKER et al. 2006; KREYE et al. 2006). Die Verringerung des Anbauabstandes in der Fruchtfolge um 1 Jahr kann daher zu einem Befallsanstieg (STEINBACH et al. 2005) bzw. Kornmassenverlusten von bis zu 50\% führen (DAEBELER et al. 1988). Ebenfalls können höhere Bestandesdichten starke Ertragseinbußen zur Folge haben (ZEISE \& SEIDEL 1990). Da sich V. longisporum fast über die gesamte Pflanzenentwicklung im Wurzelbereich aufhält und seine Verbreitung über das Xylem der Pflanze in die oberirdischen Pflanzenteile erst mit deren Abreife beginnt, ist das Pathogen in frühen Stadien des Infektionsverlaufs im Freiland lange Zeit nicht nachweisbar. Erst ca. 2-3 Wochen vor Auftreten der Symptome kann der Erreger im Feld mit diagnostischen Hilfsmitteln wie dem immunologischen „Enzyme-linked Immunosorbent Assay“ (ELISA) oder der Polymerasekettenreaktion (PCR) nachgewiesen werden (STEINBACH et al. 2005; DUNKER \& VON TIEDEMANN 2005).

Untersuchungen zum Nachweis des Pilzes an Feldpflanzen zeigten, dass das Pathogen erst sehr spät mit Abreife der Pflanzen im Spross eindeutig nachweisbar ist (GünZelmann \& Paul 1990, Z Zeise \& Seidel 1990, Zeise \& Steinbach 2004, SteinBach et al. 2005, DunKer 2005). Die späte Symptombildung (v.a. vorzeitige Seneszenz und Mikrosklerotienbildung), die unter Feldbedingungen erst mit Abreife der Pflanzen auftritt, lässt sich unter Gewächshausbedingungen allerdings vorverlagern, wobei hier vornehmlich das Symptom der Stauche auftritt (ZEISE 1992; KeuneCKE, 2005). Unter diesen Bedingungen konnten beispielsweise ZHOU et al. (2006) V. longisporum an B. napus mittels PCR auch bereits im Dreiblattstadium (BBCH 13) in der Wurzel und nach Ausbildung des ersten Seitentriebes $(\mathrm{BBCH} 21)$ bereits im Stängel nachweisen. Es bleibt daher die Frage 
offen, inwiefern die Ausbreitung des Pathogens für die Symptombildung notwendig ist bzw. diese beeinflusst.

\subsection{V. dahliae, Erreger der „Verticillium-Welke“}

Bis etwa 1997 wurde die „Krankhafte Abreife“ an Raps V. dahliae zugeordnet, der ein weitaus größeres Wirtsspektrum (Artischocke, Pfeffer, Kartoffel, Tomate, Weintrauben, Oliven, Erdbeere, Baumwolle, Flachs, Sonnenblume und holzige mehrjährige Pflanzen) besitzt (Schnathorst 1981; Domsch et al. 1980; Pegg \& Brady 2002). Zwar fanden STARK et al. schon 1961 mikroskopisch abweichende Isolate mit deutlich längeren Sporen an Merrettich, die als V. dahliae var. longisporum klassifiziert wurden, und die sich in weiteren Tests (KARAPAPA et al., 1994) als Brassica-spezifisch erwiesen, doch erst in Folge morphologischer und molekulargenetischer Untersuchungen wurde 1997 postuliert, dass es sich dabei um eine eindeutig separate, auf Brassicaceen spezialisierte, langsporige, mit höherem DNA-Gehalt ausgestattete, eigene Art handelt (KARAPAPA et al. 1997; SteVEnton et al. 2002; Collins et al. 2003). V. dahliae zeigt an einem breiten Spektrum von Wirtspflanzen unterschiedliche Symptome: Verbräunung der Leitelemente, vorzeitige Vergilbung und einseitige Welke sind jedoch typisch (PEGG \& BRADY 2002; SCHNATHORST 1981). In mehreren Studien konnte gezeigt werden, dass V. dahliae niederund hochmolekulare phytotoxische Metaboliten sekretiert (NACHMIAS et al. 1987), die als Elicitoren die Produktion von Phytoalexinen bei einer Vielzahl von Wirtspflanzen (z.B. Nicotiana benthamiana, Arabidopsis thaliana, Gossypium arboreum und Lycopersicum esculentum) induzieren und stark positiv mit der Ausbildung der Welkesymptome korrelieren (Buchner et al. 1982; MeYer et al. 1994; WANG et al. 2004). An B. napus konnte bisher keine Symptomausbildung nach Infektion mit $V$. dahliae nachgewiesen werden. Durch neuere histologische und molekulargenetische Untersuchungen mittels GFP-exprimierender Isolate von V. longisporum- und V. dahliae (EYNCK et al. 2007) konnte deutlich gemacht werden, dass $V$. dahliae zwar die Wurzeln, nicht aber den Spross von B. napus besiedelt und keine Krankheitssymptome hervorruft. B. napus kann somit als Nicht-Wirtspflanze für $V$. dahliae eingestuft werden.

\subsection{Mögliche Auslöser der V. longisporum-Symptomatik}

Anders als $V$. dahlie ist $V$. longisporum in der Lage, systemisch in den Spross von anfälligen Brassica-Genotypen einzudringen und sich dort auszubreiten. In diesem Fall besteht zwischen 
Wirt und Pathogen eine kompatible Interaktion, d.h. das Pathogen kann die Pflanze besiedeln und sich vermehren. Allerdings ist für $V$. longisporum bisher kein vergleichbarer Toxizitätsfaktor (Phytotoxin) gefunden worden und die Mechanismen mit denen die Symptombildung (Stauche und frühzeitige Reife) induziert wird sind bis dato unbekannt. Bislang ist unklar, worin die Abwehr der Pflanze besteht und ob der Pilz in der Lage ist, diese aktiv zu unterdrücken, oder ob die Pflanze das Pathogen nicht erkennt und deshalb keine Abwehr auslöst.

Es besteht die Möglichkeit, dass systemisch transportierte, entweder vom Pilz produzierte oder durch Kontakt mit dem Pathogen auf pflanzlicher Seite gebildete Signalmoleküle, z.B. reaktive Sauerstoffspezies wie Stickstoffmonoxid (NO) oder Wasserstoffperoxid $\left(\mathrm{H}_{2} \mathrm{O}_{2}\right)$, die Symptome direkt oder indirekt durch deren Einflussnahme bspw. auf den pflanzlichen Hormonstatus induzieren. Welche Funktion diese beiden Signalmoleküle für die Transduktion von Stressreaktionen haben und warum eine Beteiligung beider Moleküle in der Symptombildung dieser Interaktion als wahrscheinlich erachtet wird, soll in den folgenden Abschnitten erläutert werden.

\subsection{Funktionen von $\mathrm{H}_{2} \mathrm{O}_{2}$ in der Pflanzenzelle}

Mittlerweile ist anerkannt, dass $\mathrm{H}_{2} \mathrm{O}_{2}$ und $\mathrm{NO}$ wichtige Funktionen als Signalmoleküle in Pflanzen besitzen (NeILl et al. 1999; Durner \& KLESSIG 1999). $\mathrm{H}_{2} \mathrm{O}_{2}$ zählt, wie auch Superoxid $\left(\mathrm{O}_{2}^{-}\right)$und das Hydroxyl-Radikal $\left(\mathrm{OH}^{-}\right)$, zu den reaktiven Sauerstoffspezies (ROS). ROS sind normale Nebenprodukte des pflanzlichen Stoffwechsels, werden aber vor allem durch Störungen des Elektronentransportsystems unter oxidativen Stressbedingungen gebildet. $\mathrm{H}_{2} \mathrm{O}_{2}$ entsteht dabei als Nebenprodukt der Reduktion von Sauerstoff zu Wasser (1).

$\mathrm{O}_{2} \rightarrow(\mathrm{H}) \mathrm{O}_{2} \cdot^{-} \rightarrow \mathrm{H}_{2} \mathrm{O}_{2} \rightarrow \mathrm{OH} \cdot+\mathrm{H}_{2} \mathrm{O} \rightarrow 2 \mathrm{H}_{2} \mathrm{O}$

$\mathrm{Da} \mathrm{O}_{2}^{-}$und $\mathrm{OH}^{-}$sehr reaktiv und somit instabil sind, stellt $\mathrm{H}_{2} \mathrm{O}_{2}$ das erste stabile und transportable Produkt der ROS dar, dessen Nachweis als Indikator für oxidativen Stress genutzt werden und das aufgrund seiner Mobilität als Signalmolekül für Stressreaktionen fungieren kann (VAN Breusegem et al. 2001; LAMB \& DiXON 1997). Vor allem bei umgebungsbedingtem abiotischem Stress wie verstärkter UV-Strahlung, Temperaturerhöhungen und Trockenheit (BARTOSZ et al. 1997) oder aber durch Ozon, Verwundung, Phytohormone wie Abscisinsäure (ABA) und biotischem Stress wie Pathogenbefall kommt es zur vermehrten Bildung von $\mathrm{H}_{2} \mathrm{O}_{2}$ (LAMB \& DiXON 1997; OrOzO- 
CARDENAS \& RYAN 1999;

GUAN et al. 2000;

LANGEBARTELS et al. 2000;

GuAN \& SCANDALIOS 2000; A-H-MacKerness et al. 1999). Als Hauptquellen der ROSProduktion bei abiotischem Stress gelten Chloroplasten, Mitochondrien und Mikrosomen (VAN Breusegem et al. 2001). Die Produktion von $\mathrm{H}_{2} \mathrm{O}_{2}$ kann auf verschiedenen enzymatischen Wegen erfolgen wie durch membrangebundene NADPH-Oxidasen, zellwandlokalisierte Peroxidasen, Amin-Oxidase, Oxalat-Oxidase oder eine Flavin-haltige Oxidase (Bolwell et al. 2002). Die Balance zwischen Bildung und Abbau der ROS kann dabei über den Fortbestand oder das Absterben der Zelle entscheiden. Die spezifischen Antworten der Zelle (je nach Stressor) auf diese Signalmoleküle werden vermutlich sowohl durch die Synthese der Moleküle als auch deren Perzeption an oder in bestimmten Zellkompartimenten wie z.B. Plastiden oder Plasmamembranen ausgelöst (NEILL et al. 2002). Eine maßgebliche Verteidigungsstrategie der Pflanzen gegenüber Pathogenen ist die hypersensitive Reaktion (,hypersensitive response“, HR), die dadurch charakterisiert ist, dass an den Infektionsstellen zuerst die schnelle Akkumulation reaktiver Sauerstoffspezies (ROS) initiiert (innerhalb von Minuten) und anschließend durch eine zweite Phase der ROSProduktion der Programmierte Zelltod (,programmed cell death“, PCD) (LEVINE et al. 1994) induziert wird, der zu lokalen Nekrosen führt, welche die systemische Ausbreitung bestimmter Pathogene unterbinden (LAMB \& DiXON 1996; GREENBERG \& YAO 2004). Diese HR mit anschließendem PCD kann in den meisten Fällen durch die Interaktion eines vom Pathogen kodierten Avirulenz-Gen (avr) Produkts und einem pflanzlichen Resistenz-Gen $(R)$ Produkts ausgelöst. Die HR durch schnellen Anstieg der ROS wird aber auch durch exogene oder endogene Elicitoren, bestimmte Pathogenbestandteile oder zelleigene Strukturbestandteile, die bei Pathogenbefall z.B. durch Zersetzung von Zellwänden entstehen, induziert. Die Bildung von $\mathrm{ROS} / \mathrm{H}_{2} \mathrm{O}_{2}$ durch eine pathogeninduzierte HR führt neben dem PCD auch zur Bildung von zellwandgebundenen Phenolen (GRANT \& LOAKE 2000), der Vernetzung von Zellwandproteinen (BRADLEY et al. 1992) und kann abwehrbezogene Gene aktivieren (DESIKAN et al. 1998; JABS et al. 1997; LEVINE et al. 1994). In vielen Systemen ist die Produktion von $\mathrm{H}_{2} \mathrm{O}_{2}$ als initiale Reaktion auf Pathogenbefall bereits untersucht worden. Die Induktion des PCD durch $\mathrm{H}_{2} \mathrm{O}_{2}$ konnte z.B. in transgenen Tabakpflanzen ohne Katalase-/Peroxidaseaktivität gezeigt werden, die dadurch eine Hypersensitivität gegenüber Pathogenbefall aufwiesen (MiTTLER et al. 1999). An A. thaliana-Zellkulturen, wurden sowohl die $\mathrm{H}_{2} \mathrm{O}_{2}$-Akkumulation als auch die Folgereaktionen wie der PCD und die Expression von Abwehrgenen durch Applikation bakterieller Elicitoren (Harpine) hervorgerufen (DESIKAN et al. 1996; ClaRKE et al. 2000). In Sojabohnen (Glycine max) wurden durch $\mathrm{H}_{2} \mathrm{O}_{2-}$ 
Zugabe die beiden an der Pflanzenabwehr beteiligten Gene Glutathion-S-Transferase (GST) und Glutathion-Peroxidase (GPX, LEVINE et al. 1994) exprimiert; in A. thaliana GST und zusätzlich Phenylalanin Ammonium-Lyase (PAL, DESIKAN et al. 1998), die einen Zwischenschritt des Phenylpropanoid Weges katalysiert und dadurch Intermediate für die Produktion von Isoflavonoiden, phenolischen Derivaten und Salicylsäure (SA) bereitstellt (DiXON \& PAIVA 1995).

Auch im Hinblick auf phytohormonähnliche Mechanismen, die im Zusammenhang mit der pflanzenphysiologischen Entwicklung stehen, ist ein Einfluss von $\mathrm{H}_{2} \mathrm{O}_{2}$ nachgewiesen worden. So konnte gezeigt werden, dass Elicitoren die Bildung von $\mathrm{H}_{2} \mathrm{O}_{2}$ auslösen (Allan \& FluHr 1997) und dies die Schließung von Stomata bewirkt (McAinsch et al. 1996; LeE et al. 1999). Dass $\mathrm{H}_{2} \mathrm{O}_{2}$ gar für die Funktionalität des Schließmechanismus notwendig ist, zeigten PEI et al. (2000). In Versuchen mit A. thaliana löste die Zugabe von Abscisinsäure (ABA) eine $\mathrm{H}_{2} \mathrm{O}_{2}$-Produktion aus, die wiederum die Schließung der Stomata bewirkte. Indem die A.thaliana-Pflanzen mit einem NADPHInhibitor, behandelt wurden, der die Bildung von $\mathrm{H}_{2} \mathrm{O}_{2}$ unterbindet, konnte durch alleinige ABA-Zugabe auch keine Schließung der Stomata mehr induziert werden. $\mathrm{H}_{2} \mathrm{O}_{2}$ induziert auch Gene, die an seiner eigenen Synthese (NADPH-Oxidase, DESIKAN et al. 1996) und Degradation beteiligt sind. Darüber hinaus ist es an der Regulation des Redoxstatus der Zelle beteiligt, indem es die Expression für die Peroxisomenbildung kodierender Gene anregt, die als Syntheseort für Antioxidantien und NO dienen (LOPEZ-HuERTAS et al. 2000).

\subsection{Funktionsweise und chemische Eigenschaften von NO}

Die Funktion von Stickstoffmonoxid (NO) als biochemischer Botenstoff wurde erst Mitte der 80er Jahre entdeckt (FURCHGOTT \& ZAWADSKI 1980, FurCHGOTT et al. 1999; IGNARRO et al. 1987). Diese Signalfunktionen, bspw. in der Immunabwehr und als Neurotransmitter, sind in phylogenetisch sehr unterschiedlichen Spezies (Tieren, Pflanzen, Pilzen und Bakterien) konserviert (BELIGNI \& LAMATTINA 2001) und machen NO somit zu einem bedeutsamen Signalstoff. Durch seine lipophilen Eigenschaften kann es Zellmembranen leicht passieren und ist daher in Geweben sehr mobil, was einen schnellen Signalaustausch zwischen Zellen ermöglicht (BELIGNI \& LAMATTINA 2001). Des Weiteren ist NO aufgrund seiner Radikaleigenschaften, es besitzt ein ungepaartes Elektron, sehr reaktiv und kann mit einer Vielzahl von Molekülen reagieren. Diese Reaktionen, auf denen die Funktion von NO auf Zellebene häufig basiert, soll im Folgenden näher erläutert werden. 


\subsubsection{Bildung, Reaktionspartner und Funktion von NO in Pflanzenzellen}

Die Reaktionen zwischen NO und anderen Molekülen in der pflanzlichen Zelle sind vielfältig. Da pflanzliche Zellen ein wässriges Milieu darstellen, in denen u.a. Sauerstoff $\left(\mathrm{O}_{2}\right)$ produziert wird, findet dort in unmittelbarer Folge v.a. die Reaktion zwischen Stickstoffmonoxid (NO·) und Sauerstoff $\left(\mathrm{O}_{2}\right)$ zu Stickstoffdioxid $\left(\mathrm{NO}_{2}\right)$ statt (2).

$2 \mathrm{NO}+\mathrm{O}_{2} \rightarrow 2 \mathrm{NO}_{2}$

Dies geschieht vor allem bei fortwährend hohen Konzentrationen von $\mathrm{NO}$ und hohem $\mathrm{O}_{2}$ Partialdruck, z.B. bei der Respiration. Bei physiologischen Konzentrationen des NO im nanomolaren Bereich würde diese Reaktion etwa 15-30 min dauern (FEELISCH \& STAMLER 1996). Da NO schlecht wasserlöslich ist und unter physiologischen Bedingungen noch andere Reaktionspartner zur Verfügung stehen, spielt diese Reaktion eine untergeordnete Rolle. In der Gasphase ist das Endprodukt $\mathrm{NO}_{2}$ stabil. Unter wässrigen Bedingungen werden daraus stöchiometrische Mengen Nitrit $\left(\mathrm{NO}_{2}^{-}\right)$und Nitrat $\left(\mathrm{NO}_{3}{ }^{-}\right)$ gebildet $(3,4)$, siehe Abb. 1A.

$2 \mathrm{NO}_{2} \rightarrow \mathrm{N}_{2} \mathrm{O}_{4}$

$\mathrm{N}_{2} \mathrm{O}_{4}+\mathrm{H}_{2} \mathrm{O} \rightarrow \mathrm{NO}_{2}^{-}+\mathrm{NO}_{3}^{-}+2 \mathrm{H}^{+}$

Aufgrund seiner Radikalstabilisierung reagiert NO mit organischen Zielmolekülen eher langsam. Mit anderen Radikalen - v.a. mit $\mathrm{O}_{2}^{-}$- reagiert NO fast diffusionskontrolliert, wodurch Peroxynitrit (ONOO`) gebildet wird (5), siehe Abb. 1 B.

$\mathrm{NO}+\mathrm{O}_{2}^{-} \rightarrow \mathrm{ONOO}^{-}$

Peroxynitrit ist ein starkes Oxidationsmittel, das mit einer Vielzahl anderer biologischer Moleküle (v.a. mit Tyrosinresten von Proteinen) reagiert, und aufgrund seines hohen Oxidationspotentials starken oxidativen Schaden an zellulären Strukturen hervorrufen kann. Die Geschwindigkeitskonstante für die Reaktion mit $\mathrm{O}_{2}^{-}$ist dreimal größer als die Geschwindigkeitskonstante für die Dismutation von $\mathrm{O}_{2}{ }^{-}$durch Superoxid-Dismutase. Daher findet die Bildung von Peroxynitrit in vivo wahrscheinlich auch in Gegenwart physiologischer Konzentrationen von Superoxid-Dismutase statt (MALINSKI et al. 1993). Weitere wichtige 
Zielmoleküle sind Thiolgruppen von Proteinen und Peptiden. Unter physiologischen pHBedingungen treten daher auch Nitrosylierungsreaktionen auf, in denen die vorhandenen Thiolgruppen in Anwesenheit von $\mathrm{O}_{2}$ durch $\mathrm{NO}$ zu S-Nitrosothiolen (RSNOs) nitrosyliert werden. Diese Nitrosylierung kann über zwei Mechanismen erfolgen, zum einen durch Transfer einer Nitrosoniumgruppe $\left(\mathrm{NO}^{+}\right)$. Nitrosierungsmittel können z.B. salpetrige Säure, Alkylnitrite, Nitrosylhalogenide, $\mathrm{N}_{2} \mathrm{O}_{3}$ oder $\mathrm{N}_{2} \mathrm{O}_{4}$ sein. In Gegenwart von Sauerstoff könnte aus NO in wässriger Lösung $\mathrm{N}_{2} \mathrm{O}_{3}$ gebildet werden, welches dann entsprechend folgender Gleichung (6) reagieren würde:

$$
\mathrm{N}_{2} \mathrm{O}_{3}+2 \mathrm{RSH} \rightarrow 2 \mathrm{RS}-\mathrm{NO}+\mathrm{H}_{2} \mathrm{O}
$$

Eine andere Möglichkeit ist die Radikalreaktion (7), für die allerdings die Bildung/Anwesenheit von Thiyl-Radikalen (RS·) notwendig ist. Zur Erhaltung des Redoxstatus der Zelle werden verschiedene Thiole, wie z.B. Glutathion (GSH), benötigt. Es ist daher möglich, dass Thiyl-Radikale, also deprotonierte SH-Gruppen (Übergangsstadien von reduziertem GSH und oxidiertem Glutathiondisulfid (GSSG), in niedrigen Gleichgewichtskonzentrationen vorhanden sind und unter physiologischen Bedingungen mit NO S-Nitrosothiol (SNO) bilden.

$\mathrm{RS}^{\bullet}+\mathrm{NO} \rightarrow \mathrm{RSNO}$

S-Nitrosothiol stellt eine bevorzugte Speicher- und Transportform für NO dar und weist ein ähnliches Wirkungsprofil wie NO selbst auf. Die Freisetzung von NO aus Nitrosothiolen erfolgt langsam, kann aber in vitro durch die Anwesenheit von $\mathrm{Cu}^{+}$-Ionen beschleunigt werden. Die S-Nitrosierung übernimmt vermutlich eher regulatorische Funktionen. Die NNitrosierung von Aminogruppen hingegen hat vor allem schädliche Wirkungen. Ein Intermediat der NO-Autoxidation, vermutlich $\mathrm{N}_{2} \mathrm{O}_{3}$ kann direkt mit primären Aminen der DNA-Basen reagieren und diese nitrosieren. Des Weiteren kann die N-Nitrosierung sekundärer Amine, durch die Nitrosamine entstehen (8), ebenfalls DNA und andere Makromoleküle schädigen (PFEIFFER et al. 1999).

$\mathrm{N}_{2} \mathrm{O}_{3}+\mathrm{R}_{2} \mathrm{NH} \rightarrow \mathrm{R}_{2} \mathrm{~N}-\mathrm{NO}+\mathrm{NO}_{2}^{-}+\mathrm{H}^{+}$ 
Direkte Reaktionen von NO finden vor allem bei geringen Konzentrationen von NO (unter $1 \mu \mathrm{M})$ z.B. mit Übergangsmetallen $\left(\mathrm{Fe}^{2+} / \mathrm{Fe}^{3+}\right)$ statt (Abb. 1C). Ein Beispiel dafür ist die Bindung an die Haem-Gruppe löslicher und membrangebundener Guanylylcyclase. Diese Reaktion führt $\mathrm{zu}$ einer Konfigurationsänderung und aktiviert z.B. die enzymatische Produktion von cyclischem Guanosinmonophosphat (cGMP) aus Guanosintriphosphat (GTP) (MurAD et al. 1994). Möglich ist auch die Bindung von NO an das Haem-Zentrum der Cytochrom-P450-Enzyme, die zur Inhibierung der Enzyme führt (KATHSENKO et al. 1993). Die Bindung an Haemoglobine (Leghaemoglobine) wird als eine der Hauptreaktionen von NO in Pflanzen erachtet, denn sie bietet eine Möglichkeit, NO zu speichern, zu detoxifizieren oder weiterzuleiten (Gow et al. 1999). In einem zweistufigen Prozess wird in Pflanzen durch die Reaktion von NO mit Haemoglobin unter aeroben Bedingungen $\mathrm{NO}_{3}$ gebildet (PFEIFFER et al. 1999). Auch die Reaktionsprodukte von NO können Enzymaktivitäten beeinflussen. Peroxynitrit beispielsweise kann reversibel durch Cluster-Bildung die Funktion von Enzymen mit Eisen-Schwefel-Komplexen unterbinden (9).

$[4 \mathrm{Fe}-4 \mathrm{~S}]^{2+}+\mathrm{ONOO}^{-}+\mathrm{H}^{+} \rightarrow[3 \mathrm{Fe} 4 \mathrm{~S}]^{+}+\mathrm{NO}^{-}+\mathrm{NO}_{2}+\mathrm{Fe}^{2+}$

Eine solche Reaktion findet zum Beispiel in der Interaktion mit der cytosolischen Aconitase einem Enzym des Krebs-Zyklus statt, wodurch ein Eisen-Nitrosyl-Komplex entsteht. Diese Komplexbildung inhibiert die Aktivität des Enzyms und wandelt es zu einem RNA-bindenden Eisenregulationsprotein um (WINK et al. 1998). In dieser Funktion wirkt das Protein an der Translation von Genprodukten mit, die an der Speicherung oder Freisetzung von Eisen beteiligt sind, wie z.B. Ferretin, und verhindert ihre Translation. Diese Reaktion induziert aber wiederum oxidativen Stress, da das entstehende $\mathrm{Fe}^{2+}$ in der sogenannten Fenton-Reaktion zur Bildung von Hydroxy-Radikalen führen kann. Eine Reaktion, in der das Zusammenwirken mit $\mathrm{H}_{2} \mathrm{O}_{2}$ wieder eine Rolle spielt. Des Weiteren wird auch der Gehalt an Eisen $\left(\mathrm{Fe}^{3+}\right)$ in den Zellen erhöht (10).

$\mathrm{Fe}^{2+}+\mathrm{H}_{2} \mathrm{O}_{2} \rightarrow \mathbf{F e}^{3+}+\mathbf{O H}^{-}+\mathrm{OH}$ 


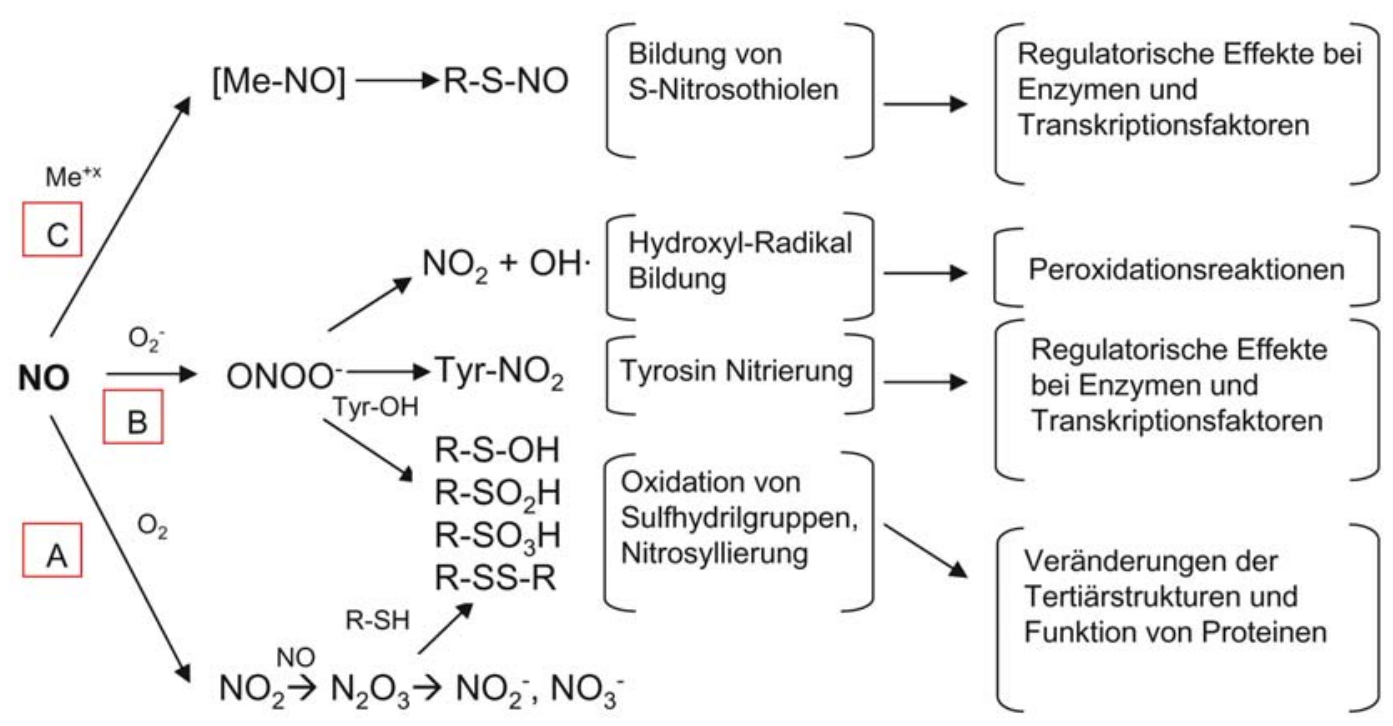

Abb. 1: Übersicht der chemischen Reaktionen endogen produzierten oder aus Donatoren freigesetzten NOs in Pflanzen. A. In Anwesenheit von Sauerstoff wird $\mathrm{NO} z u \mathrm{NO}_{2}$ oxidiert, $\mathrm{NO}_{2}$ reagiert mit einem weiteren $\mathrm{NO} z u \mathrm{~N}_{2} \mathrm{O}_{3}$ und bildet letztendlich $\mathrm{NO}_{2}-\mathrm{NO}_{3}{ }^{-}$. B. Durch die Reaktion mit Superoxid $\left(\mathrm{O}_{2}^{-}\right)$wird Peroxynitrit gebildet, das wiederum zur Bildung von $\mathrm{NO}_{2}$ und zur Bildung von Hydroxylradikalen (OH-) führt. Weitere Reaktionen des Peroxynitrit führen $\mathrm{zu}$ Nitrierung von Tyrosinen $\left(\mathrm{Tyr}-\mathrm{NO}_{2}\right)$ oder Oxidation von Thiol-Resten zu Sulfonsäure. NO·kann ebenfalls Thiol-Gruppen von Cysteinen aus Proteinen nitrosylieren (R$\mathrm{S}-\mathrm{NO})$. C. Sind Übergangsmetalle $\left(\mathrm{Me}^{+\mathrm{x}}\right)$ wie $\mathrm{Fe}, \mathrm{Cu}$ oder $\mathrm{Zn}$ vorhanden kann $\mathrm{NO}$ mit diesen interagieren und Metall-Nitrosyl-Komplexe bilden; auf diesen Reaktionen basieren die regulatorischen Effekte des NO bzgl. Transkriptionsfaktoren oder Enzymaktivitäten. In Anlehnung an LAMATTINA et al. (2003).

\subsubsection{NO-induzierte Effekte in der Pflanze}

Sowohl bei abiotischem Stress als auch in normalen physiologischen Entwicklungsprozessen spielt NO in der Pflanzenzelle eine Rolle. Die Auswirkungen von NO-Applikation auf die Stresstoleranz gegenüber abiotischen Faktoren oder auf die Pflanzenentwicklung sollen an einigen Beispielen veranschaulicht werden.

Der Einfluss von NO auf die Stressantworten der Pflanzen bzgl. abiotischer Faktoren fällt unterschiedlich aus. Beispielsweise konnte eine verstärkte Trocken- und Salztoleranz, gesteigerte UV-B Toleranz, Verzögerung der Seneszenz und Verminderung von oxidativem Stress in verschiedenen Pflanzen wie Saubohne (Vicia faba), Schilfrohr (Phragmites communis Trin.), Gerste (Hordeum vulgare cv. Himalaya) und Weizen (Triticum aestivum) bei vorheriger Zugabe von NO in Form von chemischen NO-Donatoren beobachtet werden (GARCIA-MATA \& LAMATTINA 2002; ZHAO et al. 2004;

BELIGNI et al. 2002; BELIGNi \& LAMATTINA 2002). NO wird allerdings auch durch Einfluss von abiotischem Stress produziert: UV-B Strahlung, hohe Temperaturen und hyperosmotischer Stress 
bewirkten einen NO-Anstieg sowohl in Zellkulturen als auch Epidermiszellen von Tabak (Gould et al., 2003). Ob NO als generelle Stressantwort beurteilt werden kann, ist fraglich. Widersprüchliche Ergebnisse bestehen bzgl. eines NO-Anstiegs nach Verwundung durch mechanischen- und lichtinduzierten Stress (Gould et al. 2003; GARCÊs et al. 2001; Pedroso et al. 2000b; OrozCO-CÁRDENAS \& RYAN 2002).

In der Pflanzenentwicklung konnte die Funktion von $\mathrm{NO}$ als Wachstumsregulator in Experimenten zur Ausdehnung von Erbsenblättern nachgewiesen werden (LESHEM \& HARAMATY 1996). Geringe Konzentrationen einer Mischung aus $\mathrm{KNO}_{2}$ und $\mathrm{KI} / \mathrm{H}_{2} \mathrm{SO}_{4}$, die $\mathrm{NO}$ generiert, förderten deren Wachstum, hohe Konzentrationen hatten keinen Effekt. Beligni \& LAMATtina (2000) zeigten, dass der lichtabhängige Prozess der Hypokotyl- und Internodienverkürzung in Salat (Lactuca sativa L. cv Grand Rapids) und A. thaliana durch Zugabe nanomolarer Konzentrationen NO induziert werden konnte. Des Weiteren steigerte NO die Verfügbarkeit und den Transport metabolisch aktiven Eisens (GRAZIANO et al. 2002), welches einen positiven Einfluss auf die Ausbildung von Chlorophyll und Chloroplasten z.B. in dunkel gekeimten Weizenkeimlingen hatte (Beligni \& Lamattina 2000). Auch die Phytoalexinakkumulation in Kartoffelknollen sowie Kotyledonen der Sojabohne wurde durch einen Anstieg von NO mittels NO-Donatoren wie Sodiumnitroprussid (SNP) oder Zugabe von Elicitoren induziert (NORITAKE et al. 1996; Modolo et al. 2002).

$\mathrm{Zu}$ den wichtigsten Funktionen von NO im pflanzlichen Stoffwechsel zählt aber v.a. die Inhibierung antioxidativer Systeme über Wechselwirkungen mit Katalase, AscorbatPeroxidase und Aconitase (NAVARRE et al. 2000; Clark et al. 2000). Durch die Inhibierung dieser Enzyme nimmt NO direkten Einfluss auf die Regulation und Bildung anderer ROS wie $\mathrm{H}_{2} \mathrm{O}_{2}$. Auch durch Interaktion mit der Cytochrom-Oxidase und der ATP-Synthese nimmt NO Einfluss auf die Funktionalität von Mitochondrien und Chloroplasten, was die MitochondrienAktivität verändert und in einem induzierten PCD resultieren kann (ZOTTINI et al. 2002; AKAHASHI \& YAMASAKI 2002). NO kann andererseits aber auch als Antioxidans wirken und z.B. den PCD in Gerste oder Kartoffel verzögern (BELIGNI \& LAMATTINA 1999; BeLIGNI et al. 2002). Eine weitere wichtige Funktion besitzt NO bzgl. des PCD im Hinblick auf die Ausbildung von Leitelementen. Für die Differenzierung von Zellen zu Xylemgefäßen ist gezielte Zell-Autolysis notwendig, die durch einen Anstieg an NO induziert wird. Vor allem scheint NO eine Schlüsselfunktion im letzten Schritt der LigninSynthese einzunehmen und an der Bildung von sekundären Zellwänden mitzuwirken (FerRer \& Ros BARCEló 1999; Ros BARCEló et al. 2002; Ros BARCEló 2005; 
GABALDÓN et al. 2005). Die Funktion von NO in der Interaktion mit biotischen Stressoren war Gegenstand der ersten Untersuchungen zur Signalfunktion von NO in Pflanzen (Delledonne et al. 1998; Durner et al. 1998; Klessig et al. 2000). Allerdings handelte es sich dabei zumeist um inkompatible Reaktionen, die in einer erfolgreichen Abwehrreaktion der Pflanze resultierten wie im folgenden Kapitel ausführlicher dargestellt wird.

\subsubsection{NO in der Wirt-Pathogen-Interaktion}

Der Anstieg von NO, neben $\mathrm{H}_{2} \mathrm{O}_{2}$ als eine der ersten Reaktionen auf Pathogenkontakt konnte bereits in einer Vielzahl von Systemen nachgewiesen werden. Insbesondere in den Publikationen von Delledonne et al. (1998) und Durner et al. (1998) wird die Bedeutung von NO als Signalmolekül als Antwort der Pflanzenzelle auf Pathogenbefall hervorgehoben. So konnten die Autoren beobachten, dass bei Pathogenbefall NO gleichzeitig mit $\mathrm{H}_{2} \mathrm{O}_{2}$ gebildet wird und auch ähnliche Abwehrmechanismen ausgelöst werden.

MUR et al. (2006) beobachteten an Tabak und A. thaliana, dass die HR und der NO-Anstieg durch Kontakt mit Pseudomonas syringae pv. phaseolicola und P. syringae pv. tomato bereits 30-45 min nach Inokulation ausgelöst wurden. Ein noch schnellerer Anstieg der NO-Gehalte (innerhalb von 3 Minuten) konnte in Tabakblättern nach Zugabe des aufgereinigten Elicitors Cryptogein ausgelöst werden (FOISSNER et al. 2000).

Durch Applikation von Oligogalacturonsäure, eines durch Zellwanddegradation produzierten Elicitors, wurden auch in Ginsengzellen (Panax ginseng) eine NO-Akkumulation und ein Anstieg der NOS-Aktivität nachgewiesen (Hu et al. 2003). Gleichermaßen zeigten auch Kartoffelknollen einen starken NO-Anstieg, wenn sie in Kontakt mit einem Elicitor aus Phytophthora infestans gebracht wurden (YАмАмОтО et al. 2003). Lipopolysaccharide der Zelloberflächen gram-negativer Bakterien, so genannte LPS, bewirkten in Zellkulturen sowie Blättern von A. thaliana sowohl eine lokale als auch eine systemische Erhöhung des NOLevels (ZEIDLER et al. 2004). Im Zusammenhang mit kompatiblen Pathogenen konnte in A. thaliana-Zellkulturen allerdings bisher nur ein extrem niedriger Anstieg von NO detektiert werden (DELLEDONNE et al. 1998; ClARKE et al 2000).

Zytologische Untersuchungen an infizierten Weizenzellen wiesen darauf hin, dass weder die Verwendung von NO-Donatoren noch die Veränderung von $\mathrm{H}_{2} \mathrm{O}_{2}$ alleine einen Einfluss auf die Ausbildung der HR hatten, obwohl beide Moleküle für die Weiterleitung des PCD an benachbarte Zellen nötig sind (TADA et al. 2004). Auch ist die Bildung des toxischen Reaktionsproduktes Peroxynitrit $\left(\mathrm{ONOO}^{-}\right)$aus $\mathrm{NO}$ und $\mathrm{O}_{2}^{-}$nicht Auslöser des $\mathrm{PCD}$, da die 
Zugabe verschiedener Konzentrationen Peroxynitrits zu Zellkulturen der Sojabohne (G. max cv. Williams 82) deren Vitalität nicht beeinflussten (DELLEDONNE et al. 2001).

Daraus lässt sich schließen, dass nur der gleichzeitige Anstieg von NO und ROS (insbesondere $\mathrm{H}_{2} \mathrm{O}_{2}$ ) oder deren abgestimmtes Verhältnis letztendlich zur Ausbildung einer HR führt, wohingegen der Anstieg einer einzelnen Komponente den erwünschten Zelltod nicht induzieren kann (Delledonne et al. 1998, De Pinto et al. 2002). NO scheint daher eine Rolle in der Weiterleitung des PCD von Zelle zu Zelle spielen, nicht aber bei dessen Initiierung (MUR et al. 2006; ZHANG et al. 2003).

\subsection{4. $\mathrm{H}_{2} \mathrm{O}_{2}$ und $\mathrm{NO}$ in der systemisch erworbenen Resistenz (SAR)}

Da die Infektion von Rapspflanzen mit V. longisporum Sprosssymptome auslöst, obwohl der Pilz ausschließlich über die Wurzel infiziert und sich häufig erst nach der Symptomausbildung im Spross etabliert, ist $\mathrm{zu}$ vermuten, dass systemisch aktive Signale Mechanismen auslösen, die zur Symptomausprägung führen. Dass $\mathrm{NO}$ und $\mathrm{H}_{2} \mathrm{O}_{2}$ nicht nur lokale Reaktionen auslösen, sondern auch bei der systemischen Aktivierung von Signalketten involviert sind, wird am Beispiel der systemisch erworbenen Resistenz (SAR) deutlich.

Nach Erkennung des Pathogens, der Akkumulation reaktiver Sauerstoffspezies (ROS) und von NO, sowie der Induktion des PCD werden ausgehend von den HR-betroffenen Zellen Stressmoleküle wie z.B. Salicylsäure (SA), Jasmonsäure (JA) und Ethylen gebildet und systemisch in der Pflanze verbreitet, wo sie in distalem Gewebe eine entscheidende Rolle beim Erwerb der SAR spielen. Dabei führt die HR lokal zur transkriptionellen Induktion von Pflanzenabwehrgenen in benachbarten Zellen (DANGL et al. 1996). Die Expression von pathogenesebezogenen Proteinen wie z.B. 1-3- $\beta$-Glucanase oder Chitinase ist damit eng verbunden. In den meisten Fällen handelt es sich dabei um Proteine mit direkter antimikrobieller Funktion oder Proteine, die bei Überexpression eine erhöhte Resistenz vermitteln $\quad$ (BROEKAERT et al. 1995; $\quad$ SMITH 1996; $\quad$ Hu \& REDDY 1997; Morrissey \& OSBOURn 1999). Auch die Induktion von Phytoalexinen und die Ausbildung von Penetrations- und Ausbreitungsresistenzen z.B. durch Zellwandverstärkung und Papillenbildung ist dabei von Bedeutung (Abb. 2). Diese nachhaltige systemische Reaktion auf den Befall mit avirulenten Pathogenen schützt die Pflanze vor nachfolgenden Angriffen weiterer Pathogene.

Die gleichzeitige Applikation von NO- und ROS-Donatoren bewirkte z.B. in Tabakzellen (N. tabacum cv. Bright-Yellow) einen Anstieg der Expression der für Phenolstoffwechsel und Lignifizierungsprozesse wichtigen Phenylalanin-Ammonium-Lyase

(PAL) 
(De Pinto et al. 2002). Auch Polverari et al. (2003) konnten zeigen, dass die über den Phenylpropanoid-Weg gesteuerten Abwehrreaktionen, die Expression der Cinnamat-4Hydroxylase in A. thaliana durch NO induziert wurde. Die Bildung von Phytoalexinen als eine weitere Möglichkeit der Pathogenabwehr konnte in Sojabohnen durch eine Erhöhung des NO-Levels mittels SNP-Zugabe induziert werden (NORITAKE et al. 1996; Modolo et al. 2002).

Eine wichtige Signalkomponente, über welche die Expression der Abwehrgene reguliert werden kann, ist die Akkumulation von Salicylsäure (SA). Dieses Phytohormon spielt zwar auch bei der Akkumulation der ROS und NO in der HR eine wichtige Rolle, ist aber ebenfalls an der für die SAR kennzeichnenden Expression des Abwehrgens PR1 beteiligt. Dass NO die Bildung von SA und deren Konjugaten beeinflusst, wurde bereits in Tabak nachgewiesen (DURNER et al. 1998). In Tabakmutanten, die kein SA akkumulierten (NahG), wurde die Aktivierung von PR1 durch Zugabe von NO-Donatoren erzielt (DURNER et al. 1998). Tabakpflanzen, die zuvor mit NO-Donatoren behandelt wurden, zeigten auf unbehandelten Blättern, die nachträglich mit TMV inokuliert wurden, eine verminderte Ausprägung von Lokalläsionen. Mutanten, in denen die Akkumulation von SA blockiert war, zeigten keine Verminderung der Läsionen (SONG \& GoOdMAN 2001). Daher scheint NO wie auch SA eine wichtige Rolle in der SAR-Signaltransduktionskette zu spielen. Trotzdem scheint SA nicht der Hauptauslöser der SAR zu sein. Als ein möglicher Kandidat wird Nitrosoglutathion (GSNO) diskutiert (DURNER et al. 1998). 


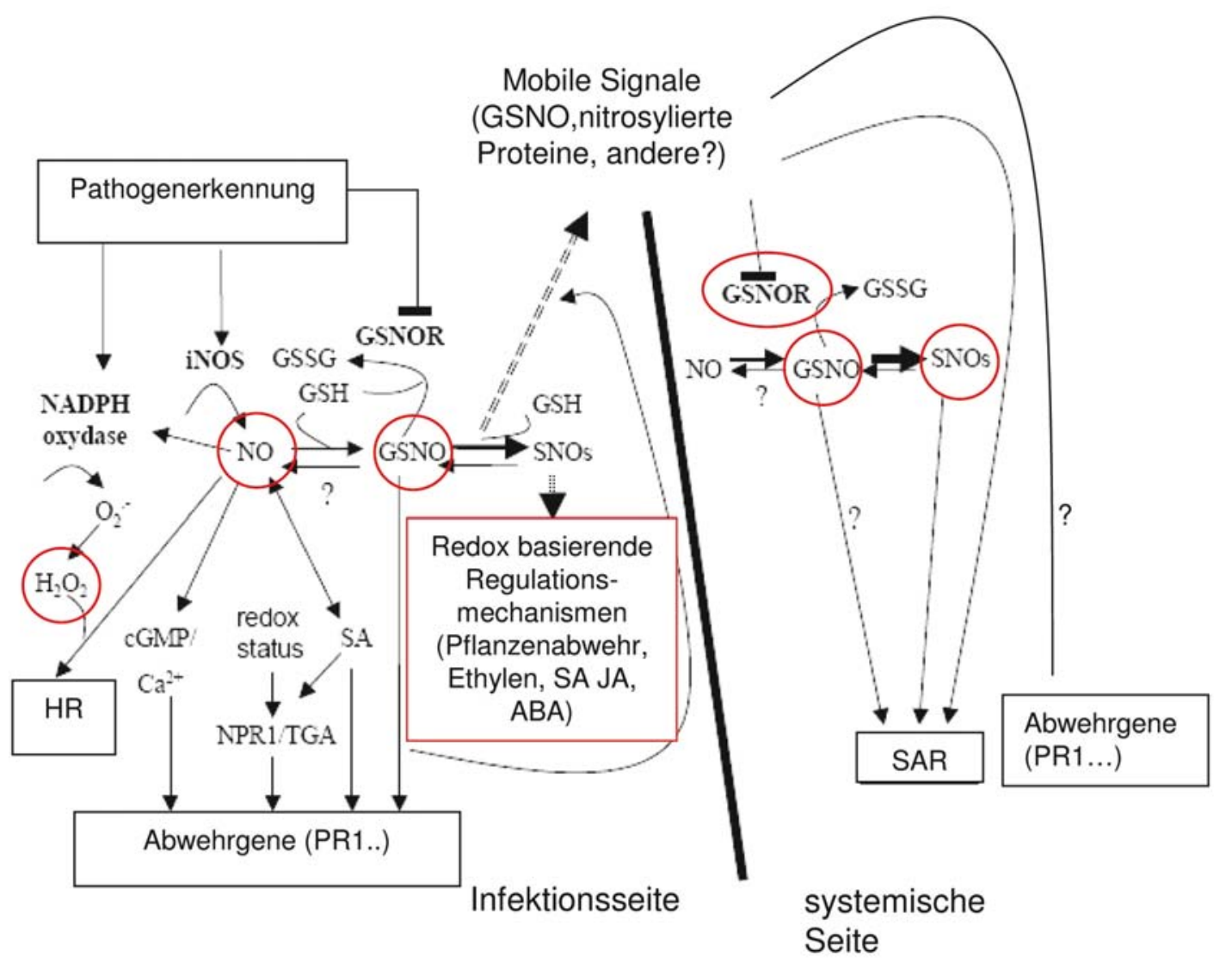

Abb. 2: Durch Pathogenbefall ausgelöste Reaktionen von $\mathrm{NO}$ und $\mathrm{H}_{2} \mathrm{O}_{2}$ und deren mögliche Signalwege auf Seiten der Infektionsstelle und im systemischen Bereich von Pflanzen. HR (hypersensitive Reaktion), cGMP (cyclisches Guanosinmonophosphat), NO (Stickstoffmonoxid), GSH (Glutathion), GSSG (Glutathiondisulfid), GSNO (Nitrosoglutathion), GSNOR (Nitrosoglutathionreduktase), SNO (nitrosylierte Proteine), iNOS (induzierte NO-Synthase), SAR (systemisch erworbene Resistenz). In dieser Arbeit untersuchte Signalmoleküle sind rot umkreist. In Anlehnung an DURNER et al. (1998).

\subsubsection{NO und Phytohormone}

Mittlerweile wurde in mehreren Experimenten bestätigt, dass NO mit einer Reihe von Phytohormonen interagiert und dadurch verschiedene Mechanismen der Pflanze direkt oder indirekt beeinflusst. Die molekularen Mechanismen sind allerdings in den meisten Fällen nicht vollständig aufgeklärt. Trotzdem ist eine Interaktion beider Komponenten in vielen Pflanzen ersichtlich. Da das Zusammenwirken von NO und SA bereits im Zusammenhang der Pathogen/Wirt-Interaktion des vorherigen Kapitels erläutert wurde, soll im Folgenden noch eine kurze Übersicht wichtigster Funktionen im Zusammenspiel mit den weiteren in dieser Arbeit untersuchten Hormonen Abszisinsäure (ABA), Indol-3-Essigsäure (IAA), Jasmonsäure (JA) und Ethylen gegeben werden. Abszisinsäure werden oftmals wachstumsmindernde Funktionen zugeschrieben, da stressinduziertes vermindertes Wachstum mit einem Anstieg 
von ABA einhergeht (MARIOn-Poll \& Leung 2006). Andererseits zeigen Mutanten von A. thaliana, die eine stark verringerte ABA-Produktion aufweisen, einen gestauchten Phänotyp. ABA kann also auch wachstumsfördernd wirken (SCHARP et al. 2000). Wasserverlust geht in Pflanzen ebenfalls mit der Akkumulation von ABA und der Induktion ABA-induzierter Gene einher (GIRAUDAT et al. 1994), da ABA die Trockentoleranz erhöht, indem es im Zusammenspiel mit NO die Schließung der Stomata auslöst (NeILL et al. 2002a; Garcia-Mata \& Lamattina 2002; Desikan et al. 2004). $\mathrm{Zu} \quad$ Beginn der Pflanzenentwicklung ist der Gehalt an ABA meist gering. Der maximale Gehalt wird während der Reifephase erreicht, wenn das Hormon die Einlagerung von Speicherstoffen induziert, Blattabwurf auftritt und die Trockentoleranz induziert wird. Durch ihre hohe Mobilität ist ABA in sämtlichen Geweben der Pflanze zu finden (MARION-Poll \& LeUnG 2006). Hauptsyntheseort scheint dabei das vaskuläre System der Pflanzen zu sein.

Auxine (Indol-3-Essigsäure) spielen in verschiedenen Phasen der Pflanzenentwicklung eine wichtige Rolle wie bei der Embryogenese (RIBNICKY et al. 2002), Fruchtreife (COHEN 1996) und Seneszenz (QUIRINO et al. 1999), die durch Auxin-gesteuerte Zellteilungs- und Zellstreckungsprozesse reguliert werden. Durch diese Zellstreckungs- und Teilungsprozesse wird auch sekundäres Dickenwachstum sowie die Differenzierung der Leitelemente reguliert. Daher findet auch eine Einflussnahme auf Spross- und Wurzelelongation durch Auxine statt. Wie bei allen Prozessen ist auch der Effekt dieses Hormons dosisabhängig. Bei höheren Konzentrationen wird das Wachstum gehemmt. In Gurkenwurzeln (Cucumis sativus) konnte durch Applikation von NO die durch IAA induzierte Ausbildung von Sekundärwurzeln beobachtet werden (PAgnUSSAT et al. 2002, 2003). Die Verlängerung von MaisWurzelspitzenzellen wurde genauso durch Zugabe von SNP und GSNO induziert (GoUvÊA et al. 1997) wie die Auxin-vermittelte Reaktion der Sekundärwurzelbildung in Tomate (CORREA-ARAGUNDE et al. 2004).

Jasmonsäure reguliert ebenfalls Wachstums- und Entwicklungsprozesse, ist an der Blattseneszenz beteiligt und übernimmt eine Schlüsselfunktion bei der Abwehr nekrotropher pilzlicher Pathogene (Thomma et al. 1998). Mit dem Fluoreszenzfarbstoff Diaminofluoresceindiacetat (DAF-2DA) konnte unter Nutzung von konfokaler LaserScanning-Mikroskopie (CLSM) in A. thaliana ein starker NO-Anstieg nach Verwundung, wie auch durch Zugabe von JA detektiert werden.

Ethylen beeinflusst jedes Stadium der Pflanzenentwicklung von der Keimung über Wachstum und Zellexpansion bis zur Fruchtreife (ABELES et al. 1992). Der Nachweis eines Zusammenspiels von Ethylen und NO wurde in Experimenten an Erbse (Pisum sativum) zur 
Funktion von NO als Wachstumsregulator erbracht. Untersuchungen an vegetativen und generativen Pflanzenorganen zeigten, dass NO antagonistisch zum Reifehormon Ethylen wirkte und Reife und Seneszenz durch eine Verringerung des NO-Gehaltes eingeleitet wurden (LESHEM, et al. 1998). Auch konnte durch die Methode der nicht-invasiven photoakustischen Laserspektroskopie gezeigt werden, dass zwischen dem Gehalt an endogenem NO und Ethylen folgende Beziehung besteht: Unreife Früchte weisen einen hohen NO- und einen niedrigen Ethylen-Gehalt auf, wobei sich dieses Verhältnis im Laufe der Reife umkehrt (LeSheM \& PinChasov 2000).

\subsubsection{Syntheseorte für NO}

In einer Vielzahl pflanzlicher Zell- und Gewebetypen (Blatt- als auch Wurzel) ist die Produktion von NO bereits nachgewiesen worden. Die Synthese von NO kann dabei über zwei unterschiedliche Mechanismen erfolgen. Zum einen kann NO enzymatisch, zum anderen nicht-enzymatisch produziert werden. Enzymatisch wird NO vor allem durch die cytosolische Nitrat-Reduktase (NR) hergestellt. Dabei dient Nitrit als Substrat und NO wird in Anwesenheit von NADH gebildet (Rockel et al. 2002; LAMATTINA et al. 2003; DorDAs et al. 2004). Unter optimalen Bedingungen (ausreichende NADH und Nitritkonzentration) beträgt die Produktionsaktivität der NR zur Herstellung von NO 1\% ihrer tatsächlichen Reduktionsaktivität. Die dazu benötigte Nitrit-Akkumulation kann durch verstärkte Nitrit-Reduktase (NiR)-Aktivität hervorgerufen werden, oder es akkumuliert nichtenzymatisch unter anaeroben Bedingungen mit herunterregulierter oder inhibierter Photosyntheseaktivität (YAMASAKI 2000). Die Bildung von NO über die NR wird als einer der Hauptbildungswege für NO in der Pathogenabwehr erachtet. SHI \& YING-ZHANG (2007) konnten zeigen, dass in A. thaliana bei Kontakt mit dem V. dahliae Toxin NO hauptsächlich über die NR produziert wird. Als weiterer Mechanismus der NO-Produktion in der Pflanze kann die Umwandlung von Nitrit zu NO auch über die Nitrit:NO Reduktase (Ni-NOR) erfolgen (MOROT-GAUDRY-TALARMAIN et al. 2002). Die Hauptproduktionsquelle von NO in tierischen Zellen ist die NO-Synthase. Unter Verwendung von Kofaktoren (FAD, FMN, Tetrahydrobiopterin $\left(\mathrm{BH}_{4}\right)$, Calcium und Calmodulin) findet hier die NADPH-abhängige Umwandlung von L-Arginin zu L-Citrulllin und NO statt (IGNARRO 2000). In einer Vielzahl von Pflanzen konnte der Nachweis einer NO-Synthase ähnlichen Produktion von NO durch die Umwandlung von L-Arginin zu L-Citrullin erbracht werden (siehe Tab.1).

Eine durch Pathogene induzierbare NOS (iNOS) wurde in N. tabacum und A. thaliana gefunden (CHANDOK et al. 2003). Nähere Untersuchungen ergaben, dass das ca. $120 \mathrm{kDa}$ 
Protein eine Variante des P-Proteins (varP) des Glycin-Decarboxylase-Komplexes ist (CHANDOK et al. 2003). Diese pflanzliche iNOS hat, verglichen mit der in tierischen Zellen induzierbaren NOS einige homologe Motive gleicher Funktion sowie ähnliche kinetische Eigenschaften. Auch werden die gleichen Kofaktoren $\left(\mathrm{BH}_{4}, \mathrm{CaM}, \mathrm{Ca}^{2+}, \mathrm{FAD}\right.$ und NADPH) benötigt (CHANDOK et al. 2003). Da in tierischen Organismen verschiedene Isoformen der NO-Synthasen vorkommen (neuronale NOS (nNOS), endotheliale NOS (eNOS) und induzierbare NOS (iNOS)), liegt es nahe, dass auch in Pflanzen nicht nur einem Protein alleine diese Funktion zukommt. GuO et al. (2003) konnten eine weitere Isoform der NOSynthase (AtNOS1) in A. thaliana nachweisen, die zwar NADPH, CaM und $\mathrm{Ca}^{2+}$ benötigt, aber unabhängig von $\mathrm{BH}_{4}, \mathrm{FAD}, \mathrm{FAM}$ und Haem arbeitet und eine Rolle bei Pflanzenwachstum, Fertilität, Hormonsignalübertragung und Stomataregulation spielt. Letztendlich konnte bisher jedoch keine dem Säugetier homologe NOS aus Pflanzen isoliert werden. Neben der NO-Synthase gibt es weitere Mechanismen der enzymatischen Produktion von NO. Ein Plasma-gebundenes Enzym aus Tabakwurzeln (STÖHR et al. 2001) kann ebenso NO generieren wie die Xanthin Oxidoreduktase (XiOR) aus Erbsenblattperoxisomen (CORPAS et al. 2004). Darüber hinaus kann die enzymatische Umwandlung von L-Arginin und $\mathrm{H}_{2} \mathrm{O}_{2}$ zu NO und L-Citrullin durch Merrettich Peroxidase erfolgen (HuANG et al. 2002). Cytochrom-P450-Enzyme werden ebenfalls als eine Quelle der NO-Produktion angesehen (BOUCHER et al. 1992). Nicht-enzymatisch wird NO durch Reduktion von Nitrit gebildet. Diese Reaktion findet bevorzugt unter sauren Bedingungen statt, bei denen aus Nitrit NO und Nitrat gebildet werden (YAMASAKI \& SAKIHAMA 2000; BERTHKE et al. 2004; STÖHR \& UlRICH 2002). Chemisch kann Nitrit bei pH 3-6 auch durch die Zufuhr von Ascorbat zu NO und Dehydroascorbatsäure reduziert werden (BELIGNI et al. 2002). Ein weiterer nicht-enzymatischer Mechanismus zur NO-Produktion ist die lichtvermittelte Reduktion von Stickstoffdioxid $\left(\mathrm{NO}_{2}\right)$ durch Carotinoide (COONEY et al. 1994). 
Tab. 1: Stickstoffmonoxid (NO)-Synthase Aktivität in verschiedenen Pflanzenspezies und verschiedenen Zell- und Gewebetypen und die entsprechenden Detektionsmethoden. In Anlehnung an DeL Río et al. (2004).

\begin{tabular}{|c|c|c|}
\hline Spezies/Gewebe/Zelltyp & Methode & Quelle \\
\hline Pisum sativum/Blätter & $\begin{array}{l}\text { Gasförmige NO Emission sensitiv } \\
\text { gegenüber NOS Inhibitoren }\end{array}$ & LESHEM \& HARAMATy (1996) \\
\hline Pisum sativum/Blatt-Peroxisomen & Arginin-Citrullin Assay & BARROSO et al. (1999) \\
\hline & Spin-Trapping ESR & CORPAS et al. (2004) \\
\hline $\begin{array}{l}\text { Lupinus albus /Wurzeln und } \\
\text { Knöllchen }\end{array}$ & Arginin-Citrullin Assay & Cueto et al. (1996) \\
\hline Mucuna hassjoo & Arginin-Citrullin Assay & NinNEMANN \& MEIER (1996) \\
\hline $\begin{array}{l}\text { Glycine max/ Ps. syringae- } \\
\text { infizierte Zellkultur }\end{array}$ & $\begin{array}{l}\text { NO-Produktion sensitiv gegenüber } \\
\text { NOS-Inhibitoren }\end{array}$ & DELLEDOnNE et al. (1998) \\
\hline $\begin{array}{l}\text { Nicotiana tabacum /TMV- } \\
\text { infizierte Blätter }\end{array}$ & Arginin-Citrullin Assay & Durner et al. (1998) \\
\hline Glycine max/Embryonenachsen & NADPH-Diaphorase Aktivität & CARo \& Puntarulo (1999) \\
\hline $\begin{array}{l}\text { Zea mays/Wurzelspitzen und } \\
\text { junge Blätter }\end{array}$ & Arginin-Citrullin Assay & RiBEIRO et al. (1999) \\
\hline Taxus brevifolia/ Kallus & $\begin{array}{l}\text { NO-Produktion sensitiv gegenüber } \\
\text { NOS-Inhibitoren }\end{array}$ & Pedroso et al. (2000) \\
\hline $\begin{array}{l}\text { Nicotiana tabacum/Blattepidermis } \\
\text {-zellen }\end{array}$ & $\begin{array}{l}\text { NO-Produktion sensitiv gegenüber } \\
\text { NOS-Inhibitoren }\end{array}$ & FOISSNER et al. (2000) \\
\hline Nicotiana tabacum/Zellkulturen & $\begin{array}{l}\text { NO-Produktion sensitiv gegenüber } \\
\text { NOS-Inhibitoren }\end{array}$ & Tun et al. (2001) \\
\hline Arabidopsis thaliana/Zellkulturen & & \\
\hline $\begin{array}{l}\text { Petrosilenum } \\
\text { crispum/Zellkulturen }\end{array}$ & & \\
\hline Glycine max/Kotyledonen & Arginin-Citrullin Assay & Modolo et al. (2002) \\
\hline Sorghum bicolor/Samen & $\begin{array}{l}\text { NADPH-Diaphorase Aktivität } \\
\text { Spin-Trapping ESR }\end{array}$ & SimOnTACCHI et al. (2004) \\
\hline
\end{tabular}

\subsubsection{Detektionsmöglichkeiten von NO in Pflanzen}

In pflanzlichem Gewebe konnte NO durch Anwendung verschiedener Methoden nachgewiesen werden. Die Vor- und Nachteile der unterschiedlichen Methoden beziehen sich vor allem auf Sensitivität, Selektivität und Anwendbarkeit auf das zu untersuchende Präparat (ARChER 1993; TARPEY et al. 2004; NAGANO 1999). Im folgenden Abschnitt soll die Anwendbarkeit einiger Detektionsmethoden kurz dargestellt werden.

Mit Hilfe von Diaminofluorescein-Fluoreszenzfarbstoffen (DAF) wurden vor allem histologische Nachweise von NO durchgeführt (KoJIMA et al, 1998). Insbesondere im Zusammenhang mit der lokalen HR hat die DAF-Methode zum Nachweis des dabei auf Zellebene entstehenden NO Anwendung gefunden (FoISSNER et al, 2000; LAMOTTE et al. 2004). Die Reaktion des Fluoreszenzmarkers mit NO kann des Weiteren auch spektrofluorimetrisch (RÄTHEL et al.2003) oder chromatographisch über HPLC nachgewiesen werden (ITOH et al. 2000). Der Nachteil von Diaminofluorescein ist, dass das fluoreszierende Triazol aus DAF und dem Nitroxylanion $\left(\mathrm{NO}^{+}\right.$, wie z.B. $\mathrm{N}_{2} \mathrm{O}_{3}$, dass durch 
Autoxidation des NO entsteht) und nicht dem NO Radikal entsteht (ESPEY et al, 2002; KoJIMA et al, 1999). Außerdem kann der Farbstoff in bestimmten Organellen akkumulieren (FoisSner et al. 2000; NAKATSUBO et al. 1998; NAGANO \& YOSHIMURA 2002) oder mit Ascorbinsäure und Dehydroascorbinsäure reagieren (ZHANG et al. 2002) und somit Artefakte bilden.

Der Oxyhaemoglobinassay beruht auf der Interaktion von NO mit Haemoglobin $\left(\mathrm{HbO}_{2}\right)$, wodurch Met-Haemoglobin (metHb) und Nitrat $\left(\mathrm{NO}_{3}{ }^{-}\right)$entstehen (MURPHY \& NOACK 1994). Unter oxidativem Stress kann diese Methode den eigentlichen Gehalt an NO überbewerten, da eine Interaktion mit anderen $\mathrm{ROS}\left(\mathrm{O}_{2}^{-}\right.$und $\left.\mathrm{H}_{2} \mathrm{O}_{2}\right)$ nicht ausgeschlossen werden kann. Die Methode hat sich aber als erfolgreicher NO-Nachweis in Zellkultursuspensionen etabliert, in denen Antioxidantien einfacher zu applizieren sind (DELLEDONNE et al. 1998; ClARKE et al. 2000).

Eines der Hauptreaktionsprodukte von $\mathrm{NO}$ sind $\mathrm{NO}_{3}{ }^{-}$und $\mathrm{NO}_{2}^{-}$. Indirekt kann über eine Bestimmung dieser Moleküle auch auf den Gehalt an NO geschlossen werden. Der so genannte „Griess-Assay“ nutzt die kolorimetrisch nachweisbare Reaktion des GriessReagenz mit $\mathrm{NO}_{2}^{-}$zur spektrophotometrischen Bestimmung von $\mathrm{NO}_{2}^{-}$und somit indirekten Bestimmung von NO (AMANO \& NODA 1995). Obwohl es sich bei dem „Griess-Assay“ um eine günstige und einfache Messmethode handelt, überwiegt jedoch in den meisten Fällen der Nachteil der schwachen Nachweisgrenze von 2-3 $\mu \mathrm{M}$.

Ein weiterer indirekter Nachweis von $\mathbf{N O}_{2}^{-}$ist durch die Reaktion mit 2,3Diaminonaphthalene (DAN) möglich. Der Nachweis des Reaktionsproduktes, 1(H)Naphthotriazol, wurde z.B. bei der Bestimmung des NO Gehaltes in Agave pacifica mittels HPLC durchgeführt (WADA et al. 2002).

Durch Massenspektrometrie (Membran-Inlet-Massen-Spektrometrie oder Kapillar-InletMassen-Spektrometrie (MIMS/RIMS)) kann ein sensitiver Nachweis z.B. von wassergelösten oder gasförmig austretendem NO erfolgen (CONRATH et al. 2004).

Der Einsatz der photoakustischen Laser Detektion gilt ebenfalls als sehr sensitive Nachweismethode und detektiert ausgasendes NO bis zu einem Detektionslimit von 20 pmol. Allerdings werden weder intrazelluläres noch interzelluläres NO mit Hilfe dieser Methode erfasst (LeSHEM \& PinCHASOV 2000; MuR et al. 2005b).

Eine weit verbreitete Messmethode ist der NO-Nachweis mittels Chemilumineszenz, der über die Reaktion von NO mit Ozon erfolgt (FEELISCH \& STAMLER 1996; MOROT-GAUdRYTALARMAin et al. 2002; MichelaKis \& ARCHER 1998; Tischner et al. 2004) und ein Detektionslimit von 20-50 pmol NO aufweist. Vorteilhaft ist, dass mit der entsprechenden 
Ausrüstung das ausgasende NO kompletter Pflanzen in vivo untersucht werden kann. Wie aber auch bei der photoakustischen Laser Detektion kann auch hier nur das in den Reaktionsraum ausgasende, mit Ozon reagierende NO gemessen werden. Im Vordergrund vieler Fragestellungen stehen aber oftmals das intra- und interzelluläre NO, welches an Reaktionen innerhalb der Zelle beteiligt ist.

Stickstoffmonoxid kann auch amperometrisch per NO-Elektrode bestimmt werden. Dieser Nachweis ist sehr sensitiv (Detektionslimit unter $1 \mathrm{nM} \mathrm{NO}$ ) aber lokal äußerst begrenzt, nämlich auf die minimale Kontaktfläche von Elektrode und Gewebe (LeShem \& HARAMATY 1996; $\quad$ Zhang \& Broderick 2000; $\quad$ KitAMURA et al. 2003; Christodoulou et al. 1996).

Eine der spezifischsten und direktesten Methoden zur Detektion von freien Radikalen, und somit auch von NO, ist die Elektronen-Spin-Resonanz-Spektrometrie (ESR) (Villamena \& Zweier 2004; Venkataraman et al. 2000; Xia et al. 2000; Xu et al. 2004; MATHIEU et al. 1998; HUANG et al. 2004b, CORPAS et al. 2004). Zur spezifischen Detektion des NO-Radikals werden bei dieser Technik so genannte Spin-Traps verwendet, welche die Radikaleigenschaften des NO stabilisieren und somit die dauerhafte Darstellung des NO per ESR ermöglichen. Häufig verwendete Spin-Traps sind z.B. N-Methyl-D-GlucaminDithiocarbamat (MGD), Dithiocarboxy-Sarcosin (DTCS) oder Eisen-Diethyldithiocarbamat $\left(\left[\mathrm{Fe}^{2+}-(\mathrm{DETC})_{2}\right]\right) \quad$ (Tsuchiy et al. 1996; $\quad$ Yoshimura \& KotaKe 2004; NEDEIANU \& PÁli 2002).

Das hydrophile Spin-Trap MGD wird für die Analyse von NO aus wässrigen Kompartimenten verwendet. Das lipophile DETC kommt zum Einsatz, wenn gewebe- bzw. membrangebundenes NO detektiert werden soll. Da DETC in organischem Lösungsmittel wie z.B. Triacetylglycerol oder Ethylacetat löslich ist, kann NO durch Ausbildung des MonoNitrosyl-Eisen Komplexes [NO-Fe ${ }^{2+}-(\text { DETC })_{2}$ ] stabilisiert, in die organische Phase überführt und somit gemessen werden. Nachweisgrenzen liegen für MGD z.B. bei $500 \mathrm{nmol} \mathrm{g}^{-1} \mathrm{FW}$ (DorDAs et al. 2004) und für DETC bei ca $100 \mathrm{nmol} \mathrm{g}^{-1} \mathrm{FW}$ (XU et al. 2004).

Die Messung von NO in biologischen Proben ist generell schwierig, da die Konzentrationen äußerst gering sind (normalerweise im nanomolaren Bereich) und das Molekül durch seine ausgesprochene Reaktivität gegenüber $\mathrm{O}_{2} \mathrm{sehr}$ instabil ist. Daher ist zu überlegen, welches Gewebe untersucht werden soll und in welcher Form (direkt, indirekt über $\mathrm{NO}_{2}^{-}, \mathrm{NO}_{3}^{-}$, $\mathrm{ONOO}^{-}$, Umwandlung von L-Arginin zu L-Citrullin, usw.) NO zu detektieren ist. Eine ausführliche Zusammenfassung vorhandener Methoden zur Darstellung und Detektion von NO ist bei NaGANo \& Yoshimura (2002) zu finden. 
Insgesamt ist zu bedenken, dass die o.a. Methoden in den meisten Fällen in Zellkulturen benutzt (äußerst homogene Bedingungen) oder in Geweben durchgeführt wurden, die eine Reaktion auf einen inkompatiblen Pathogenangriff (HR) zeigten. Die Konzentrationen von NO sind daher nur aus bestimmten Geweben und unter spezifischen Konditionen bekannt. Inwiefern NO als systemisches Signal in Xylemsäften vorkommt, wurde bisher noch nicht untersucht und stellt eine zentrale Aufgabe dieser Arbeit dar.

\subsubsection{Bedeutung von NO für Pilze}

Neben den Effekten auf die Pflanzenphysiologie können ROS auch direkte (toxische) oder indirekte Einflüsse auf das Pathogen haben. Ein direkter toxischer Einfluss von NO auf Pathogene wurde bereits von KUNERT et al.(1995) untersucht. Wachstum, Infektiösität, Keimung und Überlebensfähigkeit des Human-Pathogen Aspergillus fumigatus wurden durch Zugabe von $5 \mathrm{mM}$ Natrium-Nitrit oder S-Nitroso-N-Acetylpenicillamin (SNAP) überprüft. Nach Applikation von SNAP starben innerhalb von 24 h 30-50 \% der eingesetzten Konidien. Die Applikation von GSNO allerdings förderte die Konidienkeimung. CONRATH et al. (2004) konnten die durch Nitrit induzierte Produktion von NO in Phytium, Botrytis und Fusarium spp. massenspektrometrisch (MIMS/RIMS) nachweisen. In Phycomyces blakesleeanus (MAIER et al. 2001) und Flammulina velutipes (Song et al. 2002) wurden NOS-Funktionen bestätigt, die im Zusammenhang mit der Entwicklung von Sporangiophoren (Phycomyces) und Fruchtkörperbildung standen (Flammulina). Auch die Konidienkeimung hängt bei bestimmten Pilzen mit der Anwesenheit von NO zusammen (Neurospora crassa; Ninnemann \& MAIER 1996; Colletotrichum coccodes, WANG \& Higgins 2005; B. elliptica, VAN BAARLEN et al. 2004).

Dass die allgemeine Anwesenheit von ROS für entscheidende Prozesse pilzlichen Wachstums notwendig erscheint, zeigen auch Untersuchungen von MALAGNAC et al. (2004) an Podospora anserina. Bei normalem vegetativem Wachstum des Pilzes wurde eine regulierte basale Abgabe von ROS beobachtet. Zum Zeitpunkt der Fruchtkörperbildung und bei der Askosporenkeimung konnte allerdings ein Anstieg oxidativer Spezies beobachtet werden. Daher könnte z.B. $\mathrm{H}_{2} \mathrm{O}_{2}$ oder $\mathrm{NO}$ je nach Darreichungsform und Pilzart einen durchaus positiven Einfluss auf das Pathogenwachstum haben und dieses fördern. Ein Beispiel für die Rolle von NO als Pathogenitätsfaktor ist das Vorkommen eines NOS-Homologs in Streptomyces turgidiscabies. Das durch die NOS bereitgestellte NO übernimmt hier die Nitrierung eines für die Pathogenität benötigten Dipeptid-Phytotoxins (KERS et al. 2004). 


\subsection{Ziel der Arbeit}

Ziel dieser Arbeit war es, Signalmoleküle zu analysieren, die in der Interaktion von B. napus (Bn) und dem auf das Xylem begrenzten pathogenen Pilz V. longisporum im Hinblick auf Veränderungen des Pflanzenwachstums und der Stressphysiologie auftreten (PEGG \& BRADY, 2002). Interessanterweise beinhalten die Krankheitssymptome dieser Interaktion keine Welke, die normalerweise in anderen Wirtspflanzen bei Infektion mit anderen Verticillium-Arten auftritt. Stattdessen treten ein frühzeitiges Abreifen der Pflanzen und unter Gewächshausbedingungen eine auffällige Stauche auf. Die Beobachtung, dass die Symptome im Spross auftreten, noch bevor sich das Pathogen in den oberen Teil der Pflanze ausbreitet, lässt vermuten, dass primäre und/oder sekundäre Signalmoleküle, die vom Pilz gebildet oder vom Pilz auf pflanzlicher Seite induziert und systemisch von der Wurzel aus durch das Xylem verbreitet werden, für die physiologischen Veränderungen im Spross verantwortlich sein könnten. Da bisher keine Verticillium-resistenten Rapsgenotypen auf dem Markt sind, die als Referenzvariante dienen können, sollte als zweites System die symptomlose Nicht-Wirt Interaktion zwischen V. dahliae und B. napus untersucht werden. Dadurch besteht die Möglichkeit zu ermitteln, welche Signale bei einer symptombildenden und bei einer nicht symptombildenden Infektion verändert oder gebildet werden. Der Schwerpunkt dieser Arbeit besteht daher zunächst in der Analyse zweier für sowohl abiotischen als auch biotischen Stress charakteristischen Signalmoleküle, Stickstoffmonoxid (NO) und Wasserstoffperoxid $\left(\mathrm{H}_{2} \mathrm{O}_{2}\right)$ (Romero-PuerTAs et al. 2004; BELIGNI et al. 2002) im System V. longisporum/B. napus und V. dahliae/B. napus. Da für den vorliegenden Zweck der Untersuchungen keine geeignete Detektionsmethode vorliegt, soll eine ESR-Methode zur Detektion von NO in Xylemsaft oder Pflanzengewebe entwickelt werden, um die qualitative Analyse von NO in unterschiedlichen Teilen infizierter Pflanzen über den Zeitraum der Symptom- und Pflanzenentwicklung durchzuführen. Insgesamt sollen sowohl die Eigenschaften der zwei Interaktionen in verschiedenen Phasen der Besiedlung als auch die Beteiligung der untersuchten Signale an Veränderungen des Pflanzenwachstums und der Symptominduktion untersucht werden. Da unbekannt ist, ob unter Gewächshausbedingungen die Symptombildung mit der Ausbreitung des Pathogens einhergeht, sollen beide Pathogene während ihrer Infektion in der Pflanze per Real-Time PCR nachgewiesen werden. Erscheinungen wie modifizierte Sprossontogenese (Stauche) und vorzeitige Seneszenz weisen auch auf Veränderungen im Pflanzenhormonhaushalt hin, die mit der Infektion einhergehen. Daher ist auch die Analyse der Phytohormone Abszisinsäure (ABA), Jasmonsäure (JA), Salizylsäure (SA) und Indol-3-Essigsäure (IAA) in Relation zum Verlauf der pilzlichen 
Besiedlung ein weiteres Ziel dieser Arbeit. Der Mechanismus, mit dem V. longisporum das Wachstum und die Entwicklung seiner Wirtspflanze beeinflusst, ist bis dato unbekannt. Da für $V$. dahliae bereits welkeinduzierende Komponenten in vitro und in planta nachgewiesen wurden (YuAN et al. 2006; Zhen et al. 2004; SMIT \& DUBery 1997; Dubery \& SMIT 1994; MEYer \& DUBERY 1993), soll auch bei V. longisporum überprüft werden, ob ein Symptominduzierender Toxizitätsfaktor sekretiert wird. 


\section{Material und Methoden}

\subsection{Pflanzenmaterial}

Die Samen der in diesen Versuchen verwendeten Rapsvarietät „rapid cycling rapeseed“ (RCR, Brassica napus var. napus, Genom ACaacc) wurden von P. H. Williams aus Wisconsin bezogen (WiLliaMS \& HiLl, 1987) und im Department für Nutzpflanzenwissenschaften, Abteilung Pflanzenpathologie und Pflanzenschutz der Universität Göttingen weiter vermehrt und für experimentelle Arbeiten zur Verfügung gestellt. Im Gegensatz $\mathrm{zu}$ herkömmlichen Winterrapssorten benötigt RCR keine Vernalisation, um zur Blüte zu gelangen, entwickelt eine Wuchshöhe von ca. $80 \mathrm{~cm}$ und vollzieht seinen kompletten Entwicklungszyklus innerhalb von 55-60 Tagen. In allen Experimenten wurden die Samen für 30s einer Oberflächensterilisation mit $70 \%$ EtOH unterzogen und anschließend dreimal mit sterilem Leitungswasser (30s) gewaschen, bevor sie in sterilem, autoklaviertem Quarzsand ausgesät wurden.

\subsection{Pilzisolate}

In allen Experimenten wurde das V. longisporum-Isolat 43 aus B. napus und das V. dahliaeIsolat 73 (vegetative Kompatibilitätsgruppe VCG2 aus Linum usitatissimum) verwendet (ZEISE \& Von TIEDEMANN 2001, 2002a, b). Zur Anzucht des Pilzmaterials in

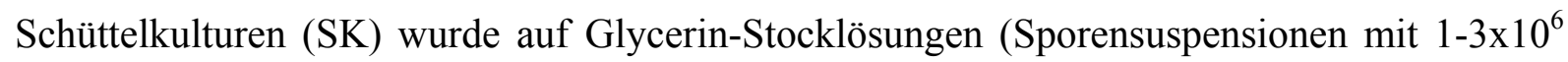
Sporen $\mathrm{ml}^{-1}$ in $\mathrm{CzD}$-Medium inkl. $25 \%$ Glycerol, gelagert bei $-80^{\circ} \mathrm{C}$ ) zurückgegriffen. Zur Inokulation der SK wurden $500 \mathrm{ml}$ Medium mit $500 \mu 1$ Stocksuspension beimpft und für 1014 Tage bei $23^{\circ} \mathrm{C}$ auf einem Schüttelinkubator (Infors AG, Schweiz) bei $100 \mathrm{rpm}$ im Dunkeln inkubiert. $\mathrm{Zu}$ Inokulationszwecken wurde das Myzel vom Medium getrennt, die für die Tauchinokulation benötigte Sporendichte mikroskopisch mit einem Haemocytometer bestimmt und auf eine Dichte von $1 \times 10^{6}$ Sporen $\mathrm{ml}^{-1}$ eingestellt.

\subsection{Inokulation und Pflanzenanzucht}

Sieben Tage nach Aussaat wurden die Rapskeimlinge vorsichtig aus dem Quarzsand ausgewaschen und die Wurzeln unter Leitungswasser vorsichtig vom Substrat gereinigt. Die

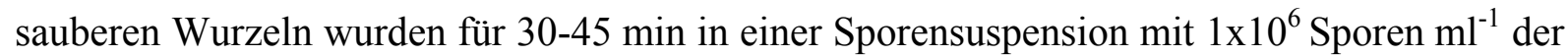
jeweiligen Pilzisolate (VL43 oder VD73) tauchinokuliert. Die als Kontrolle dienenden Rapskeimlinge wurden für 30-45 min in steriles Leitungswasser getaucht. Anschließend 
wurden die Pflanzen in ein steriles Erde/Sand-Gemisch (1:1 v/v) getopft und unter konstanten Bedingungen in einer Klimakammer (Kälte Klima, Northeim) im 16/8 h Licht/DunkelRhythmus (Philips TL5 HO Lampen) und $23 / 20^{\circ} \mathrm{C}$ aufgezogen.

\subsection{Allgemeine Parameter}

Im Verlauf der Entwicklung der RCR-Pflanzen wurde zuerst der Ablauf der Pathogenese beider zu untersuchenden Systeme beobachtet. Dazu wurden zu den Terminen 14, 21, 28 und 35 dpi die Sprosslänge sowohl von inokulierten wie nicht-inokulierten Pflanzen ermittelt. Die Pflanzen wurden anschließend aus ihrem Substrat ausgewaschen, vorsichtig abgetrocknet und in Spross und Wurzel getrennt. Anschließend wurde die Trockenmasse bestimmt, indem die Pflanzenteile bei $80^{\circ} \mathrm{C}$ im Trockenschrank (Fa. Memmert, Schwabach) bis zur Konstante (dreimaliges Auswiegen) getrocknet wurden. $\mathrm{Zu}$ den entsprechenden Terminen wurde ebenfalls eine Sichtbonitur der Pflanzen durchgeführt bei der die Symptome (Vergilbung und Schwarzadrigkeit) mit Hilfe einer Boniturskala in neun Klassen eingeordnet wurden (Tab. 2).

Tab. 2: Boniturskala zur Befallserfassung von V. longisporum an B. napus anhand der Symptomausprägung nach künstlicher Inokulation unter konstanten Klimakammerbedingungen (modifiziert nach ZEISE 1992).

\begin{tabular}{|l|l|}
\hline Boniturnote & Symptom \\
1 & keine Symptome \\
2 & leichte Symptome am ältesten Blatt (Vergilbungen, schwarze Adern) \\
3 & leichte Symptome auch an den nächst jüngeren Blättern \\
4 & etwa 50\% der Blätter mit Symptomen \\
5 & mehr als 50\% der Blätter mit Symptomen \\
6 & bis zu 50\% der Blätter abgestorben \\
7 & mehr als 50\% der Blätter abgestorben \\
8 & nur der Vegetationskegel noch vital \\
9 & Pflanze abgestorben \\
\hline
\end{tabular}

\subsection{Nachweis der Pathogenausbreitung durch Real-Time-PCR}

Um die Ausbreitung beider Pathogene unter Gewächshausbedingungen zu überprüfen und den tatsächlichen Befall der Pflanzen verifizieren zu können, wurden die Pflanzen der Zeitreihen auf Verticillium-DNA durch Verwendung einer Real-Time PCR überprüft. Zu 
diesem Zweck wurden zwei Zeitreihen beprobt. In der ersten wurden 10 Pflanzen pro Variante in Hypokotyl (H) und Spross (S) unterteilt, in der zweiten wurde an 5-6 Pflanzen eine weitere Aufteilung vorgenommen: Zum Zeitpunkt 14 dpi wurde das Hypokotyl $(\mathrm{H})$ sowie ein Zentimeter des angehenden Sprosses (S bzw S1) beprobt, zu 21 dpi der mittlere Sprossteil (S2) hinzugenommen und zu 28 und 35 dpi der Spross in drei Teilabschnitte aufgeteilt und auch der oberste Sprossabschnitt (S3) analysiert.

\subsubsection{Probenvorbereitung}

Eingefrorenes Spross- und Hypokotylgewebe wurde in einem vorgekühlten Mörser mit flüssigem $\mathrm{N}_{2}$ zu feinem Pulver zerkleinert und $100 \mathrm{mg}$ für die PCR-Analyse eingesetzt. Um eine vergleichbare und gleich bleibende Qualität der DNA-Proben zu gewährleisten, wurden alle DNA-Extraktionen mit dem DNeasy Plant Mini Kit (Fa. Qiagen, Hilden) durchgeführt.

\subsubsection{DNA-Extraktion}

Die DNA-Extraktion erfolgte nach den Herstellerangaben des DNeasy Plant Mini Kit (Qiagen GmbH, Deutschland). Nach der Extraktion wurden die Proben auf ein Agarosegel aufgetragen, elektrophoretisch aufgetrennt und die Qualität der präparierten DNA überprüft. Bis zur Durchführung der PCR wurden die Proben bei $-20^{\circ} \mathrm{C}$ gelagert.

\subsubsection{Quantitative Real-Time PCR}

Für die PCR-Analyse wurden die von ITS-Sequenzen ribosomaler DNA abgeleiteten Verticillium-spezifischen Primer OLG 70 (3'-CAGCCGAAACGCGATATGTAG-5') und OLG 71 (3'-GGCTTGTAGGGGGTTTAGA-5') verwendet (Prof. Karlovsky, pers. Mitteilung), welche in der Lage sind, ein sowohl in $V$. longisporum als auch in $V$. dahliae vorkommendes DNA-Fragment zu amplifizieren (EYNCK et al. 2007). Zur Amplifikation und zur späteren Analyse wurde das iCycler-System (Fa. BioRad, Hercules, CA, USA) verwendet. Der Reaktionsmix (Tab.3) setzte sich aus folgenden Komponenten zusammen: 10x PCRPuffer (Fa. Bioline, Luckenwalde), $\mathrm{MgCl}_{2}$ (3 mM, Fa. Bioline, Luckenwalde), dNTP-Mix (200 $\mu \mathrm{M}$, Fa. Bioline, Luckenwalde), 0,3 $\mu \mathrm{M}$ Primer, 0,25 U BIOtaq DNA-Polymerase (Fa. Bioline, Luckenwalde), $10 \mathrm{nM}$ Fluorescein (Fa. BioRad, CA, USA), SybrGreen 0,1 (Fa. Molecular Probes, Invitrogen, Karlsruhe, ) und $2 \mu$ DNA Probe auf $25 \mu$ mit $\mathrm{H}_{2} \mathrm{O}$ 
bidest. aufgefüllt. Die Filtereinstellungen für die Anregung und Emission des Fluoreszenzfarbstoffes SybrGreen wurden auf $490 \pm 10 \mathrm{~nm}$ und $530 \pm 15 \mathrm{~nm}$ festgelegt.

Alle PCR-Reaktionen wurden unter folgenden Bedingungen durchgeführt: Initiale Denaturierung bei $94^{\circ} \mathrm{C}$ für $2 \mathrm{~min}$, Denaturierung für $20 \mathrm{~s}$ bei $94^{\circ} \mathrm{C}$ über 36 Zyklen, Annealing für $30 \mathrm{~s}$ bei $59^{\circ} \mathrm{C}$ und $40 \mathrm{~s}$ bei $72^{\circ} \mathrm{C}$. Die abschließende Elongation wurde bei $72^{\circ} \mathrm{C}$ für 5 min durchgeführt (siehe Tab. 4).

Tab. 3: Zusammensetzung des PCR-Reaktionsmix zur Detektion von Verticillium-DNA aus Pflanzengewebe, Gesamtvolumen $25 \mu 1$.

\begin{tabular}{|l|l|l|l|}
\hline Chemikalien & Konzentration & Endkonzentration & $\mu \mathrm{l} /$ Reaktion \\
\hline $\mathrm{H}_{2} \mathrm{O}$ bidest. steril & & & 15,95 \\
$10 \mathrm{x} \mathrm{Puffer}($ Bioline) & $10 \mathrm{x}$ & $1 \mathrm{x}$ & 2,5 \\
$\mathrm{MgCl}_{2}$ (Bioline) & $50 \mathrm{mM}$ & $3 \mathrm{mM}$ & 1,5 \\
$\mathrm{dNTP}($ Bioline) & $2,5 \mathrm{mM}$ & $200 \mu \mathrm{M}$ & 2,0 \\
$\mathrm{~F}-$ Primer & $10 \mu \mathrm{M}$ & $0,3 \mu \mathrm{M}$ & 0,75 \\
$\mathrm{R}-$ Primer & $10 \mu \mathrm{M}$ & $0,3 \mu \mathrm{M}$ & 0,75 \\
Fluorescein & $1 \mu \mathrm{M}$ & $10 \mathrm{nM}$ & 0,25 \\
SybrGreen & $10 \mathrm{x}$ & 0,1 & 0,25 \\
BIOTaq DNA & $5 \mathrm{U} / \mu \mathrm{l}$ & $0,25 \mathrm{U}$ & 0,05 \\
Polymerase & & & \\
Probe DNA & & $\mathrm{x} \mathrm{ng}$ & \\
\hline
\end{tabular}

Tab. 4: Real-Time PCR-Programm zur Detektion von Verticillium-DNA aus Pflanzengewebe.

\begin{tabular}{|l|l|l|l|}
\hline PCR- & Bezeichnung & Zeit $[\mathrm{min}]$ & Temperatur $\left[{ }^{\circ} \mathrm{C}\right]$ \\
Schritt Nr. & & & \\
\hline 1 & Initiale Denaturierung & 2 & 94 \\
2 & Denaturierung & 0,2 & 94 \\
3 & Primer Hybridisierung (Annealing) & 0,3 & 59 \\
4 & PCR-Synthese & 0,4 & 72 \\
5 & (Wiederholung der Schritte 2-4 36x) & 5 & 72 \\
\hline
\end{tabular}

\subsection{Symptominduktionsexperimente}

\subsubsection{Inokulationsversuche in Töpfen}

Die Überprüfung, ob auch in RCR physiologische Veränderungen durch NO-Applikation hervorgerufen werden und somit NO eventuell mit der Stauche direkt in Verbindung gebracht werden kann, erfolgte zuerst in Topfversuchen. Sieben Tage alte RCR-Keimlinge, angezogen in Töpfen (7 cm Durchmesser) mit einem sterilen Erde/Sand-Gemisch (1:1 v/v), wurden mit $3 \mathrm{ml}$ einer wässrigen Lösung der NO-Donatoren SNP und SNAP in den Konzentrationen 10, 
50 und $100 \mu \mathrm{M}$ (Tab. 5) jeweils dreimal pro Woche über einen Zeitraum von 28 Tagen angegossen. Negativkontrollen wurden mit sterilem Leitungswasser angegossen; Positivkontrollen wurden mit $V$. longisporum inokuliert und bei jeder Applikation ebenfalls mit $3 \mathrm{ml}$ sterilem Leitungswasser behandelt. Die Überprüfung der Effekte auf Pflanzenlänge und weitere mögliche Veränderungen wurde durch Messungen der Sprosslänge und visueller Bonitur der Pflanzen zu den Zeitpunkten 14, 21, 28 und 35 dpi überprüft. Eine mit $\mathrm{NH}_{4} \mathrm{NO}_{3}$ gedüngte Kontrollvariante wurde ebenfalls ausgewertet, um einen möglichen Düngeeffekt der Donorlösungen ausschließen zu können. In einem folgenden Experiment wurde der NOScavenger cPTIO $(100 \mu \mathrm{M})$ sowohl auf $V$. longisporum-infizierte als auch nicht-infizierte Pflanzen appliziert, um zu überprüfen, ob eine Verringerung des NO-Gehalts die Symptominduktion umkehrt bzw. unterbindet.

Tab. 5: Varianten und Konzentrationen der Donatoren sowie Anzahl der verwendeten Keimlinge im in vivo NO-Applikationsversuch zur Symptominduktion.

\begin{tabular}{|l|ccc|}
\hline Varianten & & Konzentrationen & \\
& $10 \mu \mathrm{M}$ & $50 \mu \mathrm{M}$ & $100 \mu \mathrm{M}$ \\
\hline SNP & $\mathrm{n}=40$ & $\mathrm{n}=40$ & $\mathrm{n}=40$ \\
SNAP & $\mathrm{n}=40$ & $\mathrm{n}=40$ & $\mathrm{n}=40$ \\
$\mathrm{NH}_{4} \mathrm{NO}_{3}$ & $\mathrm{n}=40$ & $\mathrm{n}=40$ & $\mathrm{n}=40$ \\
$V L 43$ & & $\mathrm{n}=75$ & \\
$\mathrm{H}_{2} \mathrm{O}$ Kontrolle & & $\mathrm{n}=75$ & \\
\hline
\end{tabular}

\subsubsection{Inokulationsversuche in vitro}

Der Effekt von NO-Donatoren auf RCR wurde auch unter in vitro Bedingungen an Keimlingen in Anlehnung an CORREA-ARAGUndE et al. (2004) überprüft. Oberflächensterilisierte Rapssamen wurden auf Filterpapier ausgelegt, mit sterilem Leitungswasser angefeuchtet, in Aluminiumfolie eingeschlagen und für zwei Tage im Dunkeln bei RT vorgekeimt (Abb. 3A u. B). Die vorgekeimten Samen wurden in Petrischalen auf sterilem Filterpapier mittig ausgelegt und das Filterpapier mit $1 \mathrm{ml}$ NO-Donor Lösung pro Keimling (SNP, SNAP oder eine Eisencyanid-Kontrolle, Konzentrationen 10, 50, 100, 200, 300 und $500 \mu \mathrm{M})$ befeuchtet. Die Kontrolle wurde mit gleichem Volumen sterilen Leitungswassers behandelt. Die Petrischalen wurden mit Parafilm verschlossen und für fünf bis sieben Tage in einem Gewebekulturschrank (Fa. Mytron, Heiligenstadt) bei einer Tageslänge von $16 \mathrm{~h}$ und konstanten $20^{\circ} \mathrm{C}$ inkubiert (Abb. 3C). Nach der einwöchigen Inkubation wurde die Anzahl der Sekundärwurzeln, Sprosslänge und Länge der Primärwurzel ausgewertet (Abb. 3D). 


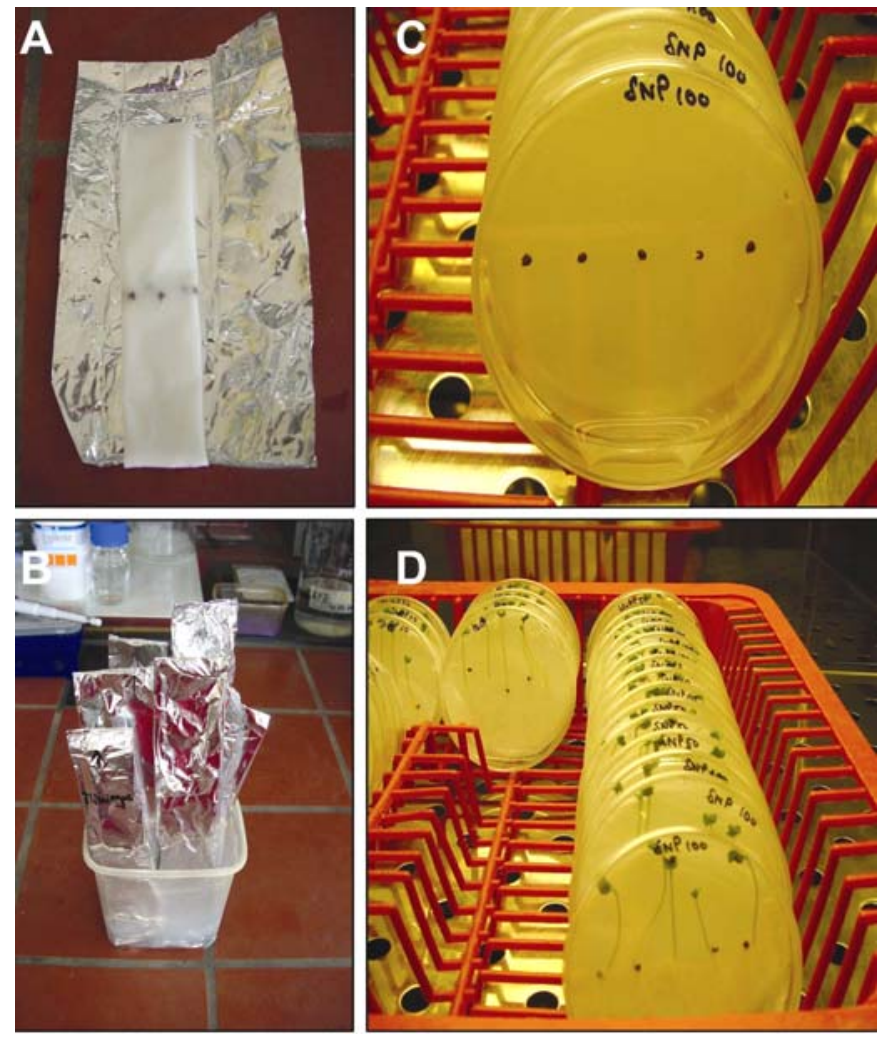

Abb. 3: Durchführung des in vitro-Versuch zur Symptominduktion mit RCR-Keimlingen mittels Applikation von NO-Donatoren. A: Ausbreiten der Rapssamen auf Filterpapier B. Vorkeimen der Samen, C. Inkubation der Keimlinge in Petrischalen im Gewebekulturschrank, D. Keimlinge nach 5 Tagen Inkubation.

\subsection{Effekt von NO auf das vegetative Wachstum von $V$. longisporum}

Ein Myzelstück einer V. longisporum-PDA-Kultur (1 cm Durchmesser) wurde in das Zentrum einer neuen PDA-Platte gelegt und mit einem gleichgroßen Stück Filterpapier (AntibiotikaApplikationsfilterpapier, Fa. Schleicher \& Schüll, Dassel) bedeckt. Der NO-Donor SNAP wurde in drei verschiedenen Konzentrationen $(10,50$ und $100 \mu \mathrm{M})$ als wässrige Lösung $(60 \mu 1) 3 \times$ pro Woche auf die Myzelstücke gegeben, indem die Lösung auf das aufliegende Filterpapier appliziert wurde. Kontrollen wurden mit sterilem Leitungswasser behandelt. Die Petrischalen wurden über den Zeitraum der Beobachtungen in einem Gewebekulturschrank (Fa. Mytron, Heiligenstadt) bei konstanten $22^{\circ} \mathrm{C}$ im Dunkeln inkubiert. Der Kolonieradius wurde über einen Zeitraum von 10 Tagen gemessen.

\subsection{Nachweis von NO}

Für den Nachweis von NO wurden Xylemsaftproben von $V$. longisporum-infizierten, $V$. dahliae-infizierten und nicht-infizierten Pflanzen aus Wurzeln (inklusive Hypokotyl) genommen. Da für die Analyse ein Xylemsaftvolumen von mind. $40 \mu 1$ notwendig war, 
musste das Mindestalter der Pflanzen 21 Tage betragen (14 dpi), da die Keimlinge zum einen vorher zu klein waren, um sie zur Xylemsaftgewinnung in die verwendete Druckkammer einzuspannen, zum anderen das Wurzelsystem noch nicht ausreichend differenziert war, um genügend Xylemsaft zu liefern. Spross-, Hypokotyl- und Wurzelgewebe wurden nach der Beprobung sofort in flüssigem $\mathrm{N}_{2}$ eingefroren und anschließend bei $-20^{\circ} \mathrm{C}$ gelagert. Teile dieser Proben wurden sowohl für die Überprüfung der Verticillium-Besiedlung über RealTime PCR (siehe Kap. 2.5) als auch für die Phytohormonanalyse (siehe Kap. 2.13) per HPLCMS (AG Molekulare Phytopathologie und Mykotoxinforschung, Dep. für Nutzpflanzenwissenschaften, Universität Göttingen) verwendet.

\subsubsection{Xylemsaftgewinnung}

Die Xylemsaftproben wurden mit Hilfe einer Druckkammer (Modell 600, PMS Instrument Company, Oregon, USA) gewonnen. Dazu wurden die Pflanzen vorsichtig zu den entsprechenden Zeitpunkten (14, 21, 28 und 35 dpi) aus ihrem Substrat entfernt, das Wurzelsystem sorgfältig unter Leitungswasser gereinigt, überschüssige Feuchtigkeit mit Gewebetuch vorsichtig abgetupft und die Pflanzen oberhalb des Hypokotylansatzes in Spross und Wurzel getrennt. Das Wurzelsystem wurde mit dem abgeschnittenen Ende des Hypokotyls so in die Druckkammer eingespannt, das die Schnittstelle eine ebene Fläche mit dem Dichtungsgummi bildete. Die Schnittstelle wurde mit $\mathrm{H}_{2} \mathrm{O}$ bidest gereinigt und durch Zugabe von Druckluft in die verschlossene Druckkammer ein Druck von 4 bar aufgebaut, der den Xylemsaft aus dem Wurzelsystem an die Hypokotylschnittstelle drückte.

Der austretende Xylemsaft $(40 \mu \mathrm{l})$ wurde sofort mit $10 \mu \mathrm{l}$ zuvor auf die Schnittfläche

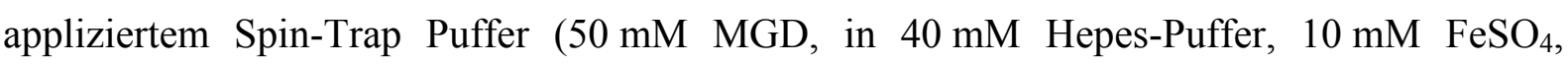
$10 \mathrm{mM} \mathrm{CaCl}_{2}, \mathrm{pH}$ 7,4) vermischt, mit einer Mikropipette aufgenommen und in ein 1,5 ml Reaktionsgefäß überführt. Während der gesamten Probenahme (ca. 10-15 min pro Probe) wurden die Proben im Dunkeln auf Eis gelagert.

\subsubsection{Probenaufbereitung zur ESR-Analyse von Xylemsaft}

Zur NO-Analyse wurden die Proben anschließend für $12 \mathrm{~h}$ lyophilisiert (Gefriertrocknungsanlage Beta 1, Fa. Christ, Osterode), zur ESR-Analyse wieder in 5-10 $\mu 1$ Hepes-Puffer (40 mM, pH 7,4) aufgenommen und in eine Mikroglaskapillare (Fa. Blaubrand, Wertheim, markiert bei 50-100 $\mu$ l) überführt. Die Kapillaren wurden an beiden Enden 
verschlossen und sofort für die ESR-Analyse verwendet. Pro Variante wurden zu jedem Zeitpunkt je 10 Pflanzen beprobt.

\subsubsection{Probenaufbereitung von Xylemsaftmischproben zur ESR-Analyse}

Um die hohen Standardabweichungen zu reduzieren und verlässlichere Resultate zu erhalten, wurde der gesamte Versuch mit gepoolten Xylemsaftproben erneut durchgeführt. Pro Variante wurden 15 Pflanzen zu drei Proben zusammengefasst; eine Xylemsaftprobe umfasste den Xylemsaft aus 5 Pflanzen. Die ausgepressten $250 \mu 1$ Xylemsaft wurden auf drei Proben aufgeteilt, lyophilisiert, wieder in 5-10 $\mu 1$ Hepes-Puffer $(40 \mathrm{mM}, \mathrm{pH} 7,4)$ resuspendiert und anschließend per ESR analysiert. Insgesamt wurde der Versuch dreimal wiederholt $(n=9)$.

\subsubsection{Detektion von NO-Signalen in Pflanzengewebe}

Die Überprüfung eines möglichen NO-Anstiegs $\mathrm{zu}$ einem sehr frühen Zeitpunkt der Interaktion wurde durch Analyse von Gewebeproben überprüft. Dazu wurden die Keimlinge in V. longisporum- oder V. dahliae-Sporensuspensionen tauchinokuliert (siehe Kap. 2.3). Zur Analyse der Zeitpunkte kurz nach Inokulation (0 min nach Inokulation, 30, 60, 90 und 180 min nach Inokulation) wurden die Keimlinge aus der Sporensuspension entfernt, vorsichtig in feuchtes Filterpapier gewickelt und bis zum Zeitpunkt der Beprobung aufbewahrt. Die Zeitpunkte 24, 48, 72 und 96 hpi wurden durch Verwendung eines Biotest (Kap. 2.8.4.1, Variante A) überprüft.

\subsubsection{Biotest mit Rapskeimlingen in vitro}

Der Biotest (Abb. 4) wurde in drei Varianten durchgeführt:

A. Für die Untersuchung der NO- und $\mathrm{H}_{2} \mathrm{O}_{2}$-Gehalte in Gewebe wurden Petrischalen $(24 \times 24$ $\mathrm{cm})$ halbseitig mit Wasseragar (1,5\%) befüllt und der Agar mit steriler Cellophane (Bringmann, Wendelstein) ausgelegt, um ein Durchwachsen der Keimlingswurzeln in den Agar zu verhindern. Die Cellophane wurde mit $V$. longisporum- oder $V$. dahliaeSporensuspension ( $1 \mathrm{ml} 1 \times 10^{6}$ Sporen) beimpft und die Platten mind. 3 Tage bis zum vollständigen Bewuchs der Cellophane bei RT im Dunkeln inkubiert. Anschließend wurden sieben Tage alte RCR-Keimlinge auf die vorinokulierte Cellophane ausgelegt, mit einem sterilen Filterpapierstreifen fixiert und über 24, 48, 72 und 96 hpi unter standardisierten 
Bedingungen in einem Gewebekulturschrank (Fa. Mytron, Heiligenstadt) bei $20^{\circ} \mathrm{C}$ und einem Tag/Nacht-Rhythmus von 16/8 h inkubiert und zu den entsprechenden Zeitpunkten beprobt.

B. Zur Überprüfung der Toxizität von Kulturüberständen (siehe Kap. 2.14) wurden die Petrischalen $(24 \times 24 \mathrm{~cm})$ mit sterilem Filterpapier ausgelegt, die Keimlinge mittig darauf ausgelegt und durch den sterilen Filterpapierstreifen fixiert. Die zu untersuchenden steril filtrierten Überstände wurden anschließend den Keimlingen über das Filterpapier appliziert. Die Inkubation erfolgte sieben Tage unter den in Punkt A beschriebenen Bedingungen.

C. Die Überprüfung der Acetonitril (AcN)-fraktionierten Kulturüberstände (siehe Kap. 2.14) erfolgte wie in A, allerdings ohne Inokulation der Cellophane. Die fraktionierten Kulturüberstände wurden sofort nach Auslegen der Keimlinge auf die Wurzeln der Keimlinge appliziert (15 ml/Schale) und die Keimlinge wie unter den in Punkt A beschriebenen Bedingungen über sieben Tage inkubiert.
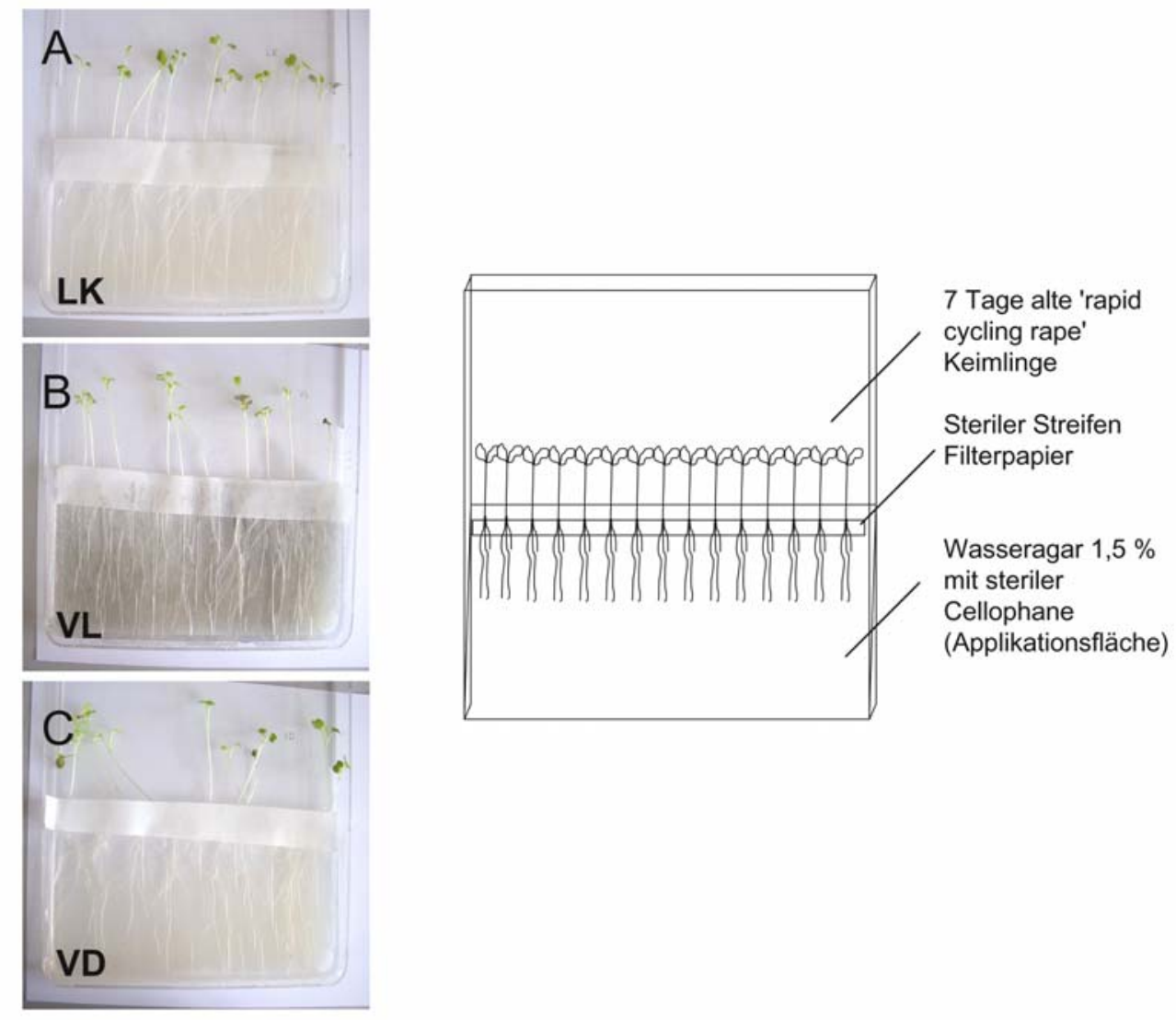

Abb. 4: Schematische Darstellung des in vitro-Biotests (Variante A) zur Überprüfung der $\mathrm{H}_{2} \mathrm{O}_{2}$ - und NO-Gehalte in Gewebe 24, 48, 72 und 96 hpi. Petrischalen mit Wasseragar wurden mit Cellophane ausgelegt und min. drei Tage mit den jeweiligen Pilzisolaten vorinokuliert $\left(1 \mathrm{ml} 1 \times 10^{6}\right.$ Sporen/ml) bevor sieben Tage alte Keimlinge für die Versuche ausgelegt wurden. 


\subsubsection{Aufbereitung der Gewebeproben}

Die Aufbereitung der Proben für die Analyse von NO im Gewebe erfolgte modifiziert nach XU et al. (2004). Aufgrund der geringen Masse einzelner Keimlinge wurden die Pflanzen gepoolt: 30 Keimlinge $(500 \mathrm{mg}$ ) wurden zu einer Probe zusammengefasst, wobei Spross und Wurzeln getrennt voneinander untersucht wurden. $500 \mathrm{mg}$ des Pflanzenmaterials wurden in flüssigem $\mathrm{N}_{2}$ gemörsert und in $1 \mathrm{ml} 100 \mathrm{mM}$,Phosphate buffered saline“ (PBS) (0,32 M Sucrose, 0,1 mM EDTA und $5 \mathrm{mM}$ Thioaethylenglykol, $\mathrm{pH}$ 7,4) aufgenommen. Das Homogenat wurde bei $13.000 \mathrm{rpm}\left(4^{\circ} \mathrm{C}\right)$ für $20 \mathrm{~min}$ zentrifugiert (Biofuge Fresco, Heraeus Instruments) und der Überstand (1 ml) mit $100 \mu 1$ Spin-Trap Puffer (200 mM DETC, $60 \mathrm{mM}$ $\mathrm{FeSO}_{4}$ ) für $1 \mathrm{~h}$ bei $30^{\circ} \mathrm{C}$ inkubiert. Als organisches Lösungsmittel zum Herauslösen des (DETC $)_{2}-\mathrm{Fe}^{2+}$-NO Komplexes wurden $200 \mu$ l Ethylacetat zugegeben und die Proben für 3 min gevortext. Anschließend wurden die Proben für 6 min bei 13.000 rpm (Tischzentrifuge, Eppendorf, Hamburg) zentrifugiert. Die Lösungsmittelphase wurde aufgenommen und zu gleichen Teilen in drei Mikrokapillaren (Fa. Blaubrand, Wertheim, markiert bei 50-100 $\mu \mathrm{l}$ ) aufgeteilt (3 Parallelproben) und als Triplet per ESR gemessen.

\subsubsection{ESR-Detektion}

Für die Detektion des für NO typischen axialen Triplet-Signals sowohl in den Xylemsaft- als auch den Gewebeproben wurde ein Elektronen-Spin-Resonanz-Spektrometer $(9 \mathrm{GHz}, \mathrm{X}$ Band, Fa. Varian, Darmstadt) verwendet. Das Signal des $\mathrm{Fe}^{2+}-\mathrm{NO}(\mathrm{MGD})_{2}$ wie auch des (DETC $)_{2}-\mathrm{Fe}^{2+}$-NO-Komplexes wurde in allen Versuchen unter folgenden Bedingungen gemessen: X-band, $100 \mathrm{kHz}$ Modulation mit variabler Amplitude, Mikrowelle $5 \mathrm{~mW}$, Magnetfeldzentrum bei 3200, Scan-Breite $100 \mathrm{G}$, Zeitkonstante 0,5 sec und Scan-Zeit 2 min. Der Peak bei $g=2.035$ und die zwei benachbarten Peaks, die zusammen das typische NOTriplet Signal ergeben, wird dem Spin-Trap-NO Komplex zugeschrieben (Xu et al., 2004). Die Höhe des ersten Peaks des Dreifachsignals wurde ausgewertet und als relative Intensität des ESR-Signals gewertet (NAGANO \& YoshimURA 2002; Xu et al. 2004). Für die Darstellung der ESR-Signale wurde die Höhe des ersten Peaks durch die verwendete Amplitude dividiert, auf $1 \mathrm{ml}$ Xylemsaft berechnet und aus den drei Parallelproben ein Mittelwert gebildet.

\subsubsection{Detektion von NO in Pflanzengewebe mit HPLC und Fluoreszenzmarker}

Da NO auch chromatographisch über die Verwendung des NO-spezifischen Fluoreszenzmarkers 4,5-Diaminofluorescein (DAF-2) bestimmt werden kann, sollte durch 
Entwicklung einer HPLC-Methode ein quantitativer NO-Nachweis etabliert werden. Der normalerweise für mikroskopisch-histologische Analysen verwendete Fluoreszenzmarker DAF-2 reagiert unter sauerstoffreichen Bedingungen spezifisch mit NO und bildet das stark fluoreszierende Triazolfluorescein (DAF-2T) (KoJIMA et al. 1998; NAKATSUBO et al. 1998). Das entsprechende Diacetat (DAF-2DA) des Fluoreszenzmarkers ist zellpermeabel und wird durch intrazellulare Esterase zu DAF-2 umgewandelt, welches dann wiederum mit NO zum fluoreszierenden Triazol weiterreagieren kann (Abb.5). Angeregt werden beide Fluoreszenzmarker bei $485 \mathrm{~nm}$. Die Fluoreszenz emittiert mit einer Wellenlänge von $538 \mathrm{~nm}$. Unter neutralen $\mathrm{pH}-$ Bedingungen liegt das Detektionslimit laut Hersteller bei 2-5 nM.<smiles>CC(=O)Oc1ccc2c(c1)Oc1cc(OC(C)=O)ccc1C21OC(=O)c2cc(N)c(N)cc21</smiles>

DAF2-DA

4,5 Diaminofluorescein Diacetate

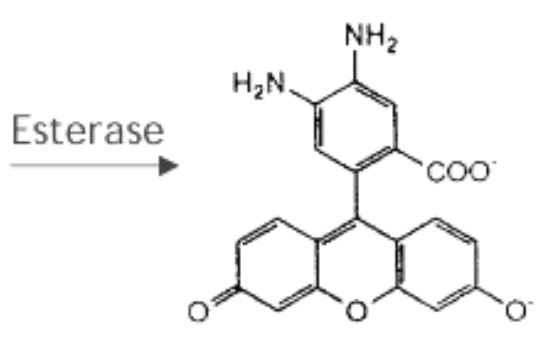

DAF2

4,5 Diaminofluorescein

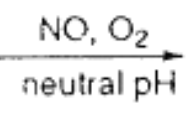<smiles>O=C([O-])c1cc2[nH]nnc2cc1-c1c2ccc(=O)cc-2oc2cc(Cl)ccc12</smiles>

DAF-2T

Triazolofluorescein

Abb. 5: Reaktion des NO-Fluoreszenzmarkers 4,5-Diaminofluorescein-Diacetat (DAF-2DA) mit NO auf Zellebene (nach KoJIMA et al., 1998). DAF-2DA wird durch intrazellulare Esterasen $\mathrm{zu}$ 4,5-Diaminofluorescein (DAF-2) umgewandelt und kann anschließend mit einem NO-Molekül unter sauerstoffreichen Bedingungen zum 180-mal stärker fluoreszierenden Triazolfluorescein (DAF-2T) reagieren, dessen Fluoreszenz bei einer Emissionswellenlänge von $538 \mathrm{~nm}$ detektiert werden kann.

\subsubsection{Probenaufbereitung}

Eine vergleichende Analyse der NO-Gehalte in Gewebeproben erfolgte an sieben Tage alten RCR-Keimlingen. Nach vorsichtigem Auswaschen unter Leitungswasser wurden die Keimlinge auf Wasseragar ausgelegt (Biotest Variante A ohne Cellophane) und die Wurzeln mit $2 \mathrm{ml}$ einer $V$. longisporum-Sporensuspension $\left(1 \times 10^{6} \quad\right.$ Sporen $\left./ \mathrm{ml}\right)$ inokuliert. Kontrollpflanzen wurden mit sterilem Leitungswasser behandelt. Die Inkubation der Keimlinge erfolgte bei $20^{\circ} \mathrm{C}$ und $16 / 8 \mathrm{~h} \mathrm{Licht/Dunkel} \mathrm{in} \mathrm{einem} \mathrm{Gewebekulturschrank} \mathrm{(Fa.}$ Mytron, Heiligenstadt). Die Probenahme erfolgte nach $14 \mathrm{~h}$. Um ausreichend Probenmaterial zu erhalten, wurden jeweils 15 Keimlinge einer Variante gepoolt und in Spross und Wurzel aufgeteilt. Je $100 \mathrm{mg}$ Pflanzenmaterial wurde für die Analysen unter $\mathrm{N}_{2}$ gemörsert und in ein $1,5 \mathrm{ml}$ Reaktionsgefäß mit in Hepes-Puffer $(1 \mathrm{ml}, 40 \mathrm{mM}, \mathrm{pH} 7,4)$ vorgequollenem PVPP 
(100 mg) eingewogen. Die Proben wurden für 15 min auf Eis inkubiert und anschließend für 5 min bei $13.000 \mathrm{rpm}$ (Tischzentrifuge, Eppendorf, Hamburg) zentrifugiert. Zur Analyse wurden pro Testansatz $380 \mu$ l Probenüberstand verwendet. Die Aufbereitung der Proben für die Analyse wurde nach folgendem Schema durchgeführt: $20 \mu \mathrm{DAF}-2 \mathrm{DA}(100 \mu \mathrm{M})$ in Hepes $(40 \mathrm{mM}, \mathrm{pH} 7,4)$ wurden mit $380 \mu \mathrm{l}$ Probenüberstand und $100 \mu \mathrm{NaOH}(0,01 \mathrm{~N})$ vermischt und für 90 min bei $37^{\circ} \mathrm{C}$ im Dunkeln inkubiert. Zur Erstellung der Standardreihen aus MAHMA NONOate in $\mathrm{NaOH}(0,01 \mathrm{~N})$ wurden zuerst $20 \mu \mathrm{DAF}(100 \mu \mathrm{M})$ vorgelegt, dann $380 \mu 1$ Hepes Puffer (40 mM, pH 7,0) zugegeben und anschließend $100 \mu 1$ NONOate (in $0,01 \mathrm{~N} \mathrm{NaOH})$ zugefügt.

\subsubsection{HPLC-Detektion von NO}

Da der Fluoreszenzmarker sehr lichtempfindlich ist, wurden die Proben unter abgedunkelten Bedingungen hergestellt und für die HPLC-Analyse in dunkle HPLC-Probengefäße überführt. Die Detektion (nach ITOH et al. 2000) erfolgte mit einer HPLC-Anlage der Firma Varian bestehend aus einem Autosampler (Modell 410, Fa. Varian, Darmstadt), einem binären Pumpensystem (Varian Pro Star, 210, Fa. Varian, Darmstadt), einem Säulenofen (K7, Techlab) und einem Fluoreszenzdetektor (Varian Pro Star, Fa. Varian, Darmstadt). Die Proben wurden mit einem Injektionsvolumen von $10 \mu \mathrm{l}$ (Vorsäule, RP-18, $5 \mu \mathrm{m}, \mathrm{Fa}$. Merck) auf die Säule (LiChrospher ${ }^{\circledR} 100, \mathrm{RP}-18$, Fa. Merck) injiziert $\left(30^{\circ} \mathrm{C}\right.$ Säulentemperatur) und

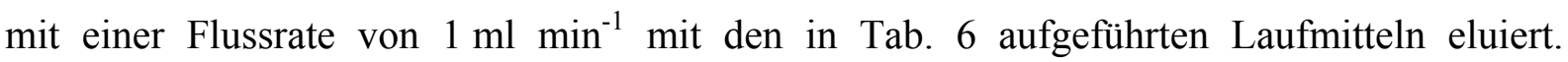
Anregung und Emission der Proben erfolgte bei 485 bzw. 538 nm. Die Dauer des Laufs betrug 18 Minuten (Tab. 7) und der DAF-Triazol Peak wurde bei einer Retentionszeit von 4 Minuten detektiert. Die Datenaufnahme erfolgte mit der Galaxie-Software (Fa. Varian, Darmstadt).

Tab. 6: Zusammensetzung der verwendeten Laufmittel zur Analyse von NO per HPLC.

\begin{tabular}{|l|cc|}
\hline Lösungsmittel & Laufmittel A pH 7,2 & Laufmittel B \\
\hline $\mathrm{KH}_{2} \mathrm{PO}_{4}(0,06 \mathrm{M})$ & $80 \%(\mathrm{v} / \mathrm{v})$ & $0 \%(\mathrm{v} / \mathrm{v})$ \\
$\mathrm{Na}_{2} \mathrm{HPO}_{4} \times 2 \mathrm{H}_{2} \mathrm{O}(0,06 \mathrm{M})$ & $20 \%(\mathrm{v} / \mathrm{v})$ & $0 \%(\mathrm{v} / \mathrm{v})$ \\
Acetonitril $100 \%$ & $0 \%(\mathrm{v} / \mathrm{v})$ & $100 \%(\mathrm{v} / \mathrm{v})$ \\
\hline
\end{tabular}


Tab. 7: Laufzeit, Flussrate und Volumenanteile der Laufmittel zur Analyse von NO per HPLC.

\begin{tabular}{|l|l|l|l|}
\hline Laufzeit in [min] & Flussrate $\mathrm{ml} / \mathrm{min}$ & Laufmittel A & Laufmittel B \\
\hline prerun & 1,00 & $93 \%$ & $7 \%$ \\
8.30 & 1,00 & $93 \%$ & $7 \%$ \\
9.30 & 1,00 & $5 \%$ & $95 \%$ \\
12.00 & 1,00 & $5 \%$ & $95 \%$ \\
13.30 & 1,00 & $93 \%$ & $7 \%$ \\
18.00 & 1,00 & $93 \%$ & $7 \%$ \\
\hline
\end{tabular}

\subsection{Nachweis von $\mathrm{H}_{2} \mathrm{O}_{2}$}

Für diesen Versuch wurden sowohl Keimlinge (sieben Tage alt) als auch adulte Pflanzen (1435 dpi) beprobt. Für die Untersuchung früher Zeitpunkte nach Inokulation wurden sieben Tage alte Keimlinge verwendet. Aufgrund der geringen Masse einzelner Keimlinge wurden die Pflanzen auch in diesem Versuch gepoolt. Fünf Keimlinge wurden zu einer Probe (100 mg) zusammengefasst, wobei Spross und Wurzeln getrennt voneinander untersucht wurden. Für die späteren Zeitpunkte der Infektion (7-35 dpi) wurden getopfte Pflanzen in Spross, Hypokotyl (inklusive des ersten cm Stängel) und Wurzel unterteilt. Für die $\mathrm{H}_{2} \mathrm{O}_{2}$-Bestimmung wurde ein Titan-Oxalat Nachweis $\left(2,5 \%\right.$ in $\left.20 \% \mathrm{H}_{2} \mathrm{SO}_{4} \mathrm{w} / \mathrm{v}\right)$ durchgeführt (FLORYSZAKWieczoreK et al. 2007; Lin \& KAO 1998; PATterson et al. 1983; BrenNAN \& FrenKeL 1977; MaCNEVIN \& URONE 1953) und modifiziert. Die Konzentrationsbestimmung erfolgte über eine entsprechende $\mathrm{H}_{2} \mathrm{O}_{2}$-Standardreihe. Das Gewebe wurde unter flüssigem $\mathrm{N}_{2}$ gemörsert, $50 \mathrm{mg}$ abgewogen und mit $500 \mu \mathrm{l}$ Hepes-Puffer $(50 \mathrm{mM}, \mathrm{pH} 7,4)$ vermischt. Anschließend wurden die Proben für $6 \mathrm{~min}$ bei $10.000 \mathrm{rpm}$ und $4^{\circ} \mathrm{C}$ zentrifugiert (Biofuge Fresco, Heraeus Instruments). Eine Dreifachprobe des Überstandes $(3$ x $100 \mu l)$ wurde mit $800 \mu 1$ Hepes-Puffer (50 mM, pH 7,4), $1 \mu \mathrm{H}_{2} \mathrm{SO}_{4}$ (97\%) und $100 \mu 1$ Titan-Oxalat vermischt und die enthaltenen $\mathrm{H}_{2} \mathrm{O}_{2}$-Gehalte photometrisch (Specord 40, Analytik Jena) bei $410 \mathrm{~nm}$ gemessen.

\subsection{GSNO-Detektion per HPLC}

Als potentielle Transportform für NO, die einen essentiellen Einfluss auf die Bildung von nitrosylierten Proteinen hat, sollte der Nitrosoglutathiongehalt (GSNO) infizierter und 
gesunder RCR-Pflanzen bestimmt und über den Verlauf der Pathogenese und Pflanzenentwicklung dargestellt werden. Da bereits eine etablierte HPLC-Methode zur Detektion von Glutathion (GSH) vorlag (SCHUPP \& RENNENBERG 1988), sollte versucht werden, diese Methode für die Detektion von GSNO zu modifizieren. Dafür wurde folgender Ansatz gewählt: Aus der Reaktion von GSNO mit der GSNO-abhängigen FormaldehydDehydrogenase (FALDH, EC 1.2.1.1) entstehen, wie in den Reaktionsgleichungen 11-13 ersichtlich, Glutathiondisulfid (GSSG) und Ammoniak $\left(\mathrm{NH}_{3}\right)$. Durch die Bestimmung des durch diese Reaktion in einer Probe entstehenden GSSG sind Rückschlüsse auf den Gehalt an GSNO möglich, da die Umsetzung stöchiometrisch erfolgt.

$$
\begin{aligned}
& \mathrm{GSNO}+\mathrm{NADH}+\mathrm{H}^{+} \rightarrow \mathrm{GSNHOH}+\mathrm{NAD}^{+} \\
& \mathrm{GSNHOH}+\mathrm{NADH}+\mathrm{H}^{+} \rightarrow \mathrm{GSNH}_{2}+\mathrm{NAD}^{+}+\mathrm{H}_{2} \mathrm{O} \\
& \mathrm{GSNH}_{2}+\mathrm{GSH} \rightarrow \mathrm{GSSG}+\mathrm{NH}_{3}
\end{aligned}
$$

Da eine fluorometrische Detektion von GSSG nicht möglich ist, wurde durch die Zugabe von 1,4-Dithiotreitol (DTT) GSSG zu GSH reduziert (14).

$$
\mathrm{GSSG}+\mathrm{DTT} \rightarrow 2 \mathrm{GSH}
$$

Der Nachweis von GSH erfolgte modifiziert nach SchupP \& RENNENBERG (1988). Die Bestimmung wurde fluorometrisch bei $480 \mathrm{~nm}$ durchgeführt und beruht auf der Reaktion von Monobromobiman-Thiolyte ${ }^{\mathrm{TM}} \mathrm{MB}(\mathrm{mBrB})$ mit den freien Thiolgruppen des GSH (15).

$\mathrm{mBrB}+$ Thiol $\rightarrow$ Bimanthioether $+\mathrm{HBr}$

\subsubsection{Probenvorbereitung}

100 mg Pflanzenmaterial wurden in einem $2 \mathrm{ml}$ Reaktionsgefäß mit $1 \mathrm{ml}$ meta-Phosphorsäure und $100 \mathrm{mg}$ über Nacht vorgequollenem PVPP eingewogen und vermischt. Die Proben wurden $15 \mathrm{~min}$ auf Eis inkubiert und anschließend bei $13.000 \mathrm{rpm}$ zentrifugiert (Tischzentrifuge, Eppendorf, Hamburg). $120 \mu 1$ ÜS wurden mit $250 \mu 1$ CHES-Puffer (2-[NCyclohexylamino]-Ethansulfonsäure, $\mathrm{pH}$ 8,0) vermischt. Um das bereits in der Probe vorhandene und nicht aus der Reduktion des GSSG stammende GSH zu eliminieren, wurde 
der Probe $40 \mu 1$ N-Ethylmaleinimid (NEM) zugefügt, welches die freien Thiolgruppen des GSH alkyliert und somit für die Reaktion mit MBB blockiert. Da NEM die Funktion der GSNO-Reduktase mindert, musste NEM durch Ausschütteln mit einem gleichen Volumen an Toluol (dreifach) aus der Probe entfernt werden. Die Reste des Lösungsmittels wurden durch Zentrifugation in einer Vakuumzentrifuge (RVC 2-25, Christ) bei $30^{\circ} \mathrm{C}$ für $10-15 \mathrm{~min}$ entfernt. Nach Zugabe von GSNO-Reduktase ( $1 \mu \mathrm{l})$ erfolgte eine Inkubation von ca. 20 min, in denen das GSNO zu GSSG umgewandelt wurde. Anschließend wurde der Probe $30 \mu 1$ DTT (3 mM) zugegeben und GSSG zu GSH reduziert (Inkubationsdauer 20-30 min im Dunkeln). Das entstandene GSH wurde mit $10 \mu \mathrm{MBB}(50 \mathrm{mM}$ in $100 \% \mathrm{AcN})$ derivatisiert und die Reaktion nach einer weiteren Inkubationszeit von 15 min mit $300 \mu 1$ Essigsäure (10\%) abgestoppt, der hydrolytische Zerfall der Alkylgruppen unterbunden und die Proben somit stabilisiert. Für die genaue Quantifizierung des GSNO musste auch der Gehalt an bereits vorhandenem GSSG bestimmt werden. Dazu wurde die Probe wie o.a. behandelt, allerdings keine Reduktase zugegeben, wodurch der Gesamtgehalt an vorhandenem GSSG bestimmt werden sollte. Der Gesamtgehalt an GSSG wurde dann von der vorherigen Messung des reagierten GSNO subtrahiert. Der erhaltene Wert entspricht dem allein aus der Reaktion von GSNO mit der Reduktase entstandenem GSSG bzw. GSH.

\subsubsection{HPLC-Analyse von GSNO}

Für die HPLC-Analyse wurden die Proben in HPLC-Probengefäße überführt. Die Analyse erfolgte mit einer HPLC-Anlage (Varian ProStar 210, Fa. Varian, Darmstadt) und einem Fluoreszenzdetektor bei $480 \mathrm{~nm}$. Die Proben wurden mit einem Injektionsvolumen von $10 \mu 1$ auf eine C18-Säule (reverse phase, $5 \mu \mathrm{m}$, Fa. Hewlett Packard) injiziert und mit einer Flussrate von $1 \mathrm{ml} \mathrm{min}^{-1}$ für 12 Minuten mit folgenden Laufmitteln (Tab. 8) und folgendem Gradienten (Tab. 9) eluiert.

Tab. 8: Zusammensetzung der verwendeten Laufmittel zur Trennung von Thiolen per HPLC.

\begin{tabular}{|l|ll|}
\hline Lösungsmittel & Laufmittel A & Laufmittel B \\
\hline Methanol & $10 \%(\mathrm{v} / \mathrm{v})$ & $90 \%(\mathrm{v} / \mathrm{v})$ \\
$\mathrm{H}_{2} \mathrm{O}$ & $90 \%(\mathrm{v} / \mathrm{v})$ & $10 \%(\mathrm{v} / \mathrm{v})$ \\
Essigsäure & $0,25 \%(\mathrm{v} / \mathrm{v})$ & $0,25 \%(\mathrm{v} / \mathrm{v})$ \\
$\mathrm{NaOH}$ & ad. $\mathrm{pH} 4,3$ & ad. $\mathrm{pH} 3,9$ \\
\hline
\end{tabular}


Die Laufmittel wurden vor ihrer Verwendung durch einen 0,2 $\mu \mathrm{m}$ PC Filter (Sartorius GmbH, Göttingen) filtriert und automatisch über einen an die HPLC angeschlossenen Entgaser entlüftet

Tab. 9: Laufzeit, Flussrate und Volumenanteile der Laufmittel zur Trennung von Thiolen per HPLC.

\begin{tabular}{|l|l|l|l|}
\hline Laufzeit in [min] & Flussrate [ml]/min & Laufmittel A & Laufmittel B \\
\hline Prerun & 1,00 & $50 \%$ & $50 \%$ \\
12,00 & 1,00 & $50 \%$ & $50 \%$ \\
\hline
\end{tabular}

\subsection{Nachweis der GSNO-Reduktaseaktivität}

Eine hohe Aktivität der GSNO-Reduktase (GSNOR) reduziert den GSNO-Pool und stellt einen Entgiftungsmechanismus dar, der überschüssiges NO verwertet. Über die Bestimmung der Aktivität der GSNOR sollte daher indirekt auf den Gehalt an vorhandenem GSNO bzw. NO geschlossen werden.

Die Enzymaktivität wurde photometrisch (Specord 40, Analytik Jena) bei $340 \mathrm{~nm}$ durch den Abbau von zugesetztem NADH überprüft, wobei der Gehalt an Endprodukt ( $\mathrm{NH}_{3}$ und GSSG) abhängig ist von vorhandenem GSH. Die Reaktion läuft nach LIU et al. (2001) dabei folgendermaßen ab (16-18):

$\mathrm{GSNO}+\mathrm{NADH}+\mathrm{H}^{+} \rightarrow \mathrm{GSNHOH}+\mathrm{NAD}{ }^{+}$

$\mathrm{GSNHOH}+\mathrm{NADH}+\mathrm{H}^{+} \rightarrow \mathrm{GSNH}_{2}+\mathrm{NAD}^{+}+\mathrm{H}_{2} \mathrm{O}$

$\mathrm{GSNH}_{2}+\mathrm{GSH} \rightarrow \mathrm{GSSG}+\mathrm{NH}_{3}$

Für die Untersuchung der GSNO-Reduktaseaktivität in V. longisporum-, V. dahliae- und nicht-inokulierten Pflanzen wurden Einzelpflanzen zu den Zeitpunkten 14, 21, 28 und 35 dpi ( $n=10$ pro Variante und Zeitpunkt) sowie Keimlinge zum Zeitpunkt 24 hpi (gepoolt, pro Probe ca 30 Keimlinge, $n=6$ ) beprobt und in Spross- und Wurzelproben unterteilt.

\subsubsection{Herstellung der Rohextrakte}

Durch die Aufarbeitung der Proben können phenolische Komponenten freigesetzt werden und die Extraktion von Enzymen behindern (LoOMIs \& BATAILlE 1966; LoOMIS 1969). Daher 
wurden alle Extraktionen mit Polyvinylpolypyrrolidone (PVPP) durchgeführt, um eine Aktivität der Enzyme zu erhalten (SCHNEIDER \& HALLIER 1970; WEIMAR \& ROTHE 1986). Zur Aufbereitung der Proben wurden $1 \mathrm{~g}$ PVPP in Zentrifugenröhrchen eingewogen, mit $8 \mathrm{ml}$ Aufbereitungspuffer (KPP-Puffer: 0,1 $\mathrm{M} \mathrm{K}_{2} \mathrm{HPO}_{4}, \mathrm{KH}_{2} \mathrm{PO}_{4}, \mathrm{pH} 7,8+1,5 \%$ Triton-X) versetzt und über Nacht bei $4^{\circ} \mathrm{C}$ vorgequollen. Die Zugabe von Detergenzien wie Triton-X bewirkt dabei die Zerstörung von Membranen durch Micellierung der Phospholipide und ermöglicht dadurch einen besseren Zellaufschluss (GOLDSTEIN \& SWAIN 1965).

Am Versuchstag wurde das zu untersuchende Pflanzenmaterial in einem vorgekühlten Mörser mit flüssigem $\mathrm{N}_{2}$ zu feinem Pulver zermahlen. Jeweils $1 \mathrm{~g}$ des Pflanzenmaterials wurde in die Zentrifugenröhrchen mit Aufbereitungspuffer und PVPP eingewogen, gevortext und für $15 \mathrm{~min}$ auf Eis inkubiert. Anschließend wurden die Proben bei $15000 \mathrm{rpm}$ und $4^{\circ} \mathrm{C}$ für eine Stunde zentrifugiert (Ultrazentrifuge, Sorvall Evolution RC, Fa. Kendro, SS34 Rotor). Der Überstand (Rohextrakt) wurde dekantiert und für die Bestimmung der GSNOR-Aktivität wie auch die Bestimmung der Gesamtproteine und nitrosylierten Proteine (SNO) weiter verwendet.

\subsubsection{Gelfiltration}

Viele niedermolekulare Stoffe der Rohextrakte (Triton X, Aminosäuren) können die Proteinbestimmung als auch enzymatische Messungen inhibieren (HILL \& STRAKA, 1988). Daher wurden die erhaltenen Extrakte durch Gelfiltration weiter aufgereinigt und dadurch von Molekülen von weniger als 1000 Da getrennt (SCHWANZ, 1997). Verwendet wurden PD-10 (NAP-5)-Säulen (Fa. Pharmacia, Freiburg) mit 2,5 ml Auftragskapazität. Zur Equilibrierung wurden die Säulen mit $10 \mathrm{ml}$ Eluierungspuffer (50 mM Kaliumphosphatpuffer, pH 7,8) vorgespült und anschließend 2,5 ml Extrakt aufgetragen. Das erste Eluat (verdrängter Equilibrierungspuffer) wurde verworfen und der Rohextrakt mit 3,5 ml Elutionspuffer von den Säulen eluiert. Das Eluat wurde für die Bestimmung nitrosylierter Proteine sofort gemessen und das Resteluat bis zur enzymatischen Analyse der GSNOR-Aktivität und Proteingesamtbestimmung bei $-20^{\circ} \mathrm{C}$ eingefroren.

\subsubsection{Photometrische Bestimmung der GSNO-Reduktaseaktivität}

Die GSNO-Reduktaseaktivität wurde photometrisch (Specord 40, Analytik Jena) über einen Zeitraum von $5 \mathrm{~min}$ bei $340 \mathrm{~nm}$ und $25^{\circ} \mathrm{C}$ bestimmt. Die Aufbereitung der Proben für die Analyse wurde nach folgendem Schema durchgeführt: $650 \mu 1$ Tris- $\mathrm{HCl}(30 \mathrm{mM}, \mathrm{pH} 8)$ 
wurden mit $100 \mu \mathrm{l}$ EDTA $(0,5 \mathrm{mM})$ und $100 \mu \mathrm{l}$ Pflanzenextrakt vermischt. Anschließend wurden $100 \mu \mathrm{l}$ GSNO ( $1 \mathrm{mM}$, frisch bereitet) und $50 \mu \mathrm{l}$ NADH $(0,3 \mathrm{mM}$ in Tris-HCl, frisch bereitet) zugefügt, mit einem Rührstäbchen gut durchmischt und sofort gemessen. Die Bestimmung des nativ vorliegenden Substrates erfolgte über Kontrollansätze, in denen statt GSNO $100 \mu \mathrm{l}$ Tris-HCl (30 mM, pH 8,0) eingesetzt wurden. Die Resultate der Kontrollen wurden von denen der Proben abgezogen und die GSNOR-Aktivität mit dem Absorptionskoeffizienten des NADH folgendermaßen berechnet:

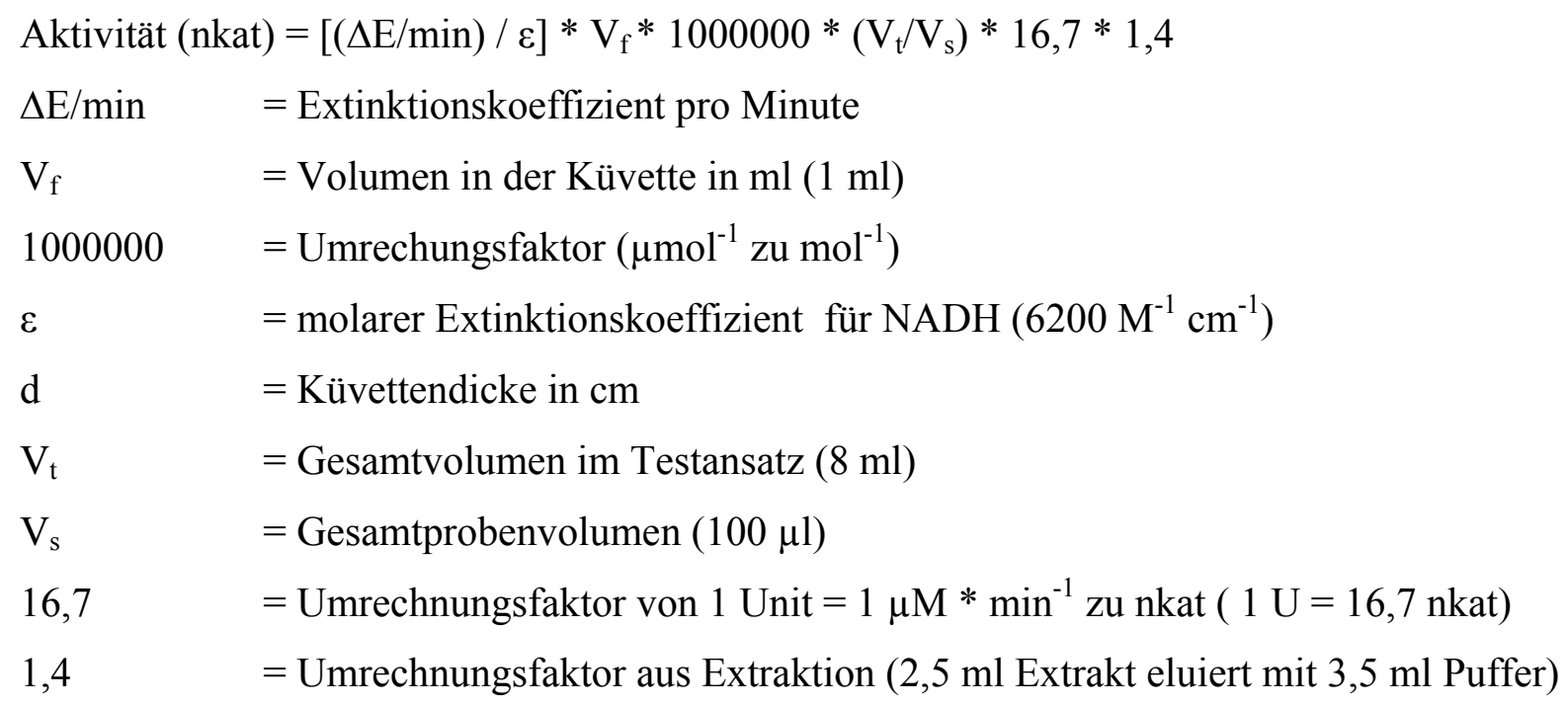

Die Enzymaktivität wurde in nkat pro Gramm Frischgewicht angegeben; 1 nkat entspricht einem Substratumsatz von $1 \mathrm{mmol} / \mathrm{s}$ (EISENTHAL \& DANSON 1992).

\subsection{Nachweis nitrosylierter Proteine}

Der Nachweis nitrosylierter Proteine erfolgte modifiziert nach SAVILLE (1958) durch die Reaktion der beiden Hauptkomponenten des Griess Assay, Sulfanilamid und N-(1-Naphthyl)Ethylendiamine (NEDD). Die Reaktion dieser beiden Komponenten mit nitrosylierten Proteinen per se erzeugt keine Veränderung der Absorption bei 400-800 nm. Durch Zugabe von $\mathrm{HgCl}_{2}$ wird allerdings das $\mathrm{NO}$ an der $\mathrm{SH}-$ Gruppe durch ein Hg-Molekül ersetzt und abgespalten. Das freigesetzte $\mathrm{NO}$ wird durch $\mathrm{O}_{2}$ oxidiert und das entstehende $\mathrm{NO}_{2}{ }^{-}$reagiert mit den beiden Reaktionskomponenten Sulfanilamid und NEDD wodurch ein Azo-Farbstoff entsteht, der eine Absorptionsänderung bei $540 \mathrm{~nm}$ hervorruft. Zur Überprüfung der nitrosylierten Proteine wurden $V$. longisporum-, $V$. dahliae- und nicht-inokulierte Pflanzen zu den Zeitpunkten 14, 21, 28 und 35 dpi beprobt. Die Pflanzen wurden in Spross und Wurzel unterteilt und je 3 Pflanzen wurden zu einer Probe zusammengefasst $(n=4$ pro Variante und 
Zeitpunkt). Neben den SNOs wurde in allen Proben auch die GSNOR-Aktivität (siehe Kap. 2.8) und der Gesamtproteingehalt nach Bradford bestimmt.

\subsubsection{Erstellung der Rohextrakte}

Die Extraktion der Rohextrakte erfolgte wie in Kap. 2.11.1 beschrieben. Dem Extraktionspuffer wurde in dieser Versuchsreihe zusätzlich ein Kupfer-Chelator zugesetzt (KPP-Puffer: 0,1 $\mathrm{M} \mathrm{K}_{2} \mathrm{HPO}_{4}, \mathrm{KH}_{2} \mathrm{PO}_{4}, 0,1 \mathrm{mM}$ EDTA, 0,1 M Neocuprione, $\mathrm{pH}$ 7,8). Die Proben wurden für $15 \mathrm{~min}$ auf Eis inkubiert und anschließend bei $15.000 \mathrm{rpm}$ und $4^{\circ} \mathrm{C}$ (Ultrazentrifuge, Sorvall Evolution RC, Fa. Kendro, SS34 Rotor) zentrifugiert. Der ÜS wurde abgenommen und wie schon zur GSNOR-Analyse gelfiltriert (Kap. 2.11.2). Der eluierte Rohextrakt wurde für die nachfolgende photometrische Analyse verwendet. Die Aufbereitung der Proben wurde nach folgendem Schema durchgeführt: $300 \mu 1$ Sulfanilamid $(2,7 \%(\mathrm{w} / \mathrm{v})$ in $0,4 \mathrm{~N} \mathrm{HCl})$ wurden mit $180 \mu$ Probenextrakt und $300 \mu 1 \mathrm{HgCl}_{2}(0,25 \%)$ in DMSO (100\%) sowie $220 \mu \mathrm{l}$-(1-Naphthyl)-Ethylendiamin (0,1\%) vermischt. Als Referenz wurden alle Messungen gegen den Probenextrakt ohne Zugabe von $\mathrm{HgCl}_{2}$ nur mit reinem DMSO gemessen. Die Konzentration des gebildeten Azo-Farbstoffes wurde 5 min nach dem Mischen der Komponenten im Photometer durch Messung der Absorption bei $540 \mathrm{~nm}$ ermittelt, die Differenz der Absorption zwischen den Proben mit und ohne $\mathrm{HgCl}_{2}$ berechnet und die Werte mit einer Standardkurve aus GSNO quantifiziert.

\subsubsection{Gesamtproteinbestimmung nach Bradford}

Um den Anteil der nitrosylierten Proteine am Gesamtgehalt an Proteinen in den jeweiligen Proben bestimmen zu können, wurde des Weiteren der Gesamtproteingehalt der Proben nach Bradford ermittelt. Diese Methode beruht auf der Bindung von Farbstoffmolekülen an die Proteine, was in einer Verschiebung des Absorptionsmaximums nach $595 \mathrm{~nm}$ resultiert. Für die Analyse wurden $10 \mu 1$ Probenextrakt mit $300 \mu$ l Bradfordreagenz (Coomassie Plus ${ }^{\mathrm{TM}}$, Fa. Perbio, USA) vermischt und für 10 min bei RT inkubiert. Die Messung der Proteine erfolgte photometrisch bei $595 \mathrm{~nm}$ ( $\mu$ Quant, BIO-TEK Instruments, Bad Friedrichshall); die Proteinkonzentrationen wurden unter Verwendung einer Rinder-Serum-Albumin (BSA) Standardreihe, $(25-2000 \mu \mathrm{g} / \mathrm{ml})$ ermittelt. 


\subsection{Phytohormonanalyse}

Die Untersuchung der Phytohormongehalte (ABA, SA, JA und IAA) erfolgte an Einzelpflanzen einer Zeitreihe, wobei jeweils 10 Pflanzen jeder Variante (V. longisporum-, V. dahliae- und nicht-inokulierte Pflanzen) zu den Zeitpunkten 14, 21, 28 und 35 dpi beprobt und in Spross und Wurzel unterteilt wurden.

\subsubsection{Extraktionsschritte}

Die zu untersuchenden Gewebeproben der Zeitreihen wurden in flüssigem $\mathrm{N}_{2}$ gemörsert, 100 mg Material (Spross oder Wurzel) abgewogen, in ein $15 \mathrm{ml}$ Falcon-Röhrchen überführt und mit $5 \mathrm{ml}$ Extraktionspuffer (Aceton/Wasser/Essigsäure 100\%=20 $791 \mathrm{v} / \mathrm{v} / \mathrm{v}$ ) für $2 \mathrm{~h} \mathrm{im}$ Dunkeln geschüttelt. Die Proben wurden anschließend für $15 \mathrm{~min}$ bei $5000 \mathrm{rpm}$ und $4^{\circ} \mathrm{C}$ zentrifugiert (4K10, Sigma, Osterode) und der Überstand in ein neues Falcon-Röhrchen überführt. Um Lipide zu entfernen, wurden die Proben mit $5 \mathrm{ml}$-Hexan ausgeschüttelt. Die obere Hexan-Phase wurde verworfen und die untere Phase mit $5 \mu 1$ Eisessig angesäuert. Durch Zugabe von $5 \mathrm{ml}$ Diethylether und unter Schütteln wurden die Phytohormone von der unteren in die obere organische Diethylether-Phase überführt. Nach deutlicher Phasentrennung wurde die obere organische Phase in einen abgedunkelten $15 \mathrm{ml}$ Glasspitzkolben überführt. Die verbleibende Phase Extraktionspuffer wurde anschließend ein zweites Mal mit $5 \mathrm{ml}$ Diethylether ausgeschüttelt. Die $10 \mathrm{ml}$ Gesamtvolumen an Diethylether wurden bis zur Trockne in einem Rotationsverdampfer aufkonzentriert. Die Proben wurden anschließend wieder in $1 \mathrm{ml}$ Methanol $(\mathrm{MeOH})$ aufgenommen und steril filtriert (sterile Aufsatzfilter Spartan 13, 0,2 $\mu \mathrm{m}$ Porengröße, Fa. Whatman, Dassel). In einer Vakuumzentrifuge (Concentrator, Fa. Eppendorf ) wurden die Proben bei $15.000 \mathrm{rpm}$ und $\max 30^{\circ} \mathrm{C}$ erneut eingetrocknet (ca. $2 \mathrm{~h}$ bis zur vollständigen Trockne) und anschließend in $100 \mu \mathrm{MeOH} / \mathrm{H}_{2} \mathrm{O}$ (50/50) wieder aufgenommen. Nach dem Resuspendieren (ca. $1 \mathrm{~h} \mathrm{im}$ Dunkeln) wurden die Proben in HPLC-Reaktionsgefäße überführt und bis zur Analyse bei minus $20^{\circ} \mathrm{C}$ gelagert. Die Detektion der Phytohormone erfolgte mit einer HPLC-ESI-MS/MS und der entsprechenden Methode zur Analyse von Phytohormonen in der Abteilung Molekulare Phytopathologie und Mykotoxinforschung, Dep. für Nutzpflanzenwissenschaften, Universität Göttingen durch Astrid Ratzinger.

\subsubsection{HPLC-MS Detektion der Phytohormone}

Die Analyse der Phytohormone erfolgte mit einem HPLC-MS System (Fa Varian, Darmstadt) bestehend aus einem Autosampler (Pro Star 430, Fa. Varian, Darmstadt), einem binären 
Pumpensystem (ProStar 210 Solvent Delivery Modul, Fa. Varian, Darmstadt, Germany), einem Säulenofen (Mistral, ProStar 510 Säulenofen, Fa. Varian, Darmstadt, Germany) mit reversed-phase Säule (Polaris C18-A, 150 x 2 mm i.d.; $5 \mu \mathrm{m}$,Fa. Varian, Darmstadt, Germany) inklusive einer Vorsäule (MetaGuard Polaris C18-A, Fa. Varian, Darmstadt, Germany) und einem Massenspektrometer (1200 LC/MS, Triple QuadrupolMassenspektrometer mit Elektrospray Ionisation-Interface, Fa. Varian, Darmstadt).

Zur HPLC-Analyse wurden $10 \mu 1$ Probe auf die Säule injiziert und isocratisch mit $7 \mathrm{mM}$ Eisessig und 50\% MeOH, 45\% $\mathrm{H} 2 \mathrm{O}$ bidest. und 5\% Acetonitril bei einer Flussrate von 0,2 $\mathrm{ml} / \mathrm{min}$ und einer Säulentemperatur von $40^{\circ} \mathrm{C}$ eluiert. Die Detektion der Proben über Elektrospray Ionisations Interface (ESI)-MS/MS am Triple Quadrupole Massenspektrometer erfolgte unter folgenden Bedingungen: Negative Elektrospray-Ionisation: ESI (-), Needle Spannung - 4400V, Schild Spannung -600 V, Trocknungsgas $\left(\mathrm{N}_{2}\right)$ Druck 18 psi, Trocknungsgas Temp. $270^{\circ} \mathrm{C}$, Nebulizing gas (Air) Druck 50 psi. MS-Modus: MS/MS, Multiple Reaction Monitoring = MRM, Scan Zeit 1sec, Isolationsbreite m/z 0.7, Detektor Spannung $1370 \mathrm{~V}$ (high gain).

Die Daten wurden per MS Workstation Version 6.41 Software (Varian, Darmstadt) verarbeitet und mit Hilfe der MS Data Review Software ausgewertet.

\subsection{Toxizitätstest}

Um zu untersuchen, ob die Seneszenz und Stauche durch einen möglicherweise toxisch wirkenden Metaboliten des Pilzes gebildet wird, wurden unterschiedliche Versuche durchgeführt. Ein einfacher Petiolentoxizitätstest zur Überprüfung des Toxizitätsfaktors, ein Topfversuch und anschließende in vitro-Experimente mit steril filtrierten Schüttelkulturüberständen zur Analyse des Stauchefaktors.

\subsubsection{Petiolentoxizitätstest mit CzD-Medium}

In diesem Experiment wurde die Toxizität 10 Tage alter V. longisporum- und V. dahliae-CzDSchüttelkulturen auf abgetrennte Blätter 21 Tage alter RCR-Pflanzen getestet.

Pilzliches Material wurde durch Dekantieren vom Medium getrennt und der zu verwendende Überstand steril filtriert (RC-Filter vliesverstärkt, 0,2 $\mu \mathrm{m}$ Porengröße, Sartorius, Göttingen). Kontrollen wurden zum einen mit sterilem Leitungswasser, zum anderen mit nichtinokuliertem Medium durchgeführt. Ein Milliliter der $V$. longisporum- oder $V$. dahliaeKulturfiltrate bzw. des Kontrollmediums wurde in ein 1,5 ml Reaktionsgefäß überführt und 
mit Parafilm abgedeckt, um Evaporation zu vermeiden. Das erste Hauptblatt 21 Tage alter Pflanzen wurde unter Wasser vom Stängel abgeschnitten und durch den Parafilm in das Kulturfiltrat gesteckt. Die Proben wurden unter konstanten Klimakammerbedingungen (20$23^{\circ} \mathrm{C}$, Tag/Nacht 16/8 h) für 24-48 h inkubiert. Um die Proben vor zu starker Transpiration zu schützen, wurden die Proben mit einer Plastikhaube abgedeckt. Die Filtrate wurden bei Bedarf wieder aufgefüllt und die Blätter nach $24 \mathrm{~h}$ auf Toxizitätssymptomen wie Vergilbung oder Welke untersucht. In einem Folgeexperiment wurde fünffach konzentriertes Medium überprüft. Auch die in Kap. 2.14.3 verwendeten steril filtrierten Kulturüberstände aus V. longisporum- und V. dahliae-inokuliertem SXM-, CzD-, RWE- und SNA-Medium sowie die entsprechenden Kontrollen aus Wasser und nicht inokuliertem Medium wurden über den Petiolentoxizitätstest auf mögliche Toxin-induzierte Symptombilder getestet.

\subsubsection{Stauchetest mit sterilen Kulturfiltraten in Topfversuchen}

Die Rapskeimlinge wurden sieben Tage nach Aussaat aus dem Quarzsubstrat ausgewaschen und per Tauchinokulation mit den steril filtrierten Überständen der V. longisporum- und V. dahliae-CzD-Schüttelkulturen, der nicht inokulierten CzD-Kontrolle sowie der unfiltrierten Sporensuspension $\left(1 \times 10^{6}\right.$ Sporen $\left.\mathrm{ml}^{-1}\right)$ inokuliert. Als dritte und vierte Variante wurden die Keimlinge getopft (siehe Kap. 2.3) und mit jeweils $5 \mathrm{ml}$ der steril filtrierten Überstände, Sporensuspension oder Kontrollmedium angegossen. Die Pflanzen wurden in der Klimakammer $\left(20-23^{\circ} \mathrm{C}\right.$, Tag/Nacht $\left.16 / 8 \mathrm{~h}\right)$ angezogen und der Einfluss auf das Pflanzenwachstum (Sprosslänge) oder den Pflanzenhabitus (Boniturnote) nach 28 Tagen dokumentiert.

\subsubsection{Stauchetest mit sterilen Kulturfiltraten in vitro}

Zur Überprüfung, ob der im Topfversuch beobachtete wachtumsreduzierende Effekt auf das Pathogen oder auf chemische Effekte der verwendeten Medien zurückzuführen ist, wurde ein zweiter Versuch mit Keimlingen unter in vitro Bedingungen durchgeführt. In diesem Versuch wurden ein nährstoffarmes Medium (SNA), ein Xylemsaft simulierendes Medium (SXM), ein Rapswurzelmedium (RWE) und CzD-Medium (CzD) verwendet (Zusammensetzungen siehe Anhang). In allen Medien wuchsen beide Isolate VL 43 und VD 73 gleichermaßen gut. Nichtinokuliertes Medium (LK), steriles Leitungswasser $\left(\mathrm{H}_{2} \mathrm{O}\right)$ und eine Variante, in der die

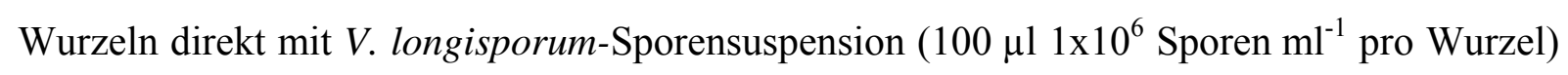
inokuliert wurden $(V L)$, dienten als Kontrollen. Je 12,5 ml der steril-filtrierten Lösungen 
wurden auf sieben Tage alte $R C R$-Keimlinge (15/Schale) appliziert, die auf sterilem Filterpapier in Petrischalen ausgelegt wurden (Abb. 6A; Biotest B, siehe 2.8.4.1 Biotest mit Rapskeimlingen in vitro). Die Petrischalen wurden zum Schutz vor Transpiration mit Parafilm abgedichtet und bei konstanten Bedingungen für fünf bis sieben Tage in einem Gewebekulturschrank (Fa. Mytron, Heiligenstadt) bei $20^{\circ} \mathrm{C}$ und 16/8 h Licht/Dunkel inkubiert (Abb. 6C). Anschließend wurden Sprosslänge, Länge der Primärwurzel und die Anzahl der sekundären Seitenwurzeln $>2$ mm dokumentiert (Abb. 6D).

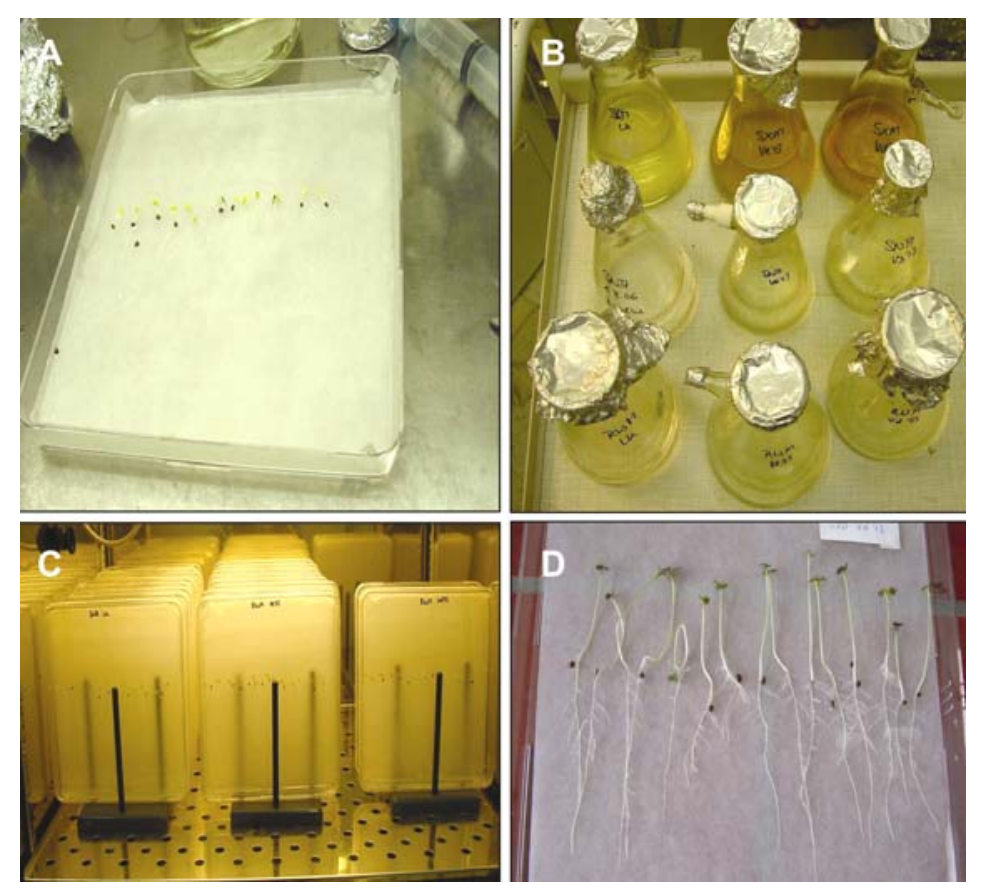

Abb. 6: Darstellung des Biotests zur Applikation von steril filtrierten Kulturüberständen auf sieben Tage alte RCR-Keimlinge im Biotest Variante B. A. Auslegen der Keimlinge auf Filterpapier, B. steril filtrierte nicht inokulierte und $V$. longisporum-inokulierte Medien (10 Tage alte Schüttelkulturen CzD-, SNA-, RWE- und SXM-Medium), C. Inkubation des Biotests im Gewebekulturschrank, D. Keimlinge nach siebentägiger Inkubation.

\subsubsection{Stauchetest mit membranfiltrierten SXM-Kulturfiltraten in vitro}

Um den potentiellen Stauchefaktor näher zu identifizieren, wurde die Gesamtfraktion in verschiedene Molekülgrößen fraktioniert. Dazu wurden Ultrafiltrationseinheiten (Cellulosefiltermembranen, Amicon/Fa. Milipore, Tullargreen, Irland) verschiedener Ausschlussgrößen (Tab. 10) verwendet. Entsprechend den Filter-Ausschlussgrößen enthielten die gewonnenen Eluate Moleküle der Größe <5000, <10000 und <50000 Da. In einem erneuten in vitro-Biotest (siehe Kap. 2.8.4.1, Biotest Variante C) wurden die Eluate auf ihre 
Effekte getestet und ausgewertet. Wie in den vorherigen Versuchen wurden auch hier zehn Tage alte SXM-Schüttelkulturen der V. longisporum- und $V$. dahliae verwendet.

Als Kontrolle wurde zum einen nicht-inokuliertes SXM-Medium fraktioniert und getestet, zum anderen die jeweiligen Kulturüberstände sowohl des nicht-inokulierten Mediums als auch der inokulierten Variante nur steril filtriert und auf die Keimlinge appliziert.

Die Kulturen wurden vom Myzel getrennt, steril filtriert (Sterilfilter RC, vliesverstärkt, 0,2 $\mu \mathrm{m}$ Porengröße, Sartorius, Göttingen) und das Filtrat in die entsprechenden Filtertubes überführt. Die Fraktionen wurden durch Zentrifugation bei $4^{\circ} \mathrm{C}(30 \mathrm{~min})$ und $4000 \mathrm{rpm}$ (4K10, Sigma, Osterode) gewonnen und $15 \mathrm{ml}$ der jeweiligen Fraktionen im Biotest auf die Keimlinge appliziert. Als Transpirationsschutz wurden die Petrischalen mit Parafilm abgedichtet und bei $20^{\circ} \mathrm{C} 16 / 8 \mathrm{~h} \mathrm{Tag} / \mathrm{Nacht}$ für sieben Tage in einem Gewebekulturschrank (Fa. Mytron, Heiligenstadt) inkubiert. Die Auswertung des Versuchs erfolgte nach sieben Tagen Inkubationszeit. Es wurde sowohl die Sprosslänge der Keimlinge als auch Wurzellänge und Anzahl der Seitenwurzeln $>2 \mathrm{~mm}$ ausgewertet. Des Weiteren wurden die Pflanzen visuell benotet und in einer Skala von 1-5 eingeordnet (Tab. 11). Der Versuch wurde in doppelter Ausführung durchgeführt; pro Variante wurden 2 Petrischalen mit insgesamt 30 Keimlingen überprüft. Die nicht fraktionierten, steril filtrierten inokulierten bzw. nicht-inokulierten Medien wurden als Fraktionsgröße 0 bezeichnet.

Tab. 10: Übersicht der Varianten und verwendeten Amicon-Filter zur Überprüfung der Stauchewirkung von SXM-Fraktionen unterschiedlicher Molekülgrößen.

\begin{tabular}{|l|cccc|}
\hline \multirow{2}{*}{ Variante } & \multicolumn{4}{|c|}{ Ausschlussgröße } \\
\cline { 2 - 5 } & $<5000 \mathrm{Da}$ & $<10000 \mathrm{Da}$ & $<50000 \mathrm{Da}$ & Kontrolle \\
\hline VL43 & $2 \times 15 \mathrm{ml}$ & $2 \times 15 \mathrm{ml}$ & $2 \times 15 \mathrm{ml}$ & $\begin{array}{c}15 \mathrm{ml} \\
\text { LK }\end{array}$ \\
& $2 \times 15 \mathrm{ml}$ & $2 \times 15 \mathrm{ml}$ & $2 \times 15 \mathrm{ml}$ & $\begin{array}{c}15 \mathrm{ml} \text { filtriert } \\
\text { Nur steril filtriert }\end{array}$ \\
\hline
\end{tabular}

Tab. 11: Visuelle Boniturnoten und entsprechende Symptombilder für RCR-Keimlinge nach Applikation der Amicon-filtrierten SXM-Kulturen und sieben Tagen Inkubation.

\begin{tabular}{|c|l|}
\hline Note & \multicolumn{1}{|c|}{ Symptome } \\
\hline 1 & $100 \%$ gesund \\
2 & Leichte Vergilbungen an einem der Keimblätter \\
3 & Vergilbungen und abgestorbene Blattteile an beiden Keimblättern \\
4 & $50 \%$ des Sprosses abgestorben \\
5 & Pflanze komplett abgestorben \\
\hline
\end{tabular}




\subsubsection{Stauchetest mit Acetonitril-fraktionierten SXM-Kulturfiltraten in vitro}

In einem weiteren Experiment wurde versucht, die SXM-Kulturfiltrate mittels verschiedener Konzentrationen des organischen Lösungsmittels Acetonitril $(\mathrm{AcN}) \mathrm{zu}$ fraktionieren. Die Auftrennung der Fraktionen erfolgt dabei entsprechend der Polarität der enthaltenen Moleküle. Diese Fraktionen wurden anschließend erneut in einem Biotest auf ihre Stauchwirkung an 7 Tage alten Rapskeimlingen überprüft.

Für die Fraktionierung wurden Mega-Bond-Elut C18 Säulen (Fa. Varian) verwendet. Zur Konditionierung wurden die Säulen mit $10 \mathrm{ml}$ Acetonitril (AcN 100\%) und anschließend $10 \mathrm{ml} \mathrm{H}_{2} \mathrm{O}$ bidest. vorgespült. Je $15 \mathrm{ml}$ des zuvor steril filtrierten Überstandes der SXMKulturen wurden auf die Säulen aufgetragen und das austretende Eluat verworfen. Anschließend wurden die Säulen zweimal mit $5 \mathrm{ml} \mathrm{H}_{2} \mathrm{O}$ bidest. gespült, um ungebundene Reste der Überstände zu entfernen. Mit unterschiedlichen Konzentrationen an $\operatorname{AcN}(10,20$, 40, 60, 80\%) wurden die an der Säule gebundenen Stoffe dann entsprechend ihrer Polarität eluiert. Das Eluat wurde aufgefangen und das enthaltene $\mathrm{AcN}$ in einer Vakuumzentrifuge (RVC 2-25, Christ) bei RT für $2 \mathrm{~h}$ abgedampft. Die zurückbleibende Fraktion wurde mit $\mathrm{H}_{2} \mathrm{O}$ bidest. auf $15 \mathrm{ml}$ aufgefüllt und in einem Biotest (siehe Kap. 2.8.4.1, Biotestvariante C) auf ihre Aktivität überprüft. Jede Fraktion $(2 \mathrm{x} 7,5 \mathrm{ml})$ wurde auf 15 Keimlinge appliziert und inkubiert. Als Negativkontrolle wurde nicht fraktioniertes, nur steril filtriertes SXM-Medium (V. longisporum, V. dahliae und steriles Wasser) auf die Keimlinge gegeben. Die Petrischalen wurden mit Parafilm verschlossen und bei $20^{\circ} \mathrm{C}$ und einem Tag/Nacht Rhythmus von 16/8 h in Gewebekulturschränken (Fa. Mytron, Heiligenstadt) kultiviert. Die Auswertung des Versuchs erfolgte nach sieben Tagen Inkubationszeit. Es wurde sowohl die Sprosslänge der Keimlinge als auch Wurzellänge und Anzahl der Seitenwurzeln $>2 \mathrm{~mm}$ ausgewertet. Des Weiteren wurden die Pflanzen visuell benotet und in einer Skala von 1-5 eingeordnet (Tab. 11). 


\section{Ergebnisse}

In dieser Arbeit wurden zwei Pathosysteme miteinander verglichen, die Interaktion von B. napus mit $V$. longisporum und die Interaktion von B. napus mit $V$ dahliae. Kennzeichnend für die beiden Pathosysteme ist die unterschiedliche Ausbreitungsdynamik. V. longisporum besiedelt die gesamte Pflanzen systemisch über die Leitgefäße, während $V$. dahliae nicht in der Lage ist, sich über das Wurzelsystem hinaus auszubreiten, keine Symptome induziert und deshalb als apathogen an Raps bezeichnet wird. Zur besseren Darstellung des Infektionsverlaufs und der Effekte des Befalls beider Pathogene auf Sprosswachstum und Frischgewicht wurden die phänotypischen Parameter der Pflanzenentwicklung über den Verlauf der Pathogenese aufgezeichnet und dargestellt.

\subsection{Auswirkungen der V. longisporum- und V. dahliae-Infektion auf Vergilbung, Spross- und Wurzelwachstum}

Die für die Zeitreihenexperimente mit $V$. longisporum-inokulierten Pflanzen wiesen bei Vergleich mit den Kontrollpflanzen einen deutlichen Phänotyp hinsichtlich Sprosslänge, Spross- und Wurzelmasse sowie der Boniturnote auf. Eine Infektion mit V.dahliae verursachte keine von den Kontrollen abweichenden Veränderungen. Der Effekt von $V$. longisporum auf die Reduktion des Sprosswachstum war schon zu Beginn des ersten Termins (14 dpi) signifikant unterschiedlich $\mathrm{zu} \quad V$. dahliae und nicht-inokulierten Kontrollpflanzen (Abb. 7). Auch die Reduktion der Trockenmasse von Spross und Wurzel (Abb. 8) wird im Vergleich zur V. dahliae-Variante und den Kontrollpflanzen deutlich. Die exemplarische Untersuchung inokulierter und nicht-inokulierter Pflanzen zum Zeitpunkt 21 dpi zeigte, das zwar der Hypokotyldurchmessers von V. longisporum-infizierten Pflanzen signifikant geringer ist, dadurch aber nicht signifikant mehr Druck benötigt wurde, um bei abgeschnittenem Hypokotyl den Xylemsaft mit Hilfe einer Druckbombe auszupressen (Abb. 9 $\mathrm{A} \& \mathrm{~B})$. 

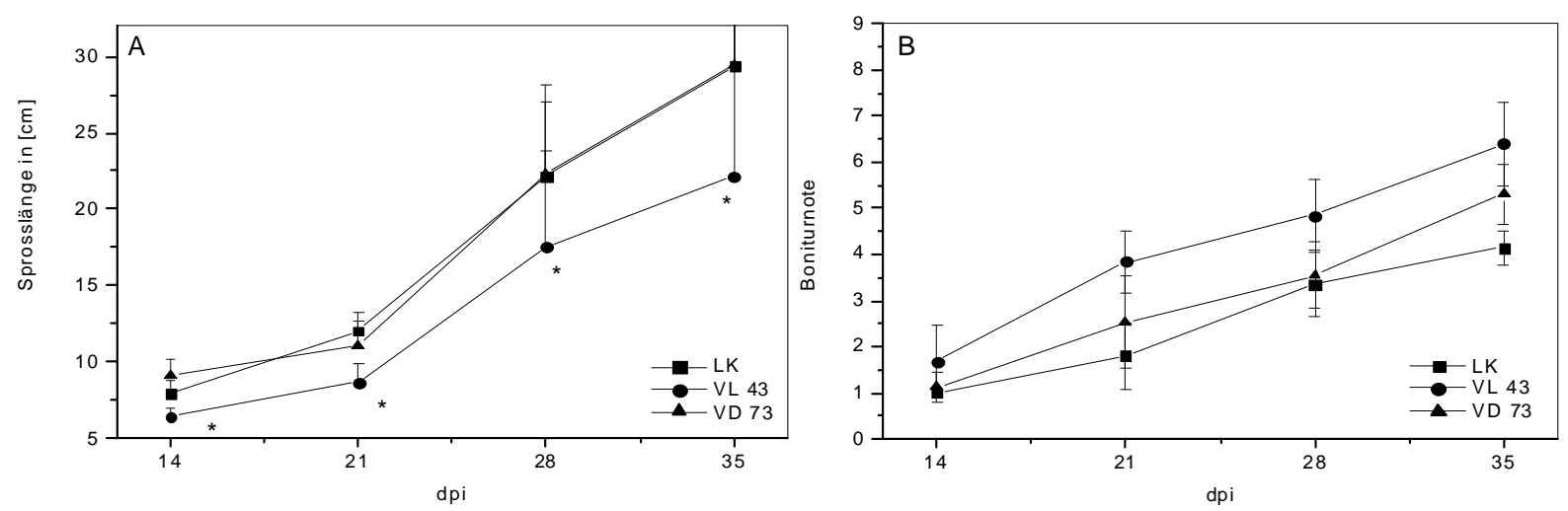

Abb. 7: Einfluss von $V$. longisporum (VL)- und $V$. dahliae (VD)-Befall im Verlauf eines Zeitreihenexperiment (14-35 dpi) auf A. die Sprosslänge und B. den Grad der Vergilbungserscheinungen erfasst als Boniturnoten nach ZEISE (1992); Anzahl der verwendeten Pflanzen: Kontrolle zu 14 dpi $\mathrm{n}=15,21$ dpi $\mathrm{n}=27,28$ dpi $\mathrm{n}=41,35$ dpi $\mathrm{n}=19 ; V L: 14$ dpi $\mathrm{n}=15,21$ dpi $\mathrm{n}=27,28$ dpi $\mathrm{n}=40,35$ dpi $\mathrm{n}=17$; VD: 14 dpi $\mathrm{n}=15,21$ dpi $\mathrm{n}=27,28$ dpi $\mathrm{n}=30,35$ dpi $\mathrm{n}=19 .{ }^{*}=$ signifikant unterschiedlich im Vergleich zur Kontrolle für $\mathrm{P}<0,05$ (LSD-Test).
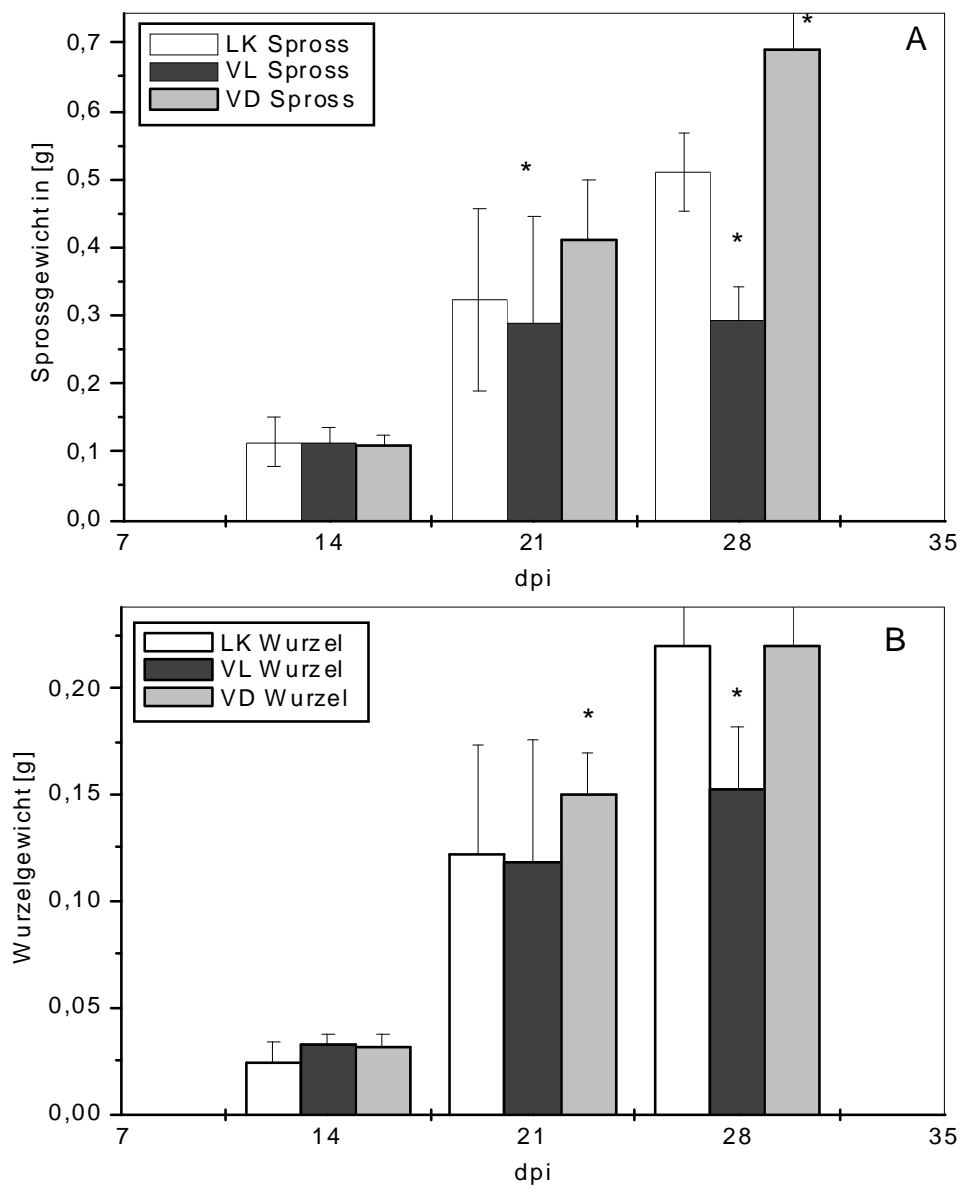

Abb. 8: A. Spross- und B. Wurzeltrockengewichte [g] V. longisporum (VL)-, V. dahliae (VD)und nicht-inokulierter RCR-Pflanzen (LK) über den Zeitraum 14-28 dpi; 14 dpi n = 25, 21 dpi $\mathrm{n}=25,28$ dpi $\mathrm{n}=7 ; *=$ signifikant unterschiedlich im Vergleich zur Kontrolle für $\mathrm{P}<0,05$ (LSD-Test). 


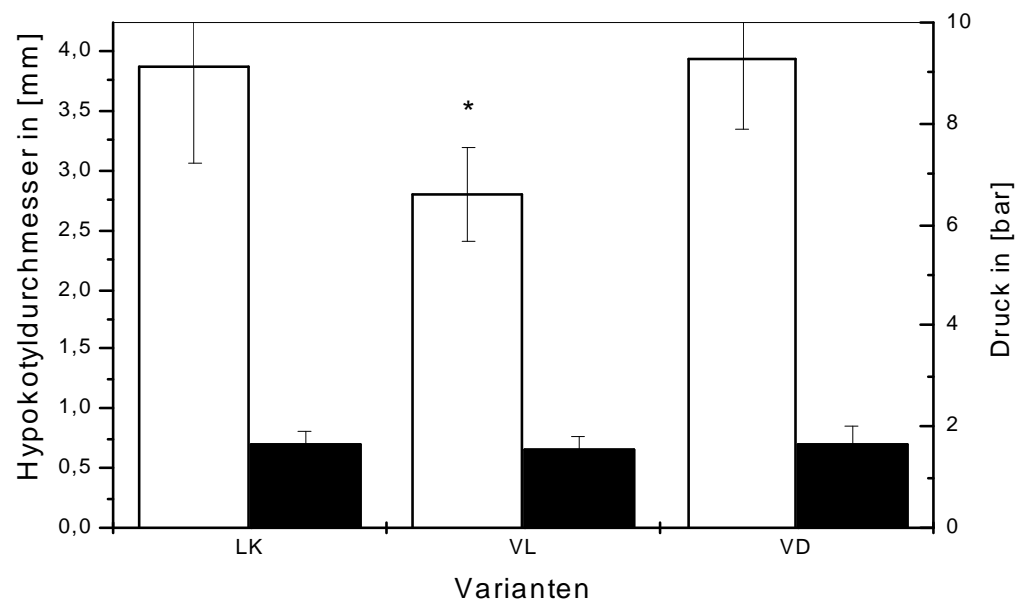

Abb. 9: Hypokotyldurchmesser [mm] V. longisporum (VL)-, V. dahliae (VD)- und nichtinokulierter RCR-Pflanzen (LK) aus einer Zeitreihe zu 21 dpi (linke Ordinate), bis zum Austreten des ersten Xylemsaftes benötigter Druck [bar] derselben Pflanzen (rechte Ordinate); $\mathrm{n}=15, *=$ signifikant unterschiedlich zur Kontrolle für $\mathrm{P}<0,05$ (LSD-Test).

\subsection{Nachweis der Pathogenausbreitung}

\subsubsection{Real-Time PCR}

Um die Ausbreitungsdifferenz der beiden Verticillium-Isolate (V. longisporum und V. dahliae) unter konstanten Klimakammerbedingungen in RCR-Pflanzen zu überprüfen und den tatsächlichen Befall der Pflanzen verifizieren zu können, wurden die Pflanzen der Zeitreihen mittels Real-Time PCR auf Verticillium-DNA überprüft. Dabei wurden zwei Zeitreihen beprobt. In Abb. 10 sind die Daten der ersten Zeitreihe, in Abb. 11 die Daten der zweiten Zeitreihe dargestellt. Schon beim ersten Beprobungstermin ist in beiden Zeitreihen eine Besiedlung des Hypokotyls V. longisporum-infizierter Pflanzen erkennbar. Innerhalb von 7 Tagen (14 auf 21 dpi) ist in der zweiten Zeitreihe eine Ausbreitung des Pilzes sowohl im Hypokotyl als auch im Spross zu verzeichnen: In der ersten Zeitreihe zeigt sich dieser Anstieg nur im Hypokotylbereich. Bis 35 dpi findet in V. longisporum-infizierten Pflanzen der ersten Zeitreihe eine stete Ausbreitung und Vermehrung des Pilzes sowohl im Hypokotyl und Sprossgewebe statt, wobei der Anstieg im Hypokotyl stärker ist als im Sprossgewebe. In der zweiten Zeitreihe hingegen stagniert das Wachstum im Hypokotyl ab 21 dpi. Über den weiteren Verlauf der Pflanzenentwicklung (28-35 dpi) findet in dieser Zeitreihe keine weitere Zunahme der V. longisporum-DNA-Menge statt. Im untersten Sprossteil (S1) ist ein starker Sprung in der Zunahme der DNA-Mengen von 14 auf 21 dpi zu erkennen. Zum nachfolgenden Termin 28 dpi findet ein Abfall der von ca. $60 \mathrm{ng} \mathrm{g} \mathrm{FW}{ }^{-1}$ auf Werte unter 10 ng Verticillium-DNA g FW ${ }^{-1}$ statt. Eine erneute Zunahme auf ca. 15-20 ng Verticillium-DNA 
$\mathrm{g} \mathrm{FW}^{-1}$ findet zum letzen Beprobungstermin 35 dpi statt. Zwar konnte in den nachfolgenden oberen Sprossteilen (S2 und S3) der zweiten Zeitreihe im obersten beprobten Sprossteil (S3) Verticillium-DNA detektiert werden, jedoch ist keine Zunahme der V.longisporum-DNA erkennbar.

In den V. dahliae-infizierten Pflanzen ist in beiden Zeitreihen zu 14 dpi nur ein minimales DNA-Signal im Hypokotyl, in den entsprechenden Sprossproben kein DNA-Signal nachweisbar. Im Gegensatz zur V. longisporum-Variante findet bei $V$. dahliae-infizierten Pflanzen im Verlauf beider Zeitreihen keine Zunahme der DNA in den Sprossteilen statt. Einzig zum letzten Beprobungstermin 35 dpi konnte in der ersten Zeitreihe ein Anstieg des DNA-Signals im Hypokotyl detektiert werden. V. dahliae scheint sich daher nicht in den Spross ausbreiten zu können und verbleibt während des gesamten beobachteten Zeitraums im Hypokotyl der Pflanzen.

Die Längen und Boniturnoten der V. longisporum-infizierten Pflanzen beider Zeitreihen wurden auf eine mögliche Korrelation mit den PCR-Daten untersucht. Es konnte insgesamt weder ein Zusammenhang zwischen Verticillium-DNA und Länge noch zwischen Verticillium-DNA und Boniturnoten hergestellt werden. Der Vergleich beider Zeitreihen zeigt, dass in den V. longisporum-infizierten Pflanzen der zweiten Zeitreihe teilweise zwanzigfach höhere Werte erreicht wurden als in der ersten Zeitreihe. Des Weiteren zeigen die Werte der V. longisporum-Variante hohe Variabilität insbesondere zu den Zeitpunkten 21 und 28 dpi beider Zeitreihen. Da eine Tauchinokulation der Pflanzen als Infektionsmethode gewählt wurde, bei der die Wurzeln direkten Kontakt zu einer Sporensuspension hatten, wurden die Wurzeln in der PCR Analyse nicht beprobt, da nicht zwischen äußerlich den Wurzeln anhaftenden und sich im Wurzelinneren entwickelndem Myzel hätte unterschieden werden können. 


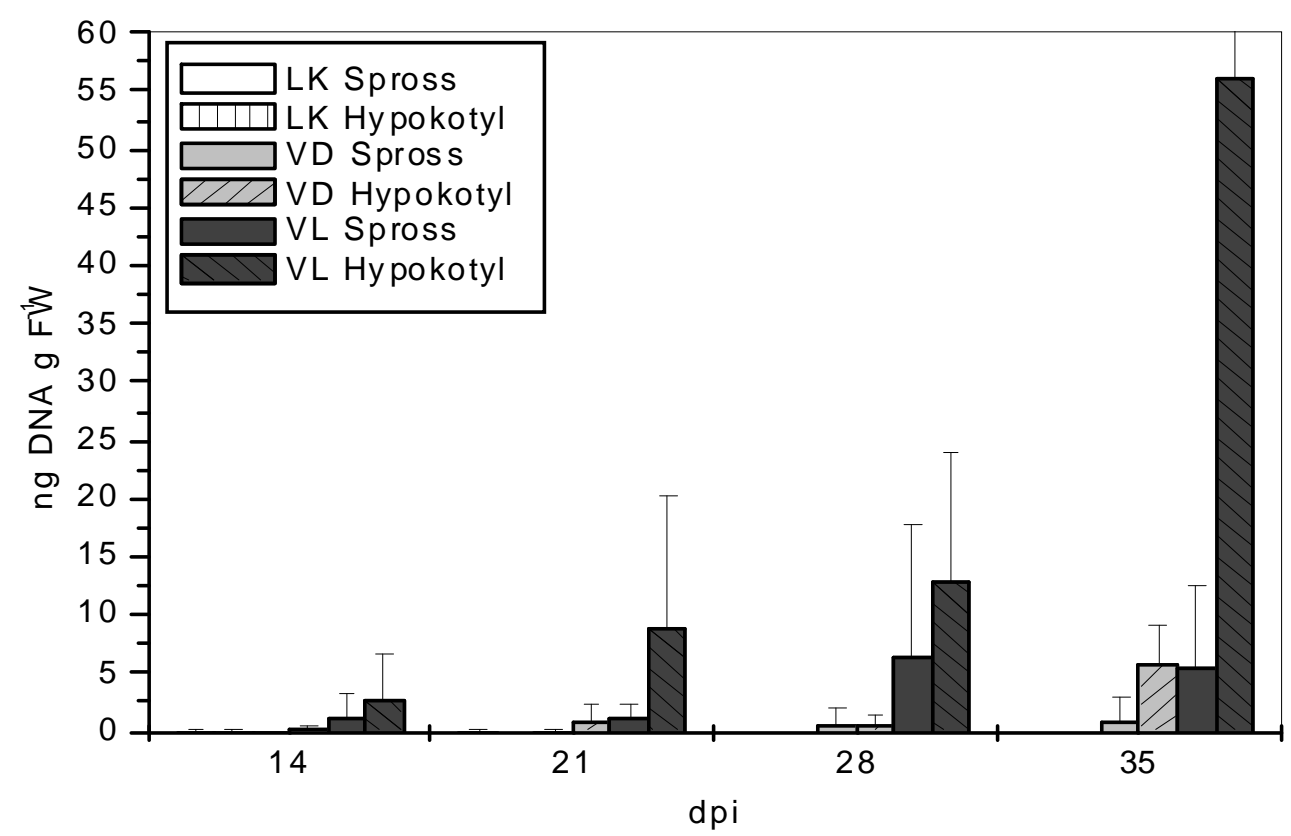

Abb. 10: PCR-Daten der ersten Zeitreihe; Nachweis von Verticillium-DNA [ng DNA g FW' ${ }^{-1}$ ] in Hypokotyl- $(\mathrm{H})$ und Sprossproben $(\mathrm{S})$ V. longisporum $(V L)$ - und V. dahliae (VD)-infizierter RCR-Pflanzen $(\mathrm{n}=10)$ aus dem ersten Zeitreihenexperimente im Zeitverlauf von 14-35 dpi.

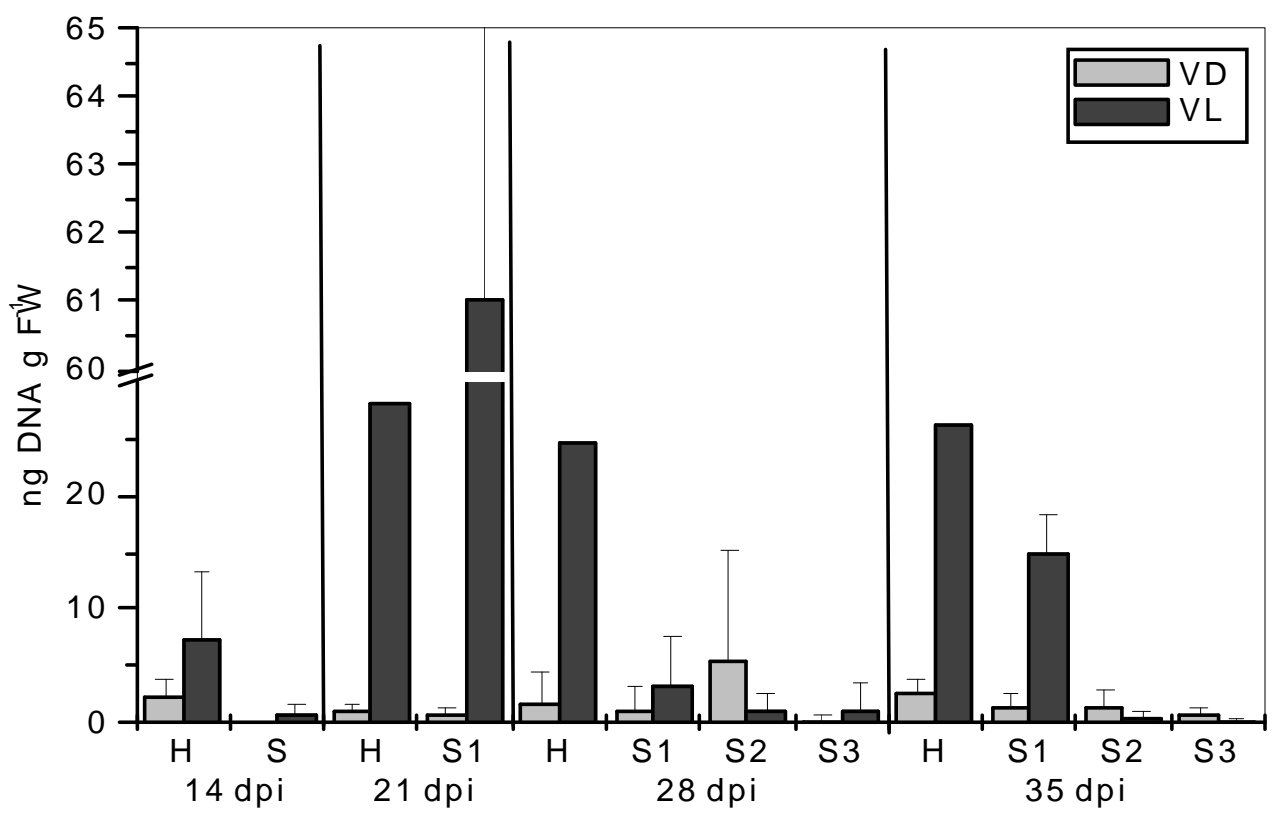

Abb. 11: PCR-Daten der zweiten Zeitreihe; Verticillium-DNA [ng DNA g FW ${ }^{-1}$ ] aus Hypokotyl (H), unterstem Sprossabschnitt (S bzw. S1), mittlerem Sprossteil (S2) und oberstem Sprossteil (S3) V. longisporum (VL)- und V. daliae (VD)-infizierter RCR-Pflanzen $(n=5)$ aus dem zweiten Zeitreihenexperiment im Zeitverlauf von 14-35 dpi. 


\subsubsection{Vorkommen von VL 43-Mikrosklerotien im Gewebe}

Im Allgemeinen konnte über den Zeitraum der Pflanzenanzucht keine Ausbildung von Mikrosklerotien oder schwarzadrigen Blättern beobachtet werden. Die Pflanzen wurden allerdings für die Versuchsreihen nie bis zur vollen Reife beprobt. Nach vollständiger Abreife der Pflanzen (2 Monate) konnte auch nur vereinzelt Mikrosklerotienwachstum an V. longisporum-infizierten Pflanzen beobachtet werden (Abb. 12). Diese waren allerdings nie im Stängelbereich oder im Mark aufzufinden, sondern nur am Übergang von Hypokotyl zur Wurzel. Schwarzadrige Schoten traten an den V. longisporum-infizierten Pflanzen nur vereinzelt auf (Abb. 13). Oberflächensterilisierte schwarzadrige Schoten zeigten nach dreitägiger Inkubation auf PDA bei $23^{\circ} \mathrm{C}$ im Dunkeln ausgeprägtes Myzelwachstum (Abb. 14) und die für $V$. longisporum typischen länglichen, mit zwei Lipidtröpfchen versehenen Konidien; Samen dieser Schoten wiesen allerdings kein Myzelwachstum auf. An inkubierten Hypokotyl- und Stängelstücken war V. longisporum-Wachstum eindeutig nachweisbar. Infizierte Pflanzen, die weder Mikrosklerotienbesatz noch schwarze Schoten aufwiesen, zeigten nach Auslegen und Inkubation von oberflächensterilisierten Gewebestücken (Samen, Schote, Stängel, Hypokotyl) kein Myzelwachstum. An nichtinfizierten Kontrollpflanzen konnte ebenfalls nach Inkubation oberflächensterilisierter Gewebestücke kein $V$. longisporum Wachstum nachgewiesen werden.

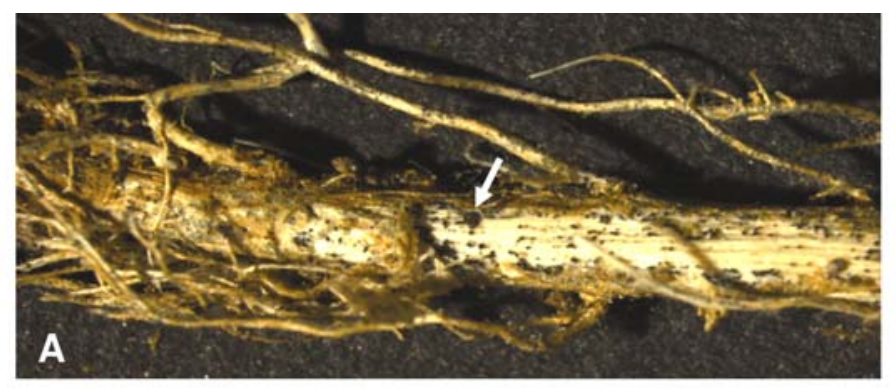

Abb. 12: A: Wurzelansatz zwei Monate alter VL43-infizierter RCRPflanze mit Mikrosklerotienbesatz; B: Detailaufnahme der Mikrosklerotien (Pfeile) am obersten Wurzelansatz.

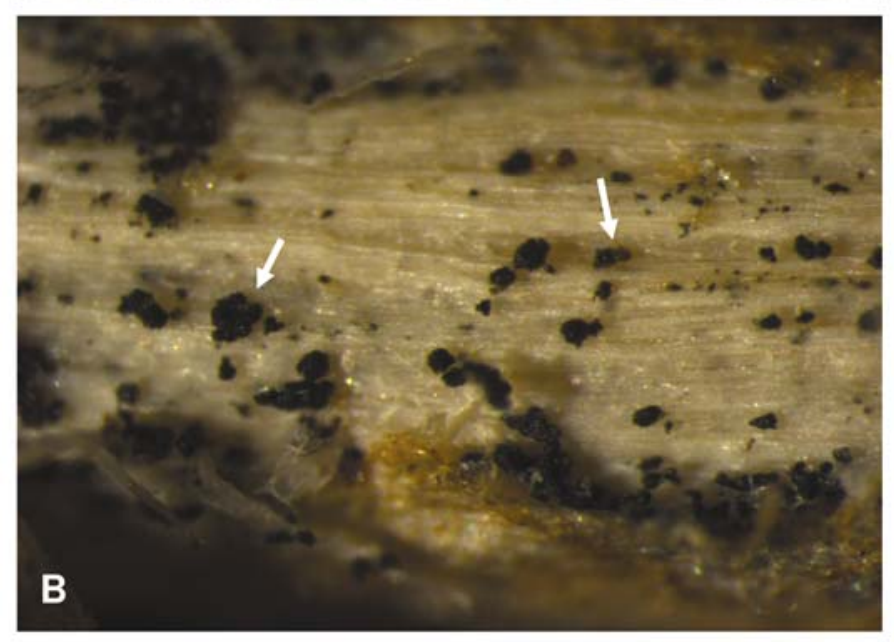



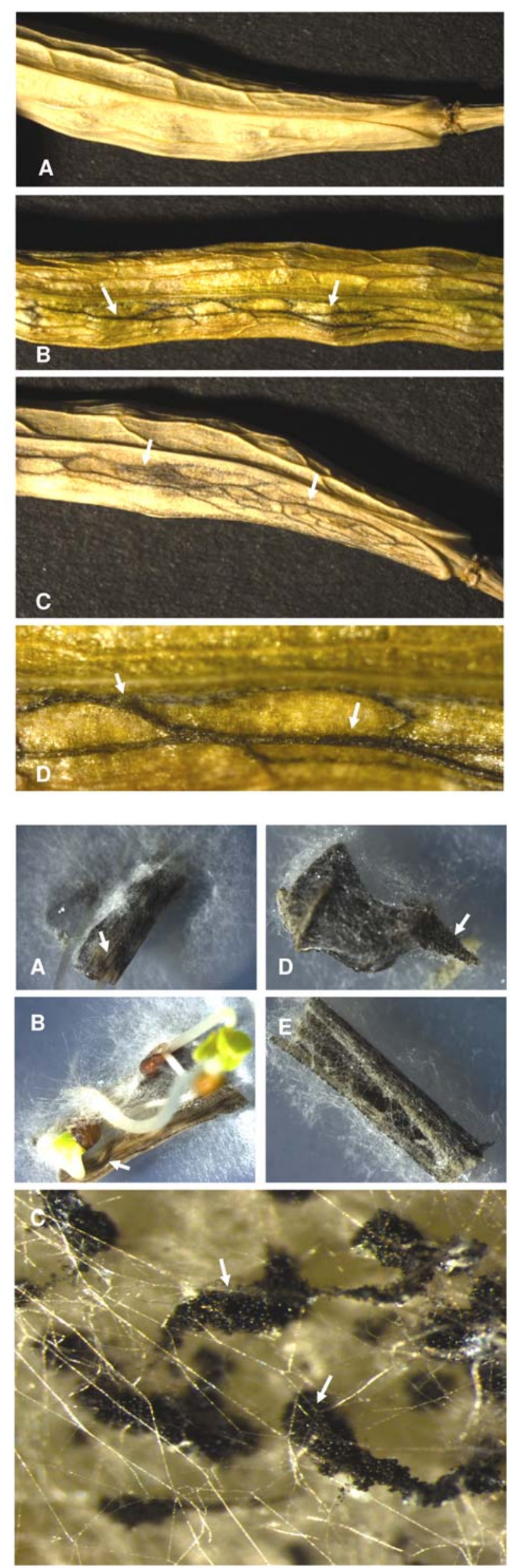

Abb. 13: Schwarzadrige Schoten zwei Monate alter VL43-infizierter RCRPflanzen. A. Schote einer nicht inokulierten Kontrollpflanze. B-D Schwarzadrige Schoten VL43-infizierter Pflanzen (Pfeile =schwarze Adern). Schwarzadrigkeit trat an Schoten infizierter Pflanzen nur vereinzelt auf.

Abb. 14: Auf Wasseragar ausgelegte Gewebestücke zwei Monate alter VL43infizierter RCR-Pflanzen nach 4 Tagen Inkubation bei $23^{\circ} \mathrm{C}$ im Dunkeln. A-B: Schwarzadrige Schote (Pfeile) mit auswachsendem Myzel von VL43. C: Mikrosklerotien (Pfeile) auf Stängelstück, D-E: Hypokotyl und Stängel mit Myzelauswuchs und Mikrosklerotienbildung (Pfeile). 


\subsection{Symptominduktionsexperimente}

Die Parallelbetrachtung von phänotypischen Veränderungen von RCR-Pflanzen bei V. longisporum-Befall (Boniturnote und Sprosswachstum) und der Ausbreitung des Pathogens in der Pflanze zeigte, dass infizierte Pflanzen bereits zu 14 dpi eine Stauche des Sprosses aufwiesen, obwohl $V$. longisporum zu diesem Zeitpunkt noch nicht bis in den Spross vorgedrungen war.

Diese Beobachtung stützt die Hypothese, dass Signalmoleküle, pflanzlicher oder pilzlicher Herkunft, systemisch verbreitet werden und zur Symptombildung im Spross führen, ohne dass dieser direkten Kontakt mit dem Pathogen hat. Als mögliche Kandidaten sollten Signalmoleküle untersucht werden, von denen bereits bekannt ist, dass sie eine wichtige Rolle in der Signaltransduktion bei abiotischem oder biotischem Stresses spielen. Stickstoffmonoxid (NO) und Wasserstoffperoxid $\left(\mathrm{H}_{2} \mathrm{O}_{2}\right)$ wurden daher in weiteren Experimenten auf ihr Vorkommen und ihren Einfluss auf die Symptombildung an RCRPflanzen untersucht.

Ob der Befall mit $V$. longisporum eventuell den NO-Gehalt in Rapspflanzen während der Pathogenese erhöht und dadurch die Stauche auslöst, wurde durch in vivoApplikationsexperimente überprüft, in denen der Effekt chemischer NO-Donatoren auf die Phänologie von Rapspflanzen untersucht wurde. Im ersten Versuchsdurchlauf wurden verschiedene Mengen des NO-Donors Sodiumnitroprussid (SNP, 10, 50 und $100 \mu \mathrm{M}$ ) dreimal wöchentlich über einen Zeitraum von 28 Tagen auf sieben Tage alte getopfte RCR-Keimlinge appliziert. Die V. longisporum-infizierte Kontrollvariante zeigte im Vergleich mit der wasserbehandelten Kontrolle eine signifikante Verringerung der Sprosslänge (Ergebnisse nicht dargestellt). Ein noch stärkerer Staucheeffekt, konnte durch Applikation von $10 \mu \mathrm{M}$ SNP hervorgerufen werden. Es konnte aber keine Dosis-Wirkungsbeziehung gezeigt und die Stauchung in wiederholten Testungen auch durch den zweiten NO-Donor NAcetylpenicillamine (SNAP) nicht reproduziert werden. Ebenfalls wurde getestet, ob eine Verminderung des NO-Gehaltes die Stauche aufhebt. Dazu wurde der NO-Scavenger cPTIO auf die Pflanzen appliziert. Auch diese Variante zeigte keinen Effekt auf das Sprosswachstum und konnte dieses weder verstärken noch aufheben. Daher wurden die Ergebnisse der in vivoExperimente als Artefakte interpretiert (Ergebnisse nicht dargestellt). In nachfolgenden in vitro-Experimenten konnte jedoch nachgewiesen werden, dass NO doch Einfluss auf das Pflanzenwachstum nimmt. Dieser Versuch zur Staucheinduktion wurde mit zwei Tage alten Keimlingen in Petrischalen durchgeführt und NO-Donor-Lösungen (SNP und SNAP in den Konzentrationen 10, 50, 100, 200, 300, $500 \mu \mathrm{M}$ ) den Keimlingen einmalig zu Beginn des 
Versuchs über Filterpapier zugeführt. Sowohl Spross- als auch Wurzelwachstum wurden dabei durch steigende Konzentrationen von SNP (200-500 $\mu \mathrm{M})$ signifikant reduziert, wobei der Effekt auf die Primärwurzellängen am deutlichsten hervortrat. Die Applikation des zweiten verwendeten Donors, SNAP, führte weder zu einer Reduktion der Sprosslänge noch zu einer Verminderung der Primärwurzellänge oder Anzahl der Seitenwurzeln. Eine Eisencyanid-Kontrolle, die verwendet wurde, um zu überprüfen, ob die in SNP enthaltenen fünf Cyanidmoleküle die Wirkung des Donors ausmachen, zeigte ebenfalls keinen Effekt auf die drei untersuchten Parameter (Tab. 12).

Tab. 12: Einfluss der NO-Donatoren SNP und SNAP sowie einer Eisencyanid (FeCN)- und unbehandelten Wasserkontrolle nach in vitro-Applikation auf die Parameter A. Anzahl Seitenwurzeln B. Pflanzenlänge und C. Primärwurzellänge von RCR-Keimlingen sechs Tage nach Applikation; Unterschiedliche Indizes zeigen signifikante Unterschiede im Vergleich zur unbehandelten Wasserkontrolle an, $\mathrm{P}<0,05$ (LSD Test); Konzentrationen 10-100 $\mathrm{n}=60$, alle anderen Varianten $n=30$, Zusammenfassung zweier unabhängiger Versuche.

\begin{tabular}{|c|c|c|c|c|c|c|c|c|c|}
\hline \multirow{2}{*}{$\begin{array}{l}\text { A. Anzahl } \\
\text { Keimlinge }\end{array}$} & \multirow{2}{*}{$\begin{array}{c}\begin{array}{c}\text { NO- } \\
\text { Donor }\end{array} \\
{[\mu \mathrm{M}]}\end{array}$} & \multicolumn{2}{|c|}{$\begin{array}{c}\text { SNAP } \\
\text { Anzahl Seitenwurzeln }\end{array}$} & \multicolumn{2}{|c|}{$\begin{array}{c}\text { SNP } \\
\text { Anzahl Seitenwurzeln }\end{array}$} & \multicolumn{2}{|c|}{$\begin{array}{c}\mathrm{FeCN} \\
\text { Anzahl Seitenwurzeln }\end{array}$} & \multicolumn{2}{|c|}{$\begin{array}{c}\text { Kontrolle } \\
\text { Anzahl Seitenwurzeln }\end{array}$} \\
\hline & & MW & $\begin{array}{l}\text { STABN } \\
W\end{array}$ & MW & $\begin{array}{l}\text { STABW } \\
\mathrm{N}\end{array}$ & MW & $\begin{array}{l}\text { STABW } \\
\mathrm{N}\end{array}$ & MW & STABWN \\
\hline $\mathrm{n}=60$ & 10 & $5,866 \mathrm{a}$ & $\pm 2,929$ & $6,566 \mathrm{a}$ & $\pm 2,929$ & $5,100 a$ & $\pm 3,295$ & $5,384 a$ & $\pm 2,815$ \\
\hline $\mathrm{n}=30$ & 50 & $4,200 a$ & $\pm 1,989$ & $5,500 \mathrm{a}$ & $\pm 1,989$ & $7,137 \mathrm{~b}$ & $\pm 3,224$ & $5,384 a$ & $\pm 2,815$ \\
\hline $\mathrm{n}=60$ & 100 & $5,700 \mathrm{a}$ & $\pm 3,848$ & $6,100 \mathrm{a}$ & $\pm 3,848$ & $7,900 \mathrm{~b}$ & $\pm 2,534$ & $5,384 \mathrm{a}$ & $\pm 2,815$ \\
\hline $\mathrm{n}=30$ & 200 & $3,466 \mathrm{a}$ & $\pm 2,199$ & $5,333 a b$ & $\pm 2,199$ & $6,200 \mathrm{~b}$ & $\pm 2,948$ & $5,384 b$ & $\pm 2,815$ \\
\hline $\mathrm{n}=30$ & 300 & $3,600 \mathrm{a}$ & $\pm 2,303$ & $4,466 a b$ & $\pm 2,303$ & $6,600 \mathrm{c}$ & $\pm 2,893$ & $5,384 \mathrm{bc}$ & $\pm 2,815$ \\
\hline $\mathrm{n}=30$ & 500 & $4,400 \mathrm{a}$ & $\pm 1,540$ & $4,666 \mathrm{a}$ & $\pm 1,540$ & $5,206 a$ & $\pm 2,719$ & $5,384 a$ & $\pm 2,815$ \\
\hline \multirow{2}{*}{$\begin{array}{l}\text { B. Anzahl } \\
\text { Keimlinge }\end{array}$} & $\begin{array}{l}\text { NO- } \\
\text { Donor }\end{array}$ & \multicolumn{2}{|c|}{$\begin{array}{l}\text { SNAP } \\
\text { Sprosslänge }\end{array}$} & \multicolumn{2}{|c|}{$\begin{array}{c}\text { SNP } \\
\text { Sprosslänge }\end{array}$} & \multicolumn{2}{|c|}{$\begin{array}{c}\mathrm{FeCN} \\
\text { Sprosslänge }\end{array}$} & \multicolumn{2}{|c|}{$\begin{array}{l}\text { Kontrolle } \\
\text { Sprosslänge }\end{array}$} \\
\hline & {$[\mu \mathrm{M}]$} & MW & $\begin{array}{l}\text { STABW } \\
\mathrm{N}\end{array}$ & MW & $\begin{array}{l}\text { STABW } \\
\mathrm{N}\end{array}$ & MW & $\begin{array}{l}\text { STABW } \\
\mathrm{N}\end{array}$ & MW & STABWN \\
\hline$n=60$ & 10 & $4,190 \mathrm{a}$ & $\pm 0,626$ & $4,280 \mathrm{a}$ & $\pm 0,768$ & $4,520 \mathrm{a}$ & $\pm 0,735$ & $4,277 \mathrm{a}$ & $\pm 0,783$ \\
\hline$n=30$ & 50 & $4,246 a$ & $\pm 0,511$ & $3,956 \mathrm{a}$ & $\pm 0,557$ & $4,172 \mathrm{a}$ & $\pm 0,881$ & $4,277 \mathrm{a}$ & $\pm 0,783$ \\
\hline $\mathrm{n}=60$ & 100 & $4,133 a b$ & $\pm 0,819$ & $3,860 \mathrm{a}$ & $\pm 0,516$ & $4,58 \mathrm{~b}$ & $\pm 0,706$ & $4,277 \mathrm{~b}$ & $\pm 0,783$ \\
\hline$n=30$ & 200 & $4,533 a b$ & $\pm 0,455$ & $3,533 a$ & $\pm 0,729$ & $4,466 \mathrm{~b}$ & $\pm 0,845$ & $4,277 a b$ & $\pm 0,783$ \\
\hline$n=30$ & 300 & $4,043 \mathrm{~b}$ & $\pm 0,637$ & $4,036 \mathrm{a}$ & $\pm 0,568$ & $4,600 \mathrm{~b}$ & $\pm 0,678$ & $4,277 \mathrm{~b}$ & $\pm 0,783$ \\
\hline$n=30$ & 500 & $3,993 a b$ & $\pm 0,704$ & $3,620 \mathrm{a}$ & $\pm 0,760$ & $4,153 a b$ & $\pm 0,798$ & $4,277 \mathrm{~b}$ & $\pm 0,783$ \\
\hline \multirow{2}{*}{$\begin{array}{l}\text { C. Anzahl } \\
\text { Keimlinge }\end{array}$} & $\begin{array}{l}\text { NO- } \\
\text { Donor }\end{array}$ & \multicolumn{2}{|c|}{$\begin{array}{c}\text { SNAP } \\
\text { Wurzellänge }\end{array}$} & \multicolumn{2}{|c|}{$\begin{array}{c}\text { SNP } \\
\text { Wurzellänge }\end{array}$} & \multicolumn{2}{|c|}{$\begin{array}{l}\text { FeCN } \\
\text { Sprosslänge }\end{array}$} & \multicolumn{2}{|c|}{$\begin{array}{c}\text { Kontrolle } \\
\text { Wurzellänge }\end{array}$} \\
\hline & {$[\mu \mathrm{M}]$} & MW & $\begin{array}{l}\text { STABW } \\
\mathrm{N}\end{array}$ & MW & $\begin{array}{l}\text { STABW } \\
\mathrm{N}\end{array}$ & MW & $\begin{array}{l}\text { STABW } \\
\mathrm{N}\end{array}$ & MW & STABWN \\
\hline $\mathrm{n}=60$ & 10 & $6,403 a$ & $\pm 2,432$ & $7,120 \mathrm{a}$ & $\pm 1,904$ & $7,103 a$ & $\pm 2,154$ & $7,382 \mathrm{a}$ & $\pm 1,876$ \\
\hline$n=30$ & 50 & $6,766 a b$ & $\pm 1,401$ & $5,990 \mathrm{a}$ & $\pm 1,999$ & $7,710 \mathrm{c}$ & $\pm 1,810$ & 7,382 bc & $\pm 1,876$ \\
\hline$n=60$ & 100 & $7,583 \mathrm{~b}$ & $\pm 1,930$ & $5,663 \mathrm{a}$ & $\pm 1,500$ & $7,406 \mathrm{~b}$ & $\pm 1,597$ & $7,382 \mathrm{~b}$ & $\pm 1,876$ \\
\hline$n=30$ & 200 & $6,233 \mathrm{~b}$ & $\pm 1,562$ & $4,606 \mathrm{a}$ & $\pm 0,863$ & 7,306 bc & $\pm 1,627$ & 7,382 bc & $\pm 1,876$ \\
\hline$n=30$ & 300 & $7,253 \mathrm{bc}$ & $\pm 1,805$ & $4,473 a$ & $\pm 0,647$ & $6,046 \mathrm{~b}$ & $\pm 1,499$ & $7,382 \mathrm{c}$ & $\pm 1,876$ \\
\hline$n=30$ & 500 & $6,013 \mathrm{~b}$ & $\pm 1,792$ & $2,873 a$ & $\pm 0,566$ & $6,753 \mathrm{bc}$ & $\pm 2,282$ & $7,382 \mathrm{c}$ & $\pm 1,876$ \\
\hline
\end{tabular}




\subsection{Effekte von NO auf das vegetative Wachstum von $V$. longisporum}

Da die Bildung von ROS auch als direkte Abwehrfunktion gegenüber Pathogenen fungieren kann, wurde parallel zu den in vivo- und in vitro-Applikationsversuchen mit RCR-Pflanzen überprüft, welchen Effekt die Zugabe von NO auf das Wachstum von V. longisporum hat. Nach der Applikation verschiedener Konzentrationen $(10,50,100 \mu \mathrm{M})$ des NO-Donors SNP konnte kein Einfluss auf das radiale Myzelwachstum von VL43 gemessen werden (Abb. 15).

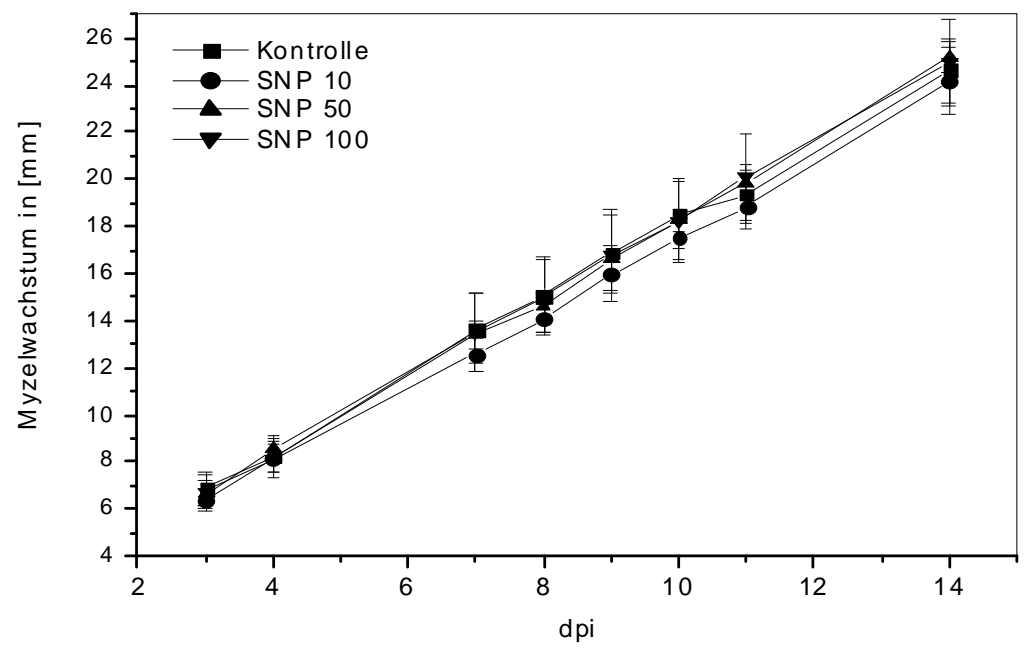

Abb. 15: Einfluss verschiedener Konzentrationen des NO-Donors Sodiumnitroprussid (SNP) auf das radiale Myzelwachstum [mm] von VL43 auf PDA über einen Zeitraum von 16 Tagen, $\mathrm{n}=10$.

\subsection{Nachweis von NO in Xylemsaftproben}

\subsubsection{Anwendbarkeit der ESR-Methode}

Die Verwendung der ESR-Methode erwies sich als geeignet, NO in Xylemsaft zu detektieren. Die Gehalte wurden als relative Intensität des ESR-Signals dargestellt (einheitslos), wobei die volle Höhe des ersten Peaks des NO-Triplet Signals ausgewertet und durch die gewählte Amplitude dividiert wurde. Sowohl mit MGD als auch DETC als Spin-Trap (Abb. 16, 23, 28) und den verschiedenen NO-Donatoren (SNAP, SNP und MAHMA NONOate) konnte das für NO typische Triplet-Signal unter den gewählten Bedingungen zweifelsfrei detektiert werden. Die Höhe der Triplet-Struktur stieg mit zunehmender Konzentration von NO linear an; $\mathrm{R}^{2}=0,991$ (Abb. 19). Mit zunehmender Konzentration des Spin-Trap MGD fand ebenfalls eine Zunahme der Signalstärke statt (Abb. 16), wobei für den Nachweis aus Xylemsaft eine mittlere MGD-Konzentration von $50 \mathrm{mM}$ gewählt wurde. Eine Überprüfung der Lagerungsfähigkeit der Proben bei plus $4^{\circ} \mathrm{C}$ und minus $20^{\circ} \mathrm{C}$ zeigte eine Abnahme der Signalstärke bei einer Lagerungstermperatur von $4^{\circ} \mathrm{C}$ über $24 \mathrm{~h}$ (Abb. 17). Alle Proben wurden daher sofort nach Erstellen gemessen, um jeglichen Signalverlust zu verhindern. 


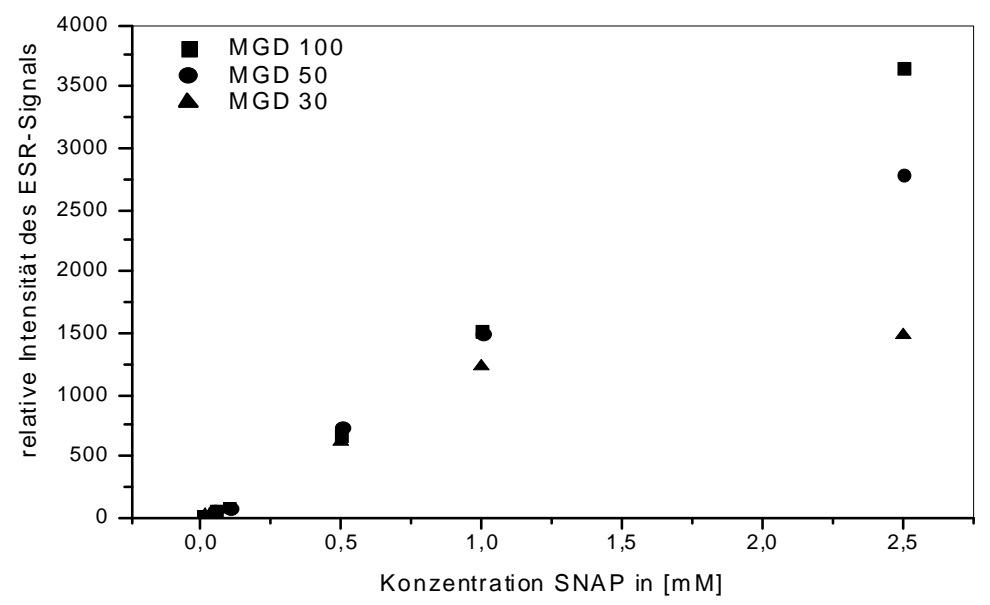

Abb. 16: Relative Intensität des Elektronen-Spin-Resonanz (ESR)-Signals von Standardreihen des MGD-Fe ${ }^{2+}$-NO Komplexes mit unterschiedlichen Konzentrationen MGDSpin-Trap (30, 50 und $100 \mathrm{mM})$.
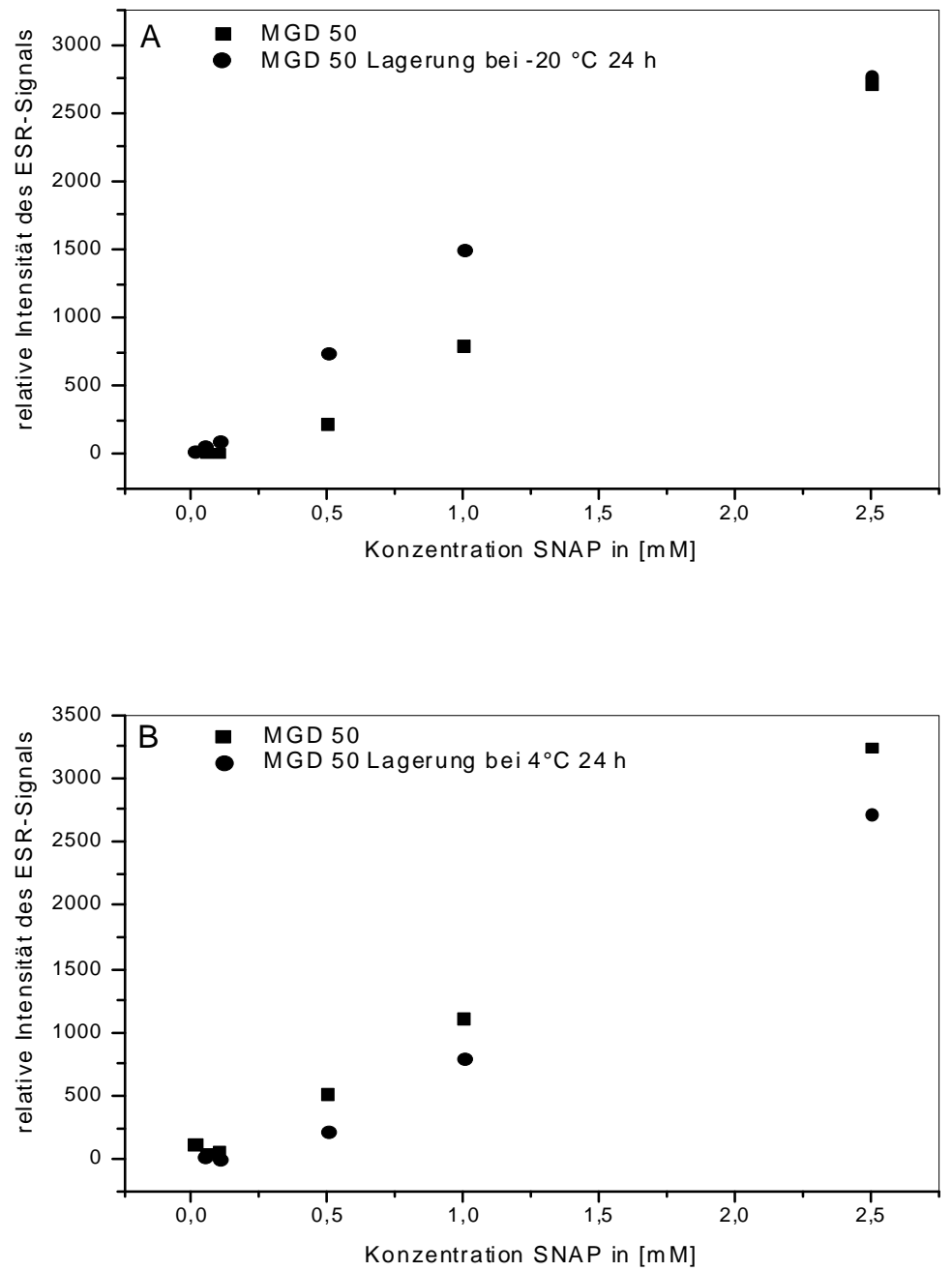

Abb. 17: Relative Intensität des Elektronen-Spin-Resonanz (ESR)-Signals einer Standardreihe des MGD-Fe ${ }^{2+}$-NO Komplexes nach unterschiedlicher Lagerung der Proben ( $24 \mathrm{~h}$ bei $4^{\circ} \mathrm{C}$ bzw. bei $-20^{\circ} \mathrm{C}$ ). 
Die Höhe des Signalausschlags ist durch Einstellung der Amplitude (Signalverstärkung) regulierbar. Der Ausschlag starker Signale musste so eingestellt (verringert) werden, dass der Schreiber das aufzuzeichnende Spektrum darstellen kann. Schwache Signale hingegen mussten teilweise verstärkt werden, um den typischen Verlauf des Spektrums deutlicher darstellen zu können. Die gemessene Peakhöhe wurde daher in allen Fällen durch die gewählte Amplitude dividiert und somit die Stärke des Signals normalisiert. Dass zwischen Verstärkung und Höhe des Peaks ein linearer Zusammenhang besteht, wurde durch Messungen von Standards mit unterschiedlicher Amplitude bestätigt (Abb. 18).

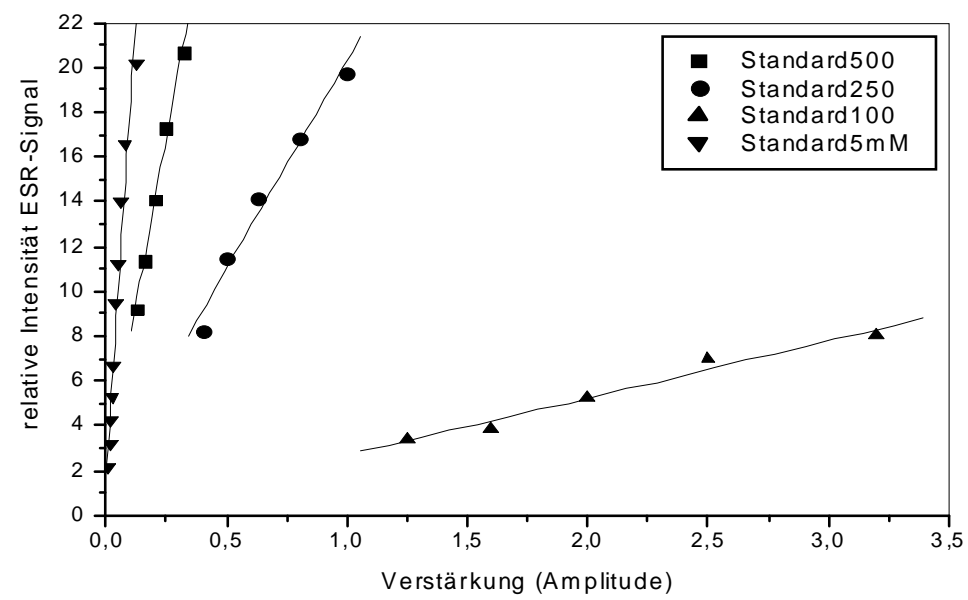

Abb. 18: Relative Intensität des Elektronen-Spin-Resonanz (ESR)-Signals von Standardreihen des MGD-Fe ${ }^{2+}$-NO Komplexes. Überprüfung eines linearen Zusammenhangs zwischen der gewählten Amplitude (Verstärkung des Signals) und der tatsächlichen Signalhöhe.

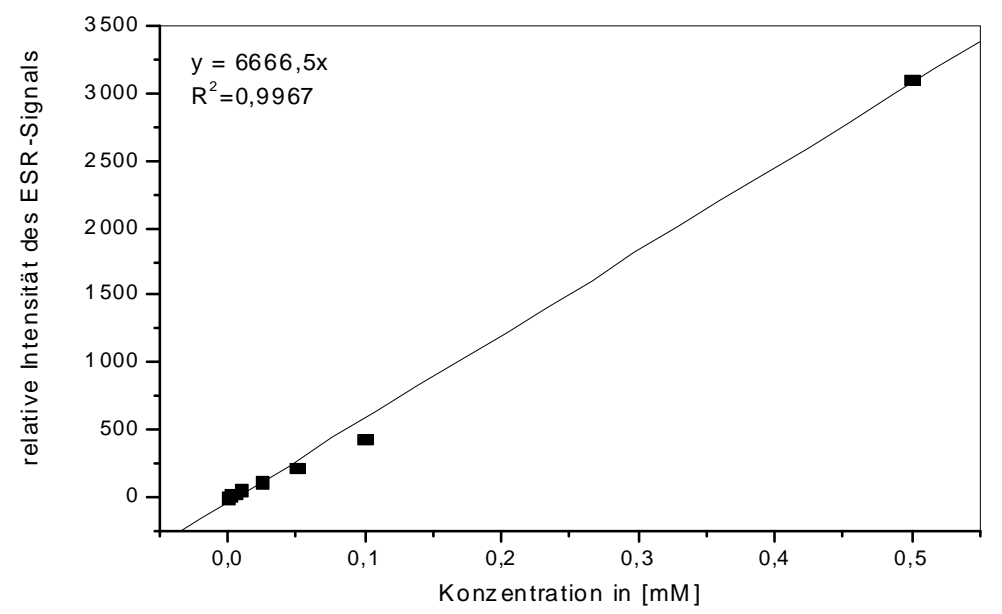

Abb. 19: Relative Intensität des Elektronen-Spin-Resonanz (ESR)-Signals einer Standardreihe aus lyophilisierten SNP-Proben [mM] mit MGD als Spin-Trap. 


\subsubsection{Detektion von NO in Xylemsaft und Gewebeproben}

Nach der Zugabe des Spin-Trap MGD zu den Xylemsaftproben wurde der Dreifachkomplex MGD-Fe ${ }^{2+}$-NO-Komplex gebildet, der den typischen Triplet-Peak (mit $\mathrm{g}=2.035$ ) hervorrief. Das Triplet-Signal der Xylemsaftproben stimmte mit dem Signal, welches durch die NODonatoren erhalten wurde, überein (Abb. 20).

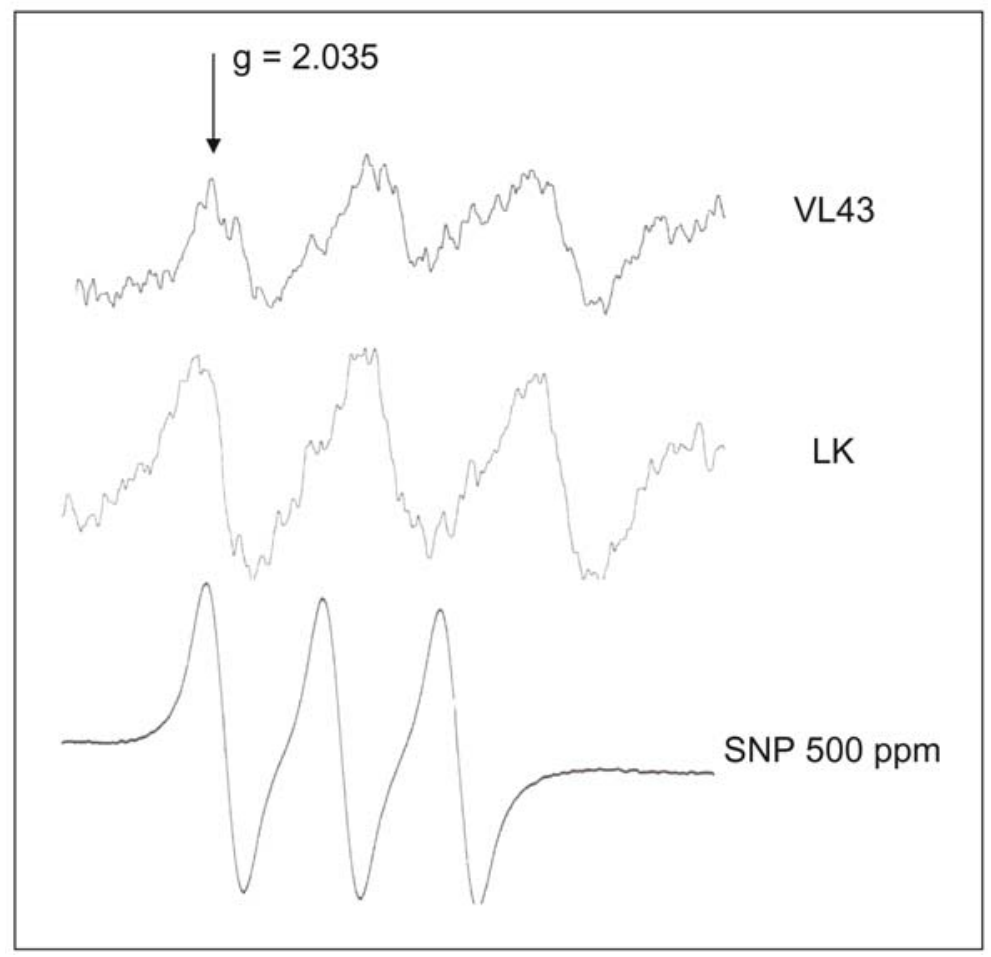

Abb. 20: Dreifach-Spektren des MGD-Fe ${ }^{2+}$-NO-Komplexes (mit erstem Peak bei $\mathrm{g}=2.035$ ) aus MGD und dem Xylemsaft einer $V$. longisporum-infizierten RCRPflanze (VL43), einer Kontrollpflanze (LK) und ohne Xylemsaft aber mit Zusatz des NO-Donors SNAP $(500 \mathrm{ppm})$ in Hepes-Puffer (40 mM, pH 7,4).

Aufgrund der geringen Stärke des NO-Signals in Xylemsaft wurden die Proben zusätzlich aufkonzentriert (Lyophilisierung des Xylemsaftes inkl. des bereits applizierten Spin-Traps MGD). In Abb. 21 ist das Dreifach-Spektrum des MGD-Fe ${ }^{2+}-\mathrm{NO}$ Komplexes mit der NOtypischen Triplet-Struktur $(\mathrm{g}=2.035)$, welches in allen beprobten Varianten auftrat, deutlich zu erkennen. Der zusätzliche Schritt der Lyophilisierung hat dabei die Qualität des Signals nicht beeinträchtigt. Um die Quelle des Triplet-Signals zu überprüfen, wurde ein Scavenger für NO appliziert (carboxy-PTIO, $100 \mu \mathrm{M}$ ), dessen Zugabe (Inkubationszeit $1 \mathrm{~h}$ ) zu einer Xylemsaftprobe das Triplet-Signal deutlich verminderte. 


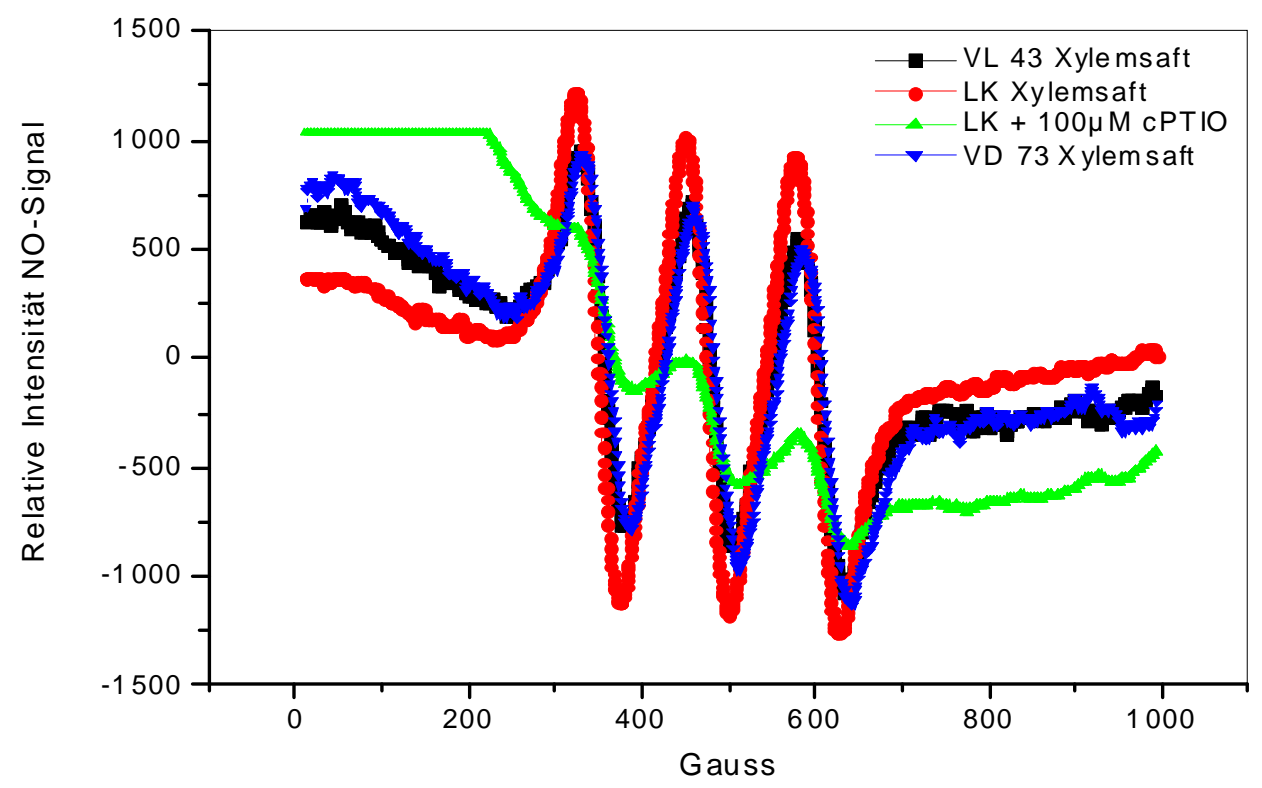

Abb. 21: ESR-Spektrum des MGD-Fe ${ }^{2+}$-NO-Komplexes in Xylemsaftproben aus $V$. longisporum-, $V$. dahliae- und nicht-inokulierten Kontroll- pflanzen vier Wochen nach Inokulation (28 dpi). Die Inkubation der Kontrollprobe (LK) mit $100 \mu \mathrm{M}$ cPTIO über eine Stunde führte zu einer deutlichen Reduktion des Triplet-Signals (grünes Spektrum).

Aus den untersuchten Xylemsaftproben der Einzelpflanzen ist ersichtlich, dass insgesamt die Stärke des NO-Signals im Verlauf der Pflanzenentwicklung abnimmt (Abb. 22). Signifikante Unterschiede zwischen den Varianten waren aber aufgrund der hohen Standardabweichungen nicht vorhanden. Um die hohen Standardabweichungen zu reduzieren und verlässlichere Resultate zu erhalten, wurde der gesamte Versuch mit gepoolten Xylemsaftproben erneut durchgeführt, wobei eine ESR-Probe aus 5 Pflanzen zusammengefasst wurde. Mit diesem Ansatz konnte die Standardabweichung reduziert und der Trend des im Verlauf der Pflanzenentwicklung abfallenden NO-Levels bestätigt werden (Abb. 23). Des Weiteren wurde deutlich, dass V. longisporum-infizierte Pflanzen allgemein ein niedrigeres NO-Signal aufwiesen als Kontroll- oder $V$. dahliae-infizierte Pflanzen. Das NO-Signal in V. longisporum-Proben war zu zwei beprobten Zeitpunkten 14 und 35 dpi signifikant niedriger als in den anderen beiden Varianten. In keinem Fall konnte $\mathrm{zu}$ den beprobten Zeitpunkten eine Erhöhung des NO-Signals aufgrund der Infektion mit einem der beiden verwendeten Pilzisolate beobachtet werden. 


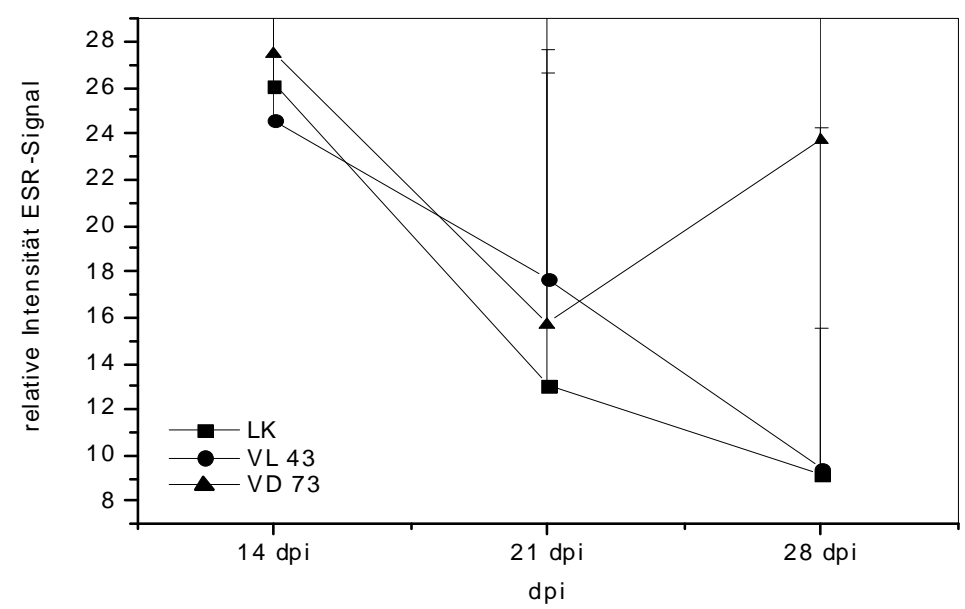

Abb. 22: Relative Intensität der Elektronen-Spin-Resonanz (ESR)-Spektren des MGD-Fe ${ }^{2+}$ NO Komplexes in lyophilisierten Xylemsaftproben aus einzelnen V. longisporum (VL)-, $V$. dahliae (VD)- und nicht-inokulierten Pflanzen (LK) über einen Zeitraum von 14-28 dpi, $\mathrm{n}=10$. Für $\mathrm{P}<0,05$ (LSD-Test) konnten keine signifikanten Unterschiede ermittelt werden.

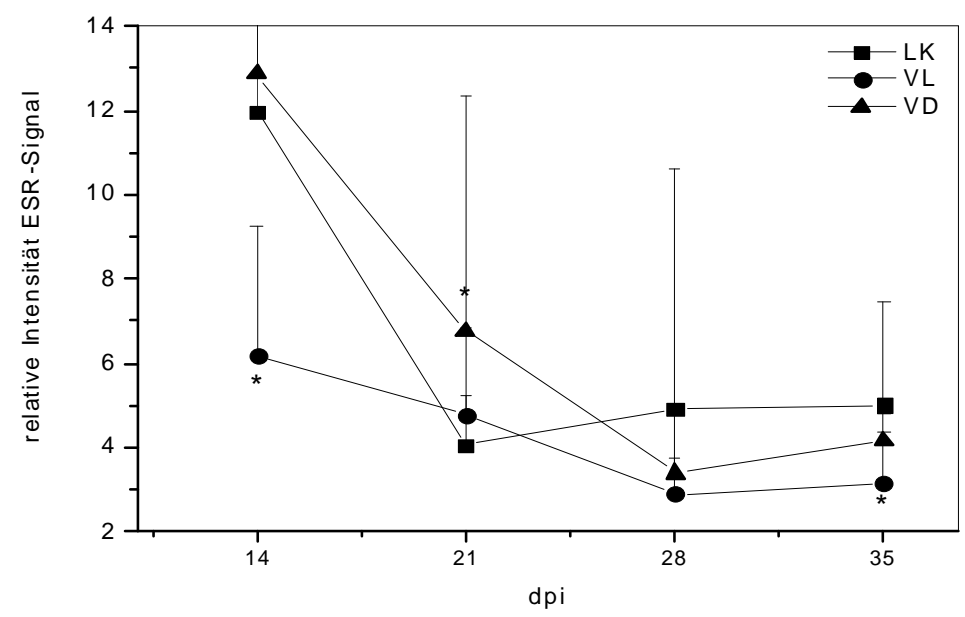

Abb. 23: Relative Intensität der Elektronen-Spin-Resonanz (ESR) Spektren des MGD-Fe ${ }^{2+}$ NO Komplexes in lyophilisierten Xylemsaftmischproben (1 Probe umfasst 5 Pflanzen) $V$. longisporum (VL)-, V. dahliae (VD)- und nicht-inokulierter Pflanzen (LK), über einen Zeitraum von 14-35 dpi. $\mathrm{n}=5-9, *=$ signifikant unterschiedlich zur Kontrollvariante für $\mathrm{P}<0,05$ (LSD-Test).

Um zu überprüfen, ob kurz nach dem ersten Kontakt der Keimlinge mit V. longisporum Veränderungen im NO-Gehalt auftreten, wurden Gewebeproben von Keimlingen zu verscheidenen Zeitpunkten (0, 30, 60, 90, 180 hpi sowie 24, 48, 72 und 96 hpi) untersucht. Zur Extraktion von NO aus Gewebe wurde das lipophile Spin-Trap DETC verwendet. Wie auch für MGD als Spin-Trap konnte für DETC unter gleichen Bedingungen das NO-typische Triplet-Signal des Dreifachkomplexes aus $\left(\right.$ DETC) ${ }_{2} \mathrm{Fe}^{2+} \mathrm{NO}$ mit $\mathrm{g}=2.035$ detektiert werden. Eine Standardreihe aus DETC und MAHMA NONOate ergab ein Bestimmtheitsmaß von 0.9989 (Abb. 24). 


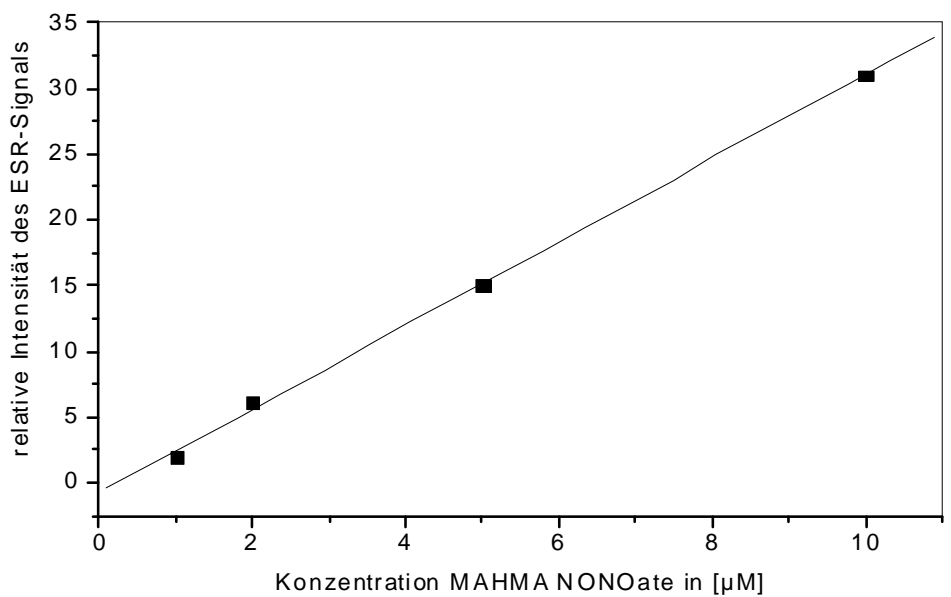

Abb. 24: Relative Intensität der Elektronen-Spin-Resonanz (ESR)-Spektren einer Standardreihe aus NO-Donor MAHMA-NONOate $[\mu \mathrm{M}]$ und DETC als Spin Trap.

Zur Überprüfung der gewählten Bedingungen wurde unter künstlichen Bedingungen ein NOAnstieg ausgelöst. Eine Inkubation der RCR-Keimlinge in Nitrit-Lösung $(200 \mu \mathrm{M}+200 \mu \mathrm{M}$ $\mathrm{NADH}$ ) führte im Vergleich $\mathrm{zu}$ Kontrolle, die keine Peaks aufwies (Daten hier nicht dargestellt), zu einem starken Anstieg des NO-Signals und konnte unter den gewählten Bedingungen zweifelsfrei nachgewiesen werden (Abb. 25). Die Analyse der mit den beiden Pathogenen inokulierten Gewebeproben zeigte $\mathrm{zu}$ einigen Zeitpunkten das NO-typische Triplet-Signal, jedoch traten die Signale unregelmäßig und in sämtlichen Varianten zu unterschiedlichen Zeitpunkten auf. Weder im Spross noch im Wurzelgewebe konnten signifikante Veränderungen detektiert werden.

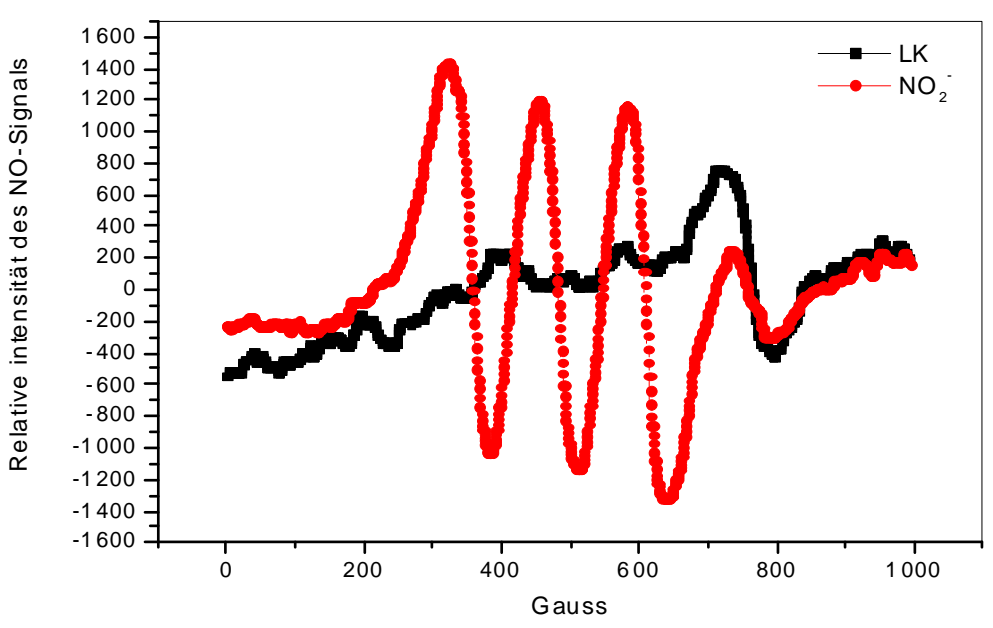

Abb. 25: Nitrit induziertes, mittels DETC Spin-Trap und Ethylacetat extrahiertes, NOSignal aus Sprossgewebe sieben Tage alter RCR-Keimlinge. Induktion des NO Anstiegs im Sprossgewebe durch Inkubation der Wurzeln mit $200 \mu \mathrm{M} \mathrm{NO}_{2}{ }^{-}$ und $200 \mu \mathrm{M}$ NADH über $2 \mathrm{~h}$ im Dunkeln unter $\mathrm{N}_{2}$-Begasung. Wasserbehandelte Kontrolle ohne Triplet Signal. 


\subsubsection{Nachweis von NO mit HPLC und dem Fluoreszenzmarker DAF-2DA}

Der in diesem Experiment verwendete NO-Donor MAHMA-NONOate hat eine ausgesprochen niedrige Halbwertszeit ( $\mathrm{t} 1 / 2=3 \mathrm{~min}$ in Phosphat-Puffer $\mathrm{pH} 7,4$ bei RT) und ist nur unter basischen Bedingungen stabil. Der Fluoreszenzfarbstoff DAF-2DA benötigt hingegen neutrale pH-Bedingungen. Zur Extraktion der Proben wurde die Menge und Konzentration des Hepes-Puffers daher so gewählt, dass die Zugabe des Standards (in 0,01 N $\mathrm{NaOH}$ ) den $\mathrm{pH}-$ Wert nicht verschiebt, sondern im neutralen Bereich hält, wodurch der Fluoreszenzmarker stabil bleibt und der Donor das NO abgeben kann. Durch Reaktion des Donors mit dem Fluoreszenzmarker DAF-2DA wurde das entstehende Triazol-Signal bei einer Retentionszeit von 3,5-4 min detektiert. Nicht abreagiertes DAF-2 und Komponenten des Puffers wurden bei 10 und 12 min Retentionszeit ausgespült. Standardreihen waren zwischen 50-200 nM linear (Abb. 26). Die Fluoreszenzintensität war des Weiteren abhängig von der Inkubationszeit (Abb. 26B). Erste HPLC-Analysen von Xylemsaftproben zeigten einen klaren Peak mit gleicher Retentionszeit wie auch beim eingesetzten Standard (Daten nicht dargestellt). Mit ansteigendem Volumen Xylemsaft stieg auch das NO-Signal linear (Abb. 27).
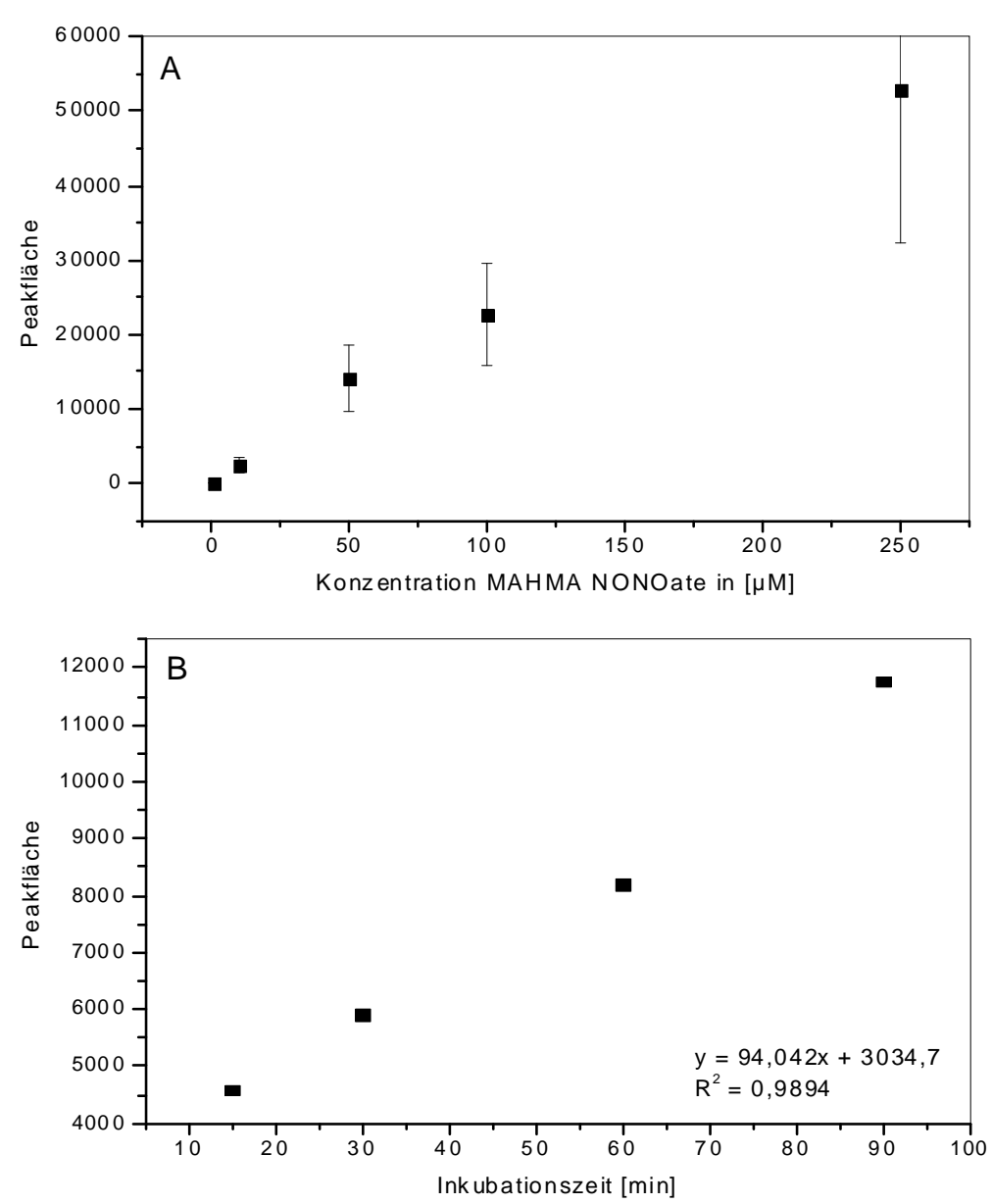

Abb. 26: Abhängigkeit der Fluoreszenzintensität von der Konzentration des NO-Donors MAHMA NONOate; $\mathrm{n}=3$ (A) und von der Länge der Inkubationszeit (B). 


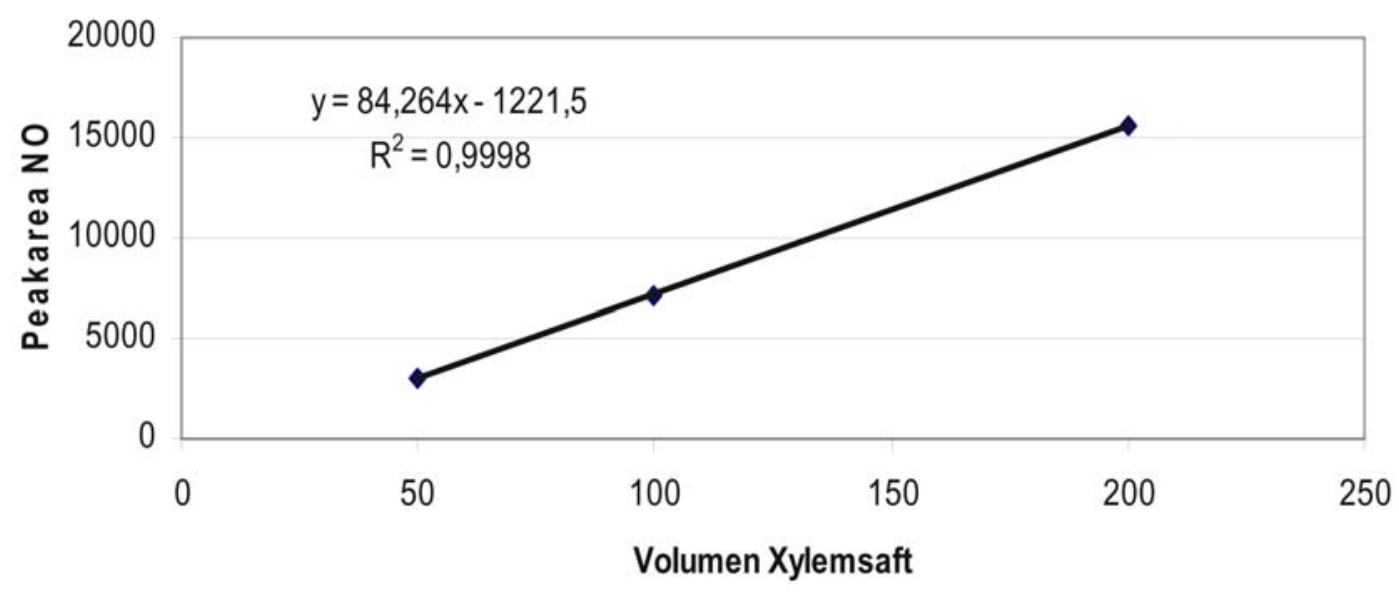

Abb. 27: Anstieg des DAF-Triazol Signals mit zunehmendem Volumen an Xylemsaft [ $\mu 1]$.

Die Analyse von Extrakten (100 mg Sprossgewebe in $1 \mathrm{ml} 40 \mathrm{mM}$ Hepes Puffer, pH 7,4 mit vorgequollenem PVPP) aus RCR-Gewebeproben $(n=4)$ zeigte wie auch die Standards einen Peak bei 3,5-4 min. Die NO-Gehalte lagen in Bereichen von 2-6 $\mathrm{nmol} \mathrm{ml}^{-1} \mathrm{~g} \mathrm{FW}^{-1}$. Wie auch bei den ESR-Untersuchungen des Xylemsaftes wurde deutlich, dass in V. longisporuminokulierten Keimlingen $14 \mathrm{~h}$ nach Inokulation der Gehalt an NO im Spross im Vergleich zur Kontrollvariante verringert war. Im Wurzelgewebe waren keine Unterschiede zwischen den beiden Varianten zu detektieren (Abb. 28).

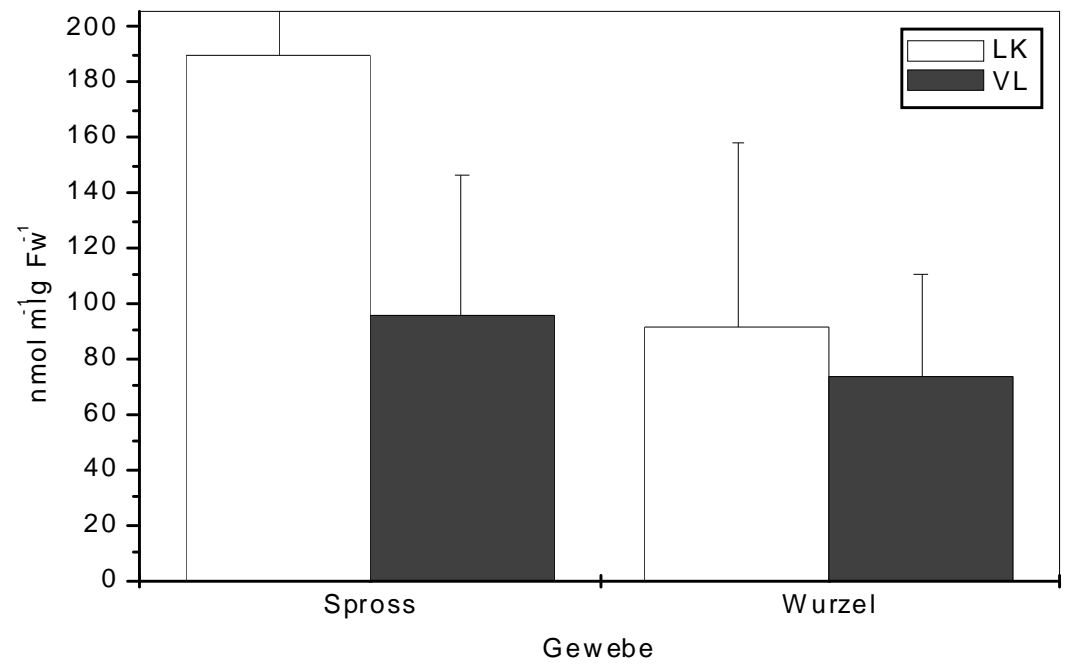

Abb. 28: Mit HPLC und DAF-2DA detektierte NO-Gehalte aus Spross- und Wurzelgewebeproben von RCR-Keimlingen $14 \mathrm{~h}$ nach Inokulation mit $V$. longisporumSporensuspension $(V L)$ und nach Wasserbehandlung (LK). Daten zusammengefasst aus zwei unabhängigen Versuchen, $\mathrm{n}=9$; für $\mathrm{P}<0,05$ (LSD-Test) konnten keine signifikanten Unterschiede ermittelt werden. 


\subsubsection{Anwendbarkeit des Biotest (Nachweis der Interaktion von B. napus und $V$. longisporum)}

Für die Versuche in denen RCR-Keimlinge auf $V$. longisporum- und $V$. dahliaevorinokulierten WA-Platten ausgelegt wurden, um frühe Zeitpunkte der Interaktion zu beproben, wurde mikroskopisch $\mathrm{zu}$ den Probeterminen überprüft, ob tatsächlich ein Zusammentreffen von Pathogen (V. longisporum und V. dahliae) und Wirtspflanze stattfindet. Dazu wurden die Keimlinge nach 24-stündiger Inkubation, also zum erst möglichen Beprobungstermin, von den WA-Platten abgenommen und die Wurzeln in 0,05\% Säurefuchsin-Lösung angefärbt. Der Farbstoff wurde anschließend mit Lactophenol abgespült, die Wurzeln auf einem Objektträgern fixiert, mit einem Deckglas abgedeckt und auf typische Formen wie Hyphen und Mikrosklerotien auf der Wurzeloberfläche untersucht. Für die Untersuchungen wurden jeweils zehn Keimlinge der jeweiligen Variante analysiert. Bei beiden Pathogenen konnte gezeigt werden, dass sowohl Hyphenwachstum als auch ein Kontakt mit auskeimenden Mikrosklerotien auf der Wurzeloberfläche stattfindet (Abb. 29 u. 34). Sowohl bei V. longisporum-infizierten Keimlingen (Abb. 29D) als auch V. dahliae-infizierten Keimlingen (Abb. 30D u. E) konnten auch die für Verticillium typischen wirteligen Konidienträger nachgewiesen werden. Ein Kontakt zwischen Pathogen und Wirtspflanzen schien dadurch in diesem Versuchsaufbau gewährleistet. Der Nachweis der erfolgreichen Interaktion und deren Effekt auf Spross-, Primärwurzelwachstum und Anzahl der Seitenwurzeln der Keimlinge wurden ebenfalls überprüft. Nach siebentägiger Inkubation der Keimlinge im Biotest bei Bedingungen von $16 \mathrm{~h}$ Licht und konstanten $20^{\circ} \mathrm{C}$ im Gewebekulturschrank (Fa. Mytron), zeigte die V. longisporum-infizierte Variante eine signifikanteVerrringerung der Primärwurzellänge (Abb. 31C) allerdings noch keinen Effekt bezüglich der Sprosslänge (Abb. 31A) oder Anzahl der Seitenwurzeln (Abb. 31B). Die V. dahliae-infizierte Variante zeigte keinen Effekt auf die Spross- und Wurzellänge aber eine signifikant verringerte Anzahl der Seitenwurzeln (Abb. 31B). 


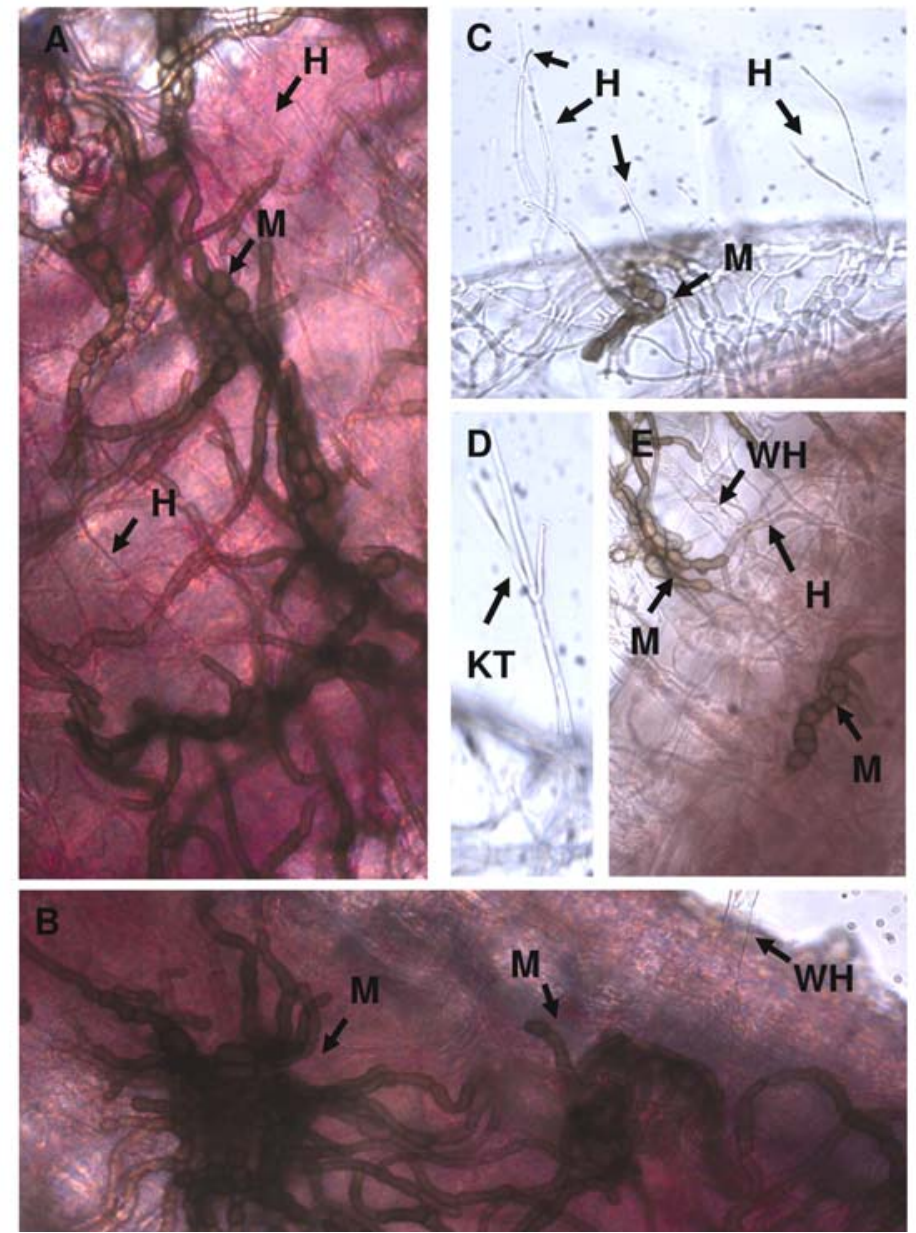

Abb. 29: A-C; E: Interaktion von Hyphen (H) und Mikrosklerotien (M) mit der Wurzeloberfläche (pink gefärbt mit Säurefuchsin $0,05 \%$ ) und Wurzelhaaren (WH) nach $24 \mathrm{~h}$ Inkubation von RCR-Keimlingen auf vorinokulierten $V$. longisporum WA-Platten für den Biotest. D: Verticillium-typische wirtelige Konidienträger (KT).
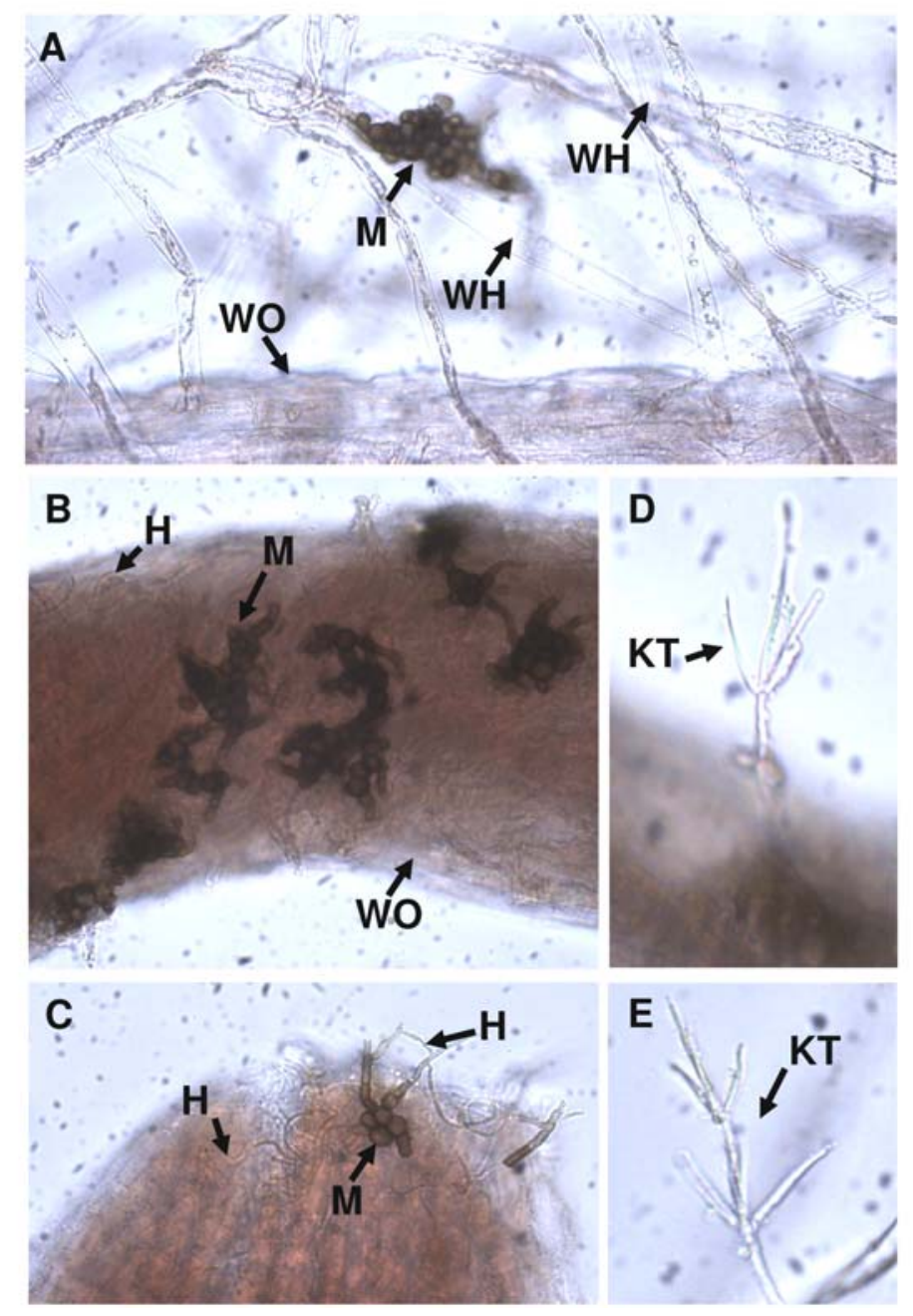

Abb. 30: A-B: Interaktion von Hyphen (H) und Mikrosklerotien (M) mit der Wurzeloberfläche (WO) und Wurzelhaaren (WH) nach $24 \mathrm{~h}$ Inkubation von RCRKeimlingen auf vorinokulierten $V$. dahliae WA-Platten für den Biotest. C. Interaktion von Hyphen und Mikrosklerotien mit Wurzelspitze. D-E: Verticillium-typische wirtelige Konidienträger (KT). 

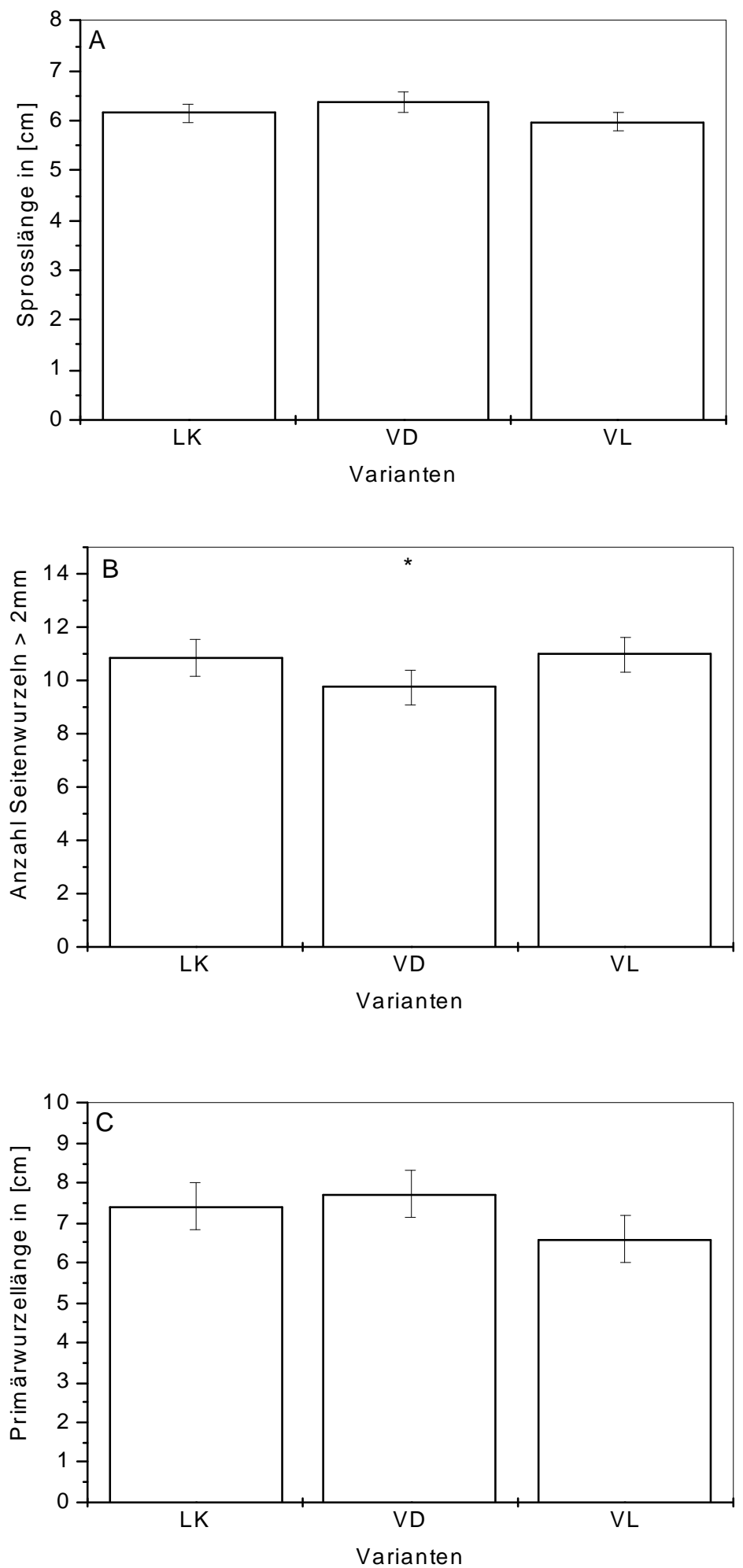

Abb. 31: Effekt der Inkubation (sieben Tage) von RCR-Keimlingen im Biotest auf $V$. longisporum (VL)- und $V$. dahliae $(V D)$-vorinokulierten oder nicht behandelten (LK) WAPlatten unter standardisierten Bedingungen $\left(16 \mathrm{~h}\right.$ Licht, konstante $\left.20^{\circ} \mathrm{C}\right)$ im Gewebekulturschrank (Fa. Mytron) auf A. das Sprosswachstum, B. die Anzahl der Seitenwurzeln $>2 \mathrm{~mm}$ und C. die Primärwurzellänge. $V L \mathrm{n}=125, V D \mathrm{n}=105, \mathrm{LK} \mathrm{n}=90 ;{ }^{*}=$ signifikant unterschiedlich zur entsprechenden Kontrolle für $\mathrm{P}<0,05$ (LSD-Test). 


\subsection{Nachweis von $\mathrm{H}_{2} \mathrm{O}_{2}$}

Die durch Titan-Oxalat $\left(\mathrm{Ti}^{4+}\right)$ nachgewiesenen $\mathrm{H}_{2} \mathrm{O}_{2}$-Gehalte in den untersuchten Gewebeproben lagen im mittleren Bereich der erzeugten Standardkurven. Die Wiederfindungsrate der Standards in Pflanzenextrakt betrug 93\% (Daten nicht dargestellt). Über den Zeitraum von 1,5 hpi bis 21 dpi konnten in den untersuchten Gewebeproben keine signifikanten Unterschiede in den $\mathrm{H}_{2} \mathrm{O}_{2}$-Gehalten gemessen werden, die auf die Infektion mit $V$. longisporum oder V. dahliae zurückzuführen wären (Abb. 32-37). Einzig zum Zeitpunkt 28 dpi zeigten $V$. longisporum-infizierte Hypokotyl- und Sprossproben einen signifikant höheren $\mathrm{H}_{2} \mathrm{O}_{2}$-Gehalt (Abb. 34). Die Untersuchungen des Xylemsaftes von V. longisporum und nicht-infizierten Pflanzen zeigten keine signifikanten Unterschiede, jedoch eine Tendenz $\mathrm{zu}$ einem $\mathrm{H}_{2} \mathrm{O}_{2}$ Anstieg in den infizierten Pflanzen $\mathrm{zu}$ den Zeitpunkten 21 und 35 dpi (Abb. 35).
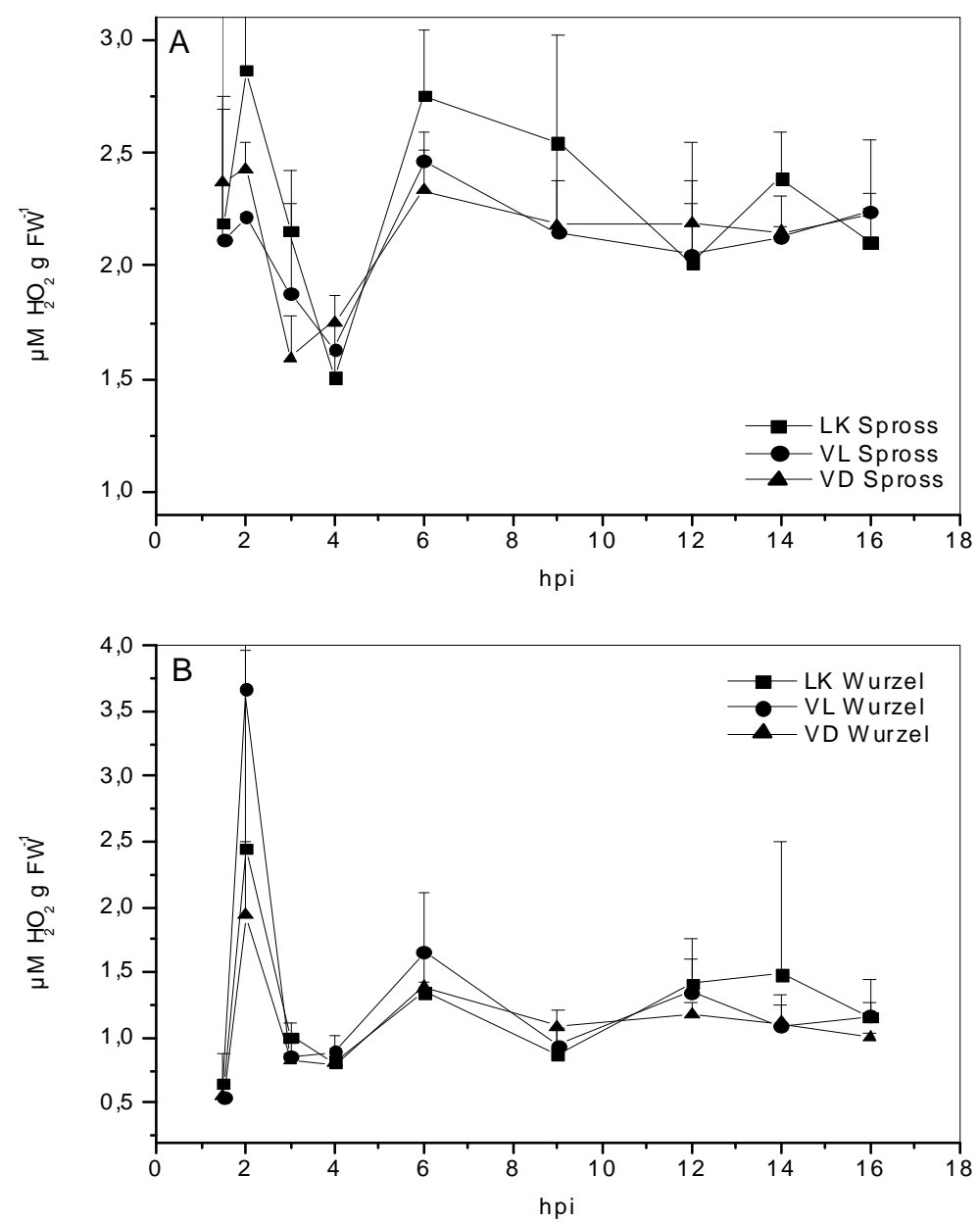

Abb. 32: Mittels Titan-Oxalat-Methode photometrisch bestimmter $\mathrm{H}_{2} \mathrm{O}_{2}$-Gehalt $\left[\mu \mathrm{M} \mathrm{H}_{2} \mathrm{O}_{2} \mathrm{~g} \mathrm{FW}^{-1}\right]$ in gepoolten A. Spross- und B. Wurzelproben (1 Probe $=5$ Keimlinge) von sieben Tage alten $V$. longisporum (VL)-, V. dahliae (VD)- oder nicht-inokulierten Rapskeimlingen (LK); Zeitverlauf 1,5 bis 96 hpi; $\mathrm{n}=15$. Für $\mathrm{P}<0,05$ (LSD-Test) konnten keine signifikanten Unterschiede ermittelt werden. 

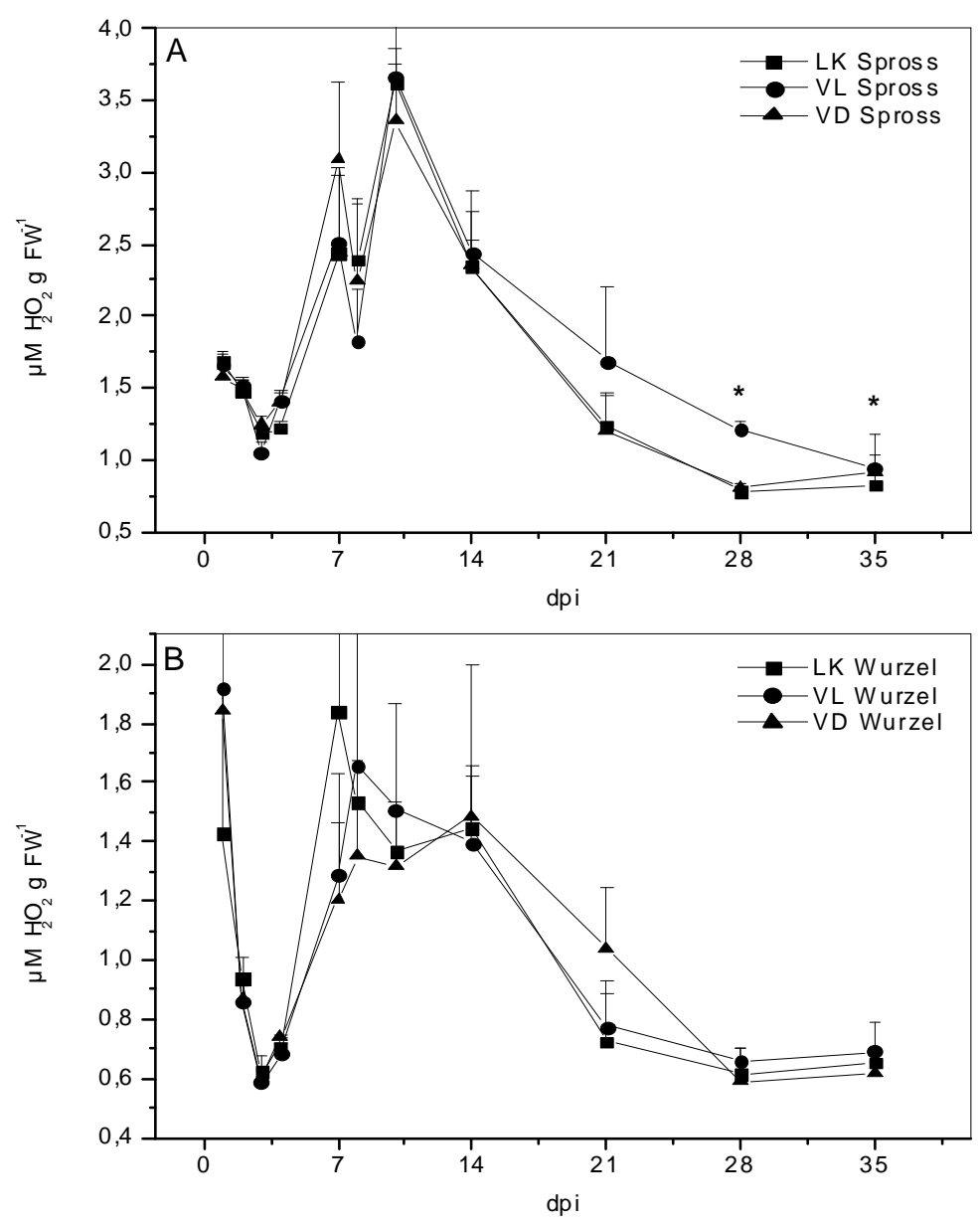

Abb. 33: Mittels Titan-Oxalat-Methode photometrisch bestimmter $\mathrm{H}_{2} \mathrm{O}_{2}$-Gehalt $\left[\mu \mathrm{M} \mathrm{H}_{2} \mathrm{O}_{2} \mathrm{~g} \mathrm{FW}^{-1}\right]$ in A. Spross- und B: Wurzelproben gepoolter Keimlinge (1-4 dpi, $\left.\mathrm{n}=15\right)$ und einzelner Pflanzen (7-35 dpi; $\mathrm{n}=10$ ); Varianten; Mit $V$. longisporum (VL)-, V. dahliae (VD)- oder nicht inokulierter $(\mathrm{LK}), *=$ signifikant unterschiedlich zur Kontrolle für $\mathrm{P}<0,05$ (LSD-Test).

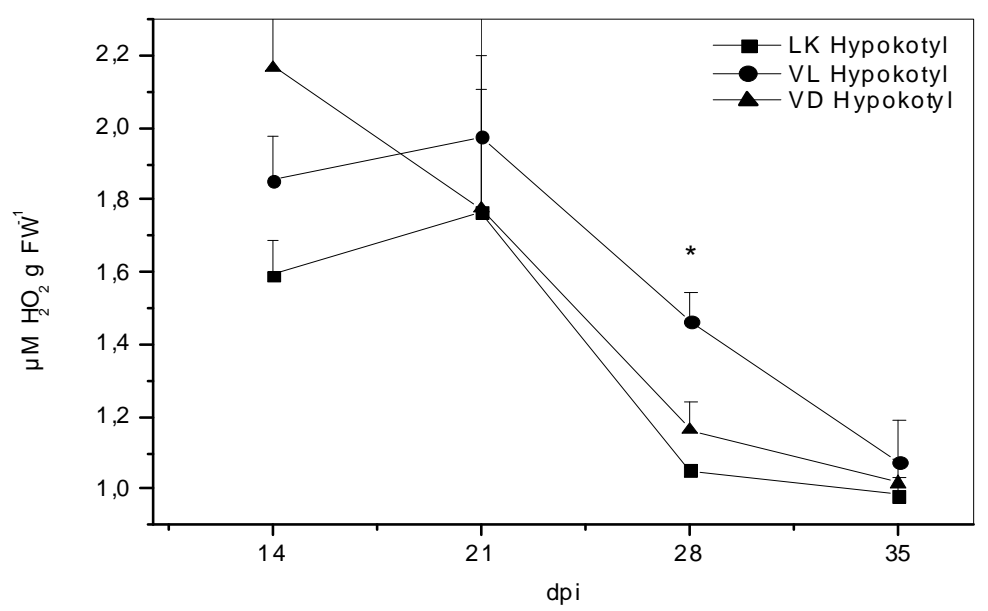

Abb. 34: Mittels Titan-Oxalat-Methode photometrisch bestimmter $\mathrm{H}_{2} \mathrm{O}_{2}$-Gehalt $\left[\mu \mathrm{Mg} \mathrm{FW}{ }^{-1}\right]$ aus Hypokotylproben einzelner V. longisporum (VL)-, V. dahliae (VD)- oder nicht inokulierter Kontrollpflanzen (LK), Zeitverlauf 14 bis 35 dpi; 14 dpi $n=15 ; 21$ dpi $n=10,28$ dpi $n=10$; 35 dpi n = 10; * = signifikant unterschiedlich zur Kontrolle für $\mathrm{P}<0,05$ (LSD-Test). 


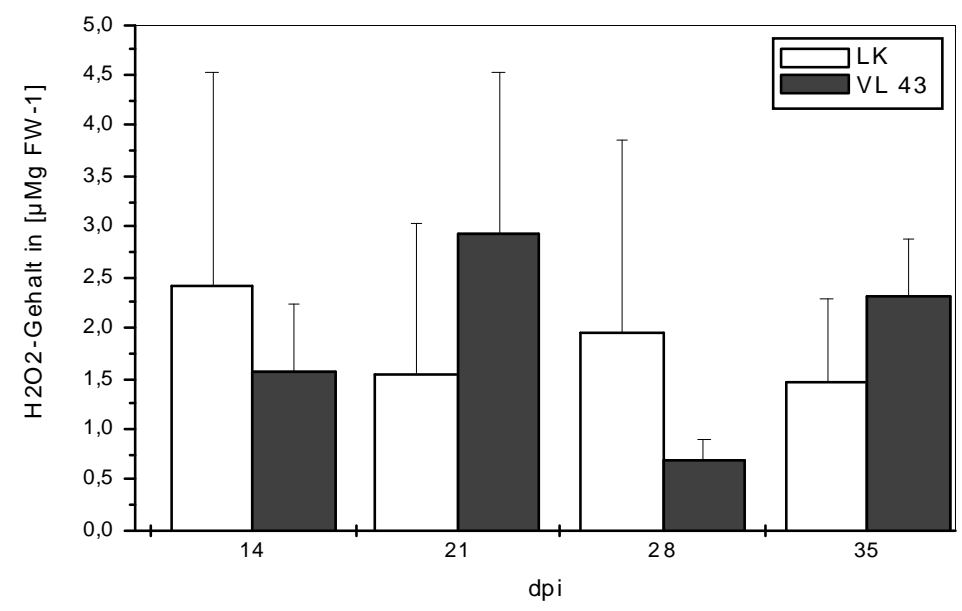

Abb. 35: Mittels Titan-Oxalat-Methode photometrisch bestimmter $\mathrm{H}_{2} \mathrm{O}_{2}$-Gehalt $\left[\mu \mathrm{Mg} \mathrm{FW}{ }^{-1}\right]$ im Xylemsaft $V$. longisporum (VL)-, und nicht-inokulierter Kontrollpflanzen (LK), Zeitverlauf 14 bis 35 dpi; 14 dpi $n=5 ; 21$ dpi $n=10,28$ dpi $n=5 ; 35$ dpi $n=10$; Es konnten für $\mathrm{P}<0,05$ (LSD-Test) keine signifikanten Unterschiede ermittelt werden.

\subsection{Nachweis von GSNO mit HPLC}

Im Zusammenhang mit der Detektion von NO spielt der Nachweis von GSNO, der vermutlich vorherrschenden Transportform von NO, eine große Rolle. Aus dem medizinischen und analytischen Bereich liegen GSNO-Nachweismethoden vor (KLUGE et al., 1997; TsIKAS et al., 1999; MESSENA et al., 2000; TSIKAS et al., 2001). Allerdings sind bisher nur wenige Veröffentlichungen zur Detektion von GSNO in Pflanzen publiziert worden, z.B. der immunohistologische Nachweis von GSNO in Erbse (BARROSO et al., 2006). In dieser Arbeit sollte eine HPLC-Methode zum indirekten Nachweis von GSNO aus Pflanzenextrakten erarbeitet werden.

Da bereits eine etablierte Methode zur HPLC-Detektion von GSH vorhanden war, sollte durch die Verwendung der GSNO-abhängigen Formaldehyd-Dehydrogenase GSNO spezifisch zu Glutathiondisulfid (GSSG) und Ammoniak $\left(\mathrm{NH}_{3}\right)$ umgewandelt und das entstandene GSSG durch 1,4-Dithiotreitol (DTT) zu GSH rückreduziert werden. Die Entstehung von GSSG aus GSNO und Reduktase konnte auch per HPLC bestätigt werden. Nur ein geringer Prozentteil (6-7\%) des entstandenen GSSG wurde dabei spontan zu GSH umgesetzt (Daten nicht dargestellt).

Der Nachweis von GSH erfolgte modifiziert nach SCHUPP \& RENNENBERG (1988). Die Bestimmung wurde fluorimetrisch bei $480 \mathrm{~nm}$ durchgeführt und beruht auf der Reaktion von Monobromobiman Thiolyte ${ }^{\mathrm{TM}} \mathrm{MB}(\mathrm{mBrB})$ mit den freien Thiolgruppen des GSH. Eine Überprüfung der Reaktion von GSNO mit dem Reduktionsmittel DTT ergab, dass auch 
GSNO von DTT zu GSH reduziert wird. Somit war eine genaue Differenzierung von GesamtGSSG-Gehalt und durch Reduktase entstandenem GSH nicht möglich. Statt DTT wurde daher in einem weiteren Ansatz L-Ascorbinsäure (Ascorbat) als Reduktionsmittel eingesetzt, welches spezifisch mit GSNO reagiert und keine Nebenreaktion mit GSSG aufweist. Ein Molekül Ascorbat reduziert dabei 2 GSNO Moleküle (HOLMES et al., 2000). Zur Überprüfung des Umsatzes von GSNO durch Ascorbat wurde die Inkubation von GSNO mit DTT über einen Zeitraum von $1 \mathrm{~h}$ und das dabei entstehende GSH als zu erreichender Maßstab von $100 \%$ gesetzt. Verschiedene Konzentrationen von Ascorbat (1 mM, 10 mM, $100 \mathrm{mM})$, die über unterschiedliche Zeiträume (1, 2, 3, 4, 6 h) inkubiert wurden, konnten dabei nur maximal $55,8 \%$ des Umsatzes mit DTT erreichen. Auch die Verwendung von $100 \mu \mathrm{M}$ Kupfer als Reaktionsbeschleuniger oder in einer weiteren Variante von $100 \mathrm{mM}$ EDTA als ReaktionsStabilisator konnte keine Verbesserung des Ergebnisses liefern. Der Ansatz des HPLCNachweises bot daher keine ausreichend hohe Quantifizierungsmöglichkeit des GSNO und wurde nicht für die Analyse von Proben verwendet.

\subsection{GSNO-Reduktaseaktivität}

Die Aktivität der GSNO-reduzierenden GSNO-Reduktase wurde in zwei Experimenten untersucht: zum einen an Einzelpflanzen $(n=10)$, zum anderen an gepoolten Pflanzen einer zweiten Zeitreihe ( $n=4$ bei 3 Pflanzen pro Probe). Im ersten Versuch war aufgrund der hohen Standardabweichungen kein signifikanter Unterschied zwischen den einzelnen Varianten erkennbar (Daten nicht dargestellt).

Im zweiten Versuch mit gepoolten Proben (Abb. 36) ist zu Beginn der Zeitreihe (14-21 dpi) in den Sprossproben der V. longisporum-infizierten Variante nur eine Tendenz zu erhöhter GSNOR-Aktivität erkennbar. Im Vergleich zu nicht-inokulierten Pflanzen konnte kein signifikanter Unterschied festgestellt werden. Zum Zeitpunkt 28 dpi ist ein signifikanter Anstieg der GSNOR-Aktivität in Wurzelproben der V. longisporum-Variante zu verzeichnen und auch im Spross ist eine deutliche Tendenz zu erhöhter Aktivität erkennbar. Ab 35 dpi ist die GSNOR-Aktivität in den gesamten Pflanzen, d.h. sowohl Wurzel- als auch Sprossproben der V. longisporum-Variante, signifikant erhöht. In Wurzelproben V. dahliae-infizierter Pflanzen konnte im Vergleich zu nicht-inokulierten Pflanzen schon ab 14 dpi eine signifikant erhöhte GSNOR-Aktivität gemessen werden. Zum Zeitpunkt 21 dpi nimmt die Aktivität der GSNO-Reduktase in Spross- und Wurzelproben dieser Variante allerdings wieder ab. Nach 28 dpi ist entsprechend den Werten der $V$. longisporum-infizierten Pflanzen auch in der V. dahliae-Variante eine signifikante Zunahme der GSNOR-Aktivität in Wurzelproben zu 
verzeichnen, ebenso wie im Spross eine Tendenz zu erhöhter Aktivität erkennbar ist. Die Analyse der $V$. dahliae-infizierten Spross- und Wurzelproben nach 35 dpi zeigt, dass die GSNO-Reduktase im Spross wie auch in der Wurzel signifikant erhöht ist. Insgesamt nimmt die Aktivität der GSNO-Reduktase in allen Varianten im Verlauf der Pflanzenentwicklung zu, wobei im Spross tendenziell eine höhere Aktivität vorliegt als in der Wurzel. V. longisporumund $V$. dahliae-infizierte Pflanzen zeigen einen ähnlichen Verlauf der GSNOReduktaseaktivität mit signifikant höheren Werten zum Ende der Pflanzenentwicklung (28-35 dpi).

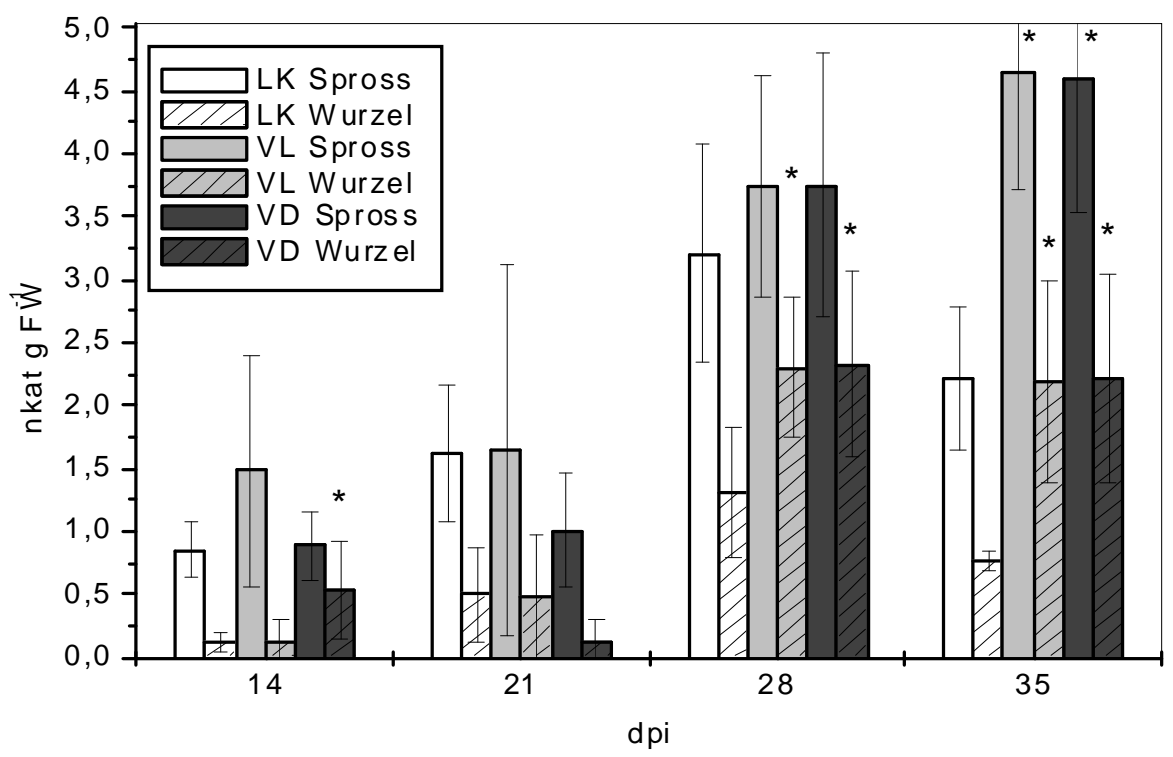

Abb. 36: GSNO-Reduktaseaktivität [nkat $\mathrm{g} \mathrm{FW}^{-1}$ ] in gepoolten Spross- und Wurzelproben, $V$. longisporum (VL)-, V. dahliae (VD)- und nicht-inokulierter Kontrollpflanzen (LK) über den Zeitraum 14-35 dpi. Pro Probe wurden 3 Pflanzen zusammengefasst, $\mathrm{n}=4$; $*=$ signifikant unterschiedlich zur Kontrolle für $\mathrm{P}<0,05$ (LSD-Test).

\subsection{Gehalt an nitrosylierten Proteinen}

Korrespondierend zur Bestimmung der GSNOR-Aktivität (Abb. 36) wurde der Gehalt an nitrosylierten Proteine (SNOs) ermittelt (Abb. 37). Durch die Gelfiltration der Rohextrakte wurden die Proben von niedermolekularen Stoffen (z.B. GSNO) getrennt und nur die nitrosylierten Proteine (SNO) bzw. cysteingebundenes NO bestimmt. Entgegen der Zunahme der GSNO-Reduktaseaktivität konnte in Sprossproben aller Varianten über den Verlauf der Probenahme ein Abfall der SNOs gemessen werden (Abb. 37-43). Allerdings wies die V. longisporum-Variante zum Zeitpunkt 14 dpi einen geringeren Gehalt an SNOs und zu 21 dpi einen erhöhten Gehalt an sprosslokalisierten SNOs auf (Abb. 38 u.44). In den 
Wurzelproben sind keine Unterschiede der SNO-Gehalte zwischen den Varianten ersichtlich (Abb. 39).

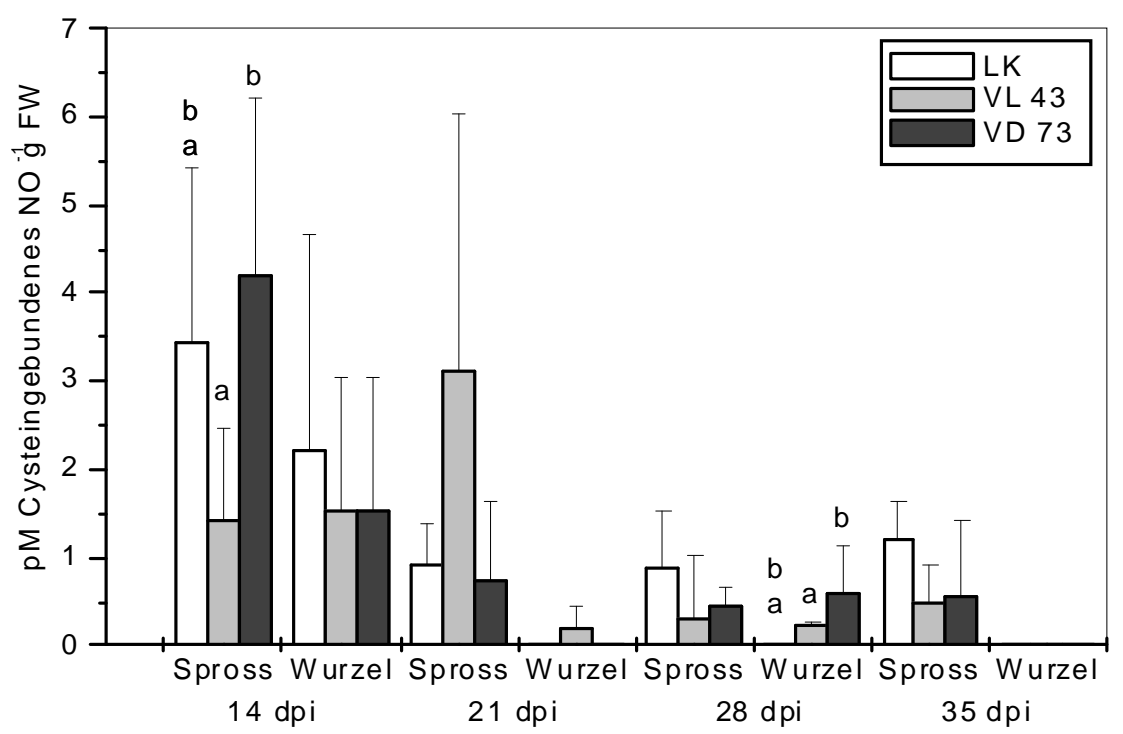

Abb. 37: Cysteingebundenes NO [pM mg Protein ${ }^{-1}$ in gepoolten Spross- und Wurzelproben, $V$. longisporum (VL)-, V. dahliae (VD)- und nicht-inokulierter Rapspflanzen (LK) im Zeitraum 14-35 dpi. Pro Probe wurden 3 Pflanzen zusammengefasst, $n=4, P<0,05$ LSDTest; Indizes zeigen signifikante Unterschiede im Vergleich zur Kontrollvariante.
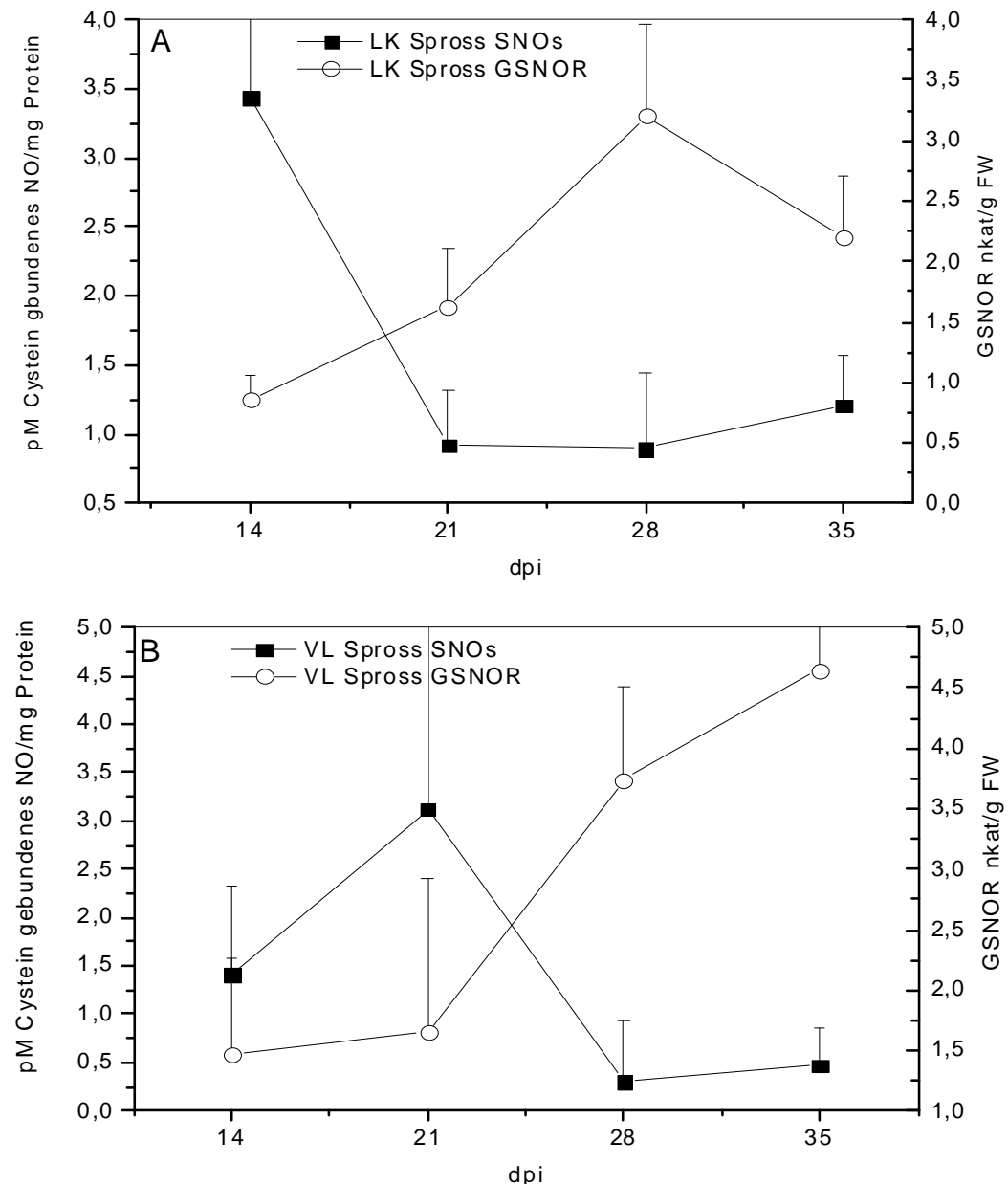


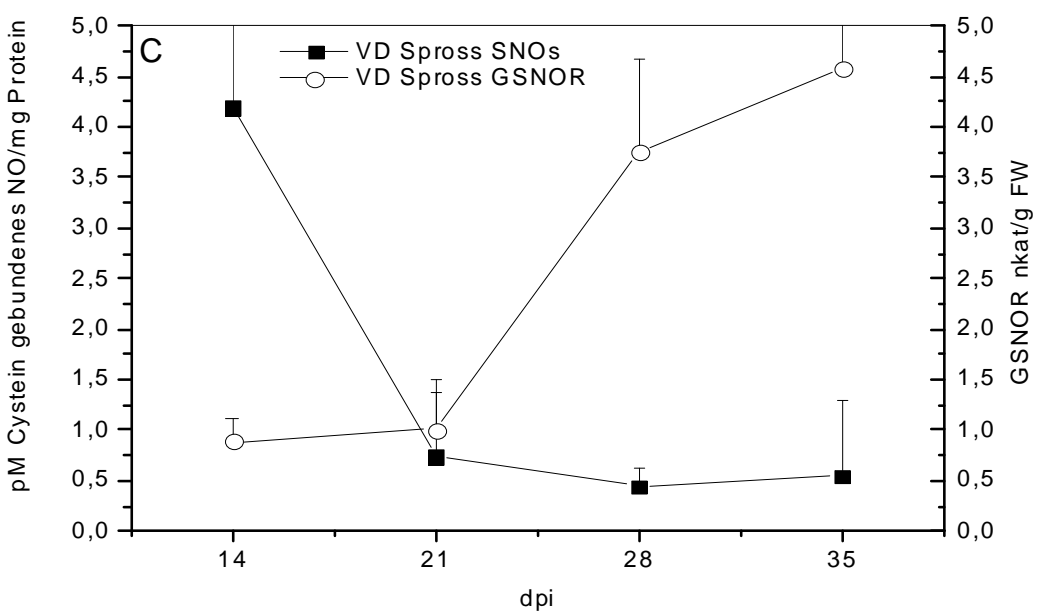

Abb. 38: GSNO-Reduktaseaktivität [nkat $\mathrm{g} \mathrm{FW}^{-1}$ ] und Gehalt an cysteingebundenem NO $\left[\mathrm{pM} \mathrm{mg}^{-1}\right.$ Protein] aus gepoolten Sprossproben A. nicht-inokulierter (LK), B. V. longisporum (VL)- oder C. V. dahliae (VD)-inokulierter Pflanzen im Zeitraum von 14-35 dpi. Pro Proben wurden 3 Pflanzen zusammengefasst, $\mathrm{n}=4$.
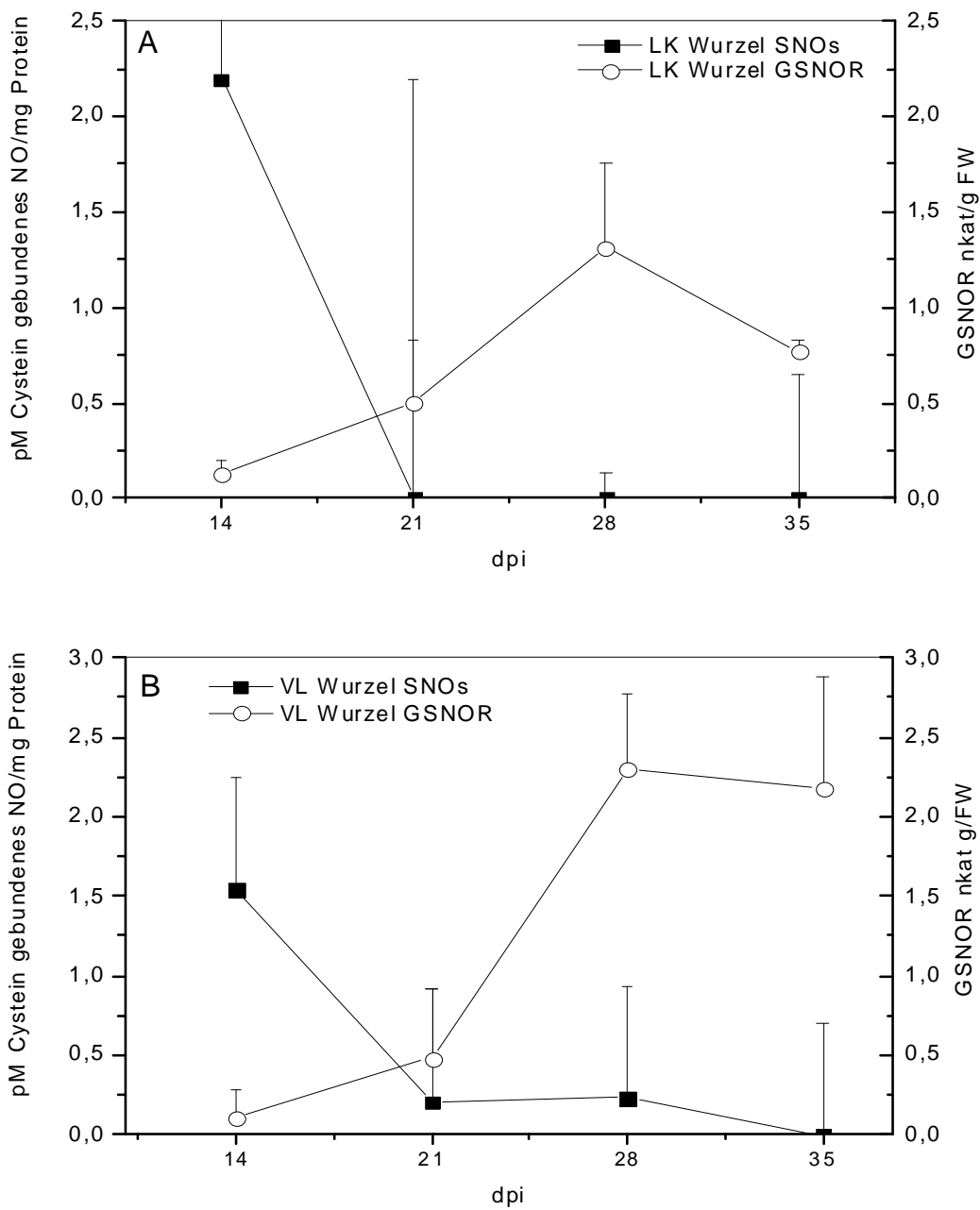


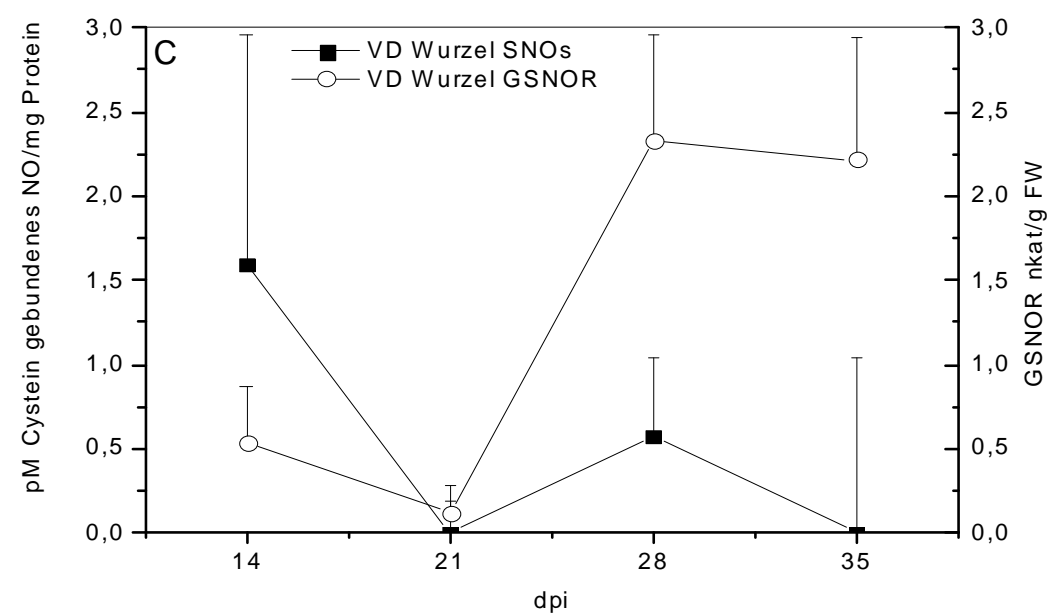

Abb. 39: GSNO-Reduktaseaktivität [nkat $\mathrm{g} \mathrm{FW}^{-1}$ ] und Gehalt an cysteingebundenem NO $\left[\mathrm{pM} \mathrm{mg}^{-1}\right.$ Protein] aus gepoolten Wurzelproben A. nicht-inokulierter (LK), B. V. longisporum (VL)- oder C. V. dahliae (VD)-inokulierter Pflanzen im Zeitraum von 14-35 dpi. Pro Proben wurden 3 Pflanzen zusammengefasst, $n=4$.

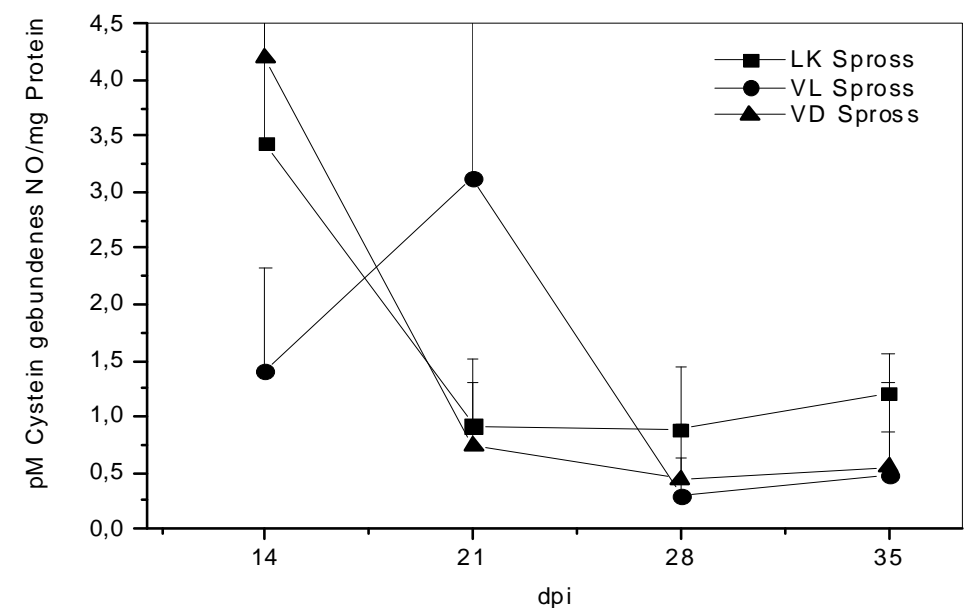

Abb. 40: Cysteingebundenes NO [pM mg Protein $\left.{ }^{-1}\right]$ in gepoolten Sprossproben nichtinokulierter (LK), V. longisporum (VL)- und V. dahliae (VD)-inokulierter Pflanzen im Zeitraum 14-35 dpi, pro Probe wurden 3 Pflanzen zusammengefasst, $\mathrm{n}=4$.

Messungen in Proben zu einem Zeitpunkt kurz nach der Inokulation (24 hpi, Biotest) zeigten, dass zu diesem Termin in Sprossproben V. longisporum- und V. dahliae-infizierter Pflanzen der SNO-Gehalt leicht erhöht und bei V.dahliae in den Wurzelproben stark erhöht war (Abb. 41). In Wurzelproben V. longisporum-infizierter Pflanzen ließen sich fast gar keine nitrosylierten Proteine nachweisen. Die Aktivität der GSNO-Reduktase (Abb. 41B) war nur in Wurzelproben V. longisporum-infizierter Pflanzen erhöht. 

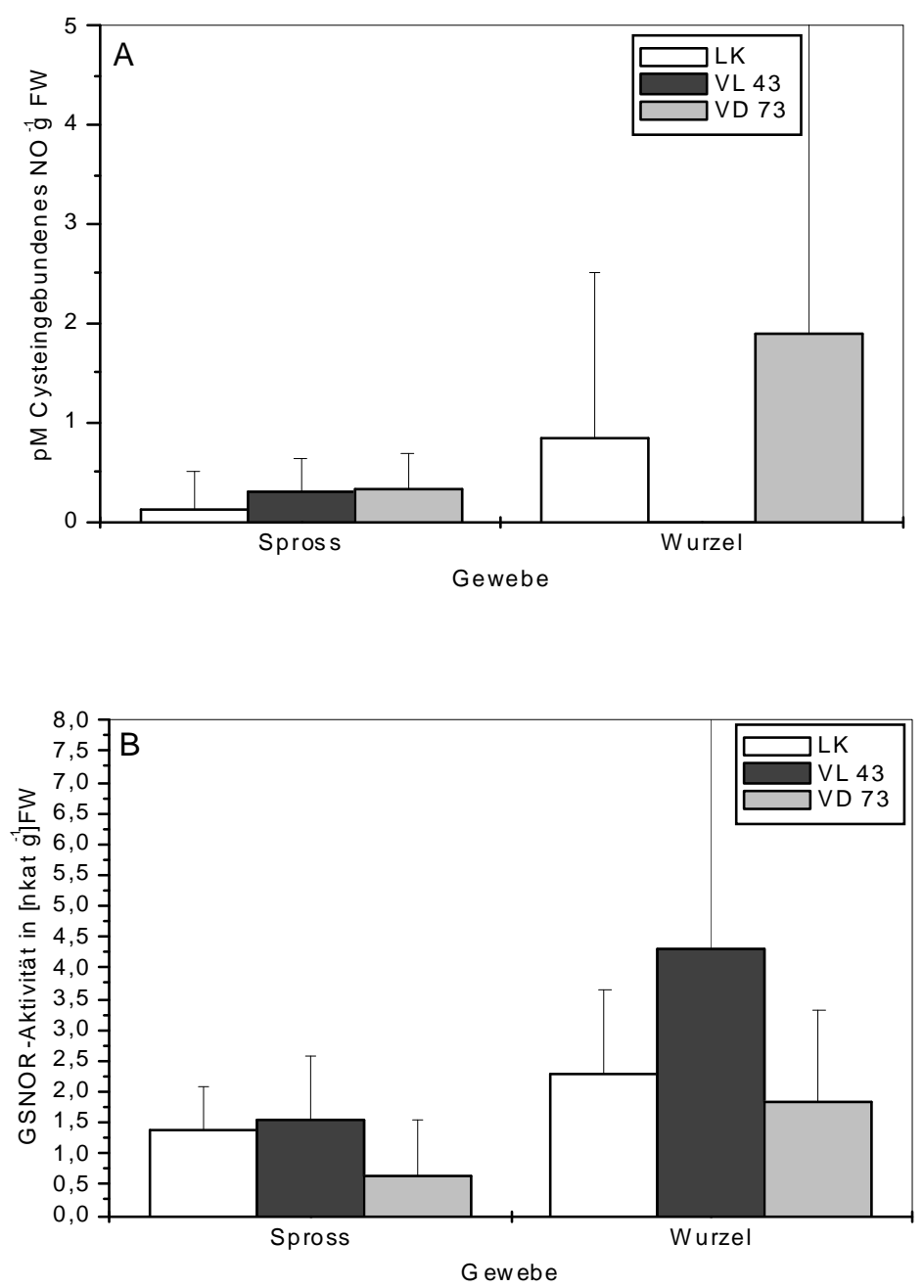

Abb. 41: A. Cysteingebundenes NO $\left[\mathrm{pM} \mathrm{mg}^{-1}\right.$ Protein $]$ und B. GSNO-Reduktaseaktivität in [nkat $\mathrm{g} \mathrm{FW}^{-1}$ ] aus Spross- und Wurzelproben V. longisporum (VL)-, V. dahliae (VD)- und nicht-inokulierter Keimlinge (LK) 24 hpi. Pro Probe wurden 30 Keimlinge zusammengefasst, $\mathrm{n}=6$; für $\mathrm{P}<0,05$ LSD-Test konnten keine signifikanten Unterschiede ermittelt werden.

\subsection{Phytohormonanalyse}

Aus der für die PCR-Analyse verwendeten Zeitreihe wurden Parallelproben für die HPLCAnalyse genommen, um den Gehalt an ABA, SA, JA und IAA zu analysieren und eine mögliche Korrelation mit NO-Gehalt, Krankheitssymptomen oder Ausbreitung des Pathogens (V. longisporum-DNA) zu untersuchen. Zu den beprobten Zeitpunkten 14 und 35 dpi konnte ein signifikant höherer ABA-Gehalt in den Sprossproben V. longisporum-infizierter Pflanzen nachgewiesen werden (Abb. 42A). In Wurzelproben zeigten die ABA-Gehalte von Kontrollund $V$. longisporum-infizierten Pflanzen prinzipiell einen parallelen Verlauf, wobei die infizierten Pflanzen ab 21 dpi aber stets einen höheren Gehalt an ABA zeigten (Abb. 42B). Die Variabilität der in den Wurzeln gemessenen ABA-Gehalte schien zum Zeitpunkt 21 dpi in 
den V. longisporum-infizierten Pflanzen sehr hoch, die Daten waren daher nicht signifikant unterschiedlich $\mathrm{zu}$ den Werten $V$. dahliae-infizierter und nicht inokulierter Pflanzen. Im Gegensatz zur V. dahliae-infizierten Variante, deren ABA-Gehalt nach 28 dpi leicht anstieg, verringerte sich das Level der V. longisporum-Variante wieder. Ab 35 dpi lagen beide inokulierten Varianten auf gleichem Niveau, gesunde Kontrollpflanzen hatten leicht niedrigere ABA-Werte.

Der Gehalt an SA war in den V. longisporum-infizierten Pflanzen, ebenso wie die ABAWerte, zu den Zeitpunkten 14 und 35 dpi im Spross signifikant erhöht (Abb 48). Ein Anstieg war auch zum Zeitpunkt 21 dpi zu verzeichnen, allerdings waren diese Werte wie auch schon bei der ABA-Analyse der Wurzelproben nicht signifikant unterschiedlich im Vergleich zur Kontrolle und V. dahliae-inokulierten Variante.Zwischen gesunden und mit V. dahliaeinfizierten Pflanzen zeigte sich über den Verlauf der Probenahme keinen Unterschied. In den Wurzelproben verliefen die SA-Werte gesunder und V. dahliae-infizierter Pflanzen parallel, wobei zu Anfang (14 dpi) die SA-Gehalte der V. dahliae-Variante noch niedriger als die der Gesundkontrolle lagen; die Werte glichen sich im Verlauf der Probenahme immer weiter an. Der SA-Gehalt in Wurzelproben V. longisporum-infizierter Pflanzen sank von 14 zu 21 dpi und stieg dann aber wieder über die Werte der Kontrolle und V. dahliae-infizierter Pflanzen an (35 dpi). Die JA-Gehalte waren in den Sprossproben der V. longisporum-Variante tendenziell niedriger als in der Kontroll- und $V$. dahliae-Variante. Eine signifikante Verminderung des JA-Levels fand zum Zeitpunkt 14 dpi statt (Abb. 44). Die Analyse der Wurzelproben wies keine signifikanten Unterschiede zwischen den einzelnen Varianten auf. Die Analyse der IAA-Daten zeigte in beiden Geweben keine signifikanten Unterschiede (Abb. 45).

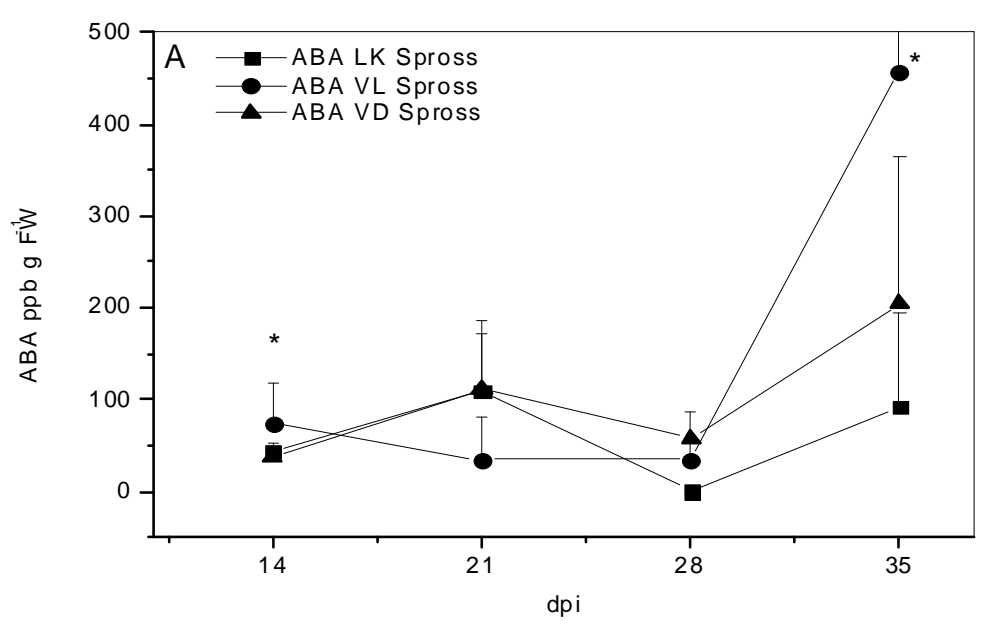




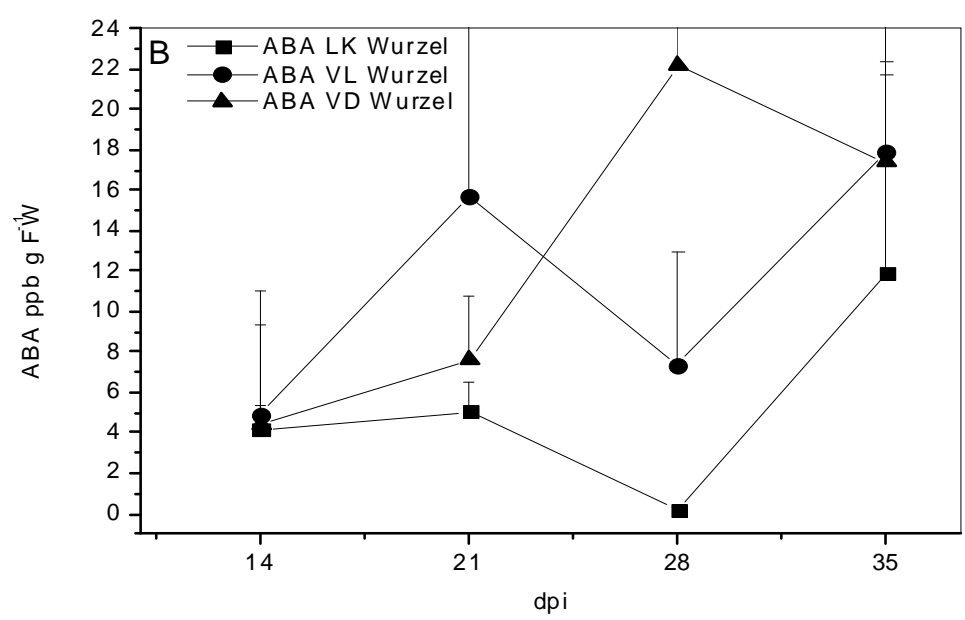

Abb. 42: ABA-Gehalte [ppb g FW ${ }^{-1}$ ] einer Zeitreihe in A. Spross- und B. Wurzelproben $V$. longisporum (VL)-, V. dahliae (VD)- und nicht-inokulierter Rapspflanzen (LK) über einen Zeitraum von 14-35 dpi, $\mathrm{n}=10$; * = signifikant unterschiedlich für $\mathrm{P}<0,05$ LSD-Test.
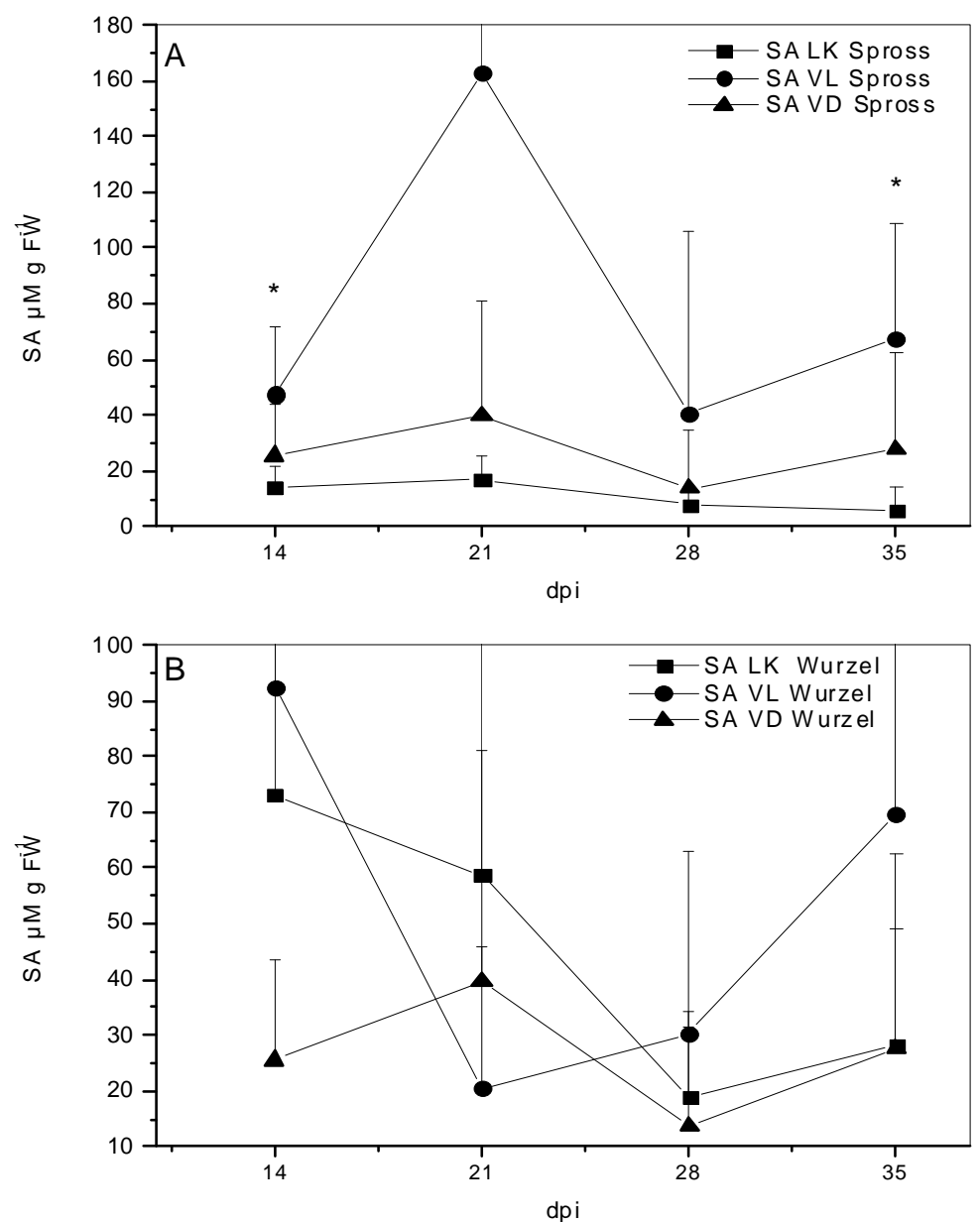

Abb. 43: SA-Gehalte $\left[\mu \mathrm{M} \mathrm{g} \mathrm{FW}^{-1}\right]$ in A. Spross- und B. Wurzelproben V. longisporum (VL)-, $V$. dahliae (VD)- und nicht-inokulierter Rapspflanzen (LK) über einen Zeitraum von 1435 dpi, $\mathrm{n}=10 ; *=$ signifikant unterschiedlich für $\mathrm{P}<0,05$ (LSD-Test). 

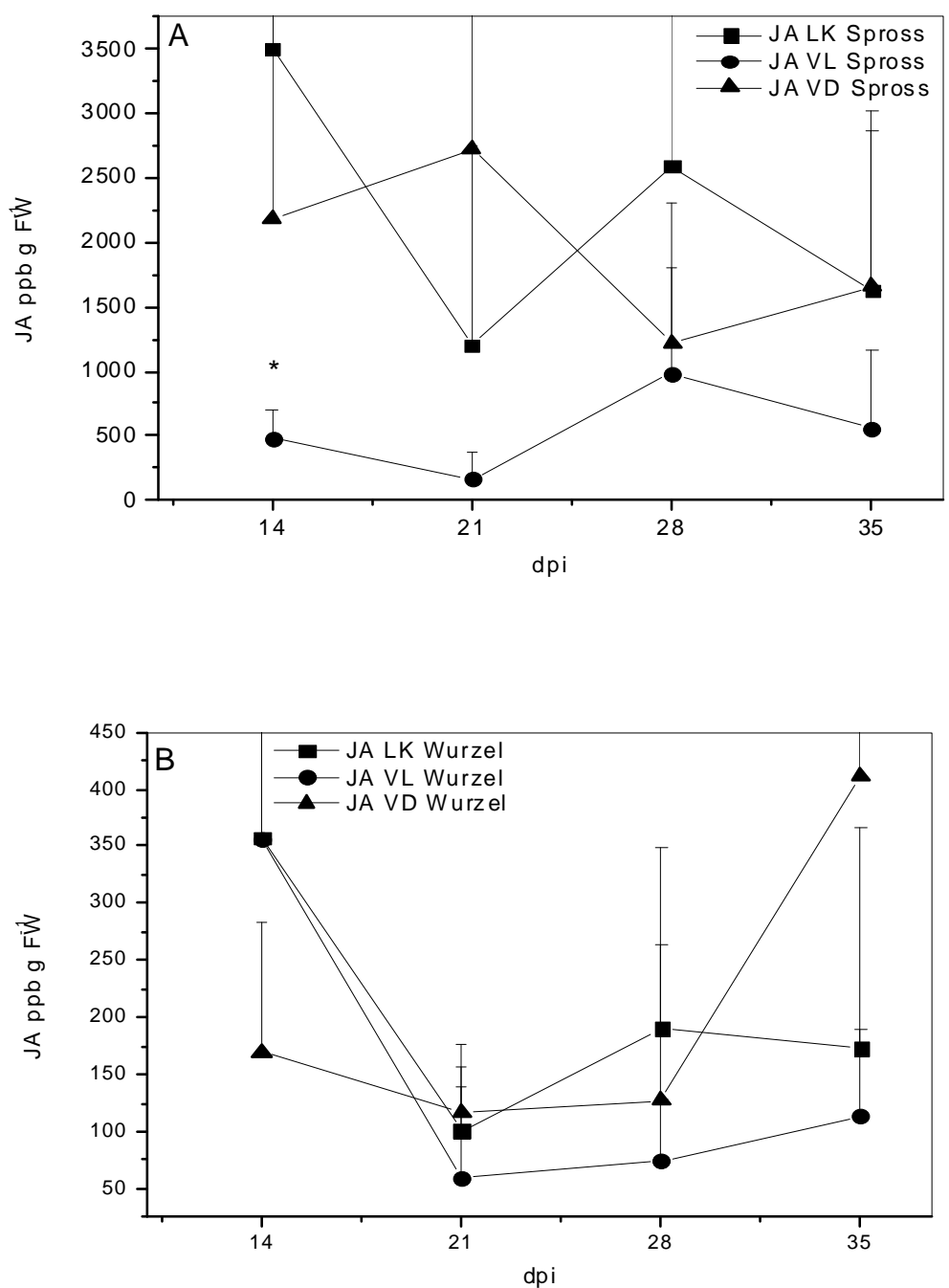

Abb. 44: JA-Gehalte [ppb g FW $\mathrm{FW}^{-1}$ ] in A. Spross- und B. Wurzelproben V. longisporum (VL)-, $V$. dahliae $(V D)$ - und nicht-inokulierter Rapspflanzen (LK) über einen Zeitraum von 14-35 dpi; $\mathrm{n}=10, *=$ signifikant unterschiedlich für $\mathrm{P}<0,05$ (LSD-Test).

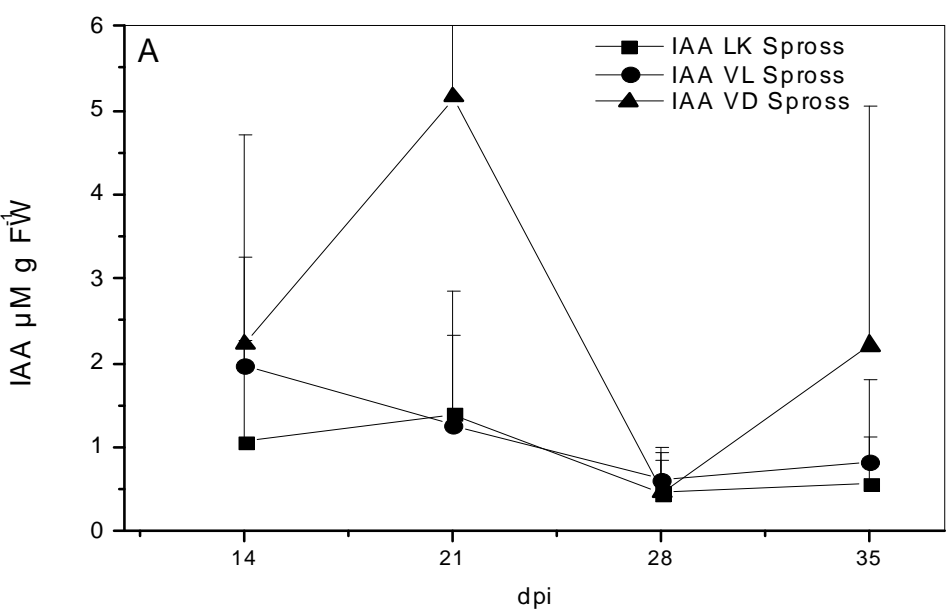




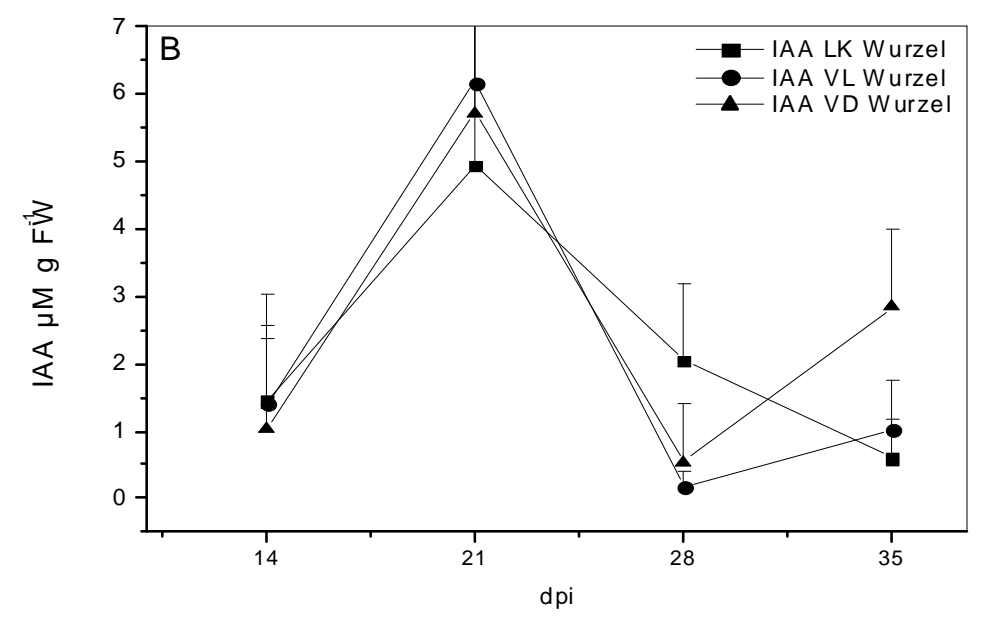

Abb. 45: IAA-Gehalte $\left[\mu \mathrm{M} \mathrm{g} \mathrm{FW}{ }^{-1}\right]$ in A. Spross- und B. Wurzelproben V. longisporum (VL), $V$. dahliae $(V D)$ - und nicht-inokulierter Rapspflanzen (LK) über einen Zeitraum von 14-35 dpi; $\mathrm{n}=10$; für $\mathrm{P}<0,05$ (LSD-Test) konnten keine signifikanten Unterschiede ermittelt werden.

\subsection{Toxizitätstest}

\subsubsection{Petiolentoxizitätstest mit CzD-Medium}

Das Auftreten und die Aktivität einer potentiell phytotoxischen Substanz, die vom Pathogen in das Kulturmedium abgegeben wird, wurde in einem in vitro-Test an abgeschnittenen Blattpetiolen überprüft. Innerhalb von $24 \mathrm{~h}$ nach der Behandlung traten keine Veränderungen wie Welke oder Vergilbung auf. Auch in 5 fach konzentrierten Filtraten konnten über den Zeitraum von $48 \mathrm{~h}$ keine klaren auf eines der beiden Pathogene zurückzuführenden phytotoxischen Effekte beobachtet werden (Abb.46). Die Zugabe der sterilen Filtrate unterschiedlicher V. longisporum- oder V. dahliae-inokulierter Medien (CzD-, SNA-, RWEund SXM-Medium) konnte ebenfalls keinen phytotoxischen Effekt an den Blättern innerhalb von $24 \mathrm{~h}$ erzeugen. Selbst die SXM-Variante, die einen Effekt im in vitro-Experiment (Kap. 3.11.3) aufwies (hier allerdings über einen längeren Wirkungszeitraum), hatte im Vergleich zu den Kontrollbehandlungen keinen Effekt (Daten nicht dargestellt). Auftretende Rotfärbungen nach $48 \mathrm{~h}$ waren sowohl in der V. longisporum-behandelten Variante als auch an Blättern der Variante, die mit nicht-inokuliertem Medium behandelt wurde, zu finden. 

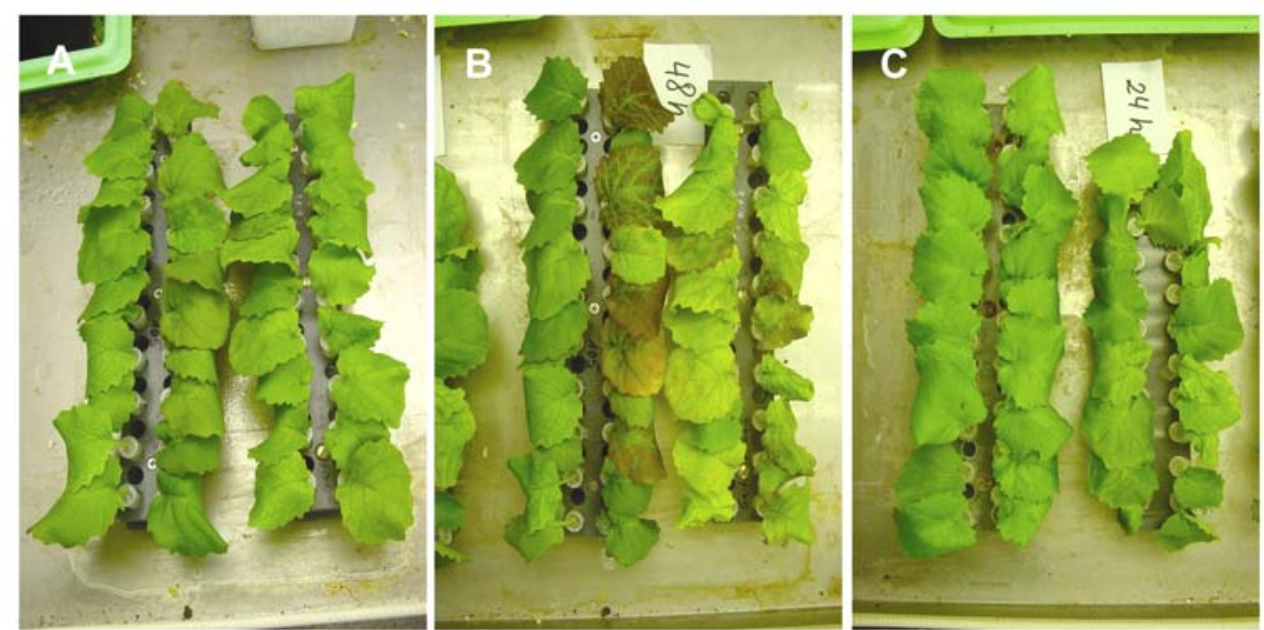

Abb. 46: Petiolentoxizitätstest; von links nach rechts angeordnet jeweils 10 Blätter 21 Tage alter RCR-Pflanzen in $\mathrm{H}_{2} \mathrm{O}$ (Kontrolle), nicht-inokuliertem CzD-Medium (K), $V$. longisporum- und V. dahliae-inokuliertem CzD-Medium; A. 1x konzentriert nach 24 h; B. 1x konzentriert nach 48 h; C. 5x konzentriert nach $24 \mathrm{~h}$.

\subsubsection{Stauchetest im Topfversuch}

In diesem Versuch wurde überprüft, ob über einen längeren Zeitraum ein Einfluss von steril filtrierten $V$. longisporum- und $V$. dahliae-inokulierten $\mathrm{CzD}$-Schüttelkulturen auf getopfte sieben Tage alte RCR-Keimlinge besteht. Die Pflanzen wurden dazu entweder mit dem Filtrat angegossen ( $5 \mathrm{ml}$ pro Pflanze) oder tauchinokuliert. Um sicherzustellen, dass unter den gewählten Bedingungen der Klimakammer eine erkennbare Stauche induziert wird, wurde eine Kontrollvariante mit der normalen unfiltrierten Sporensuspension angegossen und eine weitere Kontrolle mit der normalen Sporensuspension tauchinokuliert. Des Weiteren wurde nicht-inokuliertes CzD-Medium überprüft, um einen Effekt des reinen Mediums auszuschließen. Als Negativkontrolle diente eine Variante, in der die Pflanzen nur mit Wasser behandelt wurden. Der Einfluss auf das Pflanzenwachstum (Sprosslänge) und den Pflanzenhabitus (Boniturnote) wurde nach 28 Tagen erfaßt. Der Vergleich der Sprosslängen zeigte einen signifikanten Unterschied der V. longisporum-behandelten Pflanzen sowohl bei Anguss- als auch Tauchinokulation mit der unfiltrierten Sporensuspension (Abb. 47B). Die Tauchinokulation in dem steril filtrierten $V$. longisporum-inokulierten Medium zeigte ebenfalls einen Einfluss auf das Sprosswachstum im Vergleich zu den wasserbehandelten Kontrollen. Die Varianten, in denen das steril filtrierte Medium angegossen wurde, zeigten jedoch keinen negativen Einfluss auf das Sprosswachstum (Abb. 47B). Ein Einfluss auf die Boniturnoten konnte nur in den Varianten nachgewiesen werden, in denen die Pflanzen mit unfiltrierter Sporensuspension behandelt wurden; sowohl die Tauchinokulation- als auch die Anguss-Variante zeigte höhere Boniturwerte als die übrigen Varianten (Abb. 47A). Dennoch führte auch in den Kontrollvarianten die Applikation von steril filtriertem nicht-inokuliertem 
Medium zu reduziertem Sprosswachstum (Abb. 47B) im Vergleich zur wasserbehandelten Kontrolle. Um auszuschließen, dass der Staucheeffekt allein dem Medium zuzuschreiben ist, wurde das Experiment unter in vitro-Bedingungen mit unterschiedlichen Medien (CzD, RWE, SNA und SXM) wiederholt.

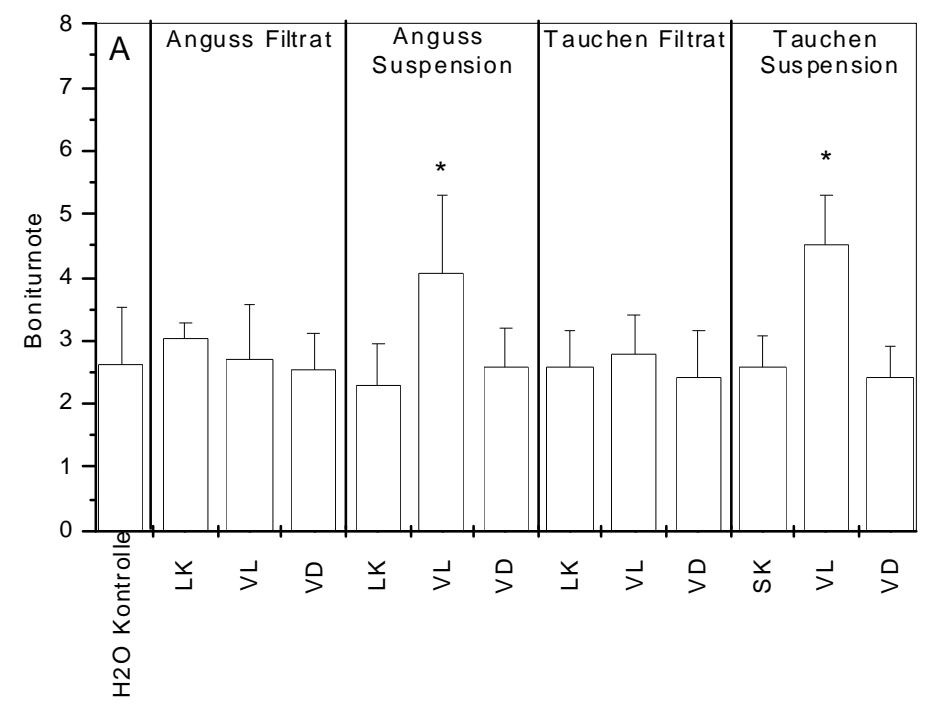

Varianten

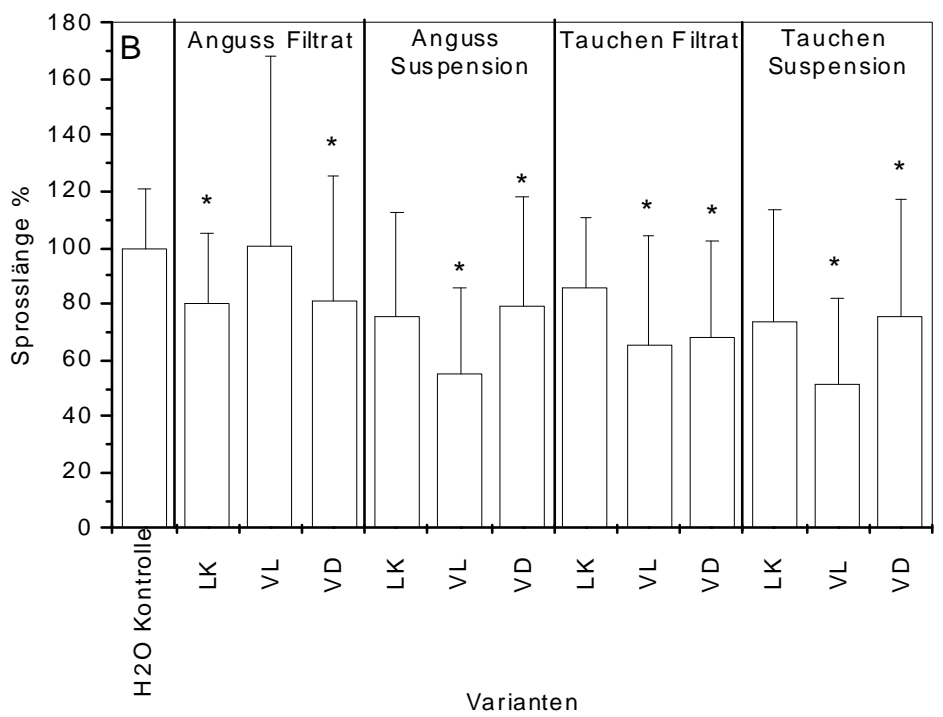

Abb. 47: Applikation steriler CzD-Kulturfiltrate im Topfversuch. A. Bonitur der Vergilbung, (Noten von 1-9 nach ZEISE, 1992) 35 Tage nach Applikation V. longisporum (VL), V. dahliae (VD)- und nicht-inokulierten Mediums (LK). B. Darstellung der entsprechenden Pflanzenlängen (\% in Bezug zur Wasserkontrolle) im selben Versuch; $\mathrm{n}=20, *=$ signifikant unterschiedlich im Vergleich zur Wasserkontrolle für $\mathrm{P}<0,05$ (LSD-Test). Zusammenfassung zweier unabhängiger Versuche. Anguss Filtrat $=$ Pflanzen wurden mit steril filtriertem Kulturüberstand angegossen, Anguss Suspension $=$ Pflanzen wurden mit Sporensuspension $1 \times 10^{6} \mathrm{Sp} / \mathrm{ml}$ angegossen, Tauchen Filtrat $=$ Pflanzen wurden mit steril filtriertem Kulturüberstand tauchinokuliert, Tauchen Suspension $=$ Pflanzen wurden in Sporensuspension $1 \times 10^{6} \mathrm{Sp} / \mathrm{ml}$ tauchinokuliert. 


\subsubsection{Stauchetest von Kulturfiltraten in vitro}

Die Applikation steriler SXM-Kulturfiltrate auf sieben Tage alte RCR-Keimlinge unter in vitro-Bedingungen führte zu einer signifikanten Reduktion der Sprosslänge (Abb. 48), der Primärwurzellänge (Abb. 49A) und der Anzahl sekundärer Wurzeln ( $\geq 2 \mathrm{~mm}$ Länge) (Abb. 49B). Kulturfiltrate der Pilze aus CzD-, RWE- und SNA-Medium zeigten keine wachstumsreduzierenden Effekte. In allen mit SNA-Filtrat behandelten Varianten war ein verstärktes Sprosswachstum im Vergleich zu den übrigen Varianten $\mathrm{zu}$ verzeichnen (Abb. 48). Die verwendeten Kontrollvarianten (Negativkontrolle $=$ Pflanzen nur mit Wasser behandelt, Positivkontrolle $=$ mit $V L 431 \times 10^{6} \mathrm{Sp} / \mathrm{ml}$ inokuliert) wiesen keinen Unterschied im Sprosswachstum (Abb. 48) und der Anzahl der gebildeten Seitenwurzeln auf (Abb. 49B). Das Wachstum der Primärwurzel war allerdings bei Pflanzen der Positivkontrolle im Vergleich mit der Negativkontrolle verringert (Abb. 49A). Filtrate der $V$. dahliae-SXM-Kultur hatten ebenfalls einen wachstumsmindernden Einfluss auf die Keimlinge (Abb. 48), allerdings keinen Effekt auf die Länge der Primärwurzel oder die Anzahl der Seitenwurzeln (Abb. 49).

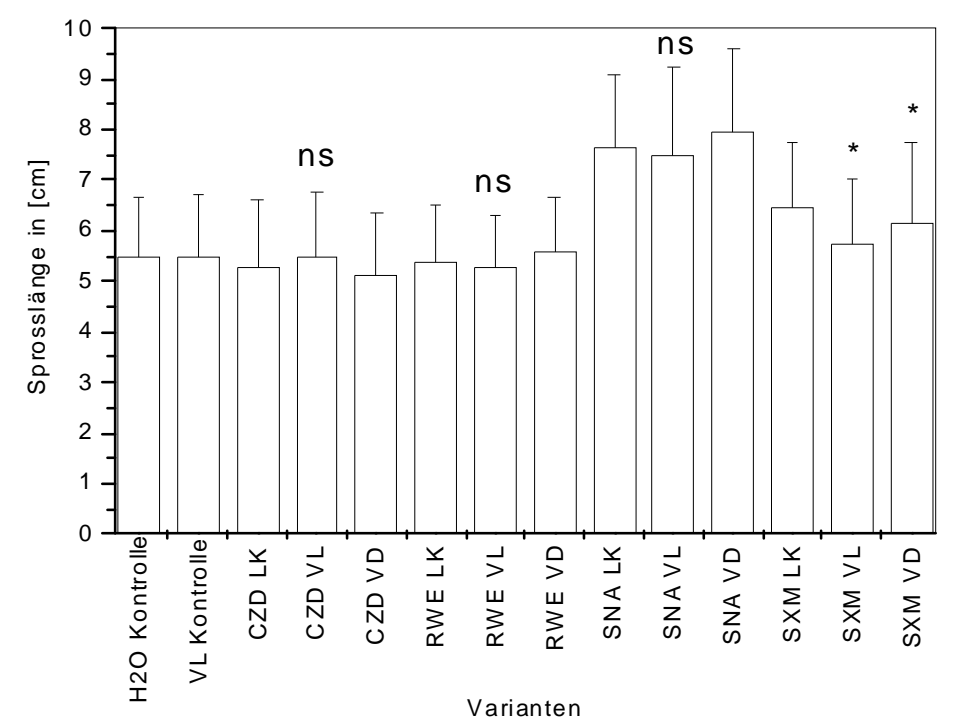

Abb. 48: Effekt steriler $V$. longisporum ( $V L)$-, V. dahliae (VD)- und nicht-inokulierter Kulturfiltrate aus unterschiedlichen Medien auf das Sprosswachstum [cm] von RCRKeimlingen in vitro nach einer Inkubationszeit von 5 Tagen. ${ }^{*}=$ signifikant unterschiedlich zur Kontrolle für $\mathrm{P}<0,05$ (LSD-Test); $\mathrm{ns}=$ nicht signifikant unterschiedlich, $\mathrm{n}=60$; Zusammenfassung dreier unabhängiger Versuche. CzD (Czapek-Dox), RWE (Rapswurzelextrakt Medium), SNA (sehr nährstoffarmes Medium), SXM (Simulierter Xylemsaft), $\mathrm{H}_{2} \mathrm{O}$-Kontrolle wurde nur mit Wasser behandelt, VL-Kontrolle nur mit Sporensuspension $1 \times 10^{6} \mathrm{Sp} / \mathrm{ml}$ inokuliert. 

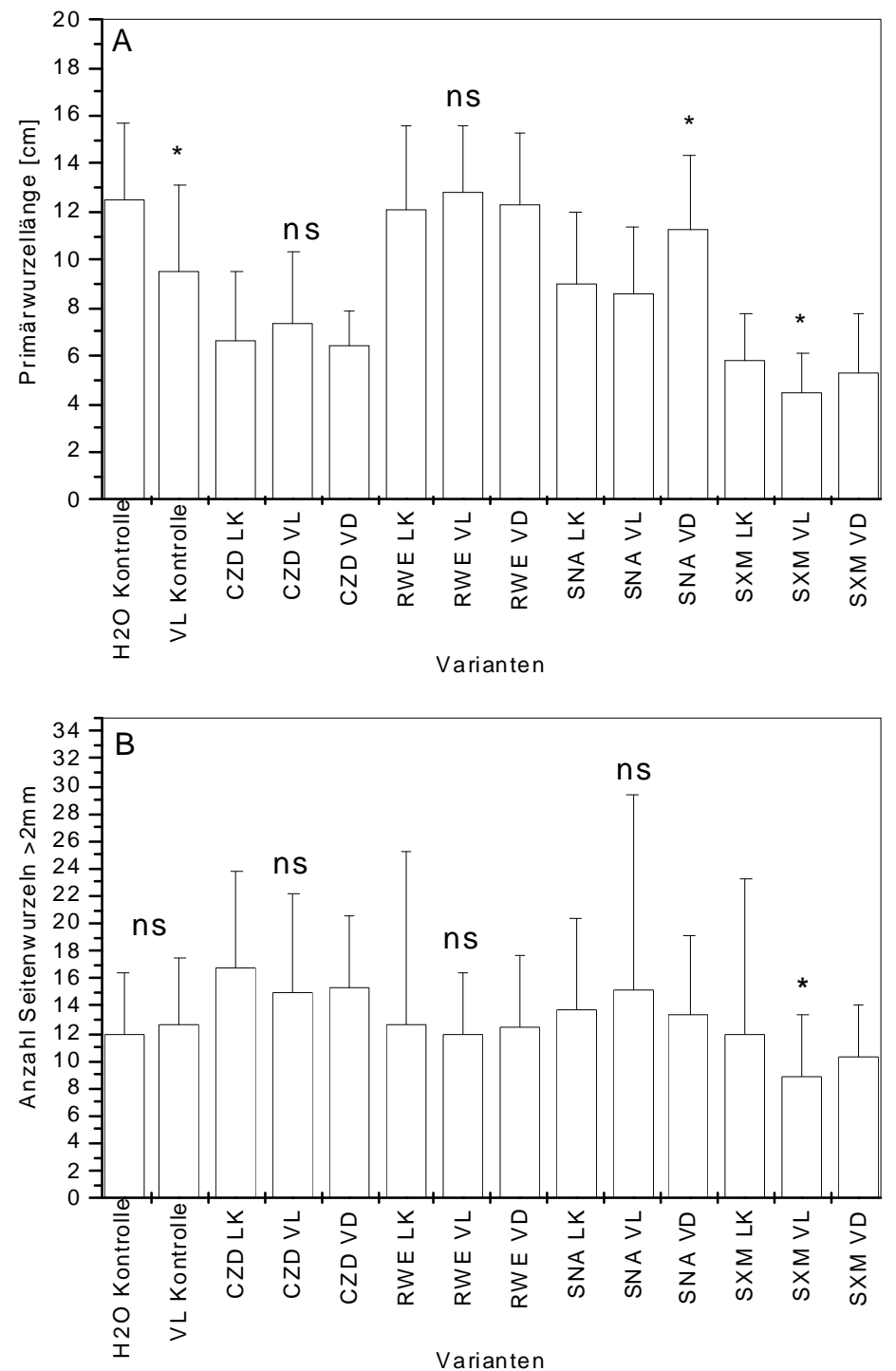

Abb. 49: Effekt steriler $V$. longisporum (VL)-, $V$. dahliae (VD)- und nicht-inokulierter Kulturfiltrate unterschiedlicher Medien in vitro auf A. die Primärwurzellänge und $\mathbf{B}$. Anzahl der Seitenwurzeln $>2 \mathrm{~mm}$ von RCR-Keimlingen nach einer Inkubationszeit von 5 Tagen. $\mathrm{n}=$ $60,{ }^{*}=$ signifikant unterschiedlich zur Kontrolle für $\mathrm{P}<0,05$ (LSD-Test), ns $=$ nicht signifikant unterschiedlich, CzD (Czapek-Dox), RWE (Rapswurzelextrakt Medium), SNA (sehr nährstoffarmes Medium), SXM (Simulierter Xylemsaft), Kontrolle $\mathrm{H}_{2} \mathrm{O}$ nur mit Wasser behandelt, Kontrolle VL43 inokuliert mit Sporensuspension 1x106 $\mathrm{Sp} / \mathrm{ml}$. Zusammenfassung dreier unabhängiger Versuche.

\subsubsection{Stauchetest membranfiltrierter SXM-Kulturfiltrate in vitro}

Durch Verwendung von Cellulosemembranfiltern unterschiedlicher Ausschlussgrößen sollte in diesem Versuch die ungefähre Molekülgröße eines potentiellen Toxizitäts- oder Stauchefaktor untersucht werden. Insgesamt wurden aus nicht-inokuliertem SXM-Medium und V. longisporum-inokuliertem SXM-Medium jeweils 3 Fraktionen mit Molekülen kleiner als 5000, 10000 und 50000 Da erhalten. Als Negativ- bzw. Positivkontrolle diente der 
unfraktionierte, nur steril filtrierte Kulturüberstand. Die Applikation der Fraktionen/Filtrate erfolgte in einem Biotest (Kap. 2.8.4.1, Variante C) und der Effekt der einzelnen Fraktionen auf die Sprosslänge und die Vergilbung wurde sieben Tage nach Inkubation des Biotest in einem Gewebekulturschrank $\left(20^{\circ} \mathrm{C}\right.$ und $16 / 8 \mathrm{~h} \mathrm{Licht/Dunkel)} \mathrm{ausgewertet.}$

Alle V. longisporum-Fraktionen und die V. longisporum-Positivkontrolle bewirkten im Vergleich zum nicht-inoklierten, fraktionierten Medium (LK < 50000 Da) Stauche (Abb. 50), wobei die Kontrollvariante, in der das steril filtrierte unfraktionierte Medium appliziert wurde, einen stärkeren Effekt hervorrief als die einzelnen Fraktionen. Der Einfluss der Fraktionen auf den Pflanzenhabitus wurde über Boniturnoten erfasst. Im Vergleich der Varianten zeigte sich deutlich, dass nur die Fraktion kleiner 5000 Da den Staucheeffekt hervorrief, ohne die Pflanze dabei zu schädigen. Die Boniturnoten waren in dieser Variante gegenüber der Kontrolle nicht erhöht (Abb. 51). Eine Wiederholung des Versuchs führte bzgl. des Sprosswachstums zu gleichen Ergebnissen. Allerdings war in diesem Versuch ein leichter Effekt der 5000er Fraktion auf bzgl. der Boniturnoten zu vermerken (s. Anhang Tab. 13).

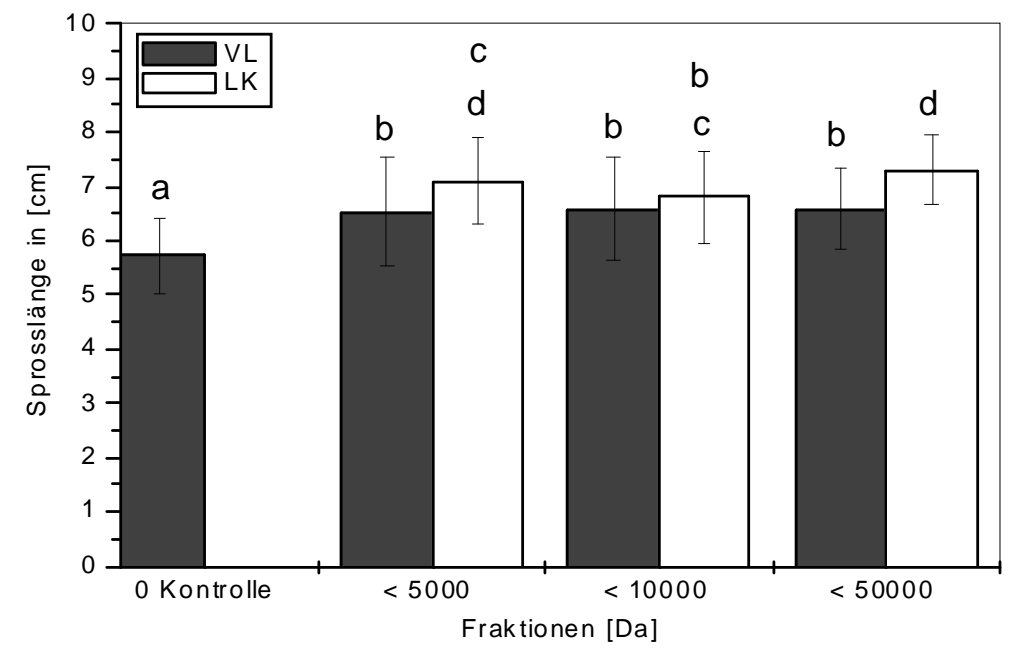

Abb. 50: Effekt membranfiltrierter Fraktionen $V$. longisporum-inokulierter $(V L)$ und nicht inokulierter (LK) SXM-Schüttelkulturen auf das Sprosswachstum [cm] von RCR-Keimlingen 7 Tage nach Applikation unter in vitro-Bedingungen; $\mathrm{n}=30, V L \quad 0$ Kontrolle $=$ Gesamtfraktion, verschiedene Indizes zeigen signifikante Unterschiede zur entsprechenden Kontrolle für $\mathrm{P}<0,05$ (Tukey-Test). 


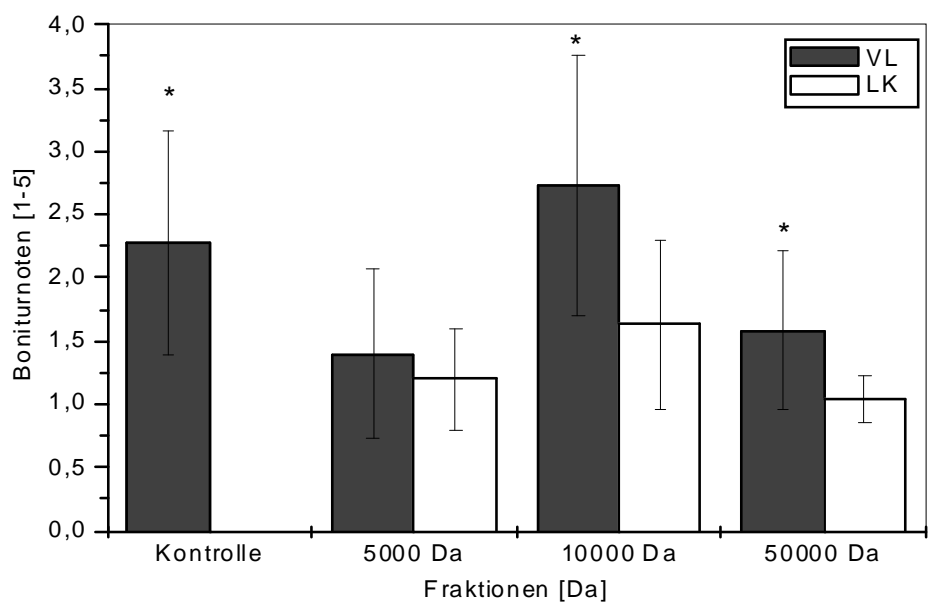

Abb. 51: Effekt membranfiltrierter Fraktionen V. longisporum (VL)- und nicht-inokulierter (LK) SXM-Schüttelkulturen auf die Boniturnote von RCR-Keimlingen sieben Tage nach Applikation unter in vitro-Bedingungen; $\mathrm{n}=30, *=$ signifikant unterschiedlich zur entsprechenden Leerkontrolle (LK) für $\mathrm{P}<0,05$ (Tukey-Test). Kontrolle = nicht fraktionierter, steril filtrierter $V L$-Kulturüberstandes (0) signifikant unterschiedlich zur 50000er LK Fraktion

\subsubsection{Stauchetest Acetonitril-fraktionierter SXM-Kulturfiltrate in vitro}

Die Fraktionierung der SXM-Kulturüberstände mit Hilfe unterschiedlicher Konzentrationen organischen Lösungsmittels sollte neben der bereits erfolgten Größeneinordnung der weiteren Charakterisierung des Stauchefaktors dienen und Aufschluss über die Polarität des gesuchten Faktors geben. Aus den ermittelten Sprosslängen ist zu erkennen, dass die Applikation der mit 10\% Acetonitril (AcN) extrahierten V. longisporum-Fraktion die Keimlinge in ihrem Sprosswachstum im Vergleich $\mathrm{zu}$ den entsprechenden Leerkontrolle- und $\mathrm{zu} V$. dahliaeFraktionen signifikant reduzierte (Abb. 52A). Die Positivkontrolle, eine nur steril filtrierte, sonst unbehandelte $V$. longisporum-Gesamtfraktion, zeigte in diesem Experiment jedoch keinen signifikanten Einfluss auf das Sprosswachstum (Abb. 52A). Die Keimlinge der mit $10 \%$ AcN extrahierten V. longisporum-Fraktion behandelten Variante waren in ihrem Wurzelwachstum im Vergleich zur Leerkontrolle- und zu $V$. dahliae ebenfalls inhibiert. Der Vergleich mit der nur mit steril filtriertem, nicht inokuliertem Medium behandelten Kontrolle (LK) wies jedoch keinen signifikanten Unterschied auf. Im Gegensatz zur Sprosslänge zeigte die Auswertung der Primärwurzellängen einen signifikanten Unterschied zwischen Kontrolle und V. longisporum (Abb. 52B). Auf die Anzahl der Seitenwurzeln $>2 \mathrm{~mm}$ konnte kein signifikanter Einfluss einer der Fraktionen ermittelt werden. Eine Reproduktion der Ergebnisse konnte trotz viermaliger Wiederholung des Versuchs nicht erbracht werden. Die Charakterisierung des Stauchefaktors über diese Methode scheint daher ungeeignet. 

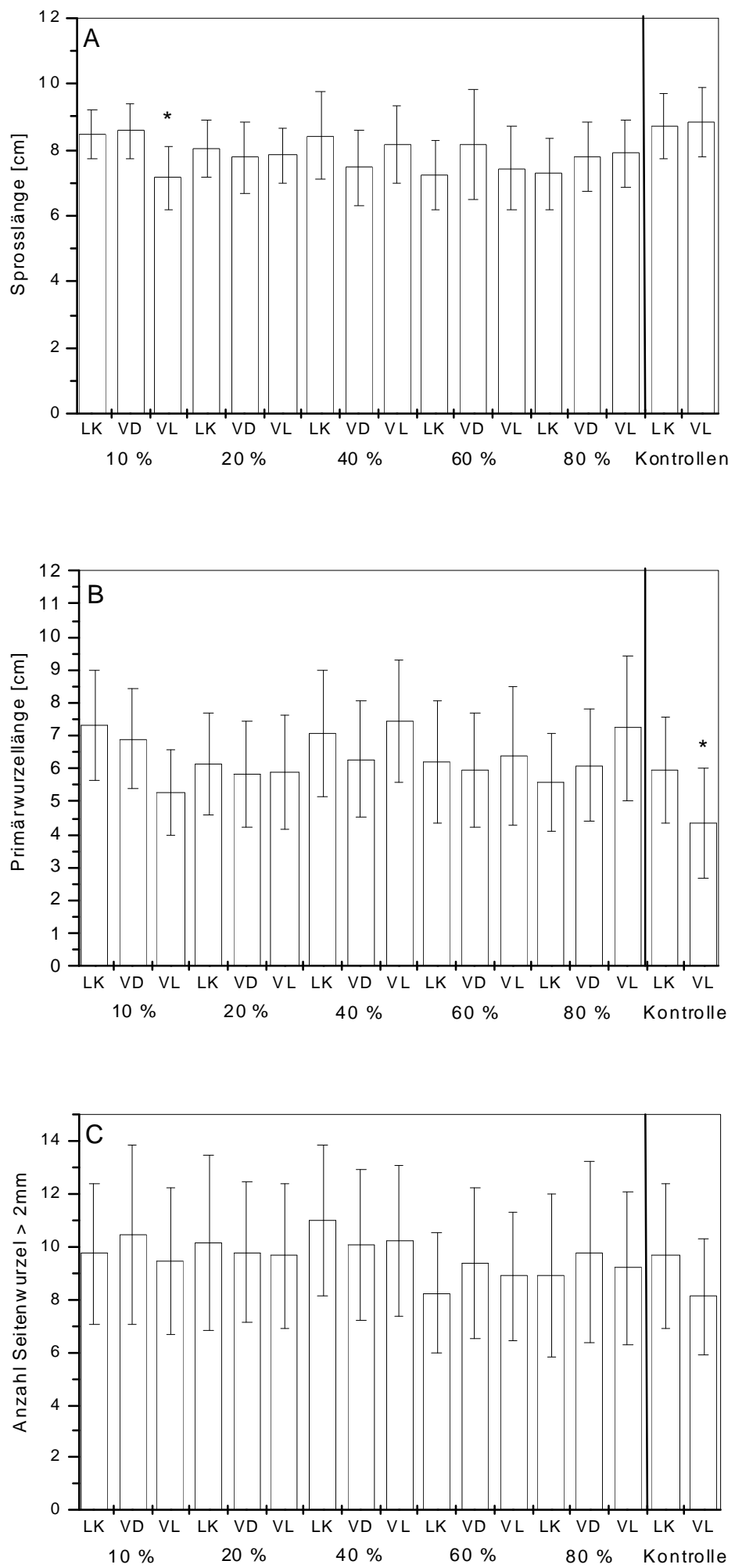

Abb. 52: Effekt der Applikation verschiedener AcN-Fraktionen (10, 20, 40, 60 und 80\%) aus $V$. longisporum (VL)- und V. dahliae (VD)-SXM-Schüttelkulturen sowie nicht-inokuliertem SXM-Medium (LK) in vitro auf sieben Tage alte RCR-Keimlinge nach sieben Tagen Inkubation. Darstellung der A. Sprosslänge $[\mathrm{cm}]$ B. Primärwurzellänge $[\mathrm{cm}]$ und C. Anzahl der Seitenwurzeln; $\mathrm{n}=30 ; *=$ signifikant unterschiedlich $\mathrm{zu}$ den entsprechenden Konzentrationsvarianten und zur Positiv- bzw. Negativkontrolle (LK, VL Kontr.) für $\mathrm{P}<0,05$ (LSD-Test). 


\section{Diskussion}

\subsection{Auswirkungen der V. longisporum- und V. dahliae-Infektion auf Vergilbung, Spross- und Wurzelwachstum von RCR}

Die Auswertung der Pflanzen bzgl. ihrer Sprosslänge, Boniturnote und Trockengewichte bestätigte vorherige Aussagen zum Effekt von V. longisporum-Befall an Brassicaceen (Zhou et al., 2006). Die Infektion von RCR mit V. longisporum führte zu einer signifikanten Reduktion der Sprosslänge (Abb.7A), zu einer Abnahme des Spross- und Wurzeltrockengewichtes (Abb. $8 \mathrm{~A} \mathrm{u.B}$ ) und $\mathrm{zu}$ einer vorzeitigen Abreife, was sich in höheren Boniturwerten ausdrückte (Abb. 7B).

Der Befall von RCR mit $V$. dahliae zeigte keine solchen Auswirkungen auf das Wachstum der inokulierten Pflanzen. Die Infektion mit $V$. dahliae hatte keinen wachstumsmindernden sondern eher einen wachstumsfördernden Effekt. Die Sprosslänge war nicht beeinflusst und das Spross- und Wurzeltrockengewicht z.T. signifikant erhöht (Abb. 7). Das ist ein weiterer Hinweis, dass B. napus keine Wirtspflanze für V. dahliae ist, wie schon in früheren Studien dargelegt wurde (ZHOU et al., 2006; EYNCK et al., 2007).

Die exemplarische Untersuchung des Hypokotyldurchmessers von $V$. longisporum-, $V$. dahliae- und nicht-inokulierten Pflanzen einer Zeitreihe (21 dpi) und des benötigten Drucks zur Extraktion von Xylemsaft zeigte, dass zwar der Hypokotyldurchmesser $V$. longisporum-infizierter Pflanzen signifikant geringer war (Abb. 9A), dadurch aber nicht mehr Druck benötigt wurde, um den Xylemsaft akropetal zu transportieren (Abb. 9B). Daraus ist $\mathrm{zu}$ schließen, dass die Wasserversorgung $V$. longisporum-infizierter Pflanzen nicht eingeschränkt war, was eine Erklärung dafür sein kann, dass verticilliuminfizierter Raps keine Welkeerscheinungen zeigt.

Dass Stauche bei Pflanzen aber durchaus eine Reaktion auf Trockenstress darstellt, konnten MePsted et al. (1995) am Beispiel der Fusarium-Welke an Ölpalmen zeigen. Die bei dieser Welkekrankheit, hervorgerufen durch Fusarium oxysporum f. sp. eaeidis auftretende Blattstauche war assoziiert mit einem milden Trockenstress. Gestauchte Blätter wiesen keine verminderte Photosyntheserate oder verminderte Transportrate auf, obwohl der Durchmesser der Xylemgefäße signifikant verringert war. Nicht gestauchte Blätter, die vor der Infektion gebildet wurden, zeigten hingegen starken, permanenten Trockenstress. Diese gestressten Blätter hatten einen hohen vaskulären Widerstand trotz minimaler Reduktion des Xylemdurchmessers und minimaler Okklusionen. MePsted et al. (1995) vermuteten daher, dass die Reduktion des Xylemgefäßduchmessers das Auftreten vaskulärer Embolien 
verringert und im Zusammenhang mit der verringerten Blattfläche eine Anpassung an den durch die Krankheit induzierten Trockenstress darstellt. Auch wenn bisherige Untersuchungen nicht darauf hindeuten, dass in $V$. longisporum-infizierten Pflanzen Trockenstress auftritt (KEUNECKE, 2005) und auch die Überprüfung des Wasserpotentials infizierter Pflanzen (Abb. 9) in diesem Versuch nicht darauf hinwies, sollten noch weitere Parameter, die auf Trockenstress hindeuten könnten (Transpirationsrate, stomatäre Leitfähigkeit u.ä.) untersucht werden, um diesen Effekt als Auslöser der Symptome definitiv ausschließen zu können.

Einen weiteren Hinweis auf das Phänomen der Stauche könnten aber auch Untersuchungen von Zimmerli et al. (2004) an A. thaliana bieten. Pflanzen, die mit dem inkompatiblen Pathogen Blumeria graminis f. sp. hordei inokuliert wurden, zeigten ein vermindertes Wachstum. Eine Mehrzahl von Genen, die bei dieser Nicht-Wirt/Pathogen-Interaktion unterdrückt wurden, erfüllten Funktionen in der Photosynthese und im allgemeinen Metabolismus. ZIMMERLI et al. (2004) vermuten daher, dass eine Verschiebung der Ressourcen von Wachstums- hin zu Abwehrfunktionen erfolgte und somit die Aktivierung der Nicht-Wirts-Resistenz signifikante metabolische Kosten verursachte. Ob eine ähnliche Situation auch in der kompatiblen Interaktion von B. napus und V. longisporum stattfindet, wäre durch Genexpressionsstudien überprüfbar.

\subsection{Ausbreitung der Pathogene in Wurzel und Spross in Bezug zur Symptombildung}

Eine Erklärung dafür, dass im Gegensatz $\mathrm{zu}$ Freilandbeobachtungen nur unter Klimakammerbedingungen das Phänomen der Stauche $\mathrm{zu}$ finden ist, könnten die standardisierten und optimierten Bedingungen sein, unter denen die Pflanzen und somit auch das Pathogen angezogen wurden. Ob diese Bedingungen das Pathogenwachstum beeinflussen und es somit $\mathrm{zu}$ einem anderen Ausbreitungsverhalten als unter Feldbedingungen kommt, sollte u.a. durch den Nachweis der Ausbreitung von Verticillium in den Pflanzen mittels RealTime PCR überprüft werden. Des Weiteren sollte so ermittelt werden, ob die Ausbreitung von $V$. longisporum mit der Symptombildung oder physiologischen Parametern (NO-Gehalt, $\mathrm{H}_{2} \mathrm{O}_{2}$-Gehalt) in Verbindung steht und verifiziert werden, ob die Inokulation der Pflanzen mit beiden Pathogenen erfolgreich war.

Während V. longisporum sich im Wurzelsystem von B. napus etablierte und mit Abreife der Wirtspflanze über das vaskuläre System in den Spross ausbreitete (deutlich ab 28 dpi), war $V$. dahliae nicht in der Lage, über das Hypokotyl hinaus den Spross zu besiedeln (Abb. $10 \mathrm{u} .11$ ). Wie schon in früheren Arbeiten mit ELISA oder PCR dargestellt 
(STEInBACH et al., 2005; Dunker \& Von Tiedemann, 2005; ZhOU et al., 2006), scheint die Ausbreitung von $V$. longisporum in den Spross von B. napus von essentieller Bedeutung für einen erfolgreichen Befall zu sein, wobei der Übergang des pflanzlichen Metabolismus in den seneszenten/generativen Status (Ausbildung der Blüte, Reifephase) offensichtlich besondere Bedeutung hat. Auch in RCR ist das Pathogen erst in dieser Phase in der Lage, sich in den oberen Teil der Pflanze durch die Gefäße in das umliegende Xylemparenchym, Stängelmark und Stängelparenchym auszubreiten, wie an dem deutlichen Anstieg des Verticillium-DNAGehaltes in Sprossproben nachzuvollziehen ist (Abb. 10 u. 11).

Für die Ausbreitung von V. dahliae in den Sprossbereich von B. napus spielt dieser Übergang in den seneszenten Status anscheinend keine Rolle. Zwar konnte der Pilz im Hypokotyl detektiert werden, eine Besiedlung des Sprosses war, unabhängig vom Alter der beprobten Pflanze, in keiner der untersuchten Proben deutlich nachweisbar (Abb. 10 u. 11). Allerdings wird durch die Besiedlung des Wurzelkörpers und des Hypokotyls auch deutlich, dass die Ausbreitung von $V$. dahliae in $B$. napus nicht durch eine Penetrationsresistenz, sondern vielmehr durch eine Ausbreitungsresistenz, die wahrscheinlich am Hypokotyl ansetzt, eingeschränkt wird. Dass gegenüber $V$. dahliae resistente Pflanzen im Wurzelbereich und auch bis zu einem gewissen Maße im Hypokotyl besiedelt werden, ist bekannt (PegG \& Brady, 2002). Ob hingegen die gleichen Mechanismen der Ausbreitungseinschränkung auch in Nicht-Wirtspflanzen wie B. napus existieren, bleibt zu untersuchen. Da zu Anfang der Arbeit davon ausgegangen wurde, dass die Ausbreitung des Pilzes möglicherweise mit der zu beobachtenden Längenreduktion zusammenhängt, wurden für die PCR-Analyse Einzelpflanzen verwendet, die anschließend für alle anderen parallelen Experimente und Untersuchungen ebenfalls als Probenmaterial dienten. Eine Korrelation zwischen Pilzmenge des Pathogens und Symptomstärke ließ sich jedoch nicht bestätigen. Laut PegG \& Brady (2002) scheint ein Zusammenhang zwischen Ausbreitung des Myzels, Konidienproduktion und Pathogenität bei Verticillium-Spezies (V.albo-atrum) eher zweifelhaft. HARRIS (1953) konnte bspw. in symptomlosen, hoch-resistenten Hopfenpflanzen eine Ausbreitung von $V$. dahliae Myzel beobachten. Andererseits zeigten andere Autoren, dass die Ausbreitung von $V$. dahliae und das Auftreten vaskulärer Verbräunungen durchaus mit der Ausbildung von Symptomen korreliert. Eine weitere mögliche Erklärung dafür, dass keine Korrelation zwischen Ausbreitung und Symptomausbildung gefunden werden konnte, könnte die hohe Variabilität der Symptomausprägung $V$. longisporum-infizierter RCRPflanzen sein. Die Ergebnisse der zweiten PCR-Analyse zeigten, dass die Besiedlung der Pflanze zwar vom Verlauf her gleich blieb, die detektierten Mengen der Verticillium-DNA im 
Vergleich zur ersten Zeitreihe allerdings stark erhöht waren. Dass keine Korrelation zwischen den untersuchten Faktoren (Phytohormongehalte, nitrosylierte Protein, u.ä.) und der Menge an Pathogen gefunden werden konnte, kann daher u.a. an der unregelmäßigen Besiedlung der Pflanzen gelegen haben. Die sehr heterogenen Daten für die Real-Time PCR könnten aber auch dadurch hervorgerufen worden sein, dass die erste bis vierte Blattetage zum Zeitpunkt 21-28 dpi bereits abgeworfen war und dabei Pilzmengen verloren gegangen sind, die eigentlich der infizierten Pflanze zugerechnet werden müssten. Zum Zeitpunkt 35 dpi war es daher nicht möglich, gleiche Blattetagen der verschiedenen Varianten auf Pathogenbefall zu untersuchen. Daher wurde, wie auch für die Phytohormonanalyse, auf Material aus Gesamtsprossproben zurückgegriffen. Dass V. longisporum sich möglicherweise zu diesen späten Zeitpunkten bereits in die Blätter ausgebreitet hat, aber aufgrund des Blattabwurfs nicht mehr in die Quantifizierung einbezogen wurde, könnte eine Erklärung für die starken Schwankungen der DNA-Gehalte infizierter Sprossproben sein.

Interessanterweise konnte entgegen den Beobachtungen in herkömmlichen Winterrapssorten (ZHOU et al., 2006; DuNKER, 2006) in RCR nur äußerst selten die Entwicklung von Mikrosklerotien nachgewiesen werden. Selbst zu 87 dpi zeigten die Stängel der Pflanzen keine für die Infektion mit $V$. longisporum sonst typischen, durch Mikrosklerotien gebildeten Schwarzfärbungen unter der Stängelepidermis oder im Stängelmark an. Einzig an Schoten und am untersten Hypokotylansatz konnten vereinzelt Mikrosklerotien gefunden werden (Abb. 12 u. 14). Da das normale vegetative Myzel bei Abreife der Pflanzen vom Hypokotyl aus degradiert und normalerweise Vermehrungs- und Überdauerungseinheiten gebildet werden, könnte auch dieser Effekt eine Erklärung für die entgegen den Erwartungen geringen DNA-Mengen im Vergleich zu bisherigen Daten aus Experimenten mit Winterraps sein. Möglicherweise machen die Mikrosklerotien, die normalerweise in Massen nach Übertreten ins parenchymatische Gewebe gebildet werden, einen Hauptteil der in Winterraps detektierten Verticillium-DANN-Mengen aus und sind für den hohen Anstieg der PCR-Werte bei Abreife im Spross verantwortlich. Des Weiteren wäre das Fehlen dieser Überdauerungsorgane eine Erklärung dafür, dass zum Zeitpunkt der Reife in infizierten Pflanzen, nachdem sie oberflächensterilisiert und auf PDA ausgelegt wurden, kein Wachstum von V. longisporum nachgewiesen werden konnte (Daten nicht dargestellt). Vermutlich war das vormals vorhandene Myzel bereits vollständig degradiert und auch keine überlebensfähigen Konidien mehr vorhanden, die ein Auswachsen von Myzel ermöglicht hätten. Weiterhin bleibt zu untersuchen, ob der Übergang von $V$. longisporum in das Sprossparenchym vom oxidativen 
Status der Pflanze abhängt (Seneszenzbeginn) oder die Ausbreitung nicht eventuell einem Nährstoffgradienten folgt.

\subsection{In vivo und in vitro Experimente zur Staucheinduktion durch NO-Donatoren}

Durch die Symptominduktionsversuche (Kap 2.6) sollte überprüft werden, ob eine Veränderung des NO-Gehaltes in RCR Stauche induzieren oder aufheben kann. Um den Gehalt an NO in den Pflanzen zu erhöhen, wurde NO in Form der chemischen Donatoren Sodiumnitroprussid (SNP) und N-Acetylpenicillamin (SNAP) appliziert. Durch Applikation des NO-Scavengers cPTIO auf $V$. longisporum-infizierte Pflanzen sollte überprüft werden, ob eine Verminderung des NO-Gehaltes eventuell die Stauche aufheben kann. In dem zuerst durchgeführten Experiment nur mit SNP, zeigten Pflanzen, die mit der niedrigsten Konzentration an SNP $(10 \mu \mathrm{M})$ behandelt wurden, ein signifikant verringertes Sprosswachstum (Daten nicht dargestellt). In nachfolgenden Experimenten, in denen SNP, SNAP und der NO-Scavenger cPTIO appliziert wurden, konnte über den gesamten Verlauf der Pflanzenentwicklung kein signifikanter Unterschied in Abhängigkeit von der Konzentration der Donatoren ermittelt werden. Die Applikation der Donatoren auf V. longisporum infizierte Pflanzen führte ebenso wenig wie die Applikation des NOScavengers cPTIO zur Verstärkung oder Aufhebung der Stauche. Eine mögliche Erklärung dafür ist eine Interaktion der Donatoren mit dem Substrat. Da die Aufnahme der Donatoren und des Scavengers in die Pflanzen zu diesem Zeitpunkt noch nicht überprüft werden konnte, ließ sich nicht nachvollziehen, ob die Pflanzen die applizierten Mengen aufgenommen haben. Die Ergebnisse wurden daher als Artefakte betrachtet und daher als Grafiken nicht dargestellt. Um mögliche Interaktionen mit dem Substrat auszuschließen, wurde der Versuch daher unter in vitro-Bedingungen wiederholt. Unter den gewählten in vitro-Bedingungen konnte bei Applikation von SNP ab Konzentrationen $>100 \mu \mathrm{M}$ eine Sprossstauche und eine verringerte Primärwurzellänge beobachtet und somit die Ergebnisse von CORREA-ARAGUNDE et al. (2004) an A. thaliana bestätigt werden (Tab. 11). Der zweite applizierte Donor, SNAP, zeigte keinen Effekt auf das Keimlingswachstum. Um einen möglichen pharmakologischen Effekt der fünf im SNP enthaltenen Cyanid-Anionen auszuschließen, die gleichzeitig mit dem NitrosoniumIon $\left(\mathrm{NO}^{+}\right)$abgegeben werden, wurde eine Eisencyanidvariante $(\mathrm{FeCN})$ mitgeführt, die allerdings keinen Effekt auf Spross und Wurzellänge zeigte. Ein Einfluss der Cyanidkomponenten im SNP kann daher ausgeschlossen werden. Eine mögliche weitere Erklärung bieten die unterschiedlichen Eigenschaften der beiden Donatoren. Die genauen 
Mengen und die Dauer der NO-Abgabe wie auch die Konzentrationen des ins Pflanzengewebe aufgenommenen NO hängen stark von der Kinetik (den chemischen Eigenschaften und Konzentrationen des Donors), der Temperatur, dem pH-Wert der Pufferlösung, der Photosensitivität und der Anwesenheit von Zielmolekülen wie z.B. Thiolen ab (FeElisch, 1991; YAmAмOTO \& Bing, 2000). Wahrscheinlich wurde das NO von den beiden verwendeten Donatoren unterschiedlich stark oder schnell abgegeben. Insgesamt lässt sich also aus dem in vitro-Experiment schließen, dass NO an der Symptombildung der Stauche beteiligt sein kann, der Effekt allerdings abhängig vom dargebrachten NO-Donor und somit wahrscheinlich pharmakologischer Natur ist.

\subsection{Effekt von NO auf das vegetative Wachstum von $V$. longisporum}

Die Produktion reaktiver Sauerstoffspezies (ROS), z.B. $\mathrm{NO}$ oder $\mathrm{O}_{2}^{-}$, kann in Pflanzen/Pathogen-Interaktionen der direkten oder indirekten Pathogenabwehr dienen. Aufgrund der Toxizität der ROS können Mikroorganismen entweder direkt abgetötet werden oder sie werden in ihrer Ausbreitung durch Auslösen der Hypersensitiven Reaktion (HR), welche in einem Programmierten Zelltod (PCD) befallener und umliegender Zellen resultieren, eingeschränkt (LAMB \& DIXON, 1997). Die Überprüfung der Auswirkung von NO auf das Wachstum von V. longisporum durch Applikation des NO-Donors SNP zeigte, dass die applizierten Konzentrationen weder eine wachstumsfördernde noch eine wachstumsreduzierende Wirkung auf das Pathogen hatten (Abb. 15). Da in diesem Experiment allerdings nur die Auswirkung auf das vegetative Myzelwachstum untersucht wurde, kann nicht ausgeschlossen werden, dass NO trotzdem einen Effekt auf eventuelle Konidienproduktion oder Keimung hat. Dass NO durchaus positiven Einfluss auf die Konidienkeimung haben kann, konnten bereits mehrere Autoren zeigen (Neurospora crassa; NinNEMANN \& MAIER, 1996; Colletotrichum coccodes, WANG \& HigGins, 2005; B. elliptica, VAN BAARLEN et al., 2004).

Auch die unterschiedlichen chemischen Eigenschaften der verwendeten NO-Donatoren können einen Einfluss auf das Pathogenwachstum nehmen. So konnten KUNERT et al. (1995) zeigen, dass Wachstum, Infektiösität, Keimung und Überlebensfähigkeit des HumanPathogen Aspergillus fumigatus durch Zugabe von $5 \mathrm{mM}$ Natrium-Nitrit oder SNAP eingeschränkt waren und nach Applikation von SNAP innerhalb von $24 \mathrm{~h} 30-50 \%$ der eingesetzten Konidien abgetötet wurden, die Applikation von GSNO die Konidienkeimung hingegen förderte. Dass NO teilweise auch von Pathogenen selbst produziert wird, wiesen CONRATH et al. (2004) nach. Durch Massenspektrometrie (MIMS/RIMS) wurde die durch 
Nitrit induzierte Produktion von NO in Phytium, Botrytis und Fusarium spp. nachgewiesen. $\mathrm{Ob} V$. longisporum selbst NO produziert, wurde anhand von 10 Tage altem CzDKulturmedium und der ESR-Analyse (mit für wässrige Lösungen geeignetem Spin-Trap MGD) überprüft (Daten nicht dargestellt). Es konnte allerdings kein NO-typisches Triplet Signal detektiert werden. V. longisporum scheint daher in Schüttelkultur und CzD-Medium kein NO zu bilden. Ob eventuell bei Konidienkeimung im Wurzelbereich der Wirtspflanzen eine Produktion von NO erfolgt könnte durch mikroskopische Studien (und unter Verwendung des NO-Fluoreszenzmarkers DAF) überprüft werden.

\subsection{NO-Nachweis im Xylemsaft}

Die Untersuchungen zur Ausbreitung des Pathogens während der Pathogenese und die gleichzeitige Dokumentation der auftretenden Krankheitssymptome infizierter RCR- Pflanzen zeigten, dass keine Korrelation zwischen der Menge an Pathogen und der Stärke der auftretenden Stauche besteht. Da die Symptome der V. longisporum-Infektion vor Ausbreitung des Pilzes in den Spross auftreten (Abb. 7, Abb. 8), wurde die Hypothese aufgestellt, dass systemische Signalmoleküle, die zu Seneszenz und Stauche im Spross führen, zu einem der Symptomausbildung vorgelagerten Zeitpunkt, gebildet werden müssen. Des Weiteren war nicht bekannt, ob diese Signalmoleküle einmalig auftreten und den weiteren Signalweg auslösen, oder als ständiges Signal in der Pflanze vorkommen. Daher sollte Xylemsaft als systemischer Transportweg der Pflanzen auf das Vorkommen möglicher Signalmoleküle $\left(\mathrm{NO}, \mathrm{H}_{2} \mathrm{O}_{2}\right)$, die bekanntermaßen Indikatoren für abiotischen und biotischen Stress darstellen und Einfluss auf die Pflanzenphysiologie haben (siehe Kap. 2.8), über den Zeitraum der Symptomentwicklung (14-35 dpi) analysiert werden.

Durch die ESR-Methode und Verwendung des für wässrige Lösungen geeigneten Spin-Traps MGD (KLESCHYOV et al., 2007) konnte in Xylemsaft das für NO typische Triplet-Signal detektiert werden. Daher scheint MGD ein geeigneter Spin-Trap für NO in Xylemsaft zu sein und bleibt auch nach Aufkonzentrierung durch Eintrocknung qualitativ stabil. Ein Beweis, dass es sich bei dem gemessenen Signal um NO handelt, konnte durch die Verringerung des Signals bei Zugabe des NO-spezifischen Inhibitors cPTIO (Abb. 21) erbracht werden. NOSignale wurden in Xylemsäften aller Varianten (V. longisporum-, V. dahliae- und nichtinokulierten Kontrollpflanzen) nachgewiesen, wobei im Laufe der Pflanzenentwicklung der Gehalt an NO generell abnahm (Abb. 22). Dass $\mathrm{Fe}^{2+}$-MGD auch in der Lage ist, gebundenes NO einzufangen, zeigten TsuchIYA et al. (2002) durch die Reaktion von MGD-Fe ${ }^{2+}$ mit GSNO und der anschließenden Bildung des NO-Fe(MGD) $)_{2}-$ Komplexes. Die aus den 
Xylemsäften erhaltenen Signale entsprechen daher wahrscheinlich dem freien NO sowie dem als GSNO oder auch als Nitrosothiol vorliegenden gebundenen NO.

Die dabei auffällige hohe Standardabweichung in den Einzelpflanzenmessungen ist wahrscheinlich auf die hohe Variabilität der einzelnen Pflanzen zurückzuführen. Schwankungen durch die benutzte Technik sind minimal (MARSH \& ANGERSTEIN, pers. Mitteilung), weshalb die Variabilität der Ergebnisse nicht auf Gerätefehler zurückzuführen ist. Eine Wiederholung des Experiments mit gepoolten Xylemsäften konnte den Trend niedrigerer NO-Gehalte in den V. longisporum-infizierten Pflanzen bestätigen (Abb. 23) und wies zudem eine geringere Standardabweichung auf. Der Abfall im NO-Gehalt wurde auch schon in seneszenten Erbsen (Pisum sativum) beobachtet, wo NO hauptsächlich in den Leitbahnen und Peroxisomen der Epidermiszellen sowie in Schwammparenchymzellen nachgewiesen wurde. Im Laufe der Pflanzenentwicklung wurde beobachtet, dass die Aktivität der in Peroxisomen vorkommenden NO-Synthase (NOS) in älteren gegenüber jüngeren Pflanzen um $72 \%$ heruntergefahren war (BARROSO et al., 1999). Eine weitere Erklärung für den Abfall des NOGehalts könnte das antagonistische Verhältnis von NO zum Reifehormon Ethylen sein, welches mit zunehmender Abreife der Pflanzen produziert wird und die Produktion von NO hemmt (LESHEM \& PINCHASOV, 2000).

Da die V. longisporum-infizierten Pflanzen eine frühzeitige Seneszenz zeigten, lässt sich vermuten, dass sowohl eine verstärkte Synthese von Ethylen als auch eine verminderte NOProduktion an der Reduktion des NO-Gehaltes beteiligt sein könnten. Die ansatzweise ermittelten Daten bzgl. der Überprüfung des Ethylenvorläufers 1-Aminocyclopropan-1Carboxylsäure (ACC) in $V$. longisporum-infizierten Pflanzen zeigten, dass zu 21 dpi ein starker Anstieg an ACC zu verzeichnen ist (siehe Anhang, Abb. 53). Dieser hohe Sprung im ACC-Gehalt ist v.a. auf zwei der fünf untersuchten Pflanzen zurückzuführen, was auch die hohe Standardabweichung erklärt. Weitere Untersuchungen bzgl. des Ethylengehaltes könnten daher die Vermutungen einer möglichen Ethylenbeteiligung stützen und eine gefestigte Aussage über den Zusammenhang mit dem Abfall an NO ermöglichen. Untersuchungen zur möglichen Rolle NO-generierender Enzyme (NR, NOS) sollten ebenfalls in nachfolgenden Experimenten überprüft werden.

Versuche von He et al. (2004) an A. thaliana konnten bspw. zeigen, dass die Applikation von SNP an Pflanzen des Wildtyps die Blüte hinauszögerte. NOX1-Mutanten von A. thaliana, die eine Überproduktion an Arginin und NO aufwiesen, blühten später als atNOS1-Mutanten, die einen geringeren Level an NO aufwiesen. Indirekt könnte daher vermutet werden, dass ein 
verringerter Gehalt an NO in $V$. longisporum-infizierten Pflanzen im Xylemsaft im Zusammenhang mit der frühzeitigen Reife bzw. Blüte steht.

Auch steht eine Reduktion an freiem NO mit dem Grad der Lignifizierung von Zellen in Zusammenhang. Unter anderem ist bekannt, dass sowohl $\mathrm{H}_{2} \mathrm{O}_{2}$ als auch $\mathrm{NO}$ an der Differenzierung der Xylemgefäße und der Zellelongation während des Gewebewachstums beteiligt sind. Insbesondere in sich ausdifferenzierenden Xylemgefäßen hat NO eine wichtige Funktion beim Aufbau (Lignifizierung) sekundärer Zellwände (BARCELÓ et al., 2002; Pedroso et al., 2000a, 2000b). Der Zusammenhang zwischen NO und dem Grad der Lignifizierung scheint dabei invers $\mathrm{zu}$ sein. Da die meisten der an der Lignifizierung beteiligten Enzyme Haem-Proteine sind, ist es wahrscheinlich, dass diese ein primäres Ziel der NO-Aktivität darstellen. Ein Anstieg nitrosylierter Proteine könnte daher eine weitere Erklärung für einen Abfall an NO darstellen. Ein Hinweis darauf könnte der Anstieg der im Sprossgewebe detektierten SNOs in V. longisporum-infizierten Pflanzen zum Zeitpunkt 21 dpi geben (Abb. 37, 43, 45).

In Pisum sativum und Zinnia elegans wurde NO vor allem im Xylem nicht aber in Kollenchymzellen, welches als Stützgewebe oftmals eng mit dem Xylem und Leitgewebe verbunden ist, detektiert (CORPAS et al., 2004b; GABALDÓN et al., 2005). Im Kollenchym von Zinnia elegans wurden eher $\mathrm{H}_{2} \mathrm{O}_{2}$ und Peroxidasen nachgewiesen, was auf deren Beteiligung an der Vernetzung von Pektinen und Hemicellulosen schließen lässt. Dadurch, dass NO die $\mathrm{H}_{2} \mathrm{O}_{2}$ verbrauchenden Enzyme Katalase und Peroxidase inhibiert (CLARK et al., 2000), könnte die Anwesenheit von NO z.B. in der gebundenen Transportform von GSNO im Kollenchym das Fortbestehen von $\mathrm{H}_{2} \mathrm{O}_{2}$ bewirken und die weitere Vernetzung und Lignifizierung benachbarter Zellen während der Zellteilung und des Elongationsprozesses ermöglichen (Ros-BARCeló, 2005; GABALdón et al., 2005). Weniger NO würde somit gleichbedeutend sein mit einer höheren Peroxidaseaktivität und einer Verringerung der Strukturfestigkeit wie auch niedrigeren $\mathrm{H}_{2} \mathrm{O}_{2}$-Gehalten. Allerdings konnte in den untersuchten B. napus-Proben keine Veränderung bzgl. des $\mathrm{H}_{2} \mathrm{O}_{2}$-Gehaltes in $V$. longisporum-infizierten Pflanzen festgestellt werden (Abb. 32-38).

$\mathrm{Ob}$ einige dieser Faktoren in V. longisporum-infizierten Pflanzen verändert sind, bleibt in Folgeexperimenten zu überprüfen und könnte durch vergleichende Analysen des LigninGehaltes sowohl zwischen infizierten und nicht-infizierten Pflanzen als auch toleranten und anfälligen Pflanzen sowie durch Analyse der GSNO-Gehalte überprüft werden. 


\subsubsection{NO-Nachweis im Gewebe}

Da eine Xylemsaftextraktion junger Keimlinge nicht möglich war, wurde an Gewebeproben untersucht, ob $\mathrm{zu}$ frühen Zeitpunkten der Pathogen-Wirt-Interaktion ( $\mathrm{ab} 30 \mathrm{~min}$ nach Inokulation) eventuell allgemeine Abwehrreaktionen in Form eines basalen unspezifischen NO-Anstiegs auftraten. Auch in diesem Versuch erfolgte die Detektion von NO mittels ESR allerdings nach einer von XU et al.(2003) erprobten Methode unter Verwendung des lipophilen Spin-Trap DETC (KLESCHYOV et al. 2007). In Gewebeproben aller drei Varianten konnte NO nachgewiesen werden . Zur Überprüfung der Eignung dieser Methode wurde ein künstlicher Anstieg des NO-Signals durch verstärkte Substratzugabe für die NO produzierende Nitrit-Reduktase induziert, indem die Keimlinge für $2 \mathrm{~h}$ im Dunkeln unter anoxischen Bedingungen $\left(\mathrm{N}_{2}\right.$-Begasung) in einer Nitritlösung $\left(200 \mu \mathrm{M} \mathrm{NO}_{2}^{-}\right.$und $200 \mu \mathrm{M}$ NADH) inkubiert und anschließend extrahiert wurden (Abb. 25). Das Auftreten des NOtypischen Triplet-Signals konnte die generelle Funktionalität dieser Methode bestätigen. Die Zeitreihenanalyse der tauchinokulierten Keimlinge erbrachte jedoch keinen mit der Inokulation in Verbindung stehenden Anstieg im NO-Gehalt; die NO-Signale traten unregelmäßig und sehr schwach auf (Daten nicht dargestellt). Dadurch, dass in allen Varianten unregelmäßige Signale detektiert wurden, kann davon ausgegangen werden, dass die Bildung von NO nicht auf einen Einfluss der Interaktion zwischen Pathogen und Pflanze zurückzuführen war. Eine möglicherweise Artefakte erzeugende Interaktion mit anderen Molekülen ist trotz der hohen Spezifität auch bei der Anwendung der ESR berichtet worden. Eine Möglichkeit stellt die Anwesenheit endogenen Kupfers dar, welches z.B. mit Eisen als Ligand für das Dithiocarbamat konkurrieren kann. Diese Konkurrenz führt dazu, dass ein Komplex gebildet wird, dessen Signal sich mit dem gesuchten NO-Signal teilweise überschneidet (XU et al. 2004). Eine zweite Artefakt bildende Reaktion kann zwischen wasserlöslichem MGD-Fe ${ }^{2+}$, und Nitrit stattfinden. Unter physiologischen pH-WertBedingungen kann MGD-Fe ${ }^{2+}$ in der Lage sein, $\mathrm{NO}_{2}^{-} \mathrm{zu} \mathrm{NO}$ zu reduzieren und so Artefakte $\mathrm{zu}$ erzeugen. Bei physiologischen Nitrit-Konzentrationen spielt diese Reaktion aber eine untergeordnete Rolle (TsuchiYA et al., 2000).

Zur Detektion von NO in Pflanzengewebe per ESR liegen relativ wenige Publikationen vor. Zwar untersuchten MATHIEU et al. (1997) den NO-Gehalt in Leguminosen-Knöllchen, die meisten anderen Publikationen beschäftigen sich jedoch mit Interaktionen von Pflanzen und inkompatiblen Pathogenen, die in einem oxidativen "burst" und somit starken Anstieg von NO resultieren. Auch in der verwendeten Methode von Xu et al. (2003) wurde die inkompatible Interaktion von Weizen (Triticum aestivum L. cv. Hanxuan 10) mit Puccinia 
striiformis CY22-2 beobachtet. Da es sich bei der Interaktion von V. longisporum und B. napus um eine kompatible Interaktion handelt und auch schon bei den Untersuchungen der Xylemsäfte keine erhöhten Gehalte an ROS zu verzeichen waren, ist es wahrscheinlich, dass weder ein „burst“ noch die basale Reaktion auf die Pathogenerkennung ausgelöst wurde, weshalb die NO-Gehalte nicht anstiegen und somit das NO-Level der Pflanzen an der Nachweisgrenze lag. Eine Art „Silencing“ der Pflanzenreaktion durch das Pathogen ist daher denkbar und würde die mit HPLC nachgewiesenen abfallenden NO-Gehalte in V. longisporum-infizierten Sprossproben 14 h nach Inokulation erklären (Abb. 22 u.Abb. 28). Ein Anstieg an ROS scheint daher nicht im Zusammenhang mit der Symptomausbildung zu stehen; eventuell hat die Verringerung der NO-Gehalte einen Einfluss auf die hormonellen Veränderungen der Pflanzen und damit die phänotypischen Veränderungen, was aber durch umfangreichere Probenanzahl statistisch bestätigt werden müsste.

\subsubsection{Nachweis von NO mit HPLC und dem Fluoreszenzfarbstoff Diaminofluorescein (DAF)}

Ergänzend $\mathrm{zu}$ den ESR-Daten sollte versucht werden, eine quantitative Methode zur Detektion von NO mittels HPLC zu etablieren. In Anlehnung an die Publikationen von ITOH et al. (2000) und RÄTHEL et al. (2003) wurde daher versucht, den NO-Nachweis mittels HPLC unter Verwendung des Fluoreszenzmarkers 4,5-Diaminofluoresccein-Diacetat (DAF2DA) auf Pflanzenproben anzuwenden. Der Nachweis von NO beruht dabei auf der Reaktion zwischen DAF-2DA und intrazellulären Esterasen, die den Fluoreszenzmarker zu DAF-2 umwandeln. Anschließend erfolgt die Reaktion zwischen DAF-2 und einem NO ${ }^{+}$-Äquivalent wie $\mathrm{N}_{2} \mathrm{O}_{2}$, das durch Autoxidation des $\mathrm{NO}$ entsteht, zu einem fluoreszierenden Triazol, dessen Fluoreszenz 180mal stärker ist als die der Ausgangssubstanz (KoJIMA et al., 1998). Die Reaktion verläuft stöchiometrisch, wodurch aus dem Signal des DAF-Triazols auf die Menge an reagiertem NO rückgeschlossen werden kann (Abb. 5). Der Einsatz von hohen Konzentrationen des Fluoreszenzmarkers erzeugte in Versuchen von RÄTHEL et al. (2003) eine starke Autofluoreszenz. Daher wurde zuerst eine Überprüfung des Fluoreszenzmarkers ohne NO-Quelle durchgeführt. Unter den gewählten Bedingungen konnte jedoch kein Autofluoreszenzpeak ermittelt werden. Zur Detektion der eher als gering eingestuften NOMengen aus RCR-Keimlingen wurde der Fluoreszenzmarker daher im Überschuss zugegeben (DAF-2DA, $100 \mu \mathrm{M}$ in $40 \mathrm{mM}$ Hepes Puffer, $\mathrm{pH}$ 7,4), um auszuschließen, dass die Menge an Fluoreszenzfarbstoff als limitierender Faktor wirkt. Da DAF-2DA zellgängig ist, wurde das Gewebe der Proben durch Mörsern in flüssigem $\mathrm{N}_{2}$ aufgeschlossen und somit intra- als auch interzelluläres NO freigesetzt. Die sofortige Aufnahme der Proben in Hepes-Puffer (40 mM, 
pH 7,4) gewährte eine stabile Umgebung für den Fluoreszenzmarker und verhinderte gleichzeitig die artifizielle nicht-enzymatische Produktion von NO aus Nitrit, die unter sauren pH-Bedingungen im pflanzlichen Apoplasten stattfinden kann (BETHKE et al., 2004). Unter in vitro-Bedingungen sind Nebenreaktionen des Fluoreszenzmarkers DAF-FM bspw. mit 0,5 $\mu \mathrm{M}$ Nitrit bekannt, die jedoch laut VITECEK et al. (2008) erst ab pH Werten unter 2,5 bei höheren Konzentrationen von $100 \mu \mathrm{M}$ Nitrit auch in ungepuffertem Wasser (pH von 5,6) stattfinden und das Fluoreszenzsignal linear ansteigen lassen.

Da die Proben gründlich zentrifugiert und ohne das Pellet aus PVPP und Pflanzenresten zu zerstören aufgenommen wurden, kann eine Reaktion zwischen Farbstoff und eventuell noch vorhandenen PVPP oder Pflanzenresten als gering eingestuft werden. Zusätzliches Filtrieren der Proben durch sterile Aufsatzfilter $(0,2 \mu \mathrm{m})$, um eventuelle PVPP- und Pflanzenreste abzufangen, brachte daher auch keine Verbesserung der Ergebnisse (Daten nicht dargestellt). Weitere Nebenreaktionen des Fluoreszenzmarkers könnten laut ZHANGet al. (2002) mit Dehydroascorbat oder Ascorbat stattfinden. Daher wurden die Proben der Pflanzenextrakte mit dem NO-Scavenger cPTIO $(10 \mathrm{mM})$ inkubiert und überprüft, ob sich der DAF-Triazol Peak tatsächlich verringert. Eine solche Reduktion des Peaks konnte bestätigt und somit der Peak als eindeutiges Reaktionsprodukt von NO und Fluoreszenzmarker identifiziert werden. Diese Beobachtung ist allerdings kritisch zu betrachten, da die Unterdrückung des NOSignals erst bei relativ hohen Konzentrationen cPTIO $(10 \mathrm{mM})$ stattfand und geringe Konzentrationen cPTIO $(100 \mu \mathrm{M})$ bei Reaktion mit dem Standard MAHMA NONOate $(100 \mu \mathrm{M}) \mathrm{zu}$ einer umgekehrten bereits von VITECEK et al. (2008) beobachteten Reaktion führten. Das Signal des Triazol-Peaks stieg an. Dies ist laut VITECEK et al. (2008) darauf zurückzuführen, dass geringe Konzentrationen 5-100 $\mu \mathrm{M}$ cPTIO die Reaktion zwischen Fluoreszenzmarker und NO innerhalb von Minuten vervollständigen und somit das Fluoreszenzsignal zuerst verstärken. Erst mit zunehmenden Konzentrationen von cPTIO wird das Fluoreszenzsignal anschließend maskiert und dadurch verringert; $100 \mu \mathrm{M}$ absorbierten bspw. $18 \%$ der Fluoreszenz (VITECEK et al. 2008).

Der Nachweis des NO-Peaks aus Gewebeproben des RCR wie auch aus A. thaliana oder Gerste (Daten nicht dargestellt) konnte unter den gewählten Bedingungen erbracht werden. Sieben Tage alte RCRKeimlinge, die mit $2 \mathrm{ml}$ sterilem Leitungswasser behandelt und auf Wasseragar ausgelegt wurden, wiesen nach $14 \mathrm{~h}$ Inkubation in einem Gewebekulturschrank (Fa. Mytron, Heiligenstadt) bei $20^{\circ} \mathrm{C}$ und $16 / 8 \mathrm{~h}$ Licht/Dunkelrythmus einen NO-Gehalt im Spross von etwa $6 \mathrm{nmol} \mathrm{ml}^{-1} \mathrm{~g} \mathrm{FW}^{-1}$ und in der Wurzel von ca. 1-2 $\mathrm{nmol} \mathrm{ml}^{-1} \mathrm{gFW}^{-1}$ auf. Im Gegensatz dazu zeigten Keimlinge, die mit $2 \mathrm{ml}$ einer $V$. longisporum-Sporensuspension 
behandelt wurden, einen verringerten Gehalt an NO im Spross. Der NO-Gehalt im Wurzelgewebe lag auf vergleichbarer Höhe wie bei der Kontrollvariante. Damit konnten die bisherigen Ergebnisse, die eine Reduktion bzw. ein „Silencing“ der ROS-Produktion vermuten ließen, bestätigt werden. Die Interaktion zwischen $V$. longisporum und B. napus führt zu einer Verringerung des NO-Gehaltes im Sprossgewebe von Beginn der Interaktion bis zu Zeitpunkten der Symptomausprägung.

Das Detektionslimit der Methode im nanomolaren Bereich liegt zwar niedriger als das des Chemilumineszenznachweises (Rockel et al., 2002; TISCHNER et al., 2004) oder der Photoakustischen Laser-Spektroskopie (Leshem \& Pinchasov, 2000; MuR et al., 2005b), die NO in picomolaren Konzentrationen nachweisen können, bietet aber die Möglichkeit intrazelluläres (zellaktives) NO quantitativ darzustellen, wenn Nebenreaktionen minimiert und die Proben bestmöglich aufgereinigt werden. Die Detektion ausgasenden NOs wie im Chemilumineszenznachweis bietet den Vorteil, dass Nebenreaktionen des NO mit Puffern oder Zellbestandteilen, die bei Extraktionen von Geweben Verwendung finden, umgangen werden. Daher ist zu erwarten, dass die Detektion von NO aus Gewebe und Zellen eine geringere Sensitivität aufweist. Des Weiteren ist NO nicht gut wasserlöslich und daher die schnelle Reaktion zwischen Fluoreszenzfarbstoff und NO limitierend. Fluoreszenzfarbstoffe mit einer schnelleren Reaktionszeit würden wahrscheinlich die Ausbeute verbessern. Ebenfalls scheint die Ausbeute der Fluoreszenz abhängig von der Konzentration und Art des jeweils verwendeten Puffers zu sein. So konnten VITECEK et al. (2008) zeigen, dass unter in vitro-Bedingungen das NO-Signal des Fluoreszenzmarkers DAF-FM sowohl vom gewählten $\mathrm{pH}-$ Wert als auch von der Pufferkonzentration abhängt. Zwischen $\mathrm{pH}$ 5,5 bis 9 konnte eine Abnahme des Fluoreszenzsignals beobachtet werden, wobei dieser Effekt verstärkt überhalb pH 7 stattfand. Eine Verstärkung des Signals fand ebenfalls statt, wenn ein 2-(Nmorpholino)ethanesulfonate (MES)-Puffer ( $\mathrm{pH}$ 5,8) anstatt eines 3-(Nmorpholino)propanesulfonate (MOPS)- oder Phosphat-Puffers ( $\mathrm{pH} 7,0)$ verwendet wurde. Die Überprüfung verschiedener Puffer und deren pH-Werte und Konzentrationen könnte daher die Ausbeute des Fluoreszenzsignals verbessern und somit das Detektionslimit weiter herabsetzen.

Nachteilig ist, dass für das System Verticillium/B. napus nicht auf Zellkulturen zurückgegriffen werden kann, die ein deutlich homogeneres Probenmaterial liefern und auch weniger störende Zellstrukturbestandteile mit sich bringen würden. Des Weiteren liegen anders als für Arbeiten mit A. thaliana keine Mutanten vor, die in ihrer NO-Synthese gehemmt sind oder NO überproduzieren und somit als Negativ- oder Positivkontrolle dienen 
könnten. Die Induktion eines NO-Anstiegs in Winterrapspetiolen durch verstärkte Substratzugabe der Nitrat-Reduktase $\left(200 \mu \mathrm{M} \mathrm{NaNO}_{2}^{-}\right.$und $\left.200 \mu \mathrm{M} \mathrm{NADH}\right)$ führte nur zu einem leichten Anstieg im NO-Gehalt. Da diese Induktion bisher hauptsächlich an ausgasendem NO gemessen wurde (Chemilumineszenzmethode), könnte eine Erklärung für den eher geringen Anstieg sein, dass das Zelllevel für NO abgesättigt war, überschüssiges NO gleich ausgaste und somit ein Unterschied im Gewebe durch die verwendete Methode nicht deutlich detektierbar war.

\subsubsection{Nachweis von $\mathrm{H}_{2} \mathrm{O}_{2}$ in Gewebeproben und mögliche Erklärungen zum Ausbleiben eines ROS-Anstiegs}

Die Rolle von $\mathrm{H}_{2} \mathrm{O}_{2}$ in der Xylemdifferenzierung und der Seneszenz wurde schon mehrfach untersucht. In Zinnea elegans sind ein schneller Anstieg und ein fast ebenso schneller Abfall des $\mathrm{H}_{2} \mathrm{O}_{2}$-Levels ein charakteristisches Merkmal der Xylemgefäßausbildung und der Lignifizierung. Das produzierte $\mathrm{H}_{2} \mathrm{O}_{2}$ wird von Xylem-spezifischen Peroxidasen verwertet, die dadurch die Polymerisation von p-Hydroxycinnamyl Alkohol zu Lignin durchführen (Ros-BARCELÓ, 2005). Auch andere ROS scheinen eine essentielle Rolle in der Elongation der Spross- und Wurzelzellen zu spielen. Wurzelwachstum in Mais benötigt beispielsweise die Auflockerung der Zellwandstrukturen durch $\mathrm{OH}^{-}$(ein Peroxidase Produkt aus $\mathrm{O}_{2}^{-}$und $\mathrm{H}_{2} \mathrm{O}_{2}$ ) (LISKAY et al., 2004). Die Analyse von $\mathrm{H}_{2} \mathrm{O}_{2}$ in der Interaktion zwischen $V$. longisporum und B. napus erfolgte über einen detaillierten Zeitraum von 1,5 h bis $96 \mathrm{~h}$ nach Inokulation in Spross- und Wurzelproben gepoolter Keimlinge sowie über den Zeitraum 14 dpi bis 35 dpi in Spross-, Hypokotyl- und Wurzelproben aus Einzelpflanzen photometrisch unter Verwendung der Titan-Oxalat-Methode.

In allen Varianten, sowohl den Keimlingen (1,5 hpi bis 96 hpi) als auch den adulten Pflanzen (14-35 dpi), konnte $\mathrm{H}_{2} \mathrm{O}_{2}$ mit der gewählten Titan-Oxalat-Methode bestimmt werden. Allerdings konnte zwischen den infizierten und nicht infizierten Varianten weder ein Unterschied im Wurzel- noch im Sprossgewebe der Pflanzen ermittelt werden (Abb. 32-34). Keimlingswurzeln, die $24 \mathrm{~h}$ in dem verwendeten Biotest auf $V$. longisporum oder $V$. dahliae vorinokulierten Wasseragarplatten inkubiert wurden, zeigten nach Anfärbung mit Säurefuchsin (EYNCK et al., 2007) eine deutliche Besiedlung der Wurzeloberfläche mit Hyphen und Mikrosklerotien (Abb. 29 u.Abb. 30). Ein Kontakt zwischen Pathogenen und Keimlingen war also $\mathrm{zu}$ den untersuchten Zeitpunkten vorhanden. Inwiefern die nicht auftretende Induktion eines basalen $\mathrm{H}_{2} \mathrm{O}_{2}$-Anstiegs auf einer möglichen Organspezifität der Hypersensitiven Reaktion beruht, ist offen. V. longisporum könnte auch in der Lage sein, mit 
bisher unbekannten Mechanismen einen solchen oxidativen Abwehrmechanismus zu unterdrücken oder zu kompensieren. Möglicherweise ist aber auch die Pflanze nicht in der Lage das Pathogen als solches zu erkennen und effektiv abzuwehren.

In Reispflanzen ist $\mathrm{H}_{2} \mathrm{O}_{2}$ an der Lipid-Peroxidation beteiligt, die dafür notwendig zu sein scheint, in den seneszenten Status der Pflanzenentwicklung überzugehen und die Blattseneszenz zu starten (LesheM \& Pinchasov, 2000; Lin \& KAO, 1998). Eventuell ist der $\mathrm{H}_{2} \mathrm{O}_{2}$ Anstieg zu 28 dpi in Spross und Hypokotylproben V. longisporum-infizierter Pflanzen (Abb. 34) damit zu erklären. Durch die Bildung der ROS wird dem Pathogen der Übergang der Pflanze in ein seneszentes Stadium übermittelt und dadurch die Ausbreitung in den Spross induziert.

Im Zusammenhang mit der Verstärkung und Elongation von Zellwänden durch $\mathrm{NO}$ und $\mathrm{H}_{2} \mathrm{O}_{2}$ steht auch die Bildung von Papillen als Abwehrmechanismus biotropher Blattpathogene. Diese lokal auftretenden Zellwandauflagerungen werden $a v r / R-G e n$ unabhängig induziert und dienen der Penetrationsresistenz. Papillen enthalten Callose, Proteine und phenolische Komponenten. Die Bildung benötigt ebenfalls oxidatives Verlinken von Zellwandproteinen durch die lokale Produktion von $\mathrm{H}_{2} \mathrm{O}_{2}$. PRATs et al. (2005) konnten zeigen, dass ein signifikanter Anstieg von NO mit der Bildung von Papillen assoziiert war, der noch vor der Akkumulation autofluoreszierender Phenole auftrat und damit frühzeitiger auftrat als $\mathrm{H}_{2} \mathrm{O}_{2}$ (THORDAL-Christensen et al., 1997). Die Unterdrückung dieser NO-Produktion führte zu einer erhöhten Penetrationsrate und erhöhte die Anfälligkeit der Pflanze gegenüber Pathogenbefall (PRATs et al., 2005). Bei der Infektion herkömmlicher Winterrapssorten mit V. longisporum konnte weder eine Papillenbildung beobachtet werden, noch scheint im Wurzelsystem eine Penetrationsresistenz vorhanden zu sein. Der Pilz kann ohne Probleme die Wurzelzellen besiedeln (EYNCK et al., 2007). Eventuell hängt die Etablierung des Pilzes in der Pflanze daher mit der verminderten Bildung stabilisierender Substanzen bzw. der verminderten Verstärkung der Zellwände durch niedrigere $\mathrm{NO}$ - und $\mathrm{H}_{2} \mathrm{O}_{2}$-Gehalte zusammen. $\mathrm{Ob}$ eventuell im Hypokotyl resistenter Rapsvarietäten im Zusammenhang mit NO und $\mathrm{H}_{2} \mathrm{O}_{2}$ verstärkte Thyllenbildung, verstärkte Bildung phenolischer Komponenten und Lignifizierung auftreten oder durch NO Zugabe induzierbar wären und somit eine Ausbreitungsresistenz etabliert werden könnte, müsste im Vergleich von resistenten und anfälligen Pflanzengenotypen überprüft werden. 


\subsubsection{Organspezifität}

Eine wichtige zu klärende Frage ist die nach einer möglichen Organspezifität der o.a. Resistenzreaktionen. HERMANNS et al. (2003) konnten mit Untersuchungen an A. thaliana und Hyaloperonospora parasitica beobachten, dass $H$. parasitica-Oosporen von befallenen A. thaliana-Wurzeln oftmals avirulent waren, wenn versucht wurde, Keimblätter zu inokulieren. A. thaliana-Blätter, die mit einem inkompatiblen Stamm von $H$. parasitica inokuliert wurden, zeigten innerhalb von $24 \mathrm{~h}$ eine HR-Reaktion. Im Gegensatz dazu bildete das Pathogen interzelluläre Hyphen und Haustorien, wie sie auch in der kompatiblen Reaktion gebildet werden, wenn die Infektion im Wurzelraum stattfand. Darüber hinaus konnte im Wurzelraum selbst nach 72 hpi keine HR-Reaktion beobachtet werden. Interessanterweise wurden sowohl bei Inokulation der Blätter als auch der Wurzeln, also mit HR- als auch ohne HR-Reaktion, Resistenzgene und einige Komponenten des zur Resistenz führenden Signalweges in der Wurzel in beiden Reaktionen aktiviert. Resistenzmechanismen wurden in diesem Pathosystem also offensichtlich organspezifisch ausgeprägt. Der Anstieg der $\mathrm{H}_{2} \mathrm{O}_{2}$ Gehalte in Hypokotyl und Spross zum Zeitpunkt 28 dpi (Abb. 33 u.38) und das gleichzeitige Ausbreiten des Pilzes in diese Gewebebereiche (Abb. 10 u.11) könnte für eine organspezifische Reaktion von B. napus sprechen.

\subsubsection{Pathogenspezifische Reaktion}

Ähnlich wie V. longisporum besiedeln die Welke induzierenden Stämme von Fusarium oxysporum ihre Wirtspflanzen über die Wurzeln und breiten sich durch das vaskuläre System der Pflanze aus, wodurch sie Vergilbung, Welke und letztendlich das Absterben der Pflanze verursachen. Insofern eignet sich dieses System zum Vergleich der spezifischen Abwehrreaktionen der Wirtspflanze mit der in dieser Arbeit untersuchten Interaktion von V. longisporum/B. napus.

Pathogene und nicht-pathogene Fusarium-Stämme können die Wurzeln penetrieren und lösen pflanzliche Abwehrreaktionen aus (OlivaIN \& AlABOUVETTE, 1999). In einem Vergleich eines pathogenen (Foln3) und nicht-pathogenen Stammes (Fo47) von F. oxysporum an Flachswurzeln und Zellkulturen konnte gezeigt werden, dass beide Stämme die äußere Cortexschicht besiedelten. Pflanzenabwehrreaktionen, Zellwandauflagerungen und kollabierte Zellen waren allerdings weniger ausgeprägt in Wurzeln, die durch den pathogenen Stamm besiedelt wurden. Beide Stämme lösten eine vorübergehende $\mathrm{H}_{2} \mathrm{O}_{2}$-Produktion in den ersten Minuten der Interaktion aus, wobei der nicht-pathogene Stamm noch einen weiteren Anstieg 
drei Stunden nach Inokulation hervorrief. Der initiale „,burst“ trat in der Reaktion auf nichtpathogene Stämme früher und intensiver auf als bei pathogenen Stämmen, was darauf hinweist, dass eine spezifische Reaktion der Pflanze auf den jeweiligen Pilz erfolgt (OLIVAIN et al. 2003).

Da das Wurzelsystem also generell in der Lage ist, auf die Besiedlung mit einem nichtPathogen mit einer $\mathrm{HR}$ zu reagieren, scheint es eher eine Frage der spezifischen Pathogenerkennung als der Organspezifität zu sein, wenn eine Wirtspflanze diese Reaktion nicht zeigt. OLIVAIN et al. (2003) konnten deutlich zeigen, dass Wurzelzellen, die mit dem nicht-pathogenen Stamm Fo47 infiziert waren, degradierte pilzliche Hyphen beinhalteten und deutliche Abwehrreaktionen wie Zellwandauflagerungen dort zeigten, wo Zellwände in Kontakt mit Hyphen traten und auch Papillen ausbildeten. Die Wurzeloberflächen von Pflanzen, die mit dem pathogenen Stamm Foln3 infiziert waren, zeigten eine ebenso intensive Besiedlung. Allerdings schienen Hypodermis und erste kortikale Zellen nicht wesentlich beeinträchtigt. Falls pflanzliche Reaktionen in einigen Zellen auftraten, so glichen diese zwar denen für Fo47, waren aber in allem weniger ausgeprägt und schwächer. Zellen, die von Foln3 besiedelt waren, zeigten im TEM keine Reaktion auf pilzliche Besiedlung.

Im Zusammenhang mit Nematodenbefall ist ebenfalls von der Ausbildung einer HR in befallenen Wurzelzellen berichtet worden. Pflanzenparasitische Nematoden sind obligate Parasiten, die sich nur vom Cytoplasma lebender Zellen ernähren. Nematoden-Resistenzgene wurden in einer Reihe von Pflanzenspezies identifiziert und waren meistens mit einer HR der Penetrationsstelle umliegenden Zellen assoziiert. Biochemische und histochemische Untersuchungen ergaben, dass gleichzeitig auch eine Aktivierung ROS-metabolisierender Enzyme stattfand (ZACHEO \& BLEVE-ZACHEO, 1988).

Die Interaktion des Nematoden Meloidogyne incognita mit anfälligen und Mi-resistenten Tomaten (Solanum lycopersicon) wurde z.B. im Hinblick auf die Ausbildung eines oxidativen „burst“ untersucht (MeliLlo et al., 2006). Die HR in resistenten Pflanzen verhinderte eine Installation des avirulenten Pathotyps, wohingegen der virulente Pathotyp die Mi-Resistenz überkam und „Feeding-sites“ in Wurzelzellen etablierte, ohne eine HR auszulösen. Bei beiden Pathotypen akkumulierten sehr früh ROS in penetrierten Zellen und zeigten einen frühen „oxidative burst" an. $\mathrm{H}_{2} \mathrm{O}_{2}$, welches in diesen Versuchen durch die Ceriumchlorid-Methode detektiert wurde, akkumulierte vornehmlich in Zellwänden, die benachbart zu solchen lagen, die den HR ausbildeten. Plasmamembran oder Zellwände und die damit assoziierte enzymatische Produktion durch die NADPH-Oxidase schienen also primäre Produktionsorte der $\mathrm{O}_{2}{ }^{-}$oder $\mathrm{H}_{2} \mathrm{O}_{2}$-Generation zu sein. Der „oxidative burst“ zu Beginn der Infektion schien 
eher der unspezifischen Kontrolle einer Nematoden-Infektion zu dienen. Erst die weitere Produktion von ROS unter gleichzeitigem Herunterfahren ROS-detoxifizierender Substanzen führte zu einer Akkumulation von ROS und induzierte Zelltod. Während inkompatibler Interaktionen, in denen das Pathogen erkannt und Zelltod initiiert wurde, schien also auf den ersten $\mathrm{H}_{2} \mathrm{O}_{2}$-Anstieg ein zweiter verlängerter Anstieg zu folgen. In der kompatiblen Reaktion wurde nur der erste Anstieg an $\mathrm{H}_{2} \mathrm{O}_{2}$ beobachtet, was darauf schließen lässt, dass dadurch nicht nur der HR ausgelöst sondern auch die Gene aktiviert wurden, die in späteren Schritten die Zelle vor oxidativem Schaden bewahrten (LEvINE et al., 1994). Die kurze Dauer des „burst“ und dessen Begrenzung auf die allererste Stufe der Infektion scheint mit der Unterdrückung des Zelltods oder anderer Abwehrmechanismen verbunden zu sein und wird eventuell durch den Nematoden ausgelöst, der die Abwehr überwindet und die Pflanze erfolgreich besiedelt. Die ROS an den Interaktionsstellen könnten zum einen an der Initiierung, zum anderen an der Unterdrückung des Zelltods beteiligt sein, je nach Konzentration, Lokalisation und Dauer des Anstiegs (MeliLlo et al., 2006). HuANG et al. (2004a) konnten die gleichen Beobachtungen mit $M$. incognita und Tomate machen und in der Interaktion von A. thaliana und dem Zystennematoden Heterodera glycines wurde ebenfalls eine HR-Reaktion und die Produktion von $\mathrm{H}_{2} \mathrm{O}_{2}$ dokumentiert (WAETZIG et al., 1999).

In kompatiblen Wirt/Pathogen-Interaktionen ist also höchstens der primäre, unspezifische Anstieg der ROS zu erwarten. Dass auch dieser nicht detektiert wurde, könnte auch durch die Art der Probenahme zu erklären sein. Eventuell fand durch das Mörsern der gesamten Wurzel ein Verdünnungseffekt der auf Zellebene stattfindenden Reaktionen statt, die einen möglichen Anstieg der ROS verwischten. Die exemplarische Überprüfung der $\mathrm{H}_{2} \mathrm{O}_{2}$-Bildung auf Zellebene durch Diaminobenzidine (DAB) zeigte allerdings auch keine Verfärbungen der Zellen (Daten nicht dargestellt).

\subsubsection{Räumliche Verschiebung und zeitliche Verzögerung der ROS-Bildung}

Auch besteht die Möglichkeit, dass die Abwehrreaktion in der Interaktion von V. longisporum und B. napus sowohl zeitlich als auch räumlich verschoben wurde. Da die Symptomausprägung in einigen $V$. longisporum-resistenten Winterrapssorten unterbunden wird (Eynck, pers. Mitteilung), die Pflanzenwurzeln aber trotzdem besiedelt werden, scheint es sich bei diesem Phänomen nicht um Penetrationsresistenzen zu handeln. Wahrscheinlicher ist, dass die Pflanzen eine Ausbreitungsresistenz ausbilden, die im Hypokotyl ansetzt und von dort aus die weitere Ausbreitung des Pathogens in der Pflanze verhindert. Diese Reaktion 
könnte auch in der Nichtwirt-Reaktion zwischen $V$. dahliae und B. napus stattgefunden haben. Das Hypokotyl des RCR ist aber frühestens ab 21 Tagen (14 dpi) vollständig ausdifferenziert. Da das Hypokotyl bzgl. seiner $\mathrm{NO}$ - und $\mathrm{H}_{2} \mathrm{O}_{2}$-Gehalte also erst zu einem Zeitpunkt untersucht werden konnte, an dem die Pathogenese schon relativ weit fortgeschritten war, ist es möglich, dass eine eventuell dort auftretende ROS-Bildung, welche eine mögliche Ausbreitungsresistenz gegen $V$. dahlie induzieren könnte, schon zu Beginn der Ausdifferenzierung stattfand und somit ab 21 dpi nicht mehr erfasst wurde. Ein Problem stellt dabei das gewählte System dar. Um zu untersuchen, ob kurz nach Inokulation eine Reaktion im Hypokotyl stattfindet, müssten 14 Tage alte Pflanzen frisch mit den beiden Pathogenen inokuliert und über den gewünschten Zeitraum beobachtet und beprobt werden oder zu frühen Zeitpunkten Proben zusammengefasst werden, um genügend Hypokotylmaterial zu erhalten. Eine Verlagerung der Abwehreaktionen von der Wurzel ins Hypokotyl konnte am System Sonnenblume/Falscher Mehltau (Plasmopara halstedii) gezeigt werden (RADWAN et al. 2005). Auch in dieser Interaktion erfolgte die Besiedlung der sowohl anfälligen als auch resistenten Sonnenblumenlinien durch diesen bodenbürtigen Oomyceten über die Wurzeln und die Ausbreitung des Pathogens in den Spross erfolgt über das Hypokotyl. Erst fünf Tage nach Infektion wurde eine HR in resistenten Hypokotylen festgestellt. In der kompatiblen Reaktion konnte nur eine sehr leichte $\mathrm{H}_{2} \mathrm{O}_{2}$-Produktion durch Diaminobenzidin (DAB)-Färbung um die penetrierenden Hyphen an der Wurzel beobachtet werden. Zellen, die von Haustorien penetriert wurden, zeigten gar keine Färbung. In der inkompatiblen Interaktion konnte 6 Tage nach Inokulation $\mathrm{H}_{2} \mathrm{O}_{2}$-Produktion in Hypokotylzellen beobachtet werden, die in direktem oder nahem Kontakt mit dem Pathogen standen. Die Resistenz der Sonnenblumen korrelierte also mit einer Akkumulation von $\mathrm{H}_{2} \mathrm{O}_{2}$. Die $\mathrm{H}_{2} \mathrm{O}_{2}$-Bildung, die um das Myzel in den Interzellularen anfälliger Hypokotylzellen beobachtet werden konnte, hängt in dieser Interaktion mit der $R$-Gen unabhängigen Produktion zusammen und entspricht der nicht-spezifischen Phase 1 der ROS-Produktion in Pflanzen.

RT-PCR Ergebnisse zeigten, dass die Resistenzausprägung in Sonnenblumen mit der Aktivierung des hsr203J-ähnlichen Gens, einem Marker der HR in Tabak, assoziiert ist. Die Aktivierung dieses Gens wurde insbesondere in der inkompatiblen Interaktion beobachtet und fand gleichzeitig mit dem Zellkollaps im Hypokotyl statt. Diese HR war ebenfalls assoziiert mit der frühen und lokalen Aktivierung des NPR1-Gens, einer Schlüsselkomponente der SAR. In kompatiblen Interaktionen konnte weder eine HR noch die Aktivierung des hsr203Jähnlichen Gens beobachtet werden. Daher lässt sich vermuten, dass die Resistenz der 
Sonnenblume mit einer HR verbunden ist, die das Pathogen zwar nicht direkt stoppt, allerdings die SAR aktiviert, welche im oberen Bereich des Hypokotyls das Pathogen am Wachstum hindern kann.

\subsubsection{Oxidative Reaktionen in B. napus}

Dass oxidative Reaktionen in B. napus durchaus vorkommen, konnten Roussel et al., (1999) zeigen. Kotyledonen von B. napus Sorten (cv. Cobra, anfällig und cv. Quinta, resistent) wurden mit einem avirulenten Isolat von L. maculans oder Cryptogein infiltriert. Dabei konnte beobachtet werden, dass nach Infiltration des Pathogens Gefäßlumen in Bereichen, die eine hypersensitive Reaktion zeigten, Okklusionen aufwiesen. Diese Ablagerungen reagierten mit Pektin-Antikörpern, nicht aber mit Antikörpern, die spezifisch für Zellulose, Kallose, Hemizellulosen oder Hydroxyprolin-reichen Glykoproteinen waren. Bei Infiltration eines virulenten Isolates von L. maculans wurden diese Ablagerungen nicht beobachtet. Durch Zugabe von Cryptogein konnten die gleichen Reaktionen wie durch Zugabe des avirulenten L. maculans-Isolates ausgelöst werden, wodurch die Autoren zeigen konnten, dass die HRassoziierten Reaktionen der vaskulären Parenchymzellen sowohl durch avirulente Isolate von L. maculans als auch durch Zugabe von Cryptogein ausgelöst werden kann. Da also die generelle Fähigkeit zur HR auch in B. napus ausgeprägt und somit nicht pflanzenartspezifisch ist, weist das Ausbleiben des ,oxidative burst“ in der V. longisporum/B. napus-Interaktion auf eine spezifische Reaktion der Pflanze auf das kompatible Pathogen hin.

\subsubsection{Zusammenfassung der ROS-Untersuchungen}

In der Interaktion zwischen biotrophen Pathogenen und Wirtspflanzen schützt die „Hypersensitive-Reaktion“ (Akkumulation von ROS) die Pflanze vor weiterer Ausbreitung des Pathogens, da durch induzierten PCD befallener und umliegender Zellen dem Pathogen die Nahrungsgrundlage entzogen wird. Im Falle fakultativ biotropher Pathogene ist es wahrscheinlicher, dass andere HR-assoziierte Abwehrfunktionen, wie die Phytoalexinproduktion eine wichtigere Abwehrfunktion als die HR übernehmen. Der Hauptteil bodenbürtiger pilzlicher Pathogene ist allerdings nekrotroph oder wie $V$. longisporum hemibiotroph und eine HR-assoziierte Resistenzreaktion gegenüber diesen Pathogenen daher normalerweise nicht zu erwarten (KLEMENT, 1986). Allerdings konnten bezüglich der HR und der Infektion mit nekrotrophen Pathogenen mittlerweile unterschiedliche Beobachtungen gemacht werden. Sowohl Von TIEDEMANN (1997) als auch 
GOVRIN \& LEVINE (2000) zeigten, dass gerade der Mechanismus der HR von B. cinerea an bestimmten Wirtspflanzen für eine vereinfachte Besiedlung ausgenutzt wird. In frühen Phasen der Infektion mit B. cinerea an Bohne (P. vulgaris) und A. thaliana wurde durch das Pathogen eine verstärkte Bildung von ROS ausgelöst, wobei die Agressivität der verwendeten Isolate mit der Bildung der $\operatorname{ROS}\left(\mathrm{H}_{2} \mathrm{O}_{2}\right.$ und $\mathrm{OH}$ bei P. vulgaris und $\mathrm{H}_{2} \mathrm{O}_{2}$ und $\mathrm{O}_{2}{ }^{-}$bei A. thaliana) eng korrelierte. Beide Autoren vermuten daher, dass die Produktion der ROS als Teil der pflanzlichen Abwehr in diesem Fall vom nekrotrophen Pathogen ausgenutzt wird und eine vereinfachte Besiedlung ermöglicht. Andererseits konnten UNGER et al., (2005) zeigen, dass an Bohnenblättern (P. vulgaris $\mathrm{N}$ 90598) bei Infektion mit einem aggressiven Isolat von $B$. cinerea zwar eine HR ausgelöst wurde, allerdings nur der erste unspezifische Teil der Reaktion, der „burst“ der an der Zellwand und im Plasmalemma stattfindet. Die zweite Phase der Superoxid-Produktion, die der spezifischen Abwehr der Pathogene dient und die Inkompatibilität einer Interaktion ausmacht, wurde unterdrückt und dadurch eine Besiedlung der Wirtspflanze ermöglicht. Es scheinen also durchaus unterschiedliche Strategien seitens der Pflanze notwendig zu sein, um auf die verschiedenen Pathogene und ihre Lebensweisen (biotroph, fakultativ biotroph, nekrotroph) zu reagieren und diese erfolgreich abzuwehren und ebenso viele Strategien auf Seite der Pathogene zu existieren, diese Mechanismen zu umgehen oder zum eigenen Vorteil auszunutzen.

Die Resistenz gegenüber bodenbürtigen Organismen ist in vielen Interaktionen mit einer verspäteten und abgeschwächten $\mathrm{HR}$ assoziiert, welche im Gegensatz zu den Blattmechansimen mehrere Tage braucht, um sichtbar zu werden. Darüber hinaus scheint die HR-Reaktion in das Hypokotyl verlagert zu werden, wo die Folgen von Zelltod weniger schädlich sind. Auch wenn Wurzelzellen generell in der Lage sind eine HR auszubilden, wie durch die o.a. Beispiele (Kap. 4.5.5) dargestellt wurde, macht es auf die allgemeine Situation der Pflanzen bezogen jedoch Sinn, in der Wurzel keine Resistenzmechanismen, die eine HR als Grundlage haben, auszubilden, da Wurzeln sich in ständigem Kontakt mit Mikroorganismen befinden. Wenn solch eine HR bei jedem Kontakt mit einem potentiell pathogenen Bodenmikroorganismus ausgebildet werden würde, käme es zu einem kontinuierlichen Absterben der Wurzelzellen, was das Fortbestehen eines intakten Versorgungssystems und somit das Überleben der gesamten Pflanze gefährden würde. Daher scheint es, dass die primäre Resistenz in der Wurzel auf anderen Mechanismen als HR, wie z.B. auf antimikrobiellen Proteinen wie Defensin oder ähnlichen Faktoren beruht und die HR in Wurzelzellen von Pflanzenseite aus eher unterdrückt wird (HERMANNS et al., 2003). Würde es sich bei $V$. longisporum, bisher als hemibiotroph beschrieben (PEGG \&BRADY, 2002), um 
ein nekrotrophes Pathogen handeln, wäre von der Pflanzenseite aus betrachtet eine Unterdrückung der HR in der Wurzel ebenso wie eine Verschiebung der HR in das Hypokotyl darüber hinaus sinnvoll, da dem Pathogen sonst bei Ausbildung des PCD eine zusätzliche Nahrungsquelle geboten würde. Das Ausbleiben eines ROS-Anstiegs zu frühen wie auch späten Zeitpunkten in der V. longisporum/B. napus-Interaktion, sowohl die NO-Produktion als auch die $\mathrm{H}_{2} \mathrm{O}_{2}$-Produktion betreffend, kann des Weiteren aber auch auf einer Unterdrückung der Abwehrmechanismen durch das Pathogen beruhen. Durch Katalaseaktivität (B. graminis f. sp. hordei, ZHANG et al., 2004), Flavorubredoxin, periplasmatische Cytochrome c Nitrit-Reduktase (NrfA), Flavohaemoglobin (Salmonella enterica serovar typhimurium, MiLls et al., 2005) oder die Produktion von 2-MethylSuccinate (B. cinerea, UNGER et al., 2005) oder Oxalsäure (S. sclerotiorum, CESSNA et al., 2000) sind Pathogene in der Lage die ROS-Produktion der Wirtspflanze, die normalerweise zur Induktion der HR führt, zu inaktivieren und somit die Abwehrreaktionen der Pflanze zu unterbinden. Für ein solches „Silencing“ würden auch die verringerten NOGehalte im Xylemsaft während der Symptomentwicklung oder die Reduktion des NOGehaltes im Gewebe $14 \mathrm{~h}$ nach Inokulation (Abb. 28) sprechen.

\subsection{GSNO/GSNO-Reduktase und nitrosylierte Proteine}

Im Zusammenhang mit NO als Signalmolekül wurden auch potentielle Transportformen dieses Radikals untersucht. Intrazellulär reagiert NO mit Proteinen und Thiolgruppen und bildet Nitrosothiole (STAMLER, 1994). Die Nitrosylierung von Proteinen geschieht durch die Reaktion mit deren Sulfhydrylgruppen (SH-Gruppe der Aminosäure Cystein z.T. auch Methionin) oder Übergangsmetallen und resultiert oftmals in einer Regulation der Proteinaktivität (STAMLER et al., 2001) z.B. durch Verhindern der Bildung von DisulfidBrücken, die normalerweise für die Tertiär- und Quartärstruktur von Proteinen und somit deren Aktivität verantwortlich ist. NO reagiert in Zellen vor allem mit Glutathion (GSH) zu Nitrosoglutathion (GSNO), welches eine potentielle Transportform von NO darstellt und sowohl NO-Donor- als auch NO-Speicherungsfunktionen hat (STAMLER et al., 1992, DIAZ et al., 2003; LINDERMAYR et al., 2005). Ein weiterer NO-Regulationsmechanismus ist daher die Umsetzung des NO-funktionsgleichen Signalmoleküls GSNO durch das Enzym GSNO-Reduktase (GSNOR), auch als Formaldehyd-Dehydrogenase oder Klasse III AlkoholDehydrogenase (FALDH, EC 1.2.1.1) bezeichnet. Dementsprechend hat die Umsetzung dieses Moleküls Auswirkungen auf die dadurch vermittelten Reaktionen der Pflanze. Die enzymatische Umsetzung von GSNO zu GSSG und $\mathrm{NH}_{3}$ durch die GSNOR ist in 
verschiedensten Spezies (von Bakterien bis zum Menschen) konserviert und bietet auch in Pflanzenzellen eine Schutzfunktion vor nitrosativem Stress (LIU et al., 2001; SAKAMOto et al., 2002; ShAFQUAT et al., 1996, MARTíneZ et al., 1996) sowie auch eine Möglichkeit, die S-Nitrosylierung von Proteinen und NO-Pufferfunktion durch GSNO zu kontrollieren (LIU et al., 2001; STAMLER et al., 2001).

Eine Analyse von Pflanzenproben auf ihren GSNO-Gehalt mittels HPLC war mit der gewählten Methode nicht möglich (siehe Kap.3.7). Anstelle eines direkten GSNONachweises wurde daher die photometrische Messung der GSNO-Reduktaseaktivität nach SAKAмото et al. (2002) und LiU et al. (2001) durchgeführt und dadurch indirekt auf den Gehalt an GSNO geschlossen. Der Gehalt an nitrosylierten Proteinen (S-Nitrosothiolen, SNO), der ebenfalls indirekt auf die Anwesenheit von GSNO schließen lässt, wurde bisher nur in A.thaliana-Pflanzen mit modifizierter GSNOR-Aktivität untersucht (FEECHAN et al., 2005; RUSTÉRUCCI et al., 2007; EsPUNYA et al., 2006). In V. longisporumund $V$. dahliae-infizierten RCR-Pflanzen wurde daher parallel zur Aktivität der GSNOReduktase auch die Menge an proteingebundenem NO (hauptsächlich Cystein-gebundenes NO) über einen photometrischen Ansatz mit $\mathrm{HgCl}_{2}$ bestimmt.

Über den Verlauf der Pathogenese zeigten V. longisporum-infizierte Pflanzen eine Tendenz zu erhöhter GSNOR-Aktivität, die aber erst mit 28 dpi im Wurzelbereich und mit 35 dpi im Wurzel- und Sprossbereich signifikant gegenüber der Kontrolle erhöht war (Abb. 36). Allerdings wiesen auch V.dahliae-inokulierte Pflanzen gleichermaßen erhöhte Aktivitäten auf. Die Aktivität der GSNO-Reduktase scheint daher zumindest nicht im Zusammenhang mit der Ausprägung der Symptome im Zusammenhang zu stehen. Der Anteil nitrosylierter Proteine sollte mit zunehmender Aktivität der GSNO-Reduktase abnehmen, da weniger GSNO zur Verfügung steht. Die gleichzeitige Messung des Cystein-gebundenen NO in Pflanzenproben bestätigte diese Vermutung. Mit zunehmender GSNOR-Aktivität nahm der Gehalt nitrosylierter Proteine sowohl in Spross- als auch Wurzelproben rapide ab (Abb. 37Abb. 39). Einzig die V. longisporum-infizierten Pflanzen zeigten einen Anstieg der nitrosylierten Proteine zu 21 dpi im Sprossgewebe (Abb. 40).

Eine Analyse von RCR-Keimlingen kurz nach Inokulation (24 hpi) zeigte eine erhöhte Aktivität der GSNOR in den Wurzeln der V. longisporum-Variante. Aufgrund des geringen Probenumfangs ließen sich aber keine signifikanten Unterschiede ermitteln (Abb. 41A). Die Überprüfung des an Cystein-gebundenen NOs zeigte keine Tendenz zu erhöhten Gehalten in den V. longisporum-infizierten Pflanzen (Abb. 41B). 
Eine mögliche Rolle spielt GSNO in der Etablierung der systemisch erworbenen Resistenz (SAR). In der Induktion der SAR, die gegenüber einer Vielzahl von Pathogenen ausgebildet wird und avr-Gen unabhängig ist, stellt Salizylsäure (SA) ein Schlüsselsignal dar. Ob die Verbreitung von SA über das Phloem zur SAR-Ausbildung führt, wird bezweifelt und das verantwortliche Signalmolekül wurde bis dato noch nicht charakterisiert. Es wird jedoch vermutet, dass nitrosylierte Proteine, S-Nitrosoglutathion (GSNO) oder SNitrosohaemoglobine, die auch als systemisch wirkende Signale im menschlichen kardiovaskulären System fungieren (JIA et al., 1996), diese Rolle übernehmen und die SAR auslösen könnten (DURNER \& KLESSIG, 1999). Die Akkumulierung von SA in frühen Phasen der Interaktion sowie die entsprechende Verringerung der JA-Gehalte in V. longisporuminfizierten Pflanzen (Abb. $43 \mathrm{u}$. Abb. 44) könnte also durch GSNO oder nitrosylierte Proteine ausgelöst worden sein. Ein möglicher Hinweis für die Funktion von GSNO als Auslöser der SAR ist die Etablierung der SAR gegen TMV durch GSNO-Applikation in Tabak (Song \& GoOdman, 2001). Auch RustÉRUCCI et al. (2007) konnten zeigen, dass transgene A. thaliana Pflanzen, die eine Verringerung der GSNO-Reduktaseaktivität sowie eine verstärkte Resistenz gegenüber Peronospora parasitica aufwiesen, einen höheren intrazellulären Gehalt nitrosylierter Proteine und eine konstitutive Expression des $P R-1-G e n s$ zeigten. Allerdings gibt es auch Daten, die dieser Hypothese widersprechen. FEECHAN et al. (2005) zeigten, dass GSNOR (atgnor1-3)-Mutanten von A. thaliana, die eine erhöhte Konzentration von S-Nitrosothiolen enthielten, eine verstärkte Anfälligkeit gegenüber P. s. pv. tomato und B. graminis f. sp. tritici und erniedrigte SA-Gehalte aufwiesen. Die Expression der GSNO reduzierenden Formaldehyd-Dehydrogenase findet in allen Geweben statt, wird aber transkriptionell als Antwort auf Signale, die mit pflanzlichen Abwehrmechanismen assoziiert sind, reguliert (MARTINEZ et al., 1996). In A. thaliana wird das für die FALDH codierende Gen $(A D H 2)$ durch Verwundung herunterreguliert und durch SA aktiviert. In Tabak wurden die FALDH-Level und enzymatische Aktivität nach JABehandlung herunterreguliert und ebenfalls durch SA-Applikation aktiviert (DIAZ et al., 2003). Die Hochregulierung des FALDH-Gens als Antwort auf verstärkte SABildung lässt vermuten, dass die GSNO-Reduktase eine Schutzfunktion vor oxidativem oder NO-Stress übernimmt, da die beiden Signalmoleküle $\mathrm{H}_{2} \mathrm{O}_{2}$ und NO die Akkumulation von SA induzieren (DIAZ et al., 2003). Eine andere Möglichkeit ist, dass durch Lipidperoxidation u.a. Formaldehyd freigesetzt wird, das ebenfalls durch die GSNO-abhängige FormaldehydDehydrogenase abgebaut wird (BOLEDA et al., 1993). 
Sowohl die Aktivität der GSNOR als auch der Gehalt an nitrosylierten Proteinen scheint daher abhängig vom jeweils untersuchten System unterschiedliche Effekte zu haben, z.B. Resistenz induzieren oder Resistenz minimieren zu können.

In der untersuchten Interaktion zwischen $V$. longisporum und B. napus scheint sie aber zumindest keinen Einfluss auf die Symptomausprägung zu haben oder mit der Besiedlung durch das Pathogen im Zusammenhang zu stehen, da auch bei V. dahliae-infizierten Pflanzen eine erhöhte GSNOR-Aktivität gemessen werden konnte.

Der Anstieg an nitrosylierten Proteinen in V. longisporum-infizierten Pflanzen wäre eine Erklärung für eine Verringerung der NO-Gehalte. Durch Bindung von NO an aktive Zentren von Proteinen wäre dieses wieder gebunden und somit nicht frei verfügbar. Allerdings findet die Abnahme des NO-Gehaltes schon relativ früh statt (14 dpi) und der Anstieg des Gehaltes nitrosylierter Proteine erst zum Zeitpunkt 21 dpi (Abb. 40). Um dies zu klären, sind weitere Untersuchungen notwendig.

Inwiefern die nitrosylierten Proteine im Zusammenhang mit der Akkumulierung von SA (Abb. 43) und ABA (Abb. 42) im Spross stehen und ob dadurch die Expression von Abwehrmechanismen gesteuert wird, bleibt in weiteren Versuchen zu überprüfen, z.B. durch Applikation von GSNO und anschließender Überprüfung der Expression von $P R-1, P A L$ oder anderen Abwehrgenen. Ob dies eventuell durch das Pathogen aktiv gesteuert wird, um dadurch effektiveren Abwehrmechanismen durch JA-induzierte Signalwege zu entgehen, bleibt ebenfalls zu untersuchen.

\subsection{Phytohormonanalyse}

Die Analyse der Ausbreitung von V. longisporum in RCR-Pflanzen durch Real-Time PCR (Abb. 10 u. 11) zeigte, dass der Pilz sich nicht vor 28 dpi im Spross ausbreitet und vorher eine verlängerte Phase eingeschränkten Wachstums im Hypokotyl einlegt. Daher scheint die Sprossstauche in der Abwesenheit einer Lokalinfektion durch systemische Effekte aus dem besiedelten basalen Pflanzenteil ausgelöst zu werden. Gleichermaßen zeigten die Schlüsselsignale der induzierten Pflanzenabwehr wie Salizylsäure (SA) oder Jasmonsäure (JA) eine starke Reaktion im Sprossgewebe, auch wenn $V$. longisporum noch immer auf die basalen Teile der Pflanze beschränkt war (Abb. 43, Abb. 44). Das Zusammenwirken der Phytohormone SA, JA und Ethylen reguliert in großem Maße die pflanzlichen Signaltransduktionswege, die verschiedene Abwehrmechanismen gegenüber pilzlichen Pathogenen induzieren (ADIE et al., 2007), wobei vereinfacht dargestellt SA an der Abwehr biotropher Pathogene beteiligt ist, während JA und Ethylen an der Abwehr nekrotropher 
Pathogene beteiligt sind. Des Weiteren wirken diese beiden Signalwege antagonistisch (Thomma et al., 2001; PieTERSE et al., 2006). Dieser SA/JA-Ethylen-Antagonismus ist auch in der V. longisporum/B. napus-Interaktion zu beobachten, bei der ein signifikanten Anstieg der SA (Abb. 43) im Sprossgewebe beginnend ab 14 dpi mit einem signifikanten Abfall im JAGehalt (Abb. 44) verbunden ist. Einige Untersuchungen zeigten allerdings, dass dieser Antagonismus bzw. dieses eingeschränkte Auftreten nur eines Signalweges als Reaktion auf ein biotrophes oder nekrotrophes Pathogen nicht zwangsläufig stattfinden muss, sondern vielmehr abhängig von den jeweiligen Interaktionspartnern ist.

Beispielsweise wurde bei Arabidopsis ein Anstieg von JA als Abwehrreaktion auf das nekrotrophe Pathogen B. cinerea induziert (Тномма et al., 1998). Dieser Effekt konnte aber bspw. in der Interaktion von Tomate und B. cinerea nicht nachgewiesen werden (AUdenAert et al., 2002). Des Weiteren konnten Thomma et al. (1998) zwar zeigen, dass JA eine Rolle in der Resistenz von Arabidopsis gegenüber B. cinerea spielt. Allerdings waren die verwendeten Arabidopsis Wildtypen hoch resistent und die Interaktion eher als eine NichtWirt-Interaktion zu bezeichnen. Bei den anfälligen, Läsionen ausbildenden Tomatenpflanzen hingegen konnten AUDENAERT et al. (2002) weder durch eine zusätzliche Applikation noch die Eliminierung von JA die Abwehrmechanismen der Pflanzen beeinflussen. In der Interaktion zwischen A. thaliana und dem Oomyceten Pythium irregulare konnte der SA/JAEthylen Antagonismus ebenfalls nicht bestätigt werden. Hier konnte ein Anstieg sowohl des SA- als auch des JA-Levels nach Infektion beobachtet werden; daher scheinen beide Abwehrwege in der Resistenzausprägung gegenüber $P$. irregulare ausgeprägt $\mathrm{zu}$ sein und $\mathrm{zu}$ kooperieren (ADIE et al., 2007).

Dass auch ABA mit diesen Signalwegen zu interagieren scheint und als positives Signal in der Aktivierung effektiver Abwehrmechanismen fungiert, konnten ADIE et al. (2007) nachweisen. Die ABA-Gehalte in A. thaliana Wildtypen stiegen nach Infektion mit $P$. irregulare rapide an und auch in SA- und JA/Ethylen-Mutanten war ein starker Anstieg an ABA nach Infektion nachzuweisen. Die entsprechend in der ABA-Biosynthese gehemmten oder insensitiven ABA-Mutanten (aao3-2, aba2-12 und abi4) zeigten eine erhöhte Anfälligkeit gegenüber P. irregulare. Auch konnten die Autoren nachweisen, dass die ABASynthese eine Voraussetzung für die JA-Produktion darstellt und dadurch erst die Aktivierung der pflanzlichen Abwehrmechanismen gegenüber P. irregulare stattfand.

Eine andere Regulation dieser Signalmoleküle konnten ANDERSON et al. (2004) an A. thaliana und dem nekrotrophen Pathogen F. oxysporum beobachten: eine inverse Beziehung zwischen ABA-Gehalt und der Induktion bestimmter Resistenzkomponenten (Unterdrückung der 
JA/Ethylen-induzierten Abwehrgene PDF1.2, HEL und $b$-CHI) führte die Autoren zu der Annahme, dass ABA antagonistisch zum JA/ET-Abwehrmechanismus wirkt, der notwendig für die Resistenz in A. thaliana gegenüber F. oxysporum ist.

In Tomate (L. esculentum Mill. cv. Moneymaker) konnten AudenAERT et al. (2002) die verminderte Anfälligkeit von Mutanten mit herabgesetztem ABA-Level gegenüber dem nekrotrophen Pathogen B. cinerea beobachten. Des Weiteren konnten die Autoren zeigen, dass die Zugabe von ABA keinen wachstumsfördernden Effekt auf das Pathogen hatte. Inwiefern ABA einen Einfluss auf die bekannteren abwehrinduzierenden Signalmoleküle SA und JA nimmt, wurde in weiteren Experimenten überprüft. NahG-Mutanten, die aufgrund der Expression bakterieller SA-Hydrolasen nicht in der Lage sind SA, zu akkumulieren, zeigten ebenfalls eine erhöhte Anfälligkeit gegenüber B. cinerea. Gleichzeitig wiesen die in ihrem ABA-Level verringerten sitiens Tomatenpflanzen einen erhöhten Gehalt an PAL-Aktivität auf, die ein Hauptenzym des für die SA-Produktion zuständigen Phenylpropanoidweges darstellt. Auch WARD et al. (1989) wiesen an Sojabohnen nach, dass exogen appliziertes ABA die PAL-Aktivität und die Synthese der PAL mRNA in der inkompatiblen Interaktion mit $P$. megasperma f. sp. glycinea unterdrückte. MoHR \& CAHILL (2007) zeigten darüber hinaus, dass in $A$. thaliana auch bei Infektion mit einem avirulenten Stamm von $P$. syringae pv. tomato ABA die Bildung sowohl von SA als auch Lignin unterdrückt und somit der ABAAnstieg in einer erhöhten Anfälligkeit resultiert.

ZiMmerLi et al. (2001) konnten ebenfalls zeigen, dass NahG-Mutanten von Arabidopsis gegenüber B. cinerea anfälliger waren als der Wildtyp. SA scheint also auch in dieser Interaktion zwischen nekrotrophem Pathogen und Wirtspflanze und nicht nur bei Befall mit biotrophen Pathogenen für die basalen Abwehrmechanismen notwendig zu sein.

In einigen Fällen scheint also die Akkumulation von ABA den basalen Mechanismus der Abwehrinduktion durch SA zu unterdrücken. ABA hat dadurch einen hemmenden Effekt auf die Abwehr biotropher Pathogene (ADIE et al., 2007). Allerdings kann ABA trotzdem nicht als allgemeines positives Signal für die Abwehr nekrotropher Pathogene gedeutet werden. Zwar zeigten ABA-Defektmutanten von $A$. thaliana eine verstärkte Anfälligkeit gegenüber $P$. irregulare und A. brassicicola und die zusätzliche Zugabe von ABA schützte Arabidopsis vor Befall mit A. brassicicola und Plectosphaerella cucumerina (Ton \& MAUCH-MANI, 2004), die Zugabe von ABA wirkte aber nicht gegen $F$. oxysporum und $B$. cinerea (AUdENAERT et al., 2002; ANDERSON et al., 2004).

Diese uneinheitlichen Resultate, die dem angenommenen Vorhandensein zweier unabhängiger antagonistischer Signalwege durch JA und Ethylen bzw. SA widersprechen und 
nachweislich auch eine Beteiligung weiterer Hormone wie ABA verdeutlichen, zeigen, dass die Lebensweise vieler Pathogene nicht rein biotrophen oder nekrotrophen Charakteristika zuzuordnen sind. Die Kooperation oder der Antagonismus beider Signalwege könnte daher eine Adaptation der Pflanze an die jeweiligen besiedelnden Pathogene sein (ADIE et al., 2007).

Interessanterweise konnten bereits mehrere Autoren die Produktion von ABA durch phytopathogene Pilze nachweisen (Dörffling et al., 1984; Crocoll et al., 1991; DANNEBerg et al., 1993) sowie die Induktion von ABA in der Pflanze aufgrund einer Pathogen-Infektion oder Besiedlung mit Mykorrhiza-Pilzen (KeTtNeR \& DöRfFLING 1995; Bothe et al., 1994; HARrison et al., 1999). Es liegt daher nahe zu untersuchen, ob in kompatiblen Interaktionen wie zwischen $V$. longisporum und B. napus durch eine eventuelle ABA-Produktion des Pathogens die Mechanismen der herkömmlichen Pathogenabwehr ausgeschaltet werden. Da SA in der V. longisporum/B. napus-Interaktion trotzdem ansteigt, sollte überprüft werden, ob die Aktivität der PAL herabgesetzt ist und eventuell die in infizierten Pflanzen gebildete SA nicht ausreicht, um eine entsprechende Abwehr zu induzieren. Nachweisbar wäre dies durch exogene Applikation größerer Konzentrationen SA und parallelem Nachweis der Pathogenausbreitung sowie durch Messung der Expression Pathogen-induzierter Abwehrgene wie bspw. PAL oder PR1.

Die Beteiligung von Ethylen an der Symptombildung bei $V$. longisporum-Befall ist ebenfalls wahrscheinlich. Bekannt ist z.B., dass Ethylen-insensitive Tomaten bei Infektion mit $X$. campestris pv vesicatoria verminderte Symptome zeigten. Des Weiteren konnte ein Zusammenhang zwischen Ethylen und SA gefunden werden. In Ethylen-insensitiven Pflanzen akkumulierte kein SA als Reaktion auf Pathogenbefall (O’DonNEL et al., 2001).

RESENDE et al. (1996) beobachteten, dass die Infektion von Kakaopflanzen (Theobroma сасаo) mit verschiedenen Isolaten von $V$. dahliae entweder zu einer massiven Entlaubung oder aber zu Welkesymptomen führte. Ein schneller Abfall der Transpirationsrate, des Wasserpotentials und des stomatären Leitfähigkeit wiesen darauf hin, dass Trockenstress ein Hauptgrund für die Symptomentwicklung dieser Interaktion war. Trockenstress trat am deutlichsten bei Pflanzen auf, die mit einem nicht-entlaubenden Isolat inokuliert wurden. Isolate, die Blattabwurf hervorriefen, führten eher $\mathrm{zu}$ einer Akkumulation von Ethylen in neuen Blättern, die dann auch zuerst Symptome zeigten. Die Anwesenheit dieses Pflanzenhormons schien der Auslöser für die Seneszenzsymptome und den darauffolgenden Blattfall zu sein, wie durch Aufhebung des Effektes durch Zugabe von Silber-Thiosulfat (STS), einem Ethylenhemmer bestätigt werden konnte (RESENDE et al., 1996). Allerdings 
konnte in diesem Beispiel kein Zusammenhang zwischen der Entwicklung des Pilzes und der Ethylen-Produktion gefunden werden. Die Behandlung der Kakaopflanzen mit STS inhibierte zwar den Blattabwurf, führte aber nicht zu einer verminderten Ausbreitung des Pathogens oder Verminderung der anderen Welkesymptome. Ebenfalls konnte kein Unterschied in der Ethylen-Produktion zwischen inokulierten, STS-besprühten und nicht besprühten Pflanzen festgestellt werden. Dies führte zu der weiteren Annahme, dass die Bindung des Ethylens nicht aber dessen Bildung gehemmt wurde, was in vermindertem Blattabwurf resultierte.

Die Untersuchung von RCR bzgl. des Auxingehaltes in infizierten und nicht-infizierten Pflanzen führte zu keinem eindeutigen Ergebnis. Bekannt ist, dass geringe AuxinKonzentrationen die Ethylenbildung verringern und dadurch Zellelongation und Teilung fördern. In hohen Konzentrationen führt Auxin zu einer Induktion der 1-Aminocyclopropan1-Carboxylsäure (ACC)-Synthase, die den Vorläufer für die Ethylenproduktion darstellt. Dieses durch IAA gesteuerte Ethylen löst seinerseits die vermehrte Produktion von ABA aus, was in vorzeitigem Blattabwurf und einer Hemmung des Wurzel und Sprosswachstums resultiert (Grossmann \& Hansen, 2001). Die Auxin-induzierte Produktion von Ethylen und der dadurch hervorgerufene Anstieg von ABA ist vor allem im Spross beobachtet worden (Grossmann et al., 1996; Grossmann, 2000) und konnte auch in Brassicaceen bereits nachgewiesen werden (HANSEN \& GROSSMANN, 2000). Eine genauere Unterteilung und Analyse der Wurzel bzgl. ihres IAA-Gehaltes könnte eventuell ein deutlicheres Bild bzgl. des Zusammenhangs dieser drei Komponenten bei Pathogenbefall ergeben. Aufgrund der bisherigen Daten, die keinen Unterschied im IAA-Gehalt zwischen den drei Varianten aufweisen, ist eine Beteiligung des Hormons in diesem Zusammenhang allerdings unwahrscheinlich. In jedem Fall sollte aber überprüft werden, ob V. longisporum in der Lage ist, Phytohormone oder deren Vorläufermoleküle zu produzieren und somit Einfluss auf die Symptomatik zu nehmen.

Zur Optimierung weiterer Phytohormonanalysen sollte zwischen Stängel und Blattproben unterschieden werden. Da aufgrund der natürlichen Seneszenz zu den Zeitpunkten 28 und 35 dpi sowohl das erste und zweite Laubblatt der nicht inokulierten Kontrollpflanzen als auch weitere Blattetagen der Verticillium-infizierten Varianten bereits abgeworfen waren, stand nur relativ wenig Blattmaterial für weitere Analysen zur Verfügung. Um eine homogene Beprobung aller Varianten zu ermöglichen, wurden daher Gesamtsprossextraktionen durchgeführt. Zum Zeitpunkt 14 dpi waren die Sprosse noch nicht deutlich in Blatt und Stängel differenziert, zu 21 dpi entwickelte sich der Stängel und zu 28 dpi hatten die Pflanzen ihre volle Wuchshöhe erreicht und fingen an die Blüte zu schieben. Dadurch, dass zu den 
verschiedenen Zeitpunkten der Probenahme eine unterschiedliche Ausdifferenzierung der Sprossorgane vorlag, die jeweils unterschiedliche Hormone bilden und akkumulieren, könnte der Einfluss des Pathogenbefalls auf den Hormonhaushalt überdeckt bzw. verschoben worden sein. Für weitere Analysen sollte daher die Pflanze in mehrere Proben unterteilt werden, was allerdings zu einem weitaus aufwändigeren Aufbau der Experimente führen würde. Eindeutig liegt hier ein Vorteil bei Versuchen, die homogene Bedingungen garantieren wie z.B. bei Verwendung von Zellkulturen oder bei der Verwendung von A. thaliana oder kloniertem Pflanzenmaterial (Gewebekulturen), die geringere Variabilität aufweisen. Des Weiteren könnte dieses Material mit weniger Aufwand in größerer Anzahl kultiviert und beprobt werden. Gleichzeitig bieten A. thaliana-Mutanten die Möglichkeit, die Mechanismen der Abwehr genauer zu untersuchen.

\subsection{Untersuchungen zum Toxizitätsfaktor}

Das Stauchesymptom, welches bei Infektion mit $V$. longisporum auftritt, wird unter Gewächshausbedingungen schon 14 Tage nach Inokulation sichtbar, obwohl der Pilz sich zu diesem Zeitpunkt, wie durch mikroskopische Studien (EYNCK et al., 2007) und Real-Time PCR-Daten nachgewiesen werden konnte (Abb. 10 , Abb. 11), noch nicht bis in den Spross ausgebreitet hat. Erst mit Beginn der Reife (28 dpi) tritt $V$. longisporum durch die Xylemgefäße in den oberen Pflanzenteil über. Ein Auftreten von Wasserstress konnte bisher nicht beobachtet werden (KEUNECKE, 2005) und auch der Verschluss von Gefäßen scheint nur vereinzelt aufzutreten (EYNCK et al., 2007). Des Weiteren treten bei Infektion von B. napus mit V. longisporum nicht die typischen Symptome einer Verticillium-Welke, wie durch $V$. dahliae an einer Vielzahl anderer Wirtspflanzen hervorgerufen, auf.

Eine weitere mögliche Erklärung für diese systemische Induktion der Stauche könnte die Produktion einer bisher unbekannten Substanz (Toxin) sein, die noch vor der Sprosskolonisation vom Pathogen produziert und systemisch mit dem Xylemstrom in den Sprossbereich transportiert wird. Die Möglichkeit, dass die Symptomatik von VerticilliumInfektionen eventuell auf toxischen Substanzen basiert und nicht immer durch Okklusionen und Wasserstress hervorgerufen wird, wurde auch schon von PEGG \& BRADY (2002) diskutiert. Diese teilten der Einfachheit halber Toxine in zwei Gruppen: erstens Moleküle mit einer Größe unter $1000 \mathrm{Da}$, die direkt wirken, indem sie Zellmembranen, Organellen und metabolische Funktionen schädigen und zweitens makromolekulare Substanzen wie Polysaccharide und/oder Proteine. In planta sind allerdings bisher nur wenige Verticillium- 
Toxine identifiziert worden. Hauptsächlich wurden Metaboliten aus Kulturfiltraten und deren Symptominduktion in Biotests untersucht (PEGG \& BRADY, 2002).

Ebenso wurde auch in ersten Ansätzen dieser Arbeit zur Identifizierung eines staucheinduzierenden Metaboliten aus V. longisporum verfahren, indem zuerst Kulturfiltrate auf toxische Effekte getestet wurden. Die Untersuchung von Kulturfiltratüberstand aus verschiedenen $V$. longisporum oder $V$. dahliae-inokulierten Medien in einem PetiolenToxizitätstest zeigte keine phytotoxischen Effekte wie Welke oder Vergilbung an Blättern 21 Tage alter RCR-Pflanzen innerhalb von 24-48 h (Abb. 46).

Die Applikation von CzD-Kulturfiltraten über einen längeren Zeitraum an getopften RCRPflanzen wie auch die Applikation der nicht-filtrierten V. longisporum-Sporensuspension führte zur Reduktion des Sprosswachstums (Abb. 47). Dieser Effekt trat allerdings auch bei reinem Medium auf, so dass über einen nachfolgenden in vitro-Versuch ein möglicher Effekt des Mediums überprüft wurde. Hier zeigte sich bei Verwendung verschiedener Medien (CzDox, Rapswurzelextrakt, sehr nährstoffarmes Medium und simulierter Xylemsaft), dass dieser Stauchefaktor anscheinend nur bei Anzucht des Pathogens in einem Xylemsaft simulierenden Medium (SXM) induziert wird und nicht auftritt, wenn ein Standardmedium verwendet wird, das sich nicht an der Zusammensetzung von Xylemsaft orientiert (Abb. 48 u.Abb. 49). Der Kontakt mit der Pflanze (oder Xylemsaftfaktoren) scheint daher eine essentielle Voraussetzung für die Produktion dieses oder dieser Metaboliten zu sein.

Ein generelles Problem der Applikation von Kulturüberständen ist, dass künstliche Medien genutzt werden, deren Kohlenstoffquelle und Zusammensetzung sich nicht an den natürlichen Bedingungen der Leitgewebe hält (PegG \& Brady, 2002). Die Sekretion von Metaboliten in die Medien ist jedoch vermutlich stark von deren Zusammensetzung und vor allem der CQuelle abhängig und kann bei Applikation der Medien einen deutlichen Einfluss auf die Pflanze haben. Es ist nicht bekannt, ob sich das Pathogen bei der Besiedlung der toten Xylemgefäße von gelösten Stoffen des Transpirationsstroms ernährt oder durch Sekretion verschiedener Enzyme (Pektinasen, Cellulasen) Zellwände zersetzt und diese als Kohlenstoffquelle nutzt. Es wurde in den durchgeführten Versuchen zwar versucht, über die Zusammensetzung des Mediums natürlichen Xylemsaft zu simulieren, die im SXM-Medium dargebotene C-Quelle Pektin könnte aber durchaus die Produktion pektolytischer Enzyme gefördert haben. Wenn der Pilz nun in Medium mit Pektin als einziger C-Quelle angezogen wurde, ist es wahrscheinlich, dass auch Pektinasen gebildet wurden, um diese Nährstoffquelle aufzuschließen. In einer Reihe von Untersuchungen an Verticillium-Spezies sind solche pektolytische Enzyme bereits nachgewiesen worden. So konnten bereits BEWLEY (1920) in 
Kulturfiltraten von $V$. albo-atrum und KAMAL \& WOOD(1956) in Kulturfiltraten von V. dahliae das Vorkommen von Polygalacturonasen zeigen, wobei letztere auch noch eine thermostabile Substanz beschrieben, die keine Verbräunung aber Welke auslöste. In planta konnte Wood (1961) eine Erhöhung von Pektinesterasen um $50 \%$ in anfälligen V. alboatrum-infizierten Tomaten im Vergleich $\mathrm{zu}$ gesunden Tomatenpflanzen nachweisen. Heale \& Gupta (1972) fanden in V. albo-atrum, isoliert aus Luzerne, sowohl konstitutiv produzierte endo-Polygalacturonasen als auch exo-Pektinlyasen und kleine Mengen an Pektinesterasen. Die Produktion von Pektinlyasen wurde dabei als ein Hauptenzym der Pathogenese erachtet, da es gleichzeitig mit der Symptomausprägung in Wurzel und Stängel gebildet wurde. Es bleiben jedoch Zweifel an dem Zusammenhang zwischen der Fähigkeit Enzyme zu produzieren und der Virulenz eines Pathogens. TALBOYs \& Busch (1970) untersuchten verschiedene Verticillium-Isolate, die Polygalacturonasen und endo-Pektinlyasen in unterschiedlichen Mengen produzierten, deren Auftreten aber nur schwach mit der jeweiligen Virulenz korrelierten.

Zur näheren Charakterisierung des von V. longisporum sekretierten Stauchefaktors wurde eine Größenaufteilung der Kulturüberstände über Membranfilter durchgeführt (Kap. 2.14.4). Dieser Versuch führte zu einer Stauche des Sprosses in allen Versuchsteilen, wobei der Effekt aber am stärksten im unfraktionierten, steril filtrierten Kulturüberstand ausgeprägt war (Abb. 50). Auswirkungen auf das weitere Krankheitsbild der Keimlinge (vorzeitige Seneszenz dargestellt als Boniturnoten) hatten sowohl das steril filtrierte Gesamtkulturfiltrat als auch die Fraktionen mit $<10000$ und $<50000$ Da. Einzig die Fraktion kleiner als 5000 Da induzierte Stauche, ohne eine starke Induktion vorzeitiger Seneszenz zu zeigen (Abb. 51). Daraus lässt sich schließen, dass es sich um zwei getrennt voneinander agierende Mechanismen (Substanzen) handelt und das Phänomen der Stauche möglicherweise getrennt vom Symptom der frühzeitigen Seneszenz betrachtet werden muss. Dass der stärkste Staucheeffekt durch das unfraktionierte Gesamtkulturfiltrat hervorgerufen wurde, kann an einem synergistischen Effekt liegen, bei dem die vorzeitige Seneszenz und Schädigung des Blattapparates zusätzlich zum Staucheeffekt das Wachstum der Keimlinge verminderte. Eine Wiederholung der Versuche zeigte reproduzierbare Ergebnisse bzgl. der Stauche. Ein Einfluss auf die Boniturnoten fand jedoch auch durch Applikation der 5000er Fraktion statt, hatte aber im Vergleich zu den anderen Fraktionen den schwächsten Effekt (Tab. 13).

Auch TALBOYs (1957) postulierte für V. albo-atrum an Hopfen ein welkeauslösendes Toxin mit niedrigem Molekulargewicht und in zahlreichen Untersuchungen mit $V$. dahliae konnten ebenfalls niedermolekulare Substanzen als toxische Faktoren identifiziert werden 
(Krasil'Nikov et al., 1965; ChePEnKo et al., 1969; Ten et al., 1977). Dass ein Zusammenspiel von Substanzen das Symptomspektrum bewirkt, wie anscheinend auch für V. longisporum zutreffend, konnte GreEN (1954) an V. dahliae Kulturen zeigen. Mit Hilfe von 90 \% Ethanol konnte ein thermolabiles Protein-Lipopolysaccharid präzipetiert werden, welches Welke an Tomatensprossen auslöste; das komplette unbehandelte Kulturfiltrat führte zusätzlich auch zu Nekrosen und Chlorosen. Kiessing \& HALLER-Kiessing (1956) zeigten für V. albo-atrum, dass ebenfalls zwei Komponenten die Symptomausbildung beeinflussten. Ein thermolabiles Molekül induzierte Welke, wohingegen ein thermostabiles Molekül Nekrosen auslöste. Eine genauere Identifizierung gelang STODDART \& CARR (1966) durch Verwendung von Gelchromatographie und gefriergetrockneten V. albo-atrum Kulturen. Ein isoliertes Protein mit schwacher Cellulaseaktivität von 1000 Da Größe und ein Fructosan von 5-10 kDa Größe induzierten in Luzerne Welkesymptome. KeEN et al.(1972) isolierten aus V. dahliae ein Protein-Lipopolysaccharid von $3000 \mathrm{kDa}$, das zu $75 \%$ aus Polysacchariden bestand, welches in Baumwollsprossen und jungen Pflanzen Symptome induzieren konnte.

Weiteren Untersuchungen zufolge produzierte ein $V$. dahliae-Isolat aus Kartoffel einen hochmolekularen Protein-Lipopolysaccharid Komplex, dessen Auftreten mit der Pathogenität des Pilzes korrelierte (BuCHNER et al., 1982). Eine nähere Charakterisierung ergab, dass der Chlorose-induzierende Teil dieses Komplexes aus einem kleinen phytotoxischen Polypeptid von $>3 \mathrm{kDa}$ bestand (NACHMIAs et al., 1985). Aus V. dahliae Isolaten aus Baumwolle wurde ein ähnlicher Protein-Lipopolysaccharidkomplex von 197 kDa isoliert, der ebenfalls Nekrosen und Welke und eine verstärkte Aktivität der Phenylalanin-Ammoniumlyase (PAL) und die Phytoalexinsynthese in Baumwollzellkulturen induzierte (MEYER et al., 1994). Weitere Phytoalexin-induzierende Moleküle wurden von DAvis et al. (1998) (65 kDa) und Chu et al. (1999) (26 kDa) isoliert. WANG et al. (2004) charakterisierten ein 233 Aminosäuren langes Protein mit Sequenzähnlichkeiten zu pilzlichen Nekrose- und Ethylen-induzierenden Proteinen aus V. dahliae. Dieses Nekrose- und Ethylen-induzierende Protein (VdNEP) aus $V$. dahliae führte in verschiedenen Wirtspflanzen zur Nekrosenbildung ( $N$. benthamiana), ROS-Produktion und Expression von PR-Genen (A. thaliana), Phytoalexin-Produktion und in hohen Konzentrationen Zelltod (G. arboreum Zellkulturen) sowie Dehydration und Welke (Gossypium arboreum Blätter und Kotyledonen). Durch die o.a. Quellen wird deutlich, dass eine Vielzahl von Elicitoren oder Phytotoxinen von V. dahliae gebildet werden. Daher scheint es nicht unwahrscheinlich, dass auch bei $V$. longisporum zwei Faktoren, ein niedermolekularer und ein höhermolekularer für die beiden unterschiedlichen Symptome verantwortlich sind. 
Um den gesuchten Faktor mit möglichst einfachen Methoden näher zu charakterisieren, wurden die Moleküle aus dem SXM-Kulturfiltrat über Säulenchromatographie mittels unterschiedlicher Konzentrationen organischen Lösungsmittels separiert. Durch ähnliche Versuche konnten auch schon Metaboliten von $V$. dahliae isoliert werden. NachmiAs et al. (1982) isolierten zwei Fraktionen aus V. dahliae-Kulturen mittels AcetonPräzipitierung, wobei die erste ein $2000 \mathrm{kDa}$ Protein-Lipopolysacharid und die zweite eine 80000 Da Fraktion enthielt. Auch bei Stauche an Tomate, hervorgerufen durch V. albo-atrum, konnte PEGG (1965) durch ätherlösliche neutrale, basische und saure Fraktionierung von Kulturüberständen wachstumsinhibierende Substanzen isolieren. Daher sollte auch V. longisporum-Kulturfiltrat durch das organische Lösungsmittel Acetonitril fraktioniert und die einzelnen Fraktionen anschließend in Biotests auf toxische Effekte überprüft werden. Ein erster Versuch schien zwar aussichtsreich, führte aber nach mehrfacher Wiederholung zu unterschiedlichen Ergebnissen (Daten nicht dargestellt) und konnte daher keinen eindeutigen Hinweis auf weitere Eigenschaften des Metaboliten geben. Die verwendete Methode der Fraktionierung mittels unterschiedlicher Konzentrationen organischen Lösungsmittels scheint daher nicht geeignet, den unbekannten Faktor näher zu charakterisieren.

Einen weiteren nützlichen Aufschluss über die Funktionsweise des bisher unbekannten Stauchefaktors ließe sich unter Verwendung des Ethylen-Inhibitors (S)-Trans-2-Amino-4-(2Aminoethoxy)-3-Butenoic Acid Hydrochlorid (AVG) erlangen. Falls die Symptomausprägung in der kompatiblen Reaktion von V. longisporum und B. napus, wie bereits bei einem Toxin von V. albo-atrum an Kartoffel gezeigt (MANSOORI \& SMITH 2005), durch die Bildung und Rezeption von Ethylen regulierbar ist und die Inhibierung der Ethylenbildung bzw. -aufnahme die Symptomausprägung unterbindet, gäbe dies einen weiteren Hinweis auf mögliche Funktionsmechanismen des Stauchefaktors. Eine externe Untersuchung von Gewebeproben mittels GC (Albrecht-Von-Haller-Institut der Pflanzenwissenschaften, Abteilung Biochemie der Pflanze, Ivo Feußner) auf 1Aminocyclopropan1-Carboxylsäure (ACC), dem Vorläufermolekül von Ethylen, über den Zeitraum 14-35 dpi zeigte bereits einen deutlichen Anstieg in V. longisporum-infizierten Pflanzen im Vergleich zu Kontrollpflanzen zum Zeitpunkt 21 dpi (siehe Anhang Abb. 53). Dieses Ergebnis scheint aber in engem Zusammenhang mit der Größe der Pflanzen zu stehen. Mit Hilfe dieser Methode sind bisher nur je 5 gesunde und $5 \mathrm{~V}$. longisporum-infizierte Pflanzen zu 14, 21, 28 und 35 dpi untersucht worden, daher konnten keine statistisch verlässliche Aussage über die Ergebnisse erstellt und kein Vergleich mit V. dahliae-infizierten 
Pflanzen durchgeführt werden. Eine Beteiligung des Ethylens an der Symptomausprägung in B. napus durch $V$. longisporum ist allerdings wahrscheinlich. 


\section{Zusammenfassung}

Ziel dieser Arbeit war es, die durch Infektion mit V. longisporum an B. napus ausgelöste vorzeitigen Reife und die unter Gewächshausbedingungen auftretende Stauche hinsichtlich einer kausalen Beteiligung von im Xylemsaft vermuteten Signalmolekülen zu untersuchen. Aufgrund ihrer Eigenschaften und Funktion bei der Signaltransduktion abiotischer und biotischer Stressfaktoren wurden dabei Wasserstoffperoxid $\left(\mathrm{H}_{2} \mathrm{O}_{2}\right)$ und Stickstoffmonoxid (NO) als infrage kommende Kandidatenmoleküle ausgewählt und näher untersucht. Da ein Einfluss der Infektion auf das Pflanzenwachstum vermutlich auch mit einer Veränderung des Phytohormonstatus einhergeht, wurden parallel Analysen bezüglich der Stress und Pathogenbefall anzeigenden Hormone Abszisinsäure, Salizylsäure, Jasmonsäure und Indol-3Essigsäure durchgeführt. Da keine Verticillium-resistenten Rapsgenotypen auf dem Markt sind, wurde parallel in allen Untersuchungen auch die nicht-symptombildende Interaktion von $V$. dahliae und B. napus untersucht, um eine mögliche Veränderung der untersuchten Parameter mit der Symptombildung in Verbindung bringen zu können.

Unter Gewächshausbedingungen traten nach Infektion mit $V$. longisporum frühzeitige Reife und eine deutliche Stauche der Pflanzen auf. Ob die Ausbildung der Symptome auch unter diesen Bedingungen unabhängig von der lokalen Anwesenheit des Pathogens im Spross ist, wurde anhand eines PCR-Nachweises der Verticillium-DNA in Spross und Hypokotyl infizierter Pflanzen überprüft. Stauche, verringertes Trockengewicht von Spross und Wurzel und Boniturnoten korrelierten jedoch nicht mit der Anwesenheit von Verticillium-DNA in den entsprechenden Spross- und Hypokotylproben. Die Symptome V. Iongisporum-infizierter Pflanzen sind daher nicht von der direkten/lokalen Anwesenheit des Pathogens im Bereich der Symptomausprägung abhängig, sondern können offenbar systemisch durch pilzliche Metaboliten ausgelöst werden.

Eine Infektion von B. napus mit $V$. dahliae hatte wachstumsfördernde Effekte (verstärktes Sprosswachstum und erhöhtes Sprosstrockengewicht) zur Folge, wobei das Pathogen über den Verlauf der Pflanzenentwicklung stets im Wurzelbereich verblieb und nicht über das Hypokotyl hinaus in den Spross übertrat.

Die Hypothese, dass NO Einfluss auf die Symptomausbildung nimmt, konnte durch in vitroSymptominduktionsexperimente, in denen NO in Form chemischer Donatoren auf Keimlinge appliziert wurde, bestätigt werden. Mit steigenden Gehalten des NO-Donors SNP war ein deutlicher Einfluss auf die Primärwurzellänge und die Sprosslänge zu verzeichnen. Allerdings 
war dieser Effekt vermutlich pharmakologischer Natur, da nur bei Applikation von SNP nicht aber SNAP ein Effekt nachgewiesen werden konnte.

Die Analyse von NO im Xylemsafte erfolgte per Elektronen-Resonanz Spektrometrie (ESR). Mit dieser Methode konnte erstmals das für NO typische Triplet-Signal in Xylemsaft detektiert werden. Die Analysen wurden über einen relativ großen Zeitraum ausgehend vom Zeitpunkt der Inokulation (NO-Detektion im Gewebe) bis zum Beginn der Symptomausbildung (14 dpi; NO Detektion im Xylemsaft) und vollständigen Besiedlung der Pflanze durch das Pathogen (35 dpi) durchgeführt. Die Untersuchungen des Xylemsaftes zeigten, dass in $V$. longisporum- im Vergleich zu V. dahliae-infizierten Pflanzen und der Kontrollvariante der NO-Gehalt zu Beginn der Symptomentwicklung (14dpi) und zum Ende (35 dpi) signifikant verringert war. Auch der NO-Nachweis mittels Diaminofluorescein Diacetat (DAF-2DA) über HPLC aus Pflanzengewebe kurz nach der Inokulation (14 hpi) zeigte, dass auch mit $V$. longisporum der Gehalt an NO im Sprossgewebe herunterreguliert wurde. Es konnte daher weder zu Zeitpunkten kurz nach Inokulation im Gewebe noch zu Zeitpunkten der Symptomausprägung (bis 28 dpi) im Xylemsaft ein Anstieg von NO in infizierten Pflanzen nachgewiesen werden. Vielmehr wurde der NO-Gehalt in der

\section{kompatiblen Interaktion mit $V$. longisporum verringert.}

Die detaillierte Untersuchung von $\mathrm{H}_{2} \mathrm{O}_{2}$ in Spross- und Wurzelgewebe zeigte keinen Unterschied zwischen infizierten Pflanzen ( $V$. dahliae oder $V$. longisporum) und den entsprechenden Kontrollpflanzen. Einzig zum Zeitpunkt 28 dpi wurde in der $V$. longisporum-Variante ein signifikanter transienter Anstieg des $\mathrm{H}_{2} \mathrm{O}_{2}$-Gehaltes in Sprossund Hypokotylproben gemessen.

Als mögliche Transportform des reaktiven NO-Moleküls wurde Nitrosoglutathion (GSNO) in Pflanzenproben gemessen. Eine für Glutathion etablierte HPLC-Methode wurde für den Nachweis von GSNO in adaptierter Form angewendet, führte aber aufgrund von Nebenreaktionen nicht zu der erwünschten Spezifität bezüglich GSNO und wurde daher auf Pflanzenproben nicht angewendet. Anstelle des direkten GSNO-Nachweises wurde daher versucht, indirekt über die Aktivität des GSNO-metabolisierenden Enzyms GSNO-Reduktase Rückschlüsse auf die GSNO-Mengen in infizierten und nicht infizierten Pflanzen zu ziehen. Die Ergebnisse der GSNO-Reduktaseaktivität zeigten, dass die Aktivität mit zunehmendem Alter in allen Varianten anstieg, allerdings in V. longisporum- und V. dahliae-infizierten Pflanzen zu den Zeitpunkten 28 bis 35 dpi sowohl im Spross als auch in der Wurzel im Vergleich zur Kontrollvariante signifikant erhöht war. Die Aktivität der GSNO-Reduktase scheint daher aufgrund der Erhöhung sowohl in der symptombildenden als auch der nicht- 
symptombildenden Interaktion nicht mit der Symptomausprägung im Zusammenhang zu stehen. Einhergehend mit den Untersuchungen der GSNO-Reduktase wurde auch der Gehalt an nitrosylierten Proteinen gemessen. Parallel mit einem Anstieg der GSNOReduktaseaktivität fand in V. dahliae- und nicht-inokulierten Kontrollpflanzen ein Abfall nitrosylierter Proteine statt. In V. longisporum-infizierten Pflanzen hingegen lag der Gehalt an SNOs zu Beginn der Pathogenese niedriger und stieg zu 21 dpi an.

Der Schwerpunkt der Bestimmung verschiedener Phytohormone lag auf den stressanzeigenden Phytohormonen Abszisinsäure (ABA), Salizylsäure (SA), Jasmonsäure (JA) und Indol-3-Essigsäure (IAA). Dabei wurde deutlich, dass sich die V. longisporuminfizierte Variante entsprechend den Ergebnissen der NO-Analyse zu den Zeitpunkten 14 und 35 dpi signifikant von der V. dahliae- und Kontrollvariante unterschied. Sowohl die SA- als auch ABA-Gehalte stiegen zu diesen Zeitpunkten signifikant im Sprossgewebe infizierter Pflanzen an. In Pflanze/Pathogen-Interaktionen ist ein SA-Anstieg Indikator für einen Befall biotropher inkompatibler Pathogene, wodurch normalerweise SAR eingeleitet wird. Antagonistisch dazu wird durch die Akkumulation der SA die Aktivierung der JA/EthylenSignalkette zur Abwehr nekrotropher Pathogene unterdrückt, was auch in dieser Interaktion durch einen Abfall der JA-Gehalte im Spross bestätigt werden konnte. Erste Analysen des Ethylenvorläufers ACC wiesen darauf hin, dass auch dieses Phytohormon einen möglichen Einfluss auf die Symptomausbildung nimmt. Aufgrund des geringen Probenumfangs lieferten diese Untersuchungen jedoch noch keine aussagekräftigen Ergebnisse.

Da bisher keine Untersuchungen bezüglich eines phytotoxischen Faktors aus V. longisporum durchgeführt wurden und dieser ebenfalls symptombildende Signalfunktionen haben kann, wurden Versuche mit V. longisporum-Kulturfiltraten durchgeführt. Durch Applikation von sterilen Kulturfiltraten sollte herausgefunden werden, ob möglicherweise in das Medium sekretierte Metaboliten für die Symptomauslösung verantwortlich sind. Durch Versuche mit unterschiedlichen Medien und durch Größenfraktionierung der Überstände mittels Cellulosefiltermembranen konnte eine Fraktion < 5000 Da gefunden werden, die nicht phytotoxisch war, aber innerhalb von sieben Tagen an Keimlingen eine Sprossstauche induzierte. Stauchewirkung fand sich jedoch nur in Filtraten aus Xylemsaft-simulierendem Medium und nicht in anderen Standardwachstumsmedien. Fraktionen $>5000$ Da stauchten die Pflanzen ebenfalls, führten aber gleichzeitig zu phytotoxischen Schäden an der Pflanze, wodurch in diesem Fall hervorgerufene Stauche möglicherweise auf pleiotrope Effekte zurückzuführen war. Es wird gefolgert, dass es sich bei der der frühzeitigen Seneszenz und der Stauche um zwei getrennt voneinander ausgelöste Symptome handelt. 
Aufgrund der Bodenbürtigkeit und biphasischen Ausbreitung des Pathogens lassen sich die Signalwege und Abwehrmechanismen in der Interaktion von $V$. longisporum und B. napus schwer einem definierten Parasitentypus zuordnen. Allgemeine initiale Abwehrstrategien gegen nekrotrophe und biotrophe Pathogene (v.a. Blattpathogene) scheinen durch V. longisporum unterdrückt zu werden. Die Auslösung von Signalen zur systemisch erworbenen Abwehr reicht offenbar nicht aus, um eine weitere vaskuläre Ausbreitung des Pathogens zu verhindern. Wodurch diese initiale Abwehr durch ROS-Akkumulation unterdrückt wird, bleibt ebenso wie die chemische Natur der symptominduzierenden Metaboliten in weiteren Versuchen zu überprüfen.

Einen Ansatzpunkt für weitere Experimente liefert die Tatsache, dass V. dahliae in seiner Ausbreitung auf das Hypokotyl begrenzt wird. Ein resistenter Rapsgenotyp, der als Vergleichsreferenz dienen könnte, war zum Zeitpunkt dieser Untersuchungen nicht verfügbar. Einen vielversprechenden Ansatzpunkt bieten daher neuere Befunde bezüglich resistenter Rapsgenotypen, die eine vermehrte Akkumulation von Lignin und Phenolen im Leitgewebe aufweisen (EYNCK, 2008). 


\section{Summary}

The main objective of this work was to study the induction of premature ripening and the appearance of stunting in the interaction between $V$. longisporum/B. napus by xylemsapassumed signaling molecules under greenhouse conditions. We focused on hydrogen peroxide and nitric oxide because of their properties and function in the signal transduction of abiotic and biotic stress. As an influence of infection on plant growth is presumably associated with alterations of phytohormone status, parallel analysis concerning the stress and pathogen attack indicating hormones abscisic acid, jasmonic acid, salicylic acid and indole-3-acetic acid were carried out. No resistant oilseed rape genotypes exist; therefore all experiments during the time course of symptom development were performed simultaneously with the symptomless interaction of $V$. dahliae and $B$. napus to associate alterations of parameters with symptom development.

Under greenhouse conditions premature ripening but most notably intensive stunting appear. Whether the symptom induction under these conditions also takes place independently from the pathogen presence in the sprout was investigated by PCR-detection of Verticillium-DNA in infected sprout and hypocotyle samples. Stunting, lower dry weight of sprout and root and visual ranking rates did not correlate with the presence of Verticillium-DNA in the appropriate sprout and hypocotyle samples. $V$. longisporum-derived symptoms thus are not dependent on the pathogen presence in the area of symptom occurence but rather induced systemically by pathogen-derived metabolites.

The infection of B. napus with $V$. dahliae promoted growth (sprout growth and higher sprout dry weight) whereas the pathogen during the whole plant development was restricted to the roots and crossed from hypocotyle into the sprout.

The hypothesis that NO is able to influence symptom develoment was proven by in vitro symptom induction experiments in which NO as chemical donors were applied on seedlings. With increasing concentrations of NO-donor SNP a clear effect on primary root length and sprout length was observed. This effect seemed to be of pharmacological nature because only SNP but not the second donor SNAP showed an effect on plant growth. The analysis of NO in xylem sap was performed by electron paramagnetic resonance spectrometry (ESR). Using this method, NO-typical signals in extracted xylem sap were detected for the first time. Samples were taken over a long period starting from the time of inoculation (NO detection in tissue) until the beginning of symptom occurence (14 dpi; NO detection in xylem sap) and complete colonization of host plant with the pathogen (35 dpi). Results revealed that V. longisporuminfected plants show a significantly diminished NO-content at the beginning of infection (14 
dpi) and at the end of infection (35 dpi) in comparison to $V$. dahliae-infected and control plants. Additionally NO-detection by HPLC and diaminofluoresceine diacetate (DAF-2DA) in plant tissue showed a lowered NO-content in V. longisporum-infected seedlings even after 14 hpi. An increase of reactive oxygen species was not detected, neither at time points shortly after infection -in plant tissue- nor at time points of symptom occurrence -in xylemsap-. In fact the NO-content in the compatible interaction with $V$. longisporum was diminished. The detailed analysis of $\mathrm{H}_{2} \mathrm{O}_{2}$ in sprout and root tissue showed no difference between infected (V. dahliae or $\boldsymbol{V}$. longisporum) and control plants. Only at $28 \mathrm{dpi}$ a significant but transient increase of $\mathrm{H}_{2} \mathrm{O}_{2}$ was detected in sprout and hypocotyle samples of $\mathrm{V}$. longisporuminfected plants.

Nitrosoglutathione (GSNO) is supposed to be a possible form of NO transport. Hence the detection of GSNO in plant tissue was performed. The appliance of an adapted HPLC method originally established for Glutathione (GSH) measurements failed because of side reactions and was not specific enough to be applied for plant sample measurements. Instead of direct detection, the indirect evidence of GSNO was analyzed by measuring the activity of the GSNO metabolizing enzyme GSNO-reductase. The results of GSNO-reductase activity showed that the acitivity increased with ongoing age of plants in all variants but was significantly higher in $V$. longisporum- and $V$. dahliae-infected plants in comparison to the control variant at 28 and 35 dpi in sprout as well as in root samples. Hence the activity of GSNO-reductase does not seem to be associated with symptom development as it increases in both the symptomless and symptom inducing interactions. The content of nitrosylated proteins was measured in parallel in addition to the analysis of GSNO reductase. With an increase of GSNO-reductase the presesce of nitrosylated proteins in sprout and root samples decreased in the $V$. dahliae and control variant. $V$. longisporum-infected plants on the other hand showed a lower content of nitrosylated proteins at the beginning of of infection and an increase at 21 dpi.

A possible connection between symptom development and phytohormone alterations was examined by analysis of the different stress-and pathogen attack indicating hormones abscisic acid (ABA), salicylic acid (SA), jasmonic acid (JA) and indole-3-acetic acid (IAA). It was shown that according to the results of nitric oxide analysis the $\boldsymbol{V}$. longisporum-infected variant was significantly different from control and $V$. dahliae variants at 14 and 35 dpi. Both SA and ABA-contents increased significantly in sprout samples at these time points. In plant/pathogen interactions an increase of SA is an indicator for the attack of a biotroph, incompatible pathogen, whereby usually SAR is induced. 
As confirmed in this interaction by a decrease of JA in sprout samples, antagonistic to the accumulation of SA, the activation of JA/ethylene signal transduction which provides the defence of necrotrophic pathogens is suppressed. First analysis of the ethylene precoursor ACC indicates that this phytohormone possibly influences symptom development, too. But due to a small amount of samples these analyses do not provide significant results and need to be repeated in more detail.

Experiments with $V$. longisporum-culture filtrates were performed because no experiments concerning a phytotoxic factor of $V$. longisporum which might have symptom inducing signalling function have been carried out until now. The influence of metabolites secreted into culture medium on symptom induction was analysed by application of sterile filtered $V$. longisporum-inoculated medium. In experiments with different media and size fractioning of supernatants by cellulose filter membranes, a fraction smaller than 5000Da was found which was not phytotoxic but induced stunting within seven days and was only produced in filtrates of xylemsap simulating medium and not in other standard growth media. Fractions $>$ $5000 \mathrm{Da}$ also diminished growth, but additionally induced phytotoxic damage by whereas the stunting in this case may be due to pleiotropic effects. Hence it can be concluded that the premature senescence and the stunting are two independently induced symptoms.

Due to its soilborn origin and biphasic dispersion the signaling pathways and defence mechanisms of this interaction with $B$. napus can hardly be determined in a tangible category or defined type of parasitism. The general defence strategies concerning necrotroph and biotroph pathogens (especially leaf-pathogens) seem to be suppressed by V. longisporum. The induction of signals for systemic defence mechanisms seem to be insufficient to stop the pathogens vascular dispersion. In proceeding experiments the means by which the initial pathogen defence of ROS-accumulation is suppressed, has to be analysed, as well as the chemical nature of symptom inducing metabolites. A purchase for further experiments is given by the fact that the disperion of $V$. dahliae is restricted to the hypocotyle. A resitant genotype, which could be used as a reference is not known. Recent information concerning resistant genotypes are promising starting points, which show an increased accumulation of lignine and phenolic compounds in the vascular system (EYNCK, 2008). 


\section{Literaturverzeichnis}

Abeles, F. B., Morgan, P. W., Saltveit, M. E. Jr. (1992). Ethylene in plant biology. San Diego, CA: Academic.

Adie, B. A. T., Perez-Perez, J., Perez-Perez, M. M., Godoy, M., SAnchez-Serrano, J. J., Schmelz, E. A., Solano, R. (2007). ABA is an essential signal for plant resistance to pathogens affecting JA biosynthesis and the activation of defenses in Arabidopsis. Plant Cell, 18, 1665-1681.

AHLERS, D. (1987). Untersuchungen über den Erreger der krankhaften Abreife an Winterraps. Gesunde Pflanzen, 39, 375-382.

A-H-Mackerness, S., Surplus, S. L., Blake, P., John, C. F., Buchanan-Wollaston, V., JORDAN, B. R., ThOMAs, B. (1999). Ultra-violet-B induced stress and changes in gene expression in Arabidopsis thaliana; role of signalling pathways controlled by jasmonic acid, ethylene and reactive oxygen species. Plant, Cell and Environment, 22, 14131423.

Allan, A. C. \& Fluhr, R. (1997). Two distinct sources of elicited reactive oxygen species in tobacco epidermal cells. The Plant Cell, 9, 1559-1572.

AMANO, F. \& NODA, T. (1995). Improved detection of nitric oxide radical (NO') production in an activated macrophage culture with a radical scavenger, carboxy PTIO, and Griess reagent. FEBS Letters, 368. 425-428.

Amelung, D., Schulz, R.-R. \& DAebeler, F. (1996). Einfluss der Fruchtfolge auf Rapskrankheiten. Raps, 14, 52-56.

Anderson, J. P., Badruzsaufari, E., Schenk, P. M., Manners, J. M. Desmond, O. J., Ehlert, C., Maclean, D. J., Ebert, P. R., Kazan, K. (2004). Antagonistic interaction between abscisic acid and jasmonate-ethylene signalling pathways modulates defence gene expression and disease resistance in Arabidopsis. Plant Cell, 16: 3460-3479.

ARCHER, S. (1993). Measurement of nitric oxide in biological models. The FASEB Journal, 7, 349-360.

Audenaert, K., De Meyer, G. B. \& Höfte, M. M. (2002). Abscisic acid determines basal susceptibility of tomato to Botrytis cinerea and suppresses salicylic acid-dependent signaling mechanisms. Plant Physiology, 128, 491-501.

Barceló, A. R., Pomar, F., Ferrer, M. A., Martinez, P., Ballesta, M. C., Pedreno, M. A. (2002). In situ characterization of a NO-sensitive peroxidase in the lignifying xylem of Zinnea elegans. Physiologia Plantarum, 114, 33-40. 
Barroso, J. B., Corpas, F. J., Carreras, A., Rodríguez-Serrano, M., Esteban, F. J., Fernández-Ocaña, A., Chaki, M., Romero-Puertas, M. C., Valderrama, R., SAndalio, L. M. \& Del Rio, L. A. (2006). Localization of S-nitrosoglutathione and expression of S-nitrosoglutathione reductase in pea plants under cadmium stress. Journal of Experimental Botany, 57, 1785-1793.

Barroso, J. B., Corpas, F. J., Carreras, A., Sandalio, L. M., Valderrama, R., Palma, J. M., LuPiÁÑEZ, J. A. \& DEL RIO, L. A. (1999). Localization of nitric-oxide synthase in plant peroxisomes. The Journal of Biological Chemistry, 274, 36729-36733.

Bartosz, G. (1997). Oxidative stress in plants. Acta Physiologica Plantarum, 19, 47-64.

Beckman, C. H. (1987). The Nature of Wilt Diseases in Plants. St. Paul, MN, USA: APS Press.

Beligni, M. V. \& Lamattina, L. (1999). Nitric oxide protects against cellular damage produced by methylviologen herbicides in potato plants. Nitric Oxide, 3, 199-208.

Beligni, M. V. \& Lamattina, L. (2000). Nitric oxide stimulates seed germination and detiolation, and inhibits hypocotyle elongation, three light-inducible responses in plants. Planta, 210, 215-21.

Beligni, M. V. \& LAmattinA, L. (2001). Nitric oxide in plants: the history is just beginning. Plant, Cell and Environment, 24, 267-278.

Beligni, M. V. \& Lamattina, L. (2002). Nitric oxide interferes with plant-photo oxidative stress by detoxifying reactive oxygen species. Plant, Cell and Environment, 25, 737748.

Beligni, M. V., Fath, A., Bethke, P. C., Lamattina, L. \& Jones, R. L. (2002). Nitric oxide acts as an antioxidant and delays programmed cell death in barley aleurone layers. Plant Physiology, 129, 1642-1650.

Berthke, P. C., Badger, M. R. \& Jones, R. L. (2004). Apoplastic synthesis of of nitric oxide in plant tissues. Plant Cell, 16, 332-341.

Bethke, P. C., Libourel, I. G. L., Reinöhl, V., Russell, L. J. (2005). Sodium nitroprusside, cyanide, nitrite, and nitrate break Arabidopsis seed dormancy in a nitric oxide-dependent manner. Planta, 2005.

Bewley, W. F. (1920). "Sleepy disease" or wilt of the tomato. Annual Report, Cheshunt Experimental and Research Station. 26-38. 
Boleda, M. D., Saubi, N., Farres, J. \& Pares, X. (1993). Physiological substrates for rat alcohol dehydrogenase classes: aldehydes of lipid peroxidation, $\omega$-hydroxyfatty acids, and retinoids, Archives of Biochemistry and Biophysics, 307, 85-90.

Bolwell, G. P., Blindschedler, L. V., Blee, K. A., Butt, V. S., Davies, D. R., Gardner, S. L., Gerrish, C., Minibayeva, F. (2002). The apoplastic oxidative burst in response to biotic stress in plants: a three component system. Journal of Experimental Botany, 53, 1367-1376.

Bothe, H., Klingner, A., Kaldorf, M., Schmitz, O., Esch, H., Hundeshagen, B., KERNEBECK, H. (1994). Biochemical approaches to the study of plant-fungal interactions in arbuscular mycorrhiza. Experientia, 50, 919-925.

Boucher, J. L., Genet, A., Vadon, S., Delaforge, Henry, Y., Mansuy, D. (1992). Cytochrome P450 catalyzes the oxidation of $\mathrm{N}^{\omega}$-hydroxy-L-aArginine by NADPH and $\mathrm{O}_{2}$ to nitric oxide and citrulline. Biochemical and Biophysical Research Communications, 187, 880-886.

Bradley, D., KJellbom, P., LAmB, C. (1992). Elicitor- and wound-induced oxidative crosslinkking of a signall-rich plant cell wall protein: a novel rapid defense response. Cell, $70,21-30$.

BRENNAN, T. \& FRENKEL, C. (1977). Involvement of hydrogen peroxide in the regulation of senescence in pear. Plant Physiology, 59, 411-416.

Broeckaert, W. F., Terras, F. R. G., Cammue, B. P. A. \& Osborn, R. W. (1995). Plant defensins: novel antimicrobial peptides as signalling of the host defense system. Plant Physiology, 108, 1353-1358.

BuCHNER, V., NACHMIAS, A. \& BURSTEIN, Y. (1982). Isolation and partial characterization of a phytotoxic glycopeptide from a protein-lipopolysaccharide complex produced by a potato isolate of Verticillium dahliae. FEBS Letters, 138, 261-264.

Caro, A. \& Puntarulo, S. (1999). Nitric oxide generation by soybean embryonic axes. Possible effect on mitochondrial function. Free Radical Research, 31, 205-212.

Cessna, S. G., Sears, V. E., Dickman, M. B. \& Low, P. S. (2000) Oxalic acid, a pathogenicity factor for Sclerotinia sclerotiorum, supresses the oxidative burst of the host plant. The Plant Cell, 12, 2191-2199.

Chandok, M. R., Ytterberg, A. J., Van Wijk, K. J., Klessig, D. F. (2003). The pathogeninducible nitric oxide synthase (iNOS) in plants is a variant of the $\mathrm{P}$ protein of the glycine decarboxylase complex. The Cell, 113, 469-482. 
Chepenko, L. I., Runov, V. I. \& Borodin, G. I. (1969). On the nature of electrophoretically mobile toxic substances of the Verticillium wilt pathogen of cotton. Uzbeksii Biologicheskii Zhurnal, 13, 13-15.

Christodoulou, D., Kudo, S., Cook, J. A., Krishna, M. C., Miles, A., Grisham, M. B. Murugesan, R., Ford, P. C. \& WinK, D. A. (1996). Electrochemical methods for detection of nitric oxide. Methods in Enzymology, 268, 69-83.

ChU, Z. Q., JiA, J. W., Zhou, X. J. \& Chen, X. Y. (1999). Isolation of glycoproteins from Verticillium dahliae and their phytotoxicity. Acta Botanica Sinica, 41, 972-976.

Clark, D., Durner, J., Navarre, D. A., Klessig, D. F. (2000). Nitric oxide inhibition of tobacco catalase and ascorbate peroxidase. Molecular Plant-Microbe Interactions, 13, $1380-1384$.

Clarke, A., Desikan, R., Hurst, R. D., Hancock, J. T. \& Neill, S. J. (2000). NO way back: Nitric oxide and programmed cell death in Arabidopsis thaliana suspension cultures. Plant Journal, 24, 667-677.

CoHEN, J. (1996). In vitro tomato fruit cultures demonstrate a role for indole-3-acetic acid in regulating fruit ripening. Journal of the American Society for Horticultural Science, $121,520-524$.

Collins, A., Okoli, C. A. N., Morton A., Parry, D., Edwards, S. G. \& Barbara, D. J. (2003). Isolates of Verticillium dahliae pathogenic to crucifers are of at least three distinct molecular types. Phytopathology, 78, 1017-1021.

Conrath, U., Amoroso, G., Köhle, H. \& SÜltemeyer, F. D. (2004). Non-invasive online detection of nitric oxide from plants and some other organisms by mass spectrometry. The Plant Journal, 38, 1015-1022.

Cooney, R. V., Harwood, P. J., Custer, L. J. \& Franke, A. A. (1994). Light-mediated conversion of nitrogen dioxide to nitric oxide by carotenoids. Environmental Health Perspectives, 102, 460-462.

Corpas, F. J., Barroso, J. B., Carreras, A., Quirós, M., León, A. M., Romero-Puertas, M. C., Esteban, F. J., Valderrama, R., Palma, J. M., Sandalio, L. M., Gómez, M. \& Del Río, L. A. (2004). Cellular and subcellular localization of endogenous nitric oxide in young and senescent pea plants. Plant Physiology, 136, 2722-2733.

Correa-Aragunde, N., Graziano, M. \& Lamattina, L. (2004). Nitric oxide plays a central role in determining lateral root development in tomato. Planta, 218, 900-905.

Crocoll, C., Kettner, J. \& Dörffling, K. (1991). Abscisic acid in saprophytic and parasitic species of fungi. Phytochemistry, 30, 1059-1060. 
Cueto, M., Hernández-Perera, O., Martín, R., Bentura, M. L., Rodrigo, J., Lamas, S., Golvano, M. P. (1996). Presence of nitric oxide synthase activity in roots and nodules of Lupinus albus. FEBS Letters, 398, 159-164.

Daebeler, F., Amelung, D. \& Zeise, K. (1988). Verticillium-Welke an Winterraps Auftreten und Bedeutung. Nachrichtenblatt für den deutschen Pflanzenschutz in der DDR, 42 (4), 71-73.

Danneberg, G., Latus, Z., Zimmer, W., Hundeshagen, B., Schneiderpoetsch, H., Bothe, H. (1993). Influence of vesicular-arbuscular mycorrhiza on phytohormone balance in maize (Zea mays L.). Journal of Plant Physiology, 141, 33-39.

Dangl, J. L., Dietrich, R. A. \& Richberg, M. H. (1996). Death don't have no mercy: Cell death programs in plant-microbe interactions. The Plant Cell, 8, 1793-1807.

Davis, D. A., Low, P. S. \& Heinstein, P. (1998). Purification of a glycoprotein elicitor of phytoalexin formation from Verticillium dahliae. Physiological and Molecular Plant Pathology, 52, 259-273.

DBV 2006: http://print.veredlungsproduktion.de/pages/de/rapsnews/cpd/1208.html

Delledonne, M., Xia, Y., Dixon, R. A. \& Lamb, C. (1998). Nitric oxide functions as a signal in plant disease resistance. Nature, 394, 585-588.

Delledonne, M., Zeier, J., Marocco, A. \& LAmb, C. (2001). Signal interactions between nitric oxide and reactive oxygen intermediates in the plant hypersensitive disease resistance response. Proceedings of the National Academy of Sciences USA, 98, 1345413459.

Del Río, L. A., Corpas, F. J. \& Barroso, J. B. (2004). Nitric oxide and nitric oxide synthase activity in plants. Phytochemistry, 65, 783-792.

De Pinto, M.C., Tommasi, F., De Gara, L. (2002). Changes in the antioxidant systems as part of the signaling pathway responsible for the programmed cell death activated by nitric oxide and reactive oxygen species in tobacco blight-yellow 2 cells. Plant Physiology, 130, 698-708.

Desikan, R., Cheung, M.-K., Bright, J., Henson, D., Hancock, J. T. \& Neill, S. (2004). ABA, hydrogen peroxide and nitric oxide signaling in stomatal guard cells. Journal of Experimental Botany, 55, Crosstalk in Plant Signal Transduction Special Issue, pp. 205-212.

Desikan, R., Hancock, J. T., Coffey, M. J., Neill, S. J. (1996). Generation of active oxygen in elicited cells of Arabidopsis thaliana is mediated by NADPH oxidase-like enzyme. FEBS Letters, 382, 213-217. 
Desikan, R., Reynolds, A., Hancock, J. T. Neill, S. J. (1998). Hairpin and hydrogen peroxide both initiate programmed cell death but have differential effects on gene expression in Arabidopsis suspension cultures. Biochemical Journal 330, 115-120.

Dörffling, K., Petersen, W., Sprecher, E., Urbasch, I. \& Hanssen, H.-P. (1984). Abscisic acid in phytopathogenic fungi of the genera Botrytis, Ceratocystis, Fusarium, and Rhizoctonia. Zeitschrift für Naturforschung Section C Biosciences, 39, 683-684.

Diaz, M., Achkor, H., Titarenko, E., Martinez, M. C. (2003). The gene encoding glutathione-dependent formaldehyde dehydrogenase/GSNO reductase is responsive to wounding, jasmonic acid and salicylic acid. FEBS Letters, 543, 136-139.

Dixelius, C., Happstadius, I. \& Berg, G. (2005). Verticillium wilt on Brassica oilseed crops-a swedish perspective. Journal of the Swedish Seed Association, 115, 36-48.

Dixon, R. A. \& PaIVA, N. L. (1995). Stress-induced phenylpropanoid metabolism. The Plant Cell, 7,1085-1097.

Domsch, K. H., Gams, W. \& Anderson, T. H. (1980). Compendium of soil fungi. London: Academic Press, 840-841.

Dordas, C., Hasinoff, B. B., Rivoal, J. \& Hill, R. D. (2004). Class-1 hemoglobins, nitrate and NO levels in anoxic maize cell-suspension cultures, Planta, 219, 66-72.

Dorey, S., Kopp, M., Geoffroy, P., Fritig, B. \& Kauffmann, S. (1999). Hydrogen peroxide from the oxidative burst is neither necessary nor sufficient for hypersensitive cell death induction, phenylalanine ammonium lyase stimulation, salicylic acid accumulation, or scopoletin consumption in cultured tobacco cells treated with elicitin. Plant Physiology, 121, 163-171.

Dubery, I. A. \& SMit, F. (1994). Phenylalanine ammonia-lyase from cotton (Gossypium hirsutum) hypocotyls: properties of the enzyme induced by a Verticillium dahliae phytotoxin. Biochimica et Biophysica Acta, 1207, 24-30.

DuNKER, S. (2006). Untersuchungen zur Schadwirkung von Sclerotinia sclerotiorum (Lib. De Bary) und Verticillium longisporum (comb. Nov. Karapapa) in Winterraps (Brassica napus). Dissertation, Georg-August Universität Göttingen.

Dunker, S., Keunecke, H., Von Tiedemann, A. (2006). Verticillium longisporum in winter oilseed rape-Impact on plant development and yield. Integrated Control in Oilseed Crops, 29, 365-374.

Dunker, S. \& Von Tiedemann, A. (2005). Zur Ertragswirkung von Pilzkrankheiten im Raps. Raps, 23, 6-19. 
DURNER, J. \& KLESSIG, D. F. (1995). Inhibition of ascorbate peroxidase by salicylic acid and 2,6-dichloroisonicotinic acid, two inducers of plant defense responses. Proceedings of the National Academy of Sciences USA, 92, 11312-11316.

Durner, J. \& Klessig, D. F. (1999). Nitric oxide as a signal in plants. Current Opinions in Plant Biology, 2, 369-374.

Durner, J., Wendehenne, D., Klessig, D. F., (1998). Defense gene induction in tobacco by nitric oxide, cyclic GMP, and cyclic ADP ribose. Proceedings of the National Academy of Sciences USA, 95, 10328-10333.

Eisenthal, R. \& DAnson, M. J. (1992). Enzyme Assays: A Practical Approach. Oxford University Press.

Espey, M. G., Miranda, K. M., Thomas, D. D., WinK, D. A. (2002). Focusing of nitric oxide mediated nitrosation and oxidative nitrosylation as a consequence of reaction with superoxide. Proceedings of the National Academy of Sciences USA, 99, 11127-11132.

Espunya, M. C., Díaz, M., Moreno-Romero, J. \& Martínez, M. C. (2006). Modification of intracellular levels of glutathione-dependent formaldehyde dehydrogenase alters glutathione homeostasis and root development. Plant, Cell and Environment, 29, 10021011.

EYNCK, C. (2008). Identification of resistance sources and characterization of resistance factors in Brassica species to Verticillium longisporum. Dissertation, Georg-AugustUniversität Göttingen.

Eynck, C., Koopmann, B., Grunewaldt-Stöcker, G., Karlovsky, P., Von Tiedemann, A. (2007). Differential interactions of Verticillium longisporum and V. dahliae with Brassica napus detected with molecular and histological techniques. European Journal of Plant Pathology, 118, 259-274.

Feechan, A., Kwon, E., Yun, B.-W., Wang, Y., Pallas, J. A. \& Loake, G. J. (2005). A central role for S-nitrosothiols in plant disease resistance. Proceedings of the National Academy of Science USA. 102, 8054-8059.

FEELISCH, M. (1991). The biochemical pathways of nitric oxide formation from nitrovasodilators: Appropriate choice of exogenous NO donors and aspects of preparation and hadling of aqueous NO solutions. Journal of Cardiovascular Pharmacology, 17 (Suppl.3), 25-33.

FeElisch, M. \& StAmLER, J. S. (1996). Methods in nitric oxide research, John Wiley \& Sons, Chichester. 
Ferrer, M. A. \& Ros Barcelo, A. (1999). Differential effects of nitric oxide on peroxidase and $\mathrm{H}_{2} \mathrm{O}_{2}$ production by the xylem of Zinnia elegans. Plant, Cell \& Environment, 22, 891-897.

Floryszak-Wieczorek, J., Arasimowicz, M., Milczarek, G., Jelen, H. \& Jackowiak, H. (2007). Only an early nitric oxide burst and the following wave of secondary nitric oxide generation enhanced effective defence response of pelargonium to a necrotrophic pathogen. New Phytologist, 175, 718-730.

Foissner, I., Wendehenne, D., LANGeBartels, C. \& Durner, J. (2000). In vivo imaging of an elicitor-induced nitric oxide burst in tobacco. The Plant Journal, 23, 817-824.

Fradin, E. F. \& Thomma, B. P. H. J. (2006). Physiology and molecular aspects of Verticillium wilt diseases caused by $V$. dahliae and V. albo-atrum. Molecular Plant Pathology, 7, 71-86.

FURCHGOTT, R. F. (1999). Endothelium-derived relaxing factor: discovery, early studies, and identification as nitric oxide. In Les Prix Nobel 1998, pp. 226-243 (The Nobel Foundation, Stockholm, Sweden) (1999). [Also published in Angewandte Chemie, 38, 1870-1880 (1999), und in Bioscience Reports, 19, 235-251 (1999)].

FurchgotT, R. F. \& ZAWADSKI, J. V. (1980). The obligatory role of endothelial cells in the relaxation of arterial smooth muscle by acetylcholine. Nature, 288, 373-376.

Gabaldon, C., Gomez Ros, L. V., Pedreño, M. A. \& Ros Barcelo, A. (2005). Nitric oxide production by the differentiating xylem of Zinnia elegans. New Phytologist, 165, 121130.

Galanopoulus, W. \& Triebe, M. T. (1974). Conidial survival of $V$. dahliae. Transactions of the British Mycological Society, 63, 85-91.

Garcês, H., Durzan, D. \&Pedroso, M. C. (2001). Mechanical stress elicits nitric oxide formation and DNA fragmentation in Arabidopsis thaliana. Annals of Botany, 87, 567574.

GARCÍA-MAtA, C. \& LAMATtinA, L. (2002). Nitric oxide and abscisic acid cross talk in guard cells. Plant Physiology, 128, 790-792.

Giraudat, J., Parcy, F., Bertauche, N., Gosti, F., Leung, J. (1994). Current advances in abscisic acid signalling. Plant Molecular Biology, 26, 1557-1577.

Gold J., LeE B. \& RoBB, J. (1996). Colonization of tomatoes by Verticillium dahliae: determinative phase II. Canadian Journal of Botany, 74, 1279-88.

Goldstein, J. L. \& SwaIn, R. (1965). The inhibition of enzymes by tannins. Phytochemistry, 4, 185-192. 
Gould, K. S., Lamotte, O., Klinguer, A., Pugin, A. \& Wendehenne, D. (2003). Nitric oxide production in tobacco leaf cells: a generalized stress response? Plant, Cell and Environment, 26, 1851-1862.

GouvêA, C. M. C. P, Souza, J. F., Magalhães, A. C. N. \& Martins, I. S. (1997). NO•releasing substances that induce growth elongation in maize root segments. Plant Growth Regulation, 21, 183-187.

Govrin, E. M. \& LEvine, A. (2000). The hypersensitive response facilitates plant infection by the necrotrophic pathogen Botrytis cinerea. Current Biology, 10, 751-757.

Gow, A. J., Luchsinger, B. P., Pawloski, J. P., Singel, D. J., Stamler, J. S. (1999). The oxyhaemoglobin reaction of nitric oxide. Proceedings of the National Academy of Sciences USA, 96, 9027-9032.

GrANT, J. J. \& LOAKE, G. J. (2000). Role of reactive oxygen intermediates and cognate redox signaling in disease resistance. Plant Physiology, 124, 21-29.

Graziano, M., Beligni, M. V., LAmattina, L. (2002). Nitric oxide improves internal iron availability in plants. Plant Physiology,130,1852-9.

GreEN, R. J. (1954). A preliminary investigation of toxins produced in vitro by Verticillium albo-atrum. Phytopathology, 44, 319-326.

Greenberg, J. T. \& YaO, N. (2004). The role and regulation of programmed cell death in plant-pathogen interactions. Cellular Microbiology, 6, 201-211.

Grossmann, K. (1996). A role for cyanide, derived from ethylene biosynthesis, in the development of stress symptoms. Physiologia Plantarum, 97, 772-775.

Grossmann, K. (2000). The mode of action of auxin herbicides: A new ending to a long, drawn out story. Trends in Plant Science, 5, 506-508.

Grossmann, K, Hansen, H. (2001). Ethylene-triggered abscisic acid: A principle in plant growth regulation? Physiologia Plantarum, 113, 9-21.

Guan, L. M. \& Scandalios, J. G., (2000). Hydrogen peroxide-mediated catalase gene expression in response to wounding. Free Radical Biology and Medicine, 28, 11821190.

GünZelmanN, H. \& PAUl, V. H. (1990). Zum Auftreten und zur Bedeutung der VerticilliumWelke an Raps in der Bundesrepublik Deutschland in 1989. Raps, 8, 23-25.

Guo, P., Okamoto, M., Crawford, N. (2003). Identification of a plant nitric oxide synthase gene involved in hormonal signalling. Science 302, 100-103.

Hansen, H. \& Grossmann, K. (2000). Auxin-induced ethylene triggers abscisic acid biosynthesis and growth inhibition. Plant Physiology, 124, 1437-1448. 
Happstadius, I., LJungberG, A., Kristiansson, B. \& DiXelius, C. (2003). Identification of Brassica oleracea germplasm with improved resistance to Verticillium wilt. Plant Breeding, 122, 30-34.

HARRIS, R. V. (1953). Wilt tolerant hops. Report of the East Malling Research Station 1953, 208-209.

HARRISON, M. J. (1999). Molecular and cellular aspects of the arbuscular mycorrhizal symbiosis. Annual Review of Plant Physiology and Plant Molecular Biology, 50, 361389.

He, Y., Tang, R.-H., Hao, Y., Stevens, R. D., Cook, C. W., Ahn, S. M., Jing, L., Yang, Z., Chen, L., Guo, F., Fiorani, F., Jackson, R. B., Crawford, N. M., Pei, Z.-M. (2004). Nitric oxide represses the Arabidopsis floral transition. Science, 305, 1968-1971.

Heale, J. B. \& Gupta, D. P. (1972). Mechanism of vascular wilting induced by Verticillium albo-atrum. Transactions of the British Mycological Society, 58, 19-28.

Heale, J. \& Karapapa, V. K. (1999). The Verticillium threat to Canada's major oilseed crop: Canola. Canadian Journal of Plant Pathology, 21, 1-7.

Hermanns, M., Slusarenko, A. J. \& Schlaich, A. J. (2003). Organ-specificity in a plant disease is determined independently of $\mathrm{R}$ gene signalling. Molecular Plant Microbe Interactions, 16, 752-759.

Hill, H. D. \& Straka, J. G. (1988). Protein determination using bicinchoninic acid in the presence of sulfhydryl reagents. Analytical Biochemistry, 170, 203-208.

Hornig, H. (1986). Krankhafte Abreife - Spätschäden durch Phoma lingam und/oder Verticillium dahliae? Raps, 4: 83-85.

Hu, X. Y., NeILl, S. J., CAL, W. M. \& TANG, Z. C. (2003). Nitric oxide mediates elicitorinduced saponin synthesis in cell cultures of Panax ginseng. Functional Plant Biology, 30, 901-907.

HU, X. \& REDDY, A. S. N. (1997). Cloning and expression of a PR5-like protein from Arabidopsis: inhibition of fungal growth by bacterially expressed protein. Plant Molecular Biology, 34, 949-959.

Huang, G., Dong, R., Maier, T., Allen, R., Davis, E. L., Baum, T. J., Hussey, R. S. (2004a). Use of solid-phase substractive hybridization for the identification of parasitism gene candidates from the root-knot nematode Meloidogyne incognita. Molecular Plant Pathology, 5, 217-222. 
Huang, J., Sommers, E. M., Kim-Shapiro, D. B., King, S. B. (2002). Horseraddish peroxidase catalyzes nitric oxide formation from hydoxyurea. Journal of the American Chemical Society, 124, 3473-3480.

Huang, X., Stettmaier, K., Michel, C., Hutzler, P., Mueller, M. J., Durner, J. (2004b). Nitric oxide is induced by wounding and influences jasmonic acid signalling in Arabidopsis thalinana. Planta, 218, 938-946.

IgNARRO, L. J. (2000). Nitric Oxide, Biology and Pathobiology. Academic Press, San Diego, CA.

Ignarro, L. J., Buga, G. M., Wood, S., Byrns, R. E. \& Chaudhuri, G. (1987). Endothelium-derived relaxing factor produced and released from artery and vein is nitric oxide. Proceedings of the National Academy of Sciences USA, 84, 9265-9269.

Itoh, Y., Ma, F. H., Hoshi, H., OKa, M., Noda, K., Ukai, Y., KoJima, H., Nagano, T. \& ToDA, N. (2000). Determination and bioimaging method for nitric oxide in biological specimens by diaminofluorescein fluorometry. Analytical Biochemistry, 287, 203-209.

Jabs, T., TschöPe, M., Colling, C., Hahlbrock, K. \& Scheel, D. (1997). Elicitorstimulated ion fluxes and $\mathrm{O}_{2}^{-}$from the oxidative burst are essential components in triggering defense gene activation and Phytoalexin synthesis in parsley. Proceedings of the National Academy of Sciences USA, 94, 4800-4805.

Jia, L., Bonaventura, C., Bonaventura, J. \& Stamler, J. S. (1996). S-nitrosohaemoglobin: a dynamic activity of blood involved in vascular control. Nature, 380, 221-226.

KAMAL, M. \& Wood, R. K. S., (1956). Pectic enzymes secreted by Verticillium dahliae and their role in the development of wilt disease in cotton. Annals of Applied Biology, 44, 322.

Karapapa, V. K., Bainbridge B. W. \& Heale, J. B. (1994). Diploid isolates of Verticillium dahliae viz. V. dahliae var. longisporum STARK causing vascular wilt disease in oilseed rape. $6^{\text {th }}$ International Verticillium-Symposium, Dead Sea, Israel, $19^{\text {th }}-25^{\text {th }}$ June.

Karapapa, V. K., Bainbridge, B. W. \& Heale, J. B. (1997). Morphological and molecular characterization of Verticillium longisporum comb. Nov., pathogenic to oilseed rape. Mycological Research, 101, 1281-1294.

Keen, N. T., Long, E. \& ERwin, D. C. (1972). Possible involvement of a pathogen produced protein-lipopolysaccharide complex in Verticillium wilt of cotton. Physiological Plant Pathology, 2, 317-331. 
Kers, J. A., Wach, M. J., Krasnoff, S. B., Widom, J., Cameron, K. D., Bukhalid, R. A., Gibson, D. M., Crane, B. R., Loria, R. (2004). Nitration of a peptide phytotoxin by bacterial nitric oxide synthase. Nature, 429, 79-82.

KettNer, J. \& DöRfFLing, K. (1995). Biosynthesis and metabolism of abscisic acid in tomato leaves infected with Botrytis cinerea. Planta, 196, 627-634.

KeUneCKE, H. (2005): Einfluss von Verticillium longisporum auf die Wurzel- und Sprossentwicklung von Winterraps unter Berücksichtigung von Fungizidapplikationen. Diplomarbeit, Georg-August Universität Göttingen.

Kiessing, R. \& Haller-Kiessing, R. (1956). Beitrag zur Kenntnis einer infektiösen Welkekrankheit der Luzerne (Verticillium albo-atrum R. et B.). Phytopathologische Zeitschrift, 31, 185-222.

Kitamura, Y., Ogawa, H. \& OKA, K. (2003). Real-time measurement of nitric oxide using a bio-imaging and an electrochemical method. Talanta, 61, 717-724.

Kleschyov, A. L., Wenzel, P. \& Munzel, T. (2007). Electron paramagnetic resonance (EPR) spin trapping of biological nitric oxide. Journal of Chromatography B, 851, 12 20 .

Klessig, D. F., Durner, J., Noad, R., Navarre, D. A., Wendehenne, D., Kumar, D., Zhou, J. M., Shah, J., Zhang, S., Kachroo, P., Trifa, Y., Pontier, D., Lam, E. \& Silva, H. (2000). Nitric oxide and salicylic acid signalling in plant defense. Proceedings of the National Academy of Sciences USA, 97, 8849-8855.

Kluge, I., Gutteck-Amsler, U., Zollinger, M. \& Do, K. Q. (1997). S-Nitrosoglutahione in rat cerebellum: identification and quantification by liquid chromatography-mass spectrometry. Journal of Neurochemistry, 69, 2599-2607.

Kojima, H., Nakatsubo, N., Kikuchi, K., Kawahara, S., Kirino, Y., Nagoshi, H., HiRAtA, Y. \& NAgAnO, T. (1998). Detection and imaging of nitric oxide with novel fluorescent indicators: Diaminofluoresceins. Analytical Chemistry, 70, 2446-2453.

Krasil'nikov, N. A., Khodzhibaeva, S. M. \& MirchinK, T. G. (1965). Formation of toxins by Verticillium dahliae, the causal agent of cotton wilt. Agrokhimiya, 10, 128-134.

Kreye, H., Steinbach, P., Wolf, G. A. (2006). Determination of risk-factors for the occurrence of Verticillium longisporum. IOBC Bulletin, 7, 361-364.

KRÜGER W. (1989). Untersuchungen zur Verbreitung von Verticillium dahliae Kleb. Und anderen Krankheits- und Schaderregern bei Raps in der Bundesrepublik Deutschland. Nachrichtenblatt Deutscher Pflanzenschutzdienst, 41, 49-56. 
KUNERT, J. (1995). Effect of nitric oxide donors on survival of conidia, germination and growth of Aspergillus fumigatus in vitro. Folia Microbiology, 40, 238-244.

Kuusk, A.-K., Happstadius I., Zhou L., Steventon L. A., Griese H., Dixelius, C. (2002). Presence of Leptospheria maculans group A and group B isolates in sweden. Journal of Phytopathology, 150, 349-356.

Lamattina, L., García-Mata, C., Graziano, M. \& Pagnussat, G. (2003). Nitric Oxide: The versatility of an extensive signal molecule. Annual Review of Plant Biology, 54, 109-136.

LAmB, C. \& Dixon, R. A. (1997). The oxidative burst in plant disease resistance. Annual Review of Plant Physiology and Plant Molecular Biology, 48, 251-275.

Lamotte, O., Gould, K., LecourieuX, D., Sequeira-Legrand, A., Lebrun-Garcia, A., Durner, J., Pugin, A. \& Wendehenne, D. (2004). Analysis of nitric oxide signalling functions in tobacco cells challenged by the elicitor cryptogein. Plant Physiology, 135, 516-529.

Langebartels, C., Schraudner, M., Heller, W., Ernst, D., Sandermann, H. (2000). Oxidative stress and defence reactions in plants exposed to air pollutants and UV-B radiation. In: Inzé, D., Van Montagu, M. eds, Oxidative stress in plants. Amsterdam: Harwood, academic Publishers, 105-135.

Lee, S., Choi, H., Suh, S., Doo, I.-S., OH, K.-Y., Chol, E. J., TAYlor, A. T. S., Low, P. S., LEE, Y. (1999). Oligalacturonic acid and chitosan reduce stomatal aperture by inducing the evolution of reactive oxygen species from guard cells of tomato and Commelina communis. Plant Physiology, 121, 147-152.

Leshem, Y. Y. \& HARAMATY, E. (1996). The characterization and contrasting effects of the nitric oxide free radical in vegetative stress and senescence of Pisum sativum Linn. foliage. Journal of Plant Physiology, 148, 258-263.

Leshem, Y. Y. \& Pinchasov, Y. (2000). Non-invasive photoacustic spectroscopic determination of relative endogenous nitric oxide and ethylene content stoichiometry during the ripening of strawberries Fragaria anannasa (Duch.) and avocados Persea americana (Mill.). Journal of Experimental Botany, 51, 1471-1473.

Leshem, Y. Y., WiLls, R. B. H. \& KU, V. V.-V. (1998). Evidence for the function of the free radical gas - nitric oxide $\left(\mathrm{NO}^{\circ}\right)$ - as an endogenous maturation and senescence regulating factor in higher plants. Plant Physiology and Biochemistry, 36, 825-833. 
Levine, A. Tenhaken, R., Dixon, R., Lamb, C. (1994). $\mathrm{H}_{2} \mathrm{O}_{2}$ from the oxidative burst orchestrates the plant hypersensitive disease resistace response. Current Biology, 6, 427-437.

LIN, J. N. \& KAO, C. H. (1998). Effect of oxidative stress caused by hydrogen peroxide on senescence of rice leaves. Botanical Bulletin of Academia Sinica, 39, 161-165.

Lindermayr, C., SaAlbach, G., Durner, J. (2005). Proteomic identification of Snitrosylated proteins in Arabidopsis. Plant Physiology, 137, 921-930.

Liszkay, A., Van Der Zalm, E., Schopfer, P. (2004). Production of reactive oxygen intermediates $\left(\mathrm{O}_{2}, \mathrm{H}_{2} \mathrm{O}_{2}\right.$ and $\left.\mathrm{OH}\right)$ by maize roots and their role in wall loosening and elongation growth. Plant Physiology, 136, 3114-3123.

Liu, L., Hausladen, A., Zeng, M., Que, L., Heitman, J., Stamler, J. S. (2001). A metabolic enzyme for S-nitrosothiol conserved from bacteria to humans. Nature, 410, 490-494.

Loomis, W. D. (1969). Removal of phenolic compounds during the isolation of plant enzymes. In: LowensteIn, J. M. eds. Methods in Enzymology, 13, 555-563.

Loomis, W. D. \& Bataille, J. (1996). Plant phenolic compounds and the isolation of plant enzymes. Phytochemistry, 5, 423-438.

lopez-Huertas, E., Charlton, W. L., Johnson, B., Graham, I. A., Baker, A. (2000) Stress induces peroxisome biogenesis genes. EMBO Journal, 19, 6770-6777.

MacNevin, W. M. \& Urone, P. F. (1953). Separation of hydrogen peroxide from organic hydroperoxides. Analytical Chemistry, 25, 1760-1761.

Maier, J., Hecker, R., Rockel, P. \& Ninnemann, H. (2001). Role of nitric oxide synthase in the light-induced development of sporangiophores in Phycomyces blakesleeanus. Plant Physiology, 126, 1323-1330.

Malagnac, F., Lalucque, H., Lepère, G., Silar, P. (2004). Two NADPH oxidase isoforms are required for sexual reproduction and ascospore germination in the filamentous fungus Podospora anserina. Fungal Genetics and Biology, 41, 98-997.

MAlinski, T., BAiley, F., ZhANG, Z. G. \& ChOpP, M. (1993). Nitric oxide measured by a porphyrinic microsensor in rat brain after transient middle cerebral artery occlusion. Journal of Cerebral Blood Flow and Metabolism, 13, 355-358.

MANSOORI, B. \& SMITH, C. J. (2005). Elicitation of ethylene by Verticillium albo-atrum phytotoxins in potato. Journal of Phytopathology, 153, 143-149. 
Marion-Poll, A. \& Leung, J. (2006). Abscisic acid synthesis, metabolism and signal transduction. In: Plant Hormone Signaling, Annual Plant Reviews, Vol. 24, eds.: Hedden, P. \& Thomas, S. G. Blackwell Publishing Ltd.

Martínez, M. C., AchKor, H., Persson, B., Fernández, M. R., Shafquat, J., Farrés, J., JÖRnVAlL, H. \& PARÉS, X. (1996). Arabidopsis formaldehyde dehydrogenase. Molecular properties of plant class III alcohol dehydrogenase provide further insights into the origins, structure and function of plant class $\mathrm{P}$ and liver class I alcohol dehydrogenases. European Journal of Biochemistry, 241, 849-857.

Mathieu, C., Moreau, S., Frendo, P., Puppo, A. \& Davies, M. J. (1998). Direct detection of radicals in intact soybean nodules: Presence of nitric oxide-leghaemoglobin complexes. Free Radical Biology \& Medicine, 24, 1242-1249.

McAinsch, M. R., Clayton, H., Mansfield, T. A., Hetherington, A. M. (1996). Changes in stomatal behaviour and guard cell cytosolic free calcium in response to oxidative stress. Plant Physiology, 111, 1031-1042.

Melillo, T., Leonetti, P., Bongiovanni, M., Castagnone-Sereno, P., \& Bleve-Zacheo, T. (2006). Modulation of reactive oxygen species activities and $\mathrm{H}_{2} \mathrm{O}_{2}$ accumulation during compatible and incompatible tomato-root knot nematode interactions. New Phytologist, 170, 501-5012.

Menzies, J. D., \& GRIEBEL, G. E. (1967). Survival and saprophytic growth of Verticillium dahliae in uncropped soil. Phytopathology, 57, 703-709.

Mepsted, R., Flood, J., CoOPeR, R. M. (1995). Fusarium wilt of oil palm II. Stunting as a mechanism to reduce water stress. Physiological and Molecular Plant Pathology, 46, 373-387.

Messena, I., Rossetti, D. V., Misiti, F., Vincenzoni, F., Tellone, E., Giardina, B., Castagnole, M. (2000) Determination of S-nitrosoglutathione in erythrocytes by capillary zone electrophoresis. Electrophoresis, 21, 1606-1610.

Meyer, O. \& Schlegel, H. G. (1983). Biology of aerobic carbon monoxide-oxidizing bacteria. Annual Review of Microbiology, 37, 277-310.

MEYer, R. \& Dubery, I. A. (1993). High-affinity binding of a protein-lipopolysaccharide phytotoxin from Verticillium dahliae to cotton. FEBS Letters, 335, 203-206.

Meyer, R., Slater, V. \& Dubery, I. A. (1994). A phytotoxic protein-lipopolysaccharide complex produced by Verticillium dahliae. Phytochemistry, 35, 1449-1453. 
Michelakis, E. D. \& ARChER, S. L. (1998). The measurement of NO in biological systems using chemiluminescence. Methods in Molecular Biology, 100, Nitric Oxide Protocols, 111-127.

Mills, P. C., Richardson, D. J., Hinton, J. C. D. \& Spiro, S. (2005). Detoxification of nitric oxide by the flavorubredoxin of Salmonella enterica serovar typhimurium. Biochemical Society Transactions, 33, 198-199.

Mittler, R., Herr, E. H., Orvar, B. L., Van CAmp, W., Willekens, H., Inzé, D., Ellis, B. E. (1999). Transgenic tobacco plants with reduced capability to detoxify reactive oxygen intermediates are hyperresponsive to pathogen infection. Proceedings of the National Academy of Sciences USA; 96, 14165-14170.

Modolo, L. V., Cunha, F. Q., Braga, M. R. \& Salgado, I. (2002) Nitric oxide synthasemediated phytoalexin accumulation in soybean cotyledons in response to the Diaporthe phaseolorum f. sp. meridionalis elicitor. Plant Physiology, 130, 1288-1297.

Mohr, P. G. \& CAHILl, D. M. (2007). Suppression by ABA of salicylic acid and lignin accumulation and the expression of multiple genes, in Arabidopsis infected with Pseudomonas syringae pv. tomato. Functional \& Integrative Genomics, 7, 181-191.

MOL, L. (1995). Effects of plant roots on the germination of microsclerotia of Verticillium dahliae. II. Quantitative analysis of the luring effect of crops. European Journal of Plant Pathology, 101, 679-685.

Mol, L. \& Scholte, K. (1995). Formation of microsclerotia of Verticillium dahliae Kleb. on various plant parts of two potato cultivars. Potato Research, 38, 143-150.

Morot-Gaudry-Talarmain, Y., Rockel, P., Moureaux, T., Quilleré, I., Leydecker, M. T., Kaiser, W. M., Morot-Gaudry, J. F. (2002). Nitrite accumulation and nitric oxide emission in relation to cellular signaling in nitrite reductase antisense tobacco. Planta, 215, 708715.

Morrissey, J. P. \& Osborn, A. E. (1999). Fungal resistance to plant antibiotics as a mechanism of pathogenesis. Microbiology and Molecular Biology Reviews, 63, 708724.

Mur, L. A. J., Carver, T. L. W. \& Prats, E. (2006). NO way to live; the various roles of nitric oxide in plant-pathogen interactions. Journal of Experimental Botany, 57, 489505. 
Mur, L. A. J., Santosa, I. E., LaArhoven, L. J. J., Holton, N. J., Harren, F. M., Smith, A. R. (2005b). Laser photoacustic detection allows in planta detection of NO in tobacco following challenge with avirulent and virulent Pseudomonas syringae pathovars. Plant Physiology, 138, 1247-1258.

MURAD F. (1994). The nitric oxide-cyclic GMP signal transduction system for intracellular and intercellular communication. Recent Progress in Hormone Research, 49, 239-248.

MurPHY, M. E. \& NOACK, E. (1994). Nitric oxide assay using haemoglobin method. Methods in Enzymology, 233, 240-250.

Nachmias, A., Buchner, V. \& Krikun, J (1982). Comparison of protein-lipopolysaccharide complexes produced by pathogenic and non-pathogenic strain of Vericillium dahliae Kleb. from potato. Physiological Plant Pathology, 20, 213-221.

Nachmias, A., Buchner, V., \& Burstein, Y. (1985). Biological and immunochemical characterization of a low molecular weight phytotoxin isolated from a proteinlipopolysaccharide complex produced by a potato isolate of Verticillium dahliae Kleb. Physiological Plant Pathology, 26, 43-55.

Nachmias, A., Buchner, V., Tsror, L., Burstein, Y. \& Keen, N. (1987). Differential phytotoxicity of peptides from culture fluids of Verticillium dahliae races 1 and 2 and their relationship to pathogenicity of the fungi on tomato. Phytopathology, 77, 506-510.

NAgAnO, T. (1999). Practical methods for detection of nitric oxide. Luminescence, 14, 283 290.

Nagano, T. \& Yoshimura, T. (2002). Bioimaging of nitric oxide. Chemical Reviews, 102, 1235-1269.

Nakatsubo, N., Kojima, H., Kikuchi, K., Nagoshi, H., Hirata, Y., Maeda, D., Imai, Y., IRIMURA, T. \& NAGANO. T. (1998). Direct evidence of nitric oxide production from bovine aortic endothelial cells using new fluorescence indicators: diaminofluoresceins. FEBS Letters, 427, 263-266.

Navarre, D. A., Wendehenne, D., Durner, J., Noad, R. \& Klessig, D. F. (2000). Nitric oxide modulates the activity of tobacco aconitase. Plant Physiology, 122, 573-582.

Nedeianu, S. \& PÁli, T. (2002). EPR Spectroscopy of common nitric oxide-spin trap complexes. Cellular \& Molecular Biology Letters, 7, 142-143.

NeILl, S. J., Desikan, R., Clarke, A., HANCOCK, J. T. (1999). $\mathrm{H}_{2} \mathrm{O}_{2}$ signalling in plant cells. In: Clavert, C., Smallwood, M., Bowles, D. eds. Plant responses to environmental stress. UK: BIOS Scientific Publishers, 59-63. 
Neill, S. J., Desikan, R., Clarke, A., Hancock, J. T. (2002). Nitric oxide is a novel component of abscisic acid signaling in stomatal guard cells. Plant Physiology, 128, 13 16.

Neill, S. J, Desikan, R., Clarke, A., Hurst, R. D., Hancock, J. T. (2002b). Hydrogen peroxide and nitric oxide as signalling molecules in plants. Journal of Experimental Botany, 372, 1237-1247.

Neumann, M. J. \& Dobinson, K. F. (2003). Sequence tag analysis of gene expression during pathogenic growth and microsclerotia development in the vascular wilt pathogen Verticillium dahliae. Fungal Genetics and Biology, 38, 54-62.

NIRENBERG, H. I. (1976): Untersuchungen über die morphologische und biologische Differenzierung in der Fusarium-Sektion Liseola . Mitteilungen aus der Biologischen Bundesanstalt für Land- und Forstwirtschaft, 169, 1-117.

NinNEMANN, H. \& MAIER, J. (1996). ). Indications for the occurence of nitric oxide synthases in fungi and plants and the involvment in photoconidiation of Neurospora crassa. Photochemistry and Photobiology, 64, 393-398.

Noritake, T., Kawakita, K. \& Doke, N. (1996). Nitric oxide induces phytoalexin accumulation in potato tuber tissue. Plant and Cell Physiology, 37, 113-116.

O’Donnell, P. J., Jones, J. B., Antoine, F. R., Ciardi, J. \& Klee, H. J. (2001). Ethylenedependent salicylic acid regulates an expanded cell death response to a plant pathogen. The Plant Journal, 25, 315-323.

Olivain, C. \& Alabouvette, C. (1999). Process of tomato root colonization by a pathogenic strain of Fusarium oxysporum f. sp. lycopersici discussed in comparison to a nonpathogenic strain. New Phytologist, 141, 497-510.

Olivain, C., Trouvelot, S., Binet, M.-N., Cordier, C., Pugin, A. \& Alabouvette, C. (2003). Colonization of flax roots and early physiological responses of flax cells inoculated with pathogenic and non-pathogenic strains of Fusarium oxysporum. Applied and Environmental Microbiology, 69, 5453-5463.

OrozCo-CÁRdenAs, M. L. \& RYAN, C. A. (2002). Nitric oxide negatively modulates wound signalling in tomato plants. Plant Physiology, 130, 487-493.

Pagnussat, G. C., Lanteri, M. L. \& Lamattina, L. (2003). Nitric oxide and cyclic GMP are messengers in the indole acetic acid-induced adventitious rooting process. Plant Physiology, 132, 1241-1248.

Pagnussat, G. C., Simontacchi, M., Puntarulo, S., Lamattina, L. (2002). Nitric oxide is required for root organogenesis. Plant Physiology, 129, 954-956. 
Patterson, B. D., MacRae, E. A. \& Ferguson, I. B. (1983). Estimation of hydrogen peroxide in plant extracts using titanium (IV). Analytical Biochemistry, 139, 487-492.

Pedroso, M. C. \& Durzan, D. J. (2000). Effect of different gravity environments on DNA fragmentation and cell death in Kalanchoë leaves. Annals of Botany, 86, 983-994.

Pedroso, M. C., Magalahes, J. R., Durzan, D. J. (2000a). A nitric oxide burst precedes apoptosis in angiosperm and gymnosperm foliar tissues. Journal of Experimental Botany, 51, 1027-1036.

Pedroso, M. C., Magalhaes, J. R., Durzan, D. J. (2000b). Nitric oxide induces cell death in Taxus cells. Plant Science, 157, 173-180.

PegG, G. F. (1965). Phytotoxin Production by Verticillium albo-atrum Reinke et Berthold. Nature, 208, 1228-1229.

PegG, G. F. \& Brady, B. L. (2002): Verticillium wilts. CABI-Publishing, Oxon, New York.

PegG, G. F. \& Cronshaw, D. K. (1976). Ethylene production in tomato plants infected with Verticillium albo-atrum. Physiological Plant Pathology. 8, 279-295.

Pei, Z.-M., Murata, Y., Benning, G., Thomine, S., Klusener, B., Allen, G. J., Grill, E., Schroeder, J. L. (2000). Calcium channels activated by hydrogen peroxide mediate abscisic acid signalling in guard cells. Nature, 406, 731-734.

Pfeiffer, S., Meyer, B. \& Hemmens, B. (1999). Stickstoffmonoxid: die rätselhafte Chemie eines biologischen Botenstoffes. Angewandte Chemie, 111, 1824-1844.

Pieterse, C. M. J., Schaller, A., Mauch-Mani, B., Conrath, U. (2006). Signaling in plant resistance responses: Divergence and cross-talk of defense pathways. In: Tuzun S. \& Bent E. (eds.) Multigenic and Induced Systemic Resistance in Plants. Springer, pp. 166196.

Polverari, A., Molesini, B., Pezzotti, M., Buonaurio, R., Marte, M. \& Delledonne, M. (2003). Nitric oxide-mediated transcriptional changes in Arabidopsis thaliana. Molecular Plant Microbe Interactions, 16, 1094-1105.

Prats, E., Mur, L. A. J., SAnderson, R., CArver, T. L. W. (2005). Nitric oxide contributes both to papilla-based resistance and the hypersensitive response in barley attacked by Blumeria graminis f. sp. hordei. Molecular Plant Pathology, 6, 65-78.

Quirino, B., Normanly, J. \& AMASINO, R. (1999). Diverse range of gene activity during Arabidopsis thaliana leaf senescence includes pathogen-independent induction of defense-related genes. Plant Molecular Biology, 40, 267-278. 
Radwan, O., Mouzeyar, S., Venisse, J. S., Nicolas, P. \& Bouzidi, M. F. (2005). Resistance of sunflower to the biotrophic oomycete Plasmopara halstedii is associated with a delayed hypersensitive response within the hypocotyls. Journal of Experimental Botany, 56, 2683-2693.

RÄThel, T. R., Leikert, J. F., Vollmar, A. M. \& Dirsch, V. M. (2003) Application of 4,5diaminofluorescein to reliably measure nitric oxide released from endothelial cells in vitro. Biological Procedures Online, 5, 136-142.

Resende, M. L. V., Mepsted, R., Flood, J. \& Cooper, R. M. (1996). Water relations and ethylene production as related to symptom expression in cocoa seedlings infected with defoliating and non-defoliating isolates of Verticillium dahliae. Plant Pathology, 45, 964-972.

Ribero, E. A., Cunha, F. Q., Tamashiro, W. M. S. C., Martins, I. S. (1999). Growth phasedependent subcellular localization of nitric oxide synthase in maize cells. FEBS Letters, 445, 283-286.

Ribnicky, D., Cohen, J., Hu, W.-S. \& CoOKe, T. (2002). An extraordinary auxin source following fertalization in carrot: its significance for plant totipotency. Planta, 214, 505509.

Rockel, P., Strube, F., Rockel, A., Wildt, J. \& Kaiser, W. M. (2002). Regulation of nitric oxide (NO) production by plant nitrate reductase in vivo and in vitro. Journal of Experimental Botany, 53, 103-110.

Romero-Puertas, M. C., Perazzolli, M., Zago, E. D. \& Delledonne, M. (2004). Nitric oxide signalling functions in plant-pathogen interactions. Cellular Microbiology, 6, 795803.

Ros-BARCeló, A. (2005). Xylem parenchyma cells deliver the $\mathrm{H}_{2} \mathrm{O}_{2}$ necessary for lignification on differentiating xylem vessels. Planta, 220, 747-756.

Ros-Barceló, A., Pomar, F., Ferrer, M. A., Martínez, P., Ballesta, M. C. \& Pedreño, M. A. (2002). In situ characterization of a NO-sensitive peroxidase in the lignifying xylem of Zinnia elegans. Phytologia Plantarum, 114, 33-40.

Roussel, S., Nicole, M., Lopez, F., Ricci, P., Geiger, J.-P., Renard, M., Brun, H. (1999). Leptospheria maculans and cryptogein induce similar vascular responses in tissues undergoing the hypersensitive reaction in Brassica napus. Plant Science, 144, 17-28.

Rusterucci, C., Espunya, M. C., Diaz, M., Chabannes, M. \& Martinez, M. C. (2007). SNitrosoglutathione reductase affords protection against pathogens in Arabidopsis, both locally and systemically. Plant Physiology, 143, 1282-1292. 
Rygulla, W., Snowdon, R. J., Eynck, C., Koopmann, B., Von Tiedemann, A., Lühs, W. \& FRIEDT, W. (2007). Broadening the genetic basis of Verticillium longisporum resistance in Brassica napus by interspecific hybridization. Phytopathology, 11, 1391-1396.

Sakamoto, A., Ueda, M., Morikawa, H. (2002). Arabidopsis glutathione-dependent formaldehyde dehydrogenase is an S-nitrosoglutathione reductase. FESB Letters, 515, 20-24.

SAVILlE, B. (1958). A scheme for the colorimetric determination of microgram amounts of thiols. The Analyst, 83, 670-672.

Scharp, R. E., Lenoble, M. E., Else, M. A., Thorne, E. T. \& Gherardi, F. (2000). Endogenous ABA maintains shoot growth in tomato independently of effects on plant water balance: evidence for an interaction with ethylene. Journal of Experimental Botany, 51, 1575-1584.

SCHNATHORST, W.C. (1981). Life cycle and epidemiology of Verticillium. In: Fungal Wilt Diseases of Plants. (Mace, M. E., Bell, A. A. \& Beckman, C. H., eds), New York, USA; Academic Press, 81-111.

Schneider, V. \& HAllier, U. W. (1970). Polyvinylpyrolidone als Schutzstoff bei der Untersuchung gerbstoffgehemmter Enzymreaktionen. Planta, 94, 134-139.

SCHUPP, R. \& RENNENBERG, H. (1988). Diurnal changes in the glutathione content of spruce needles (Picea abies, L.). Plant Science, 57, 113-117.

SCHWANZ, P. (1997). Einfluss von erhöhten $\mathrm{CO}_{2}$-Konzentrationen und oxidativem Stress auf das antioxidative System verschiedener Baumspezies.

Shafquat, J., El-Ahmad, M., Danielsson, O., Martínez, M. C., Persson, B., Parés, X. \& JÖRnVAll, H. (1996). Pea formaldehyde-active class III alcohol dehydrogenase: common derivation of the plant and animal forms but not of the corresponding ethanolactive forms (classes I and P). Proceedings of the National Academy of Sciences USA, 93, 5595-5599.

ShI, F.-M. \& YING-ZHANG, L. (2007). Verticillium dahliae toxins-induced nitric oxide production in Arabidopsis is major dependent on nitrate reductase. Biochemistry and Molecular Biology Reports, 79-85.

Simontacchi, M., Jasid, S., Puntarulo, S. (2004). Nitric oxide generation during early germination of sorghum seeds. Plant Science, 167, 839-847.

SMIT, F. \& DUBERY, I. A. (1997). Cell wall reinforcement in cotton hypocotyls in response to a Verticillium dahliae elicitor. Phytochemistry, 44, 811-815. 
SMiTH, C. J. (1996). Accumulation of phytoalexins defence mechanism and stimulus response system. The New Phytologist, 132, 1-45.

Song, F. \& Goodmann, R. M. (2001). Activity of nitric oxide is dependent on, but is partially required for function of, salicylic acid in the signaling pathway in tobacco systemic acquired resistance. Molecular Plant-Microbe Interactions, 14, 1458-1462.

SONG, N.-K., JEONG, C.-S. \& CHOI, H.-S. (2002). Identification of nitric oxide synthase in Flammulina velutipes. Mycologia, 92, 1027-1032.

STAMLER, J. S. (1994). Redox signalling: nitrosylation and related target interactions of nitric oxide. Cell, 78, 931-936.

Stamler, J. S., LAmas, S., FANG, F. C. (2001). Nitrosylation: the prototypic redox-based signalling mechanism. Cell, 116, 617-628.

Stamler, J. S., Singel, D. J., \& Loscalzo, J. (1992). Biochemistry of nitric oxide and its redox-activated forms. Science, 258, 1898-1902.

STARK, C. (1961). Das Auftreten der Verticillium-Tracheomykosen in Hamburger Gartenbaukulturen. Gartenbauwissenschaft, 26, 493-528.

Steinbach, P., Kreye, H., \& Wolf, G. A. (2005). Bundesweites „Verticillium-Monitoring“. Bewertung von Diagnosesicherheit und Risikofaktoren. Raps, 23, 20-26.

Steventon, L. A., Fahleson J., Hu, Q., \& Dixelius, C. (2002). Identification of the causal agent of Verticillium wilt of winter oilseed rape in Sweden, V. longisporum. Mycological Research, 106, 570-578.

Stoddart, J. L. \& CArr, A. J. H. (1966). Properties of wilt toxins produced by Verticillium albo-atrum Reinke \& Berth. Annals of Applied Biology, 58, 81-92.

Stöhr, C., Strube, F., MarX, G., Ulrich, W. R., Rockel, P. (2001). A plasmamembranebound enzyme of tobacco roots catalyses the formation of nitric oxide from nitrite. Planta, 212, 835-841.

STÖHR, C. \& Ulrich, W. R. (2002). Generation and possible roles of NO in plant roots and their apoplastic space. Journal of Experimental Botany, 53, 2293-2303.

TAda, Y., Mori, T., Shinogi, T., NAN, Y., TAKahashi, S. (2004). Nitric oxide and reactive oxygen species do not elicit hypersensitive cell death but induce apoptosis in the adjacent cells during the defence response of oat. Molecular Plant-Microbe Interactions, 17, 245-253.

TAKAHASHI, S. \& YAMASAKI, H. (2001). Reversible inhibition of photophosphorylation in chloroplasts by nitric oxide. FEBS Letters, 512, 145-148. 
Talboys, P. W. (1957). The possible significance of toxic metabolites of Verticillium alboatrum in the development of hop wilt symptoms. Transactions of the British Mycological Society, 40, 415-427.

Talboys, P. W. \& Busch, L. V. (1970). Pectic enzymes produced by Verticillium wilt species. Transactions of the British Mycological Society, 55, 367-381.

TARPEY, M. M., WinK, D. A., \& GrishaM, M. B. (2004). Methods for detection of reactive metabolites of oxygen and nitrogen: in vitro and in vivo considerations. American Journal of Physiology: Regulatory, Integrative and Comparative Physiology, 286, R431-R444.

Ten, L. N., Mukhimedshanov, S. Z., \& Otroshenko, O. S. (1981). Structure of the peptide moiety of verticillin. Khimiya Prirodnykh Soedinenii Tashkent, 4, 476-479.

Thomma, B. P. H. J., Eggermont, K., Penninckx, I. A. M. A., Mauch-Mani, B., Vogelsang, R., Cammue, B. P. A. \& Broekert, W. F. (1998). Seperate jasmonatedependent and salicylate-dependent defense-repsonse pathways in Arabidopsis are essential for resistance to distinct microbial pathogens. Proceedings of the National Academy of Sciences USA, 95, 15107-15111.

Thordal-Christensen, H., Zhang, Z., Wei, Y., Collinge, D. B. (1997). Subcellular localization of $\mathrm{H}_{2} \mathrm{O}_{2}$ in plants. $\mathrm{H}_{2} \mathrm{O}_{2}$ accumulation in papillae and hypersensitive response during the barley_powdery mildew interaction. The Plant Journal, 11, 11871194.

Tischner, R., Planchet, E. \& Kaiser, W. M. (2004). Mitochondrial electron transport as a source for nitric oxide in the unicellular green algae Chlorella sorokiniana. FEBS Letters, 576, 151-155.

Ton, J. \& MaUch-Mani, B. (2004). $\beta$-amino-butyric acid-induced resistance against necrotrophic pathogens is based on ABAdependent priming of callose. The Plant Journal, 38, 119-30.

TsikAS, D., DenKer, K., Frölich, J. C. (2001). Artifactual free analysis of Snitrosoglutathione and S-nitroglutathione by neutral-pH, anion-pairing, highperformance liquid chromatography study on peroxynitrite-mediated S-nitration of glutathione to S-nitroglutathione under physiological conditions. Journal of Chromatography A, 915, 107-116. 
Tsikas, D., Sandmann, J., Holzberg, D., Pantazis, P., Raida, M. \& Frölich, J. C. (1999). Determination of S-Nitrosoglutathione in human and rat plasma by HighPerformance Liquid Chromatography with fluorescence and ultraviolet absorbance detection after precolumn derivatization with o-pthalaldehyde. Analytical Biochemistry, 273, 32-40.

Tsuchiya, K., Kirima, K., Yoshizumi, M., Houchi, H., Tamaki, T., Mason, R. P. (2002). The role of thiol and nitrosothiol compounds in the nitric oxide-forming reactions of the iron- $N$-methyl-D-glucamine dithiocarbamate complex. Biochemical Journal, 367, 771779 .

Tsuchiya, K., Takasugi, M., Minakuch, K. \& Funuzawa, K. (1996). Sensitive quantitation of nitric oxide by EPR spectroscopy. Free Radical Biology and Medicine, 21, $733-737$.

Tsuchiya, K., Yoshizumi, M., Houci, H., Mason, R. P. (2000). Nitric oxide-forming reaction between the iron-N-methyl-D-glucamine dithiocarbamate complex and nitrite. The Journal of Biological Chemistry, 275, 1551-1556.

Tun, N. N., Holk, A., Scherer, G. F. E. (2001). Rapid increase of NO release in plant cell cultures induced by cytokinin. FEBS Letters, 509, 174-176.

UFOPa 2007: http://www.ufop.de/2160.php

UFOPb 2007: http://www.ufop.de/2472.php

Unger, C., Kleta, G., Jandl, G. \& Von Tiedemann, A. (2005). Supression of the defencerelated oxidative burst in bean leaf tissue and bean suspension cells by the necrotrophic pathogen Botrytis cinerea. Journal of Phytopathology, 153, 15-26.

VAN BAARlen, P., STAATS, M. \& VAN KANN, J. A. L. (2004). Induction of programmed cell death in lily by the fungal pathogen Botrytis elliptica. Molecular Plant Pathology, 5, $559-574$.

Van Breusegem, F., Vranova, E., Dat, J. F. \& Inzé, D. (2001). The role of active oxygen species in plant signal transduction. Plant Science, 161, 405-414.

Venkataraman, S., Martin, S. M., Schafer, F.Q., Buettner, G. R. (2000). Detailed methods for the quantification of nitric oxide in aqueous solutions using either an oxygen monitor or EPR. Free Radical Biology \& Medicine, 29, 580-585.

VERBAND DEUTSCHER OELMÜHLEN 2004: http://print.veredlungsproduktion.de/pages/de/raps news/cpd/1454.html

ViLlamena, F. A. \& ZWEIER, J. L. (2004). Detection of reactive oxygen species by EPR spin trapping. Antioxidants \& Redox Signaling, 6, 619-629. 
ViteceK, J., ReINOHL, V. \& Jones, R. L. (2008). Measuring NO production by plant tissues and suspension cultured cells. Molecular Plant, 7, 1-15.

Von Tiedemann, A. (1997). Evidence for a primary role of active oxygen species in induction of host cell death during infectio of bean leaves with Botrytis cinerea. Physiological and Molecular Plant Pathology, 80, 151-166.

Wada, M., Morinaka, C., Ikenaga, T., Kuroda, N., Nakashima, K. (2002). A simple HPLC-fluorescence detection of nitric oxide in cultivated plant cells by in situ derivatization with 2,3-Diaminonaphthalene. Analytical Sciences, 18, 631-634.

Waetzig, G. H., Sobczak, M., Grundler, F. M. W. (1999). Localization of hydrogen peroxide during the defence response of Arabidopsis thaliana against the plant-parasitic nematode Heterodea glycines. Nematology, 1, 681-686.

WANG, J. \& Higgins, V. J. (2005). Nitric oxide has a regulatory effect in the germination of conidia of Colletotrichum coccodes. Fungal Genetics and Biology, 42, 284-292.

Wang, J.-Y., Cai, Y., Gou, J.-Y., MaO, Y.-B., Xu, Y.-H., Jiang, W.-H. \& Chen, X.-Y. (2004). VdNEP, an elicitor from Verticillium dahliae, induces cotton plant wilting. Applied and Environmental Microbiology, 70, 4989-4995.

Ward, E. W. B., Cahill, D. M. \& Bhattacharyya, M. K. (1989). Abscisic acid suppression of Phenylalanine ammonia-lyase activity and mRNA, and resistance of soybeans to Phytophthora megasperma f. sp. glycinea. Plant Physiology, 91, 23-27.

Weimar, M. \& Rothe, G. M. (1986). Preparation of extracts from mature spruce needles for enzymatic analyses. Physiologia Plantarum, 69, 692-698.

Williams, P. H. \& HiLl, C. B. (1987). Rapid-cycling populations of Brassica. Science, 232, $1385-1389$

Wink, D. A. \& Mitchell, J. B. (1998). Chemical biology of nitric oxide: Insights into regulatory, cytotoxic and cytoprotective mechanisms of nitric oxide. Free Radical Biology and Medicine, 25, 434-456.

Wood, R. K. S. (1961). Verticillium wilt of tomatoes - the role of pectic and cellulolytic enzymes. Annals of Applied Biology, 49, 120-139.

Xia, Y., Cardounel, A. J., Vanin, A. F., Zweier, J. L. (2000). Electron paramagnetic resonance spectroscopy with N-Methyl-D-Glucamine Dithiocarbamate iron complexes distinguishes nitric oxide and nitroxyl anion in a redox dependent manner: Applications in identifying nitrogen monoxide from nitric oxide synthase. Free Radical Biology \& Medicine, 29, 793-797. 
Xu, Y. C., CaO, Y. L., GuO, P., Tao, Y., \& ZhaO, B. L. (2004). Detection of nitric oxide in plants by electron spin resonance. Phytopathology, 94, 402-407.

Yamamoto, A., Katou, S., Yoshioka, H., Doke, N. \& Kawakita, K. (2003). Nitrate reductase, a nitric oxide-producing enzyme: induction by pathogen signals. Journal of General Plant Pathology, 69, 218-229.

Yamamoto, T., \& Bing, R. J. (2000). Nitric oxide donors. Proceedings of the Society for Experimental Biology and Medicine, 225, 200-206.

YAMASAKI, H. (2000). Nitrite-dependent nitric oxide production pathway: implications for involvment of active nitrogen species in photoinhibition in vivo. Philosophical Transactions of the Royal Society of London, Series B: Biological Sciences, 355, 1477 1488.

YAMASAKI, H. \& SAKIHAMA, Y. (2000). Simultaneous production of nitric oxide and peroxynitrite by plant nitrate reductase: in vitro evidence for NR-dependent formation of reactive oxygen species. FEBS Letters, 468, 89-92.

Yoshimura, T. \& Kotake, J. (2004). Spin trapping of nitric oxide with the irondithiocarbamate complex: Chemistry and Biology. Antioxidants \& Redox Signaling, 6, 639-647.

YuAn, H. Y, YAO, L. L, JiA, Z. Q., LI. Y., LI, Y. Z. (2006). Verticillium dahliae toxin induced alterations of cytoskeletons and nucleoli in Arabidopsis thaliana suspension cells. Protoplasma, 229, 75-82.

Zacheo, G. \& Bleve-Zacheo, T. (1988). Involvement of superoxide dismutases and superoxide radicals in the susceptibility and resistance of tomato plants to Meloidogyne incognita attack. Physiological and Molecular Plant Pathology, 32, 313-322.

Zeidler, D., Zähringer, U., Gerber, I., Dubery, I., Hartung, T., Bors, W., Hutzler, P. \& DURner, J. (2004). Innate immunity in Arabidopsis thaliana: Lipopolysaccharides activate nitric oxide synthase (NOS) and induce defense genes. Proceedings of the National Academy of Sciences USA, 101, 15811-15816.

ZeISE K. \& SEIDEL, D. (1990). Zur Entwicklung und Schadwirkung der VerticilliumWelkekrankheit am Winterraps. Raps, 8, 20-22.

Zeise K. \& SteinBACH, P. (2004). Schwarze Rapswurzel und der Vormarsch der Verticillium-Rapswelke. Raps, 22, 170-174.

ZEISE, K. (1992). Gewächshaustest zur Resistenzprüfung von Winterraps (Brassica napus L. var. oleifera Metzger) gegen den Erreger der Rapswelke Verticillium dahliae Kleb. Nachrichtenblatt Deutscher Pflanzenschutzdienst, 44, 125-128. 
Zeise, K. \& Von Tiedemann, A. (2001). Morphological and physiological differentiation among vegetative compatibility groups of Verticillium dahliae in relation to $V$. longisporum. Journal of Phytopathology, 149, 469-475.

Zeise, K. \& Von Tiedemann, A. (2002a). Application of RAPD-PCR for virulence type analysis within Verticillium dahliae and Verticillium longisporum. Journal of Phytopathology, 150, 557-563.

Zeise, K. \& Von Tiedemann, A. (2002b). Host specialization among vegetative compatibility groups of Verticillium dahliae in relation to Verticillium longisporum. Journal of Phytopathology, 150, 112-119.

Zimmerli, L., Stein, M., LipkA, V., Schulze-Lefert, P. \& Somerville, S. (2004). Host and non-host pathogens elicit different jasmonate/ethylene responses in Arabidopsis. The Plant Journal, 40, 633-646.

Zhang, C., CzymmeK, K. J. \& Shapiro, A. D. (2003). Nitric oxide does not trigger early programmed cell death events but may contribute to cell-to-cell signalling governing progression of the Arabidopsis hypersensitive response. Molecular Plant Microbe Interactions, 16, 962-972.

Zhang, D., Xiong, J., Hu, J. \& ZhaO, B. (2001). Improved method to detect nitric oxide in biology systems. Applied Magnetic Resonance, 20, 345-356.

ZHANG, T. \& BRODERICK, K. E. (2000). Amperometric detection of nitric oxide. Modern Aspects in Immunobiology, 1, 160-165.

Zhang, X., Kim, W.-S., Hatcher, N., Potgieter, K., Moroz, L. L., Gillettes, R. \& SWEEDLER, J. V. (2002). Interfering with nitric oxide measurements. The Journal of Biological Chemistry, 277, 48472-48478.

ZhANG, Z., Henderson, C. \& GURR, S. J. (2004). Blumeria graminis secretes an extracellular catalase during infection of barley: potential role in suppression of host defence. Molecular Plant Pathology, 5, 537-547.

ZhaO, L., Zhang, F., GuO, J., YANG, Y., LI, B. \& Zhang, L. (2004). Nitric Oxide functions as a signal in salt resistance in the calluses from two ecotypes of Reed. Plant Physiology, 134, 849-857.

ZHEN, X. H. \& LI, Y. Z. (2004). Ultrastructural changes and location of beta-1, 3-glucanase in resistant and susceptible cotton callus cells in response to treatment with toxin of Verticillium dahliae and salicylic acid. Journal of Plant Physiology, 161, 1367-1377. 
Zhou, L., Hu, Q., Johansson, A., Dixelius, C. (2006). Verticillium longisporum and V. dahliae: infection and disease in Brassica napus. Plant Pathology, 55, 137-144.

Zhou, Y., Fitt, B. D. L., Welham, S. J., Gladders, P., Sansford, C. E., West, J. S. (1999). Effects of severity and timing of stem canker (Leptosphaeria maculans) symptoms on yield of winter oilseed rape (Brassica napus) in the UK. European Journal of Plant Pathology, 105, 715-728

ZMP 2007: http://www.zmp.de/presse/agrarwoche/marktanalysen/ma18.pdf

Zottini, M., Formentin, E., Scattolin, M., Carimi, F., Schiavo, L., Terzi, M. (2002). Nitric oxide affects plant mitochondrial functionality in vivo. FEBS Letters, 515, 75-78. 


\section{Anhang}

\subsection{Nachweis der ACC-Gehalte}

Ethylen stellt ein weiteres Phytohormon dar, welches einen Einfluss auf die Symptombildung der zu untersuchenden Interaktion haben könnte. Da die Untersuchungen bzgl. des Ethylengehaltes infizierter und gesunder Pflanzen innerhalb dieser Arbeit nicht möglich waren, wurden Proben ans Albrecht-Von-Haller-Institut der Pflanzenwissenschaften, Abteilung Biochemie der Pflanze (Arbeitsgruppe Ivo Feußner) weitergegeben. Jeweils fünf Sprossproben V. longisporum-infizierter und 5 gesunder Pflanzen wurden pro Termin per Gaschromatigraphie auf den Ethylenvorläufer 1-Aminocyclopropane-1-Carboxylsäure (ACC) untersucht.

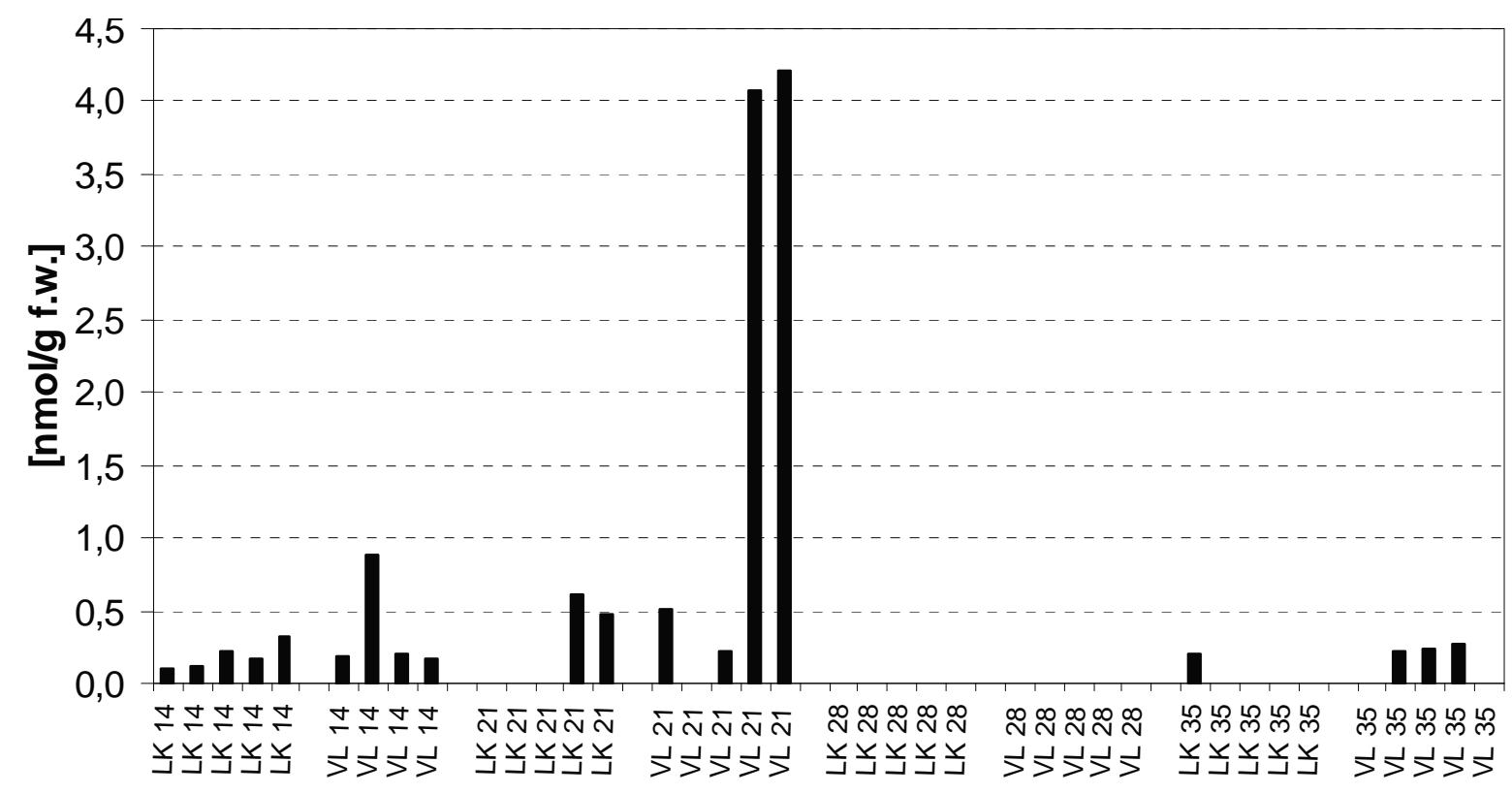

Abb. 53: Darstellung des ACC-Gehaltes $\left[\mathrm{nmol} \mathrm{g} \mathrm{FW}^{-1}\right]$ in Einzelsprossproben $V$. longisporum- und nicht infizierter Rapspflanzen über den Zeitraum 14-35 dpi, $\mathrm{n}=5$. Die Analyse der Proben erfolgte per Gas-Chromatographie im Albrecht-Von-Haller-Institut der Pflanzenwissenschaften, Abteilung Biochemie der Pflanze, Ivo Feußner. 
Tab. 13: Mittelwerte der Boniturnoten und Sprosslängen (cm) von RCR-Keimlingen sieben Tage nach Applikation membranfiltrierter Fraktionen V. longisporum-inokulierter $(V L)$ und nicht inokulierter (LK) SXM-Schüttelkulturen unter in vitro-Bedingungen; die jeweilige Standardabweichung ist in Klammern aufgeführt; $\mathrm{n}=25, *$ und verschiedene Indizes zeigen signifikante Unterschiede zur entsprechenden Kontrolle für $\mathrm{P}<0,05$ (LSD-Test).

\begin{tabular}{|l|l|l|l|}
\hline Fraktion & Variante & MW Boniturnote & Mittelwert Sprosslänge in [cm] \\
\hline 5000 & LK & $1,38( \pm 0,497)$ & $8,328( \pm 0,980)$ \\
& VL43 & $2,62( \pm 2,289)$ a & $6,751( \pm 0,843) *$ \\
\hline \multirow{2}{*}{10000} & LK & $1,76( \pm 0,908)$ & $7,615( \pm 1,265)$ \\
& VL43 & $3,4( \pm 1,290)$ ab & $6,832( \pm 1,068) *$ \\
\hline \multirow{2}{5}{50000} & LK & $1,68( \pm 0,859)$ & $7,962( \pm 0,983)$ \\
& VL43 & $3,56( \pm 1,227)$ cb & $7,188( \pm 0,882) *$ \\
\hline \multirow{2}{*}{ Kontrolle } & LK & $1,10( \pm 0,314)$ & $8,288( \pm 1,374)$ \\
& VL43 & $4,29( \pm 0,868)$ c & $6,055( \pm 0,795) *$ \\
\hline
\end{tabular}

\subsection{Chemikalienverzeichnis}

Sämtliche aufgeführte Chemikalien wurden, sofern nicht anders gekennzeichnet, aus Deutschland bezogen.

Acetonitril (100\%)

Agar Agar (hochrein)

Ascorbat

BIOTaq DNA Polymerase

Biotin

$\mathrm{CaCl}_{2}$

Casaminosäuren

CHES

cPTIO

Czapek Dox Broth (CzDB)

DAF-2

DAF-2 DA

DETC

Diethylether

dNTP-Mix

DTT

EDTA

Essigsäure (100\%)

Ethanol (100\%)

Etylenacetat

$\mathrm{FeCN}$

$\mathrm{FeSO}_{4}$

Fluorescein

GSH

GSNO

GSNOR

GSSG

$\mathrm{H}_{2} \mathrm{O}_{2}(30 \%)$

$\mathrm{H}_{2} \mathrm{SO}_{4}$
Roth, Karlsruhe

Merck, Darmstadt

Sigma, Taufkirchen

Bioline, Luckenwalde

Merck, Darmstadt

Difco, Becton Dickinson, Le Pont des Claix,

Frankreich

Sigma, Taufkirchen

Invitrogen,

Duchefa, Haarlem, Niederlande

Sigma, Taufkirchen

Sigma, Taufkirchen

Sigma, Taufkirchen

Roth, Karlsruhe

Bioline, Luckenwalde

Sigma, Taufkirchen

Sigma, Taufkirchen

Roth, Karlsruhe

Sigma, Taufkirchen

Merck, Darmstadt

Sigma, Steinheim

Fluka, Buchs, Schweiz

BioRad, Hercules, CA, USA

Sigma, Taufkirchen

Sigma, Taufkirchen

Sigma, Taufkirchen

Boehringer, Mannheim

Sigma, Taufkirchen

Roth, Karlsruhe 
$\mathrm{HCl}$

Hepes

$\mathrm{HgCl}_{2}$

$\mathrm{K}_{2} \mathrm{HPO}_{4}$

Katalase

$\mathrm{KCl}$

$\mathrm{KH}_{2} \mathrm{PO}_{4}$

MAHMA NONOate

$\mathrm{mBrB}$

Meta-Phosphorsäure

Methanol

$\mathrm{MgCl}_{2}$

$\mathrm{MGD}$

$\mathrm{MgSO}_{4}$

N-(1-Naphthyl)-Ethylenediamine

$\mathrm{Na}_{2} \mathrm{HPO}_{4}$

$\mathrm{NaCl}$

$\mathrm{NADH}$

Na-Pektin

NEM

n-Hexan

PCR-Puffer 10x

Potato Dextrose Broth (PDB)

PVPP

Säure-Fuchsin (Fuchsin sauer Natriumsalz)

SNAP

SNP

Sulfanilamid

Sybr Green Solution I

TBAHS

TiOx

Tris-HCl

Triton-X 100
Roth, Karlsruhe

biomol, Hamburg

Sigma, Steinheim (Fluka)

Applichem Darmstadt

Sigma, Taufkirchen

Merck, Darmstadt

Merck, Darmstadt

Sigma, Taufkirchen

Merck, Darmstadt

Sigma, Seelze

Roth, Karlsruhe

Bioline, Luckenwalde

Alexis Biochemicals/Axxora, Grünberg

Merck, Darmstadt

Sigma, Taufkirchen

Merck, Darmstadt

Merck, Darmstadt

Applichem, Darmstadt

Fluka, Buchs, Schweiz

Sigma, Taufkirchen

Roth, Karlsruhe

Bioline, Luckenwalde

(Fluka) Sigma, Steinheim

Applichem, Darmstadt

Merck, Darmstadt

Sigma, Taufkirchen

Riedel-De-Haë (Sigma, Seelze)

Sigma, Taufkirchen

Invitrogen, Karlsruhe

Fluka, Buchs

Sigma, Seelze

Sigma, Taufkirchen

Applichem, Darmstadt 


\subsection{Verwendete Medien, Puffer und Lösungen}

Alle verwendeten Medien wurden in destilliertem Wasser angesetzt. Die einzelnen Komponenten wurden zuerst in einer geringen Menge Wasser suspendiert, der pH-Wert adjustiert und das Volumen anschließend auf 11 Gesamtvolumen aufgefüllt. Anschließend wurden alle Medien bei $121^{\circ} \mathrm{C}$ für 15 min autoklaviert.

$\underline{\text { Nährstoffarmes Medium (SNA) (pro Liter) nach Nirenberg (1976) }}$

$\begin{array}{ll}\text { Komponente } & \text { Menge } \\ \mathrm{KH}_{2} \mathrm{PO}_{4} & 1 \mathrm{~g} \\ \mathrm{KNO}_{3} & 1 \mathrm{~g} \\ \mathrm{MgSO}_{4} \times 7 \mathrm{H}_{2} \mathrm{O} & 0,5 \mathrm{~g} \\ \mathrm{KCl} & 0,5 \mathrm{~g} \\ \text { Glucose } & 0,2 \mathrm{~g} \\ \text { Sucrose } & 0,2 \mathrm{~g} \\ \text { Agar (optional) } & 15 \mathrm{~g} \\ \text { pH 5 } & \end{array}$

$\underline{\text { Xylemsaft simulierendes Medium (SXM) modifiziert nach NEUMANN \& DoBINSON, (2003) }}$

$\begin{array}{ll}\text { Komponente } & \text { Menge } \\ \text { Na-Pectin } & 2,0 \mathrm{~g} \\ \text { Casaminosäuren } & 4,0 \mathrm{~g} \\ \mathrm{KCl} & 0,52 \mathrm{~g} \\ \mathrm{MgSO}_{4} \times 7 \mathrm{H}_{2} \mathrm{O} & 0,52 \mathrm{~g} \\ \mathrm{KH}_{2} \mathrm{PO}_{4} & 1,52 \mathrm{~g} \\ \text { Biotin }_{\text {Spurenelementlösung (SL2) }} & 0,1 \mu \mathrm{M} \\ \text { pH 6-6,5 } & \end{array}$

Spurenelementlösung (SL2) nach MEYER \& SCHLEGEL, (1983)

$\begin{array}{ll}\text { Komponente } & \text { Menge } \\ \mathrm{ZnSO}_{4} \times 7 \mathrm{H}_{2} \mathrm{O} & 900 \mathrm{mg} \\ \mathrm{FeSO}_{4} \times 7 \mathrm{H}_{2} \mathrm{O} & 20 \mathrm{mg} \\ \mathrm{MnCl}_{2} \times 4 \mathrm{H}_{2} \mathrm{O} & 30 \mathrm{mg} \\ \mathrm{CaCl}_{2} \times \mathrm{H}_{2} \mathrm{O} & 100 \mathrm{mg} \\ \mathrm{H}_{3} \mathrm{BO}_{3} & 300 \mathrm{mg} \\ \mathrm{Co}\left(\mathrm{NO}_{3}\right)_{2} \times 6 \mathrm{H}_{2} \mathrm{O} & 200 \mathrm{mg} \\ \mathrm{CuCl}_{2} \times \mathrm{H}_{2} \mathrm{O} & 10 \mathrm{mg} \\ \mathrm{NiSO}_{4} \times 6 \mathrm{H}_{2} \mathrm{O} & 20 \mathrm{mg} \\ \left(\mathrm{NH}_{4}\right) 6 \mathrm{Mo}_{7} \mathrm{O}_{24} \times 4 \mathrm{H}_{2} \mathrm{O} & 5500 \mathrm{mg} \\ \left(\mathrm{Na}_{2} \mathrm{SeO}_{3}\right) & 20 \mathrm{mg} \\ \text { bidest. } \mathrm{H}_{2} \mathrm{O} & \text { ad. } 1000 \mathrm{ml}\end{array}$




\section{$\underline{\text { Rapswurzelmedium (RWE) }}$}

Saubere Rapswurzeln wurden bei $35^{\circ} \mathrm{C}$ für 3 Tage getrocknet und $4 \mathrm{~g}$ der Trockenmasse zerkleinert. Das homogenisierte Wurzelgewebe wurde in einem Liter Wasser gelöst und autoklaviert. Das entstandene Extrakt wurde filtriert, $100 \mathrm{ml}$ Filtrat mit $300 \mathrm{ml}$ Wasser verdünnt und als Nährmedium für Schüttelkulturen verwendet.

\section{Wasseragar}

15 g Agar Agar

Auffüllen auf $11 \mathrm{H}_{2} \mathrm{O}$ dest.

$\underline{\text { CzD-Broth }}$

CzDox Broth 33,36 g

Auffüllen auf $11 \mathrm{H}_{2} \mathrm{O}$ dest.

PDA-Agar

PDA $39 \mathrm{~g}$

Auffüllen auf $11 \mathrm{H}_{2} \mathrm{O}$ dest.

Verwendete Puffer und Lösungen

Alle Puffer und Lösungen wurden in $\mathrm{H}_{2} \mathrm{O}$ bidest. angesetzt.

$\underline{\text { Spin-Trap Puffer für die ESR Analyse von Xylemsaft }}$

$\begin{array}{ll}\text { Komponente } & \text { Konzentration } \\ \text { MGD } & 50 \mathrm{mM} \\ \text { Hepes-Puffer } & 40 \mathrm{mM} \\ \mathrm{FeSO}_{4} & 10 \mathrm{mM} \\ \mathrm{CaCl}_{2} & 10 \mathrm{mM} \\ \mathrm{pH} 7,4 & \end{array}$

$\underline{\text { Extraktionspuffer für die ESR-Analyse von Geweben }}$

$\begin{array}{ll}\text { Komponente } & \text { Konzentration } \\ \text { (PBS)-Puffer, Phosphat gepufferte Saline } & 100 \mathrm{mM} \\ \text { Sucrose } & 0,32 \mathrm{M} \\ \text { EDTA } & 0,1 \mathrm{mM} \\ \text { Thioaethylenglykol } & 5 \mathrm{mM} \\ \text { pH 7,4 } & \end{array}$


$\underline{\text { Spin-Trap Puffer für die ESR-Analyse von Gewebe }}$

$\begin{array}{ll}\text { Komponente } & \text { Konzentration } \\ \text { DETC } & 200 \mathrm{mM} \\ \text { FeSO}_{4} & 60 \mathrm{mM} \\ \text { In } \mathrm{PBS}^{\text {Puffer gelöst }} & \end{array}$

$\underline{\text { Extraktionspuffer zur Analyse der GSNO-Reduktaseaktivität }}$

$\begin{array}{ll}\text { Komponente } & \text { Konzentration } \\ \mathrm{K}_{2} \mathrm{HPO}_{4} & 0,1 \mathrm{M} \\ \mathrm{KH}_{2} \mathrm{PO}_{4} & 0,1 \mathrm{M} \\ \text { Triton-X } & 1,5 \% \\ \text { pH } 7,8 & \end{array}$

Elutionspuffer zur Analyse der GSNO-Reduktase

$\begin{array}{ll}\text { Komponente } & \text { Konzentration } \\ \mathrm{K}_{2} \mathrm{HPO}_{4} & 0,1 \mathrm{M} \\ \mathrm{KH}_{2} \mathrm{PO}_{4} & 0,1 \mathrm{M} \\ \mathrm{pH} 7,8 & \end{array}$

Extraktionspuffer zur Analyse nitrosylierter Proteine

$\begin{array}{ll}\text { Komponente } & \text { Konzentration } \\ \mathrm{K}_{2} \mathrm{HPO}_{4} & 0,1 \mathrm{M} \\ \mathrm{KH}_{2} \mathrm{PO}_{4} & 0,1 \mathrm{M} \\ \text { EDTA } & 0,1 \mathrm{mM} \\ \text { Neocuprione } & 0,1 \mathrm{M} \\ \text { pH 7,8 } & \end{array}$

\subsection{Geräteverzeichnis}

\begin{tabular}{|l|l|}
\hline Bezeichnung & Firma \\
\hline Cellulosefiltermembranen & Amicon/Milipore, Tulalrgreen, Irland \\
Druckkammer & Modell 600, PMS Instrument Company, \\
& Oregon \\
Elektronen Spin Resonanz Spektrometer & 9 GHz, X-band, Varian, Darmstadt \\
Elektrophorese Power Pac 300 & BIORad, CA, USA \\
Elektrophoresekammer Wide Mini Sub Cell GT & BIORad, CA, USA \\
Gefriertrocknungsanlage Beta 1 & Christ, Osterode \\
Gelfiltrationssäulen PD-10 (NAP-5) & Pharmacia, Freiburg \\
Gewebekulturschrank & Mytron, Heiligenstadt \\
iCycler-System & BIORad, Hercules, CA USA \\
Klimakammer (Pflanzenwuchskammer) & Kälte Klima, Northeim \\
Megabond Elut C-18 Säulen & Varian, Darmstadt \\
Petrischalen 24x24 cm & Nalgene \\
Photometer $\mu$ Quant & BIOTek Instruments, Bad Friedrichshall \\
Photometer Specord 40 & Analytik Jena \\
Rotationsverdampfer Büchi 011 & Büchi, Schweiz \\
Schüttler (Mini Shaker) & Adolf Kühner AG, Schweiz \\
Schüttler Infors CH-4103 & Infors AG, Bottmingen, Schweiz \\
Tischzentrifuge & Eppendorf, Hamburg \\
Trockenschrank & Memmert, Schwabach \\
\hline
\end{tabular}




\begin{tabular}{|l|l|}
\hline Ultrazentrifuge, Sorvall Evolution RC, & Sorvall, Fa. Kendro, USA \\
Rotor SS34 & \\
Vakuumkzentrifuge Concentrator 5301 & Eppendorf, Hamburg \\
Vakuumzentrifuge RVC 2-25 & Christ \\
Zentrifuge 4K10 & Sigma, Osterode \\
Zentrifuge Biofuge Fresco & Heraeus Instruments \\
\hline \multicolumn{2}{|c|}{ HPLC-Anlage zur GSNO- und NO Detektion } \\
\hline Bezeichnung & Firma \\
\hline Autosampler Pro Star Modell 410 & Varian, Darmstadt \\
Binäres Pumpensystem Pro Star 210 & Varian, Darmstadt \\
Entgaser Degas 1 & Techlab \\
Fluoreszenzdetektor Varian Pro Star & Varian, Darmstadt \\
HPLC-Vorsäule LiChrospher ${ }^{R} 100$, RP-18, & Merck, Darmstadt \\
5 $\mu$ m & \\
Säulenofen K7 & Techlab \\
Trennsäule LiChrospher ${ }^{\circ} 100 R P-18$ & Merck, Darmstadt \\
\hline \multicolumn{2}{|c|}{ HPL-Anlage zur Phytohormonanalyse } \\
\hline Bezeichnung & Firma \\
\hline Autosampler Pro Star Modell 430 & Varian, Darmstadt \\
Binäres Pumpensystem Pro Star 210 & Varian, Darmstadt \\
Massenspektrometer 1200 LC/MS Triple & Varian, Darmstadt \\
Quadrupol- mit Elektrospray Ionisation- & \\
Interface & \\
Säulenofen Mistral Pro Star 510 & Varian, Darmstadt \\
Trennsäule Polaris C18-A, 150x2 mm, 5 $\mu$ m & Varian, Darmstadt \\
\hline
\end{tabular}

\section{Verwendete Filter und Zubehör}

\begin{tabular}{|l|l|}
\hline Bezeichnung & Firma \\
\hline Antibiotika-Applikationsplättchen & Schleicher \& Schüll, Dassel \\
Cellophane (Zellglas, Einmach Fix) & Bringmann, Wendelstein \\
Spritzenaufsatzfilter Minisart ® CE, 0,2 ${ }^{\mathrm{m}}$ & Sartorius, Göttingen \\
Spritzenaufsatzfilter Spartan $13,0,2 \mu \mathrm{m}$ RC & Whatman, Dassel \\
Sterilfilter RC, vliesverstärkt $0,2 \mu \mathrm{m}$ & Sartorius, Göttingen \\
\hline
\end{tabular}




\section{Danksagung}

Mein besonderer Dank gilt Herrn Prof. Dr. Andreas von Tiedemann für die Bereitstellung des Themas, die Übernahme der Betreuung, die Unterstützung sowie für Diskussionen und Anregungen bei der Durchführung dieser Arbeit.

Mein weiterer Dank gilt Herrn Prof. Dr. Petr Karlovsky für die Übernahme des Korreferats sowie die Bereitstellung von Equipment und Arbeitsmaterialien für die PCR- und Phytohormonanalyse.

Herrn Dr. Birger Koopmann danke ich insbesondere für die stete Hilfsbereitschaft, große Unterstützung und Motivation bei jeglichen Problemen.

Herrn Dr. Andres Schützendübel danke ich für seine unermüdliche Diskussionsbereitschaft, die große Unterstützung im Labor und dem besonderen Interesse an der Thematik.

Bei Brigitta Angerstein und Herrn Dr. Derek Marsh vom Max-Planck-Institut Göttingen für Biophysikalische Chemie bedanke ich mich herzlich für die große Unterstützung bzgl. der ESR-Messungen, das dargebrachte Vertrauen und die schönen Messzeiten in ihrer Abteilung.

Bei Evelin Vorbeck, Dagmar Tacke und Jutta Schaper möchte ich mich für die schöne Arbeitsatmosphäre, stete Unterstützung im Labor und vor allem für die schöne gemeinsame Zeit außerhalb des Instituts bedanken.

Bei Siv Ahlers bedanke ich mich für ihre Unterstützung als Hiwi im Labor.

Bei Christina Eynck, Heike Thiel und Elke Nitschke möchte ich mich für die schöne Zeit, die vielen lustigen Erlebnisse, das viele Lachen, die kleinen Streiche und ihre Freundschaft bedanken.

Allen anderen Doktoranden, Master-Studenten und anderen Mitarbeitern der Arbeitsgruppe danke ich für die herzliche und freundliche Atmosphäre und die große Hilfsbereitschaft während meiner gesamten Promotionszeit.

Dem Gewächshaus-Team Hubertus Reintke, Eugen Hodyl und Frank Gremmes danke ich für die stete Hilfsbereitschaft bei mechanischen Problemen, der Pflanzenpflege und dem Organisieren der Doktorandenfeiern.

Bei Frau Bode bedanke ich mich ganz herzlich für die Hilfe und Unterstützung bei allen administrativen Problemen.

Der DFG danke ich für die finanzielle Unterstützung und der DFG Forschergruppe FOR-546 für die gute Zusammenarbeit und rege Diskussion.

Zum Schluss danke ich meinen Eltern Peter und Marion Riediger und meinem Freund Christian Bruns, die mir alles bedeuten. 


\section{Eidesstattliche Erklärung}

Hiermit erkläre ich, dass diese Arbeit weder in gleicher noch in ähnlicher Form bereits anderen Prüfungsbehörden vorgelegen hat.

Weiter erkläre ich, dass ich mich an keiner anderen Hochschule um einen Doktorgrad beworben habe.

Göttingen, den 


\section{Lebenslauf}

Persönliche Daten

Name:

Geburtsdatum:

Wohnort:

Schulausbildung:

1985-1989

1989-1991

1991-1998

Hochschulausbildung: 1998-2004

2004-2008

\section{Berufliche Tätigkeit:}

Juni 2004 bis Sept. 2004
Nadine Riediger

19.06.1979 in Georgsmarienhütte / Osnabrück Breite Str. 7, 37077 Göttingen

Grundschule Nienstädt
Orientierungsstufe Helpsen
Ratsgymnasium Stadthagen
Abitur als Abschluss

Studium der Biologie an der Universität Hannover

Diplomarbeit am Institut für Pflanzenkrankheiten und Pflanzenschutz der Universität Hannover zum Thema „Molekularbiologische Untersuchungen zum Nachweis des resistenzinduzierenden Wurzelendophyten Acremoniumm strictum“.

Hauptprüfungsfach Botanik

Erstes Nebenfach Ökologie

Zweites Nebenfach Phytomedizin

Diplomabschluss mit der Note sehr gut mit Auszeichnung.

Anfertigung einer Dissertation an der Georg-AugustUniversität Göttingen zum Thema „Beteiligung systemischer Signale an der Symptomauslösung bei Brassica napus nach Infektion mit Verticillium longisporum und V. dahliae“

wiss. Hilfskraft am Institut für Pflanzenkrankheiten und Pflanzenschutz (Betreuung des Konfokalen Laser Scanning Mikroskops) 